Transportation Consortium of South-Central States

Tran-SET

Solving Emerging Transportation Resiliency, Sustainability, and Economic Challenges through the Use of Innovative Materials and Construction Methods: From Research to Implementation

\title{
Rails to Resilience: Evaluating New Orleans and Baton Rouge Rail Terminals and Transit Links
}

Project No. 19PPLSU11

Lead University: University of New Orleans

Final Report

November 


\section{Disclaimer}

The contents of this report reflect the views of the authors, who are responsible for the facts and the accuracy of the information presented herein. This document is disseminated in the interest of information exchange. The report is funded, partially or entirely, by a grant from the U.S. Department of Transportation's University Transportation Centers Program. However, the U.S. Government assumes no liability for the contents or use thereof.

\section{Acknowledgements}

The research team recognizes the assistance of the Project Review Committee in guiding development of this study and providing valuable data and feedback:

Karen Parsons, Principal Planner, New Orleans Regional Planning Commission

Laura Phillips, Transportation Planner, FHWA LA Division

Jason Sappington, Deputy Director, New Orleans Regional Planning Commission

Susanna Schowen, Workforce Initiatives Manager, Louisiana Economic Development

Dr. Li Zhang, Associate Professor, Mississippi State University 


\section{TECHNICAL DOCUMENTATION PAGE}

\begin{tabular}{|c|c|}
\hline 2. Government Accession No. & 3. Recipient's Catalog No. \\
\hline 4. Title and Subtitle & \begin{tabular}{|l|} 
5. Report Date \\
November 2020 \\
\end{tabular} \\
\hline $\begin{array}{l}\text { Rails to Resilience: Evaluating New Orleans and Baton Rouge Rail } \\
\text { Terminals and Transit Links }\end{array}$ & 6. Performing Organization Code \\
\hline $\begin{array}{l}\text { 7. Author(s) } \\
\text { PI: Tara M. Tolford https://orcid.org/0000-0002-9080-7590 } \\
\text { Co-PI: James Amdal https://orcid.org/0000-0001-5174-5414 } \\
\text { Addl. Staff: Guang Tian https://orcid.org/0000-0002-4023-3912 } \\
\text { GRA: Alahna Moore https://orcid.org/0000-0002-3648-7020 } \\
\text { GRA: Marin Tockman https://orcid.org/0000-0003-4859-9094 }\end{array}$ & 8. Performing Organization Report No. \\
\hline \multirow{2}{*}{$\begin{array}{l}\text { 9. Performing Organization Name and Address } \\
\text { Transportation Consortium of South-Central States (Tran-SET) } \\
\text { University Transportation Center for Region } 6 \\
3319 \text { Patrick F. Taylor Hall, Louisiana State University, Baton Rouge, } \\
\text { LA } 70803\end{array}$} & 10. Work Unit No. (TRAIS) \\
\hline & $\begin{array}{l}\text { 11. Contract or Grant No. } \\
69 \mathrm{~A} 3551747106\end{array}$ \\
\hline \multirow{2}{*}{$\begin{array}{l}\text { 12. Sponsoring Agency Name and Address } \\
\text { United States of America } \\
\text { Department of Transportation } \\
\text { Research and Innovative Technology Administration }\end{array}$} & $\begin{array}{l}\text { 13. Type of Report and Period Covered } \\
\text { Final Research Report Sep. } 2019 \text { - Nov. } 2020\end{array}$ \\
\hline & 14. Sponsoring Agency Code \\
\hline
\end{tabular}

\section{Supplementary Notes}

Report uploaded and accessible at Tran-SET's website (http://transet.lsu.edu/).

\section{Abstract}

This study evaluates the multimodal linkages to and opportunities for proposed terminal sites for a potential future passenger rail connection between Baton Rouge and New Orleans, Louisiana. The project included a comprehensive analysis of recent planning processes and documents and distribution of a statewide survey aimed at understanding ridership potential (including non-work trips) and the needs of likely users, the results of which were modeled to illuminate key considerations for service design and station area planning. This study finds a strong foundation for, and support of, the proposed rail service, but distinct deficiencies in the current multimodal transportation environment connecting to and from proposed stations. In addition, previous analyses include potentially faulty assumptions about likely rail passenger trip purposes, which have critical implications for service design. The findings of this study reflect the priorities of likely rail passengers and advance efforts to plan for successful passenger rail service operation in Southeast Louisiana.

\section{Key Words}

Transit, land use, planning, passenger rail, active transportation, COVID-19, bicycling, walking,

\section{Distribution Statement}

No restrictions. This document is available through the National Technical Information Service, Springfield, VA 22161.

\begin{tabular}{|l|l|l|l|}
\hline $\begin{array}{l}\text { 19. Security Classif. (of this report) } \\
\text { Unclassified }\end{array}$ & $\begin{array}{l}\text { 20. Security Classif. (of this page) } \\
\text { Unclassified }\end{array}$ & $\begin{array}{l}\text { 21. No. of Pages } \\
207\end{array}$ & 22. Price \\
\hline
\end{tabular}

Form DOT F 1700.7 (8-72)

Reproduction of completed page authorized. 


\begin{tabular}{|c|c|c|c|c|}
\hline \multicolumn{5}{|c|}{$\begin{array}{c}\text { S** (MODERN METRIC) CONVERSION FACTORS } \\
\text { APPROXIMATE CONVERSIONS TO SI UNITS }\end{array}$} \\
\hline Symbol & When You Know & Multiply By & To Find & Symbol \\
\hline \multicolumn{5}{|c|}{ LENGTH } \\
\hline in & inches & 25.4 & millimeters & $\mathrm{mm}$ \\
\hline $\mathrm{ft}$ & feet & 0.305 & meters & $\mathrm{m}$ \\
\hline yd & yards & 0.914 & meters & $\mathrm{m}$ \\
\hline $\mathrm{mi}$ & miles & 1.61 & kilometers & $\mathrm{km}$ \\
\hline \multicolumn{5}{|c|}{ AREA } \\
\hline$i^{2}$ & square inches & 645.2 & square millimeters & $\mathrm{mm}^{2}$ \\
\hline $\mathrm{ft}^{2}$ & square feet & 0.093 & square meters & $\mathrm{m}^{2}$ \\
\hline$y d^{2}$ & square yard & 0.836 & square meters & $\mathrm{m}^{2}$ \\
\hline ac & acres & 0.405 & hectares & ha \\
\hline $\mathrm{mi}^{2}$ & square miles & 2.59 & square kilometers & $\mathrm{km}^{2}$ \\
\hline \multicolumn{5}{|c|}{ VOLUME } \\
\hline $\mathrm{floz}$ & fluid ounces & 29.57 & milliliters & $\mathrm{mL}$ \\
\hline gal & gallons & 3.785 & liters & $\mathrm{L}$ \\
\hline $\mathrm{ft}^{3}$ & cubic feet & 0.028 & cubic meters & $\mathrm{m}^{3}$ \\
\hline$y d^{3}$ & cubic yards & 0.765 & cubic meters & $\mathrm{m}^{3}$ \\
\hline \multicolumn{5}{|c|}{ NOTE: volumes greater than $1000 \mathrm{~L}$ shall be shown in $\mathrm{m}^{3}$} \\
\hline \multicolumn{5}{|c|}{ MASS } \\
\hline $\mathrm{oz}$ & ounces & 28.35 & grams & $\mathrm{g}$ \\
\hline $\mathrm{lb}$ & pounds & 0.454 & kilograms & \\
\hline $\mathrm{T}$ & short tons $(2000 \mathrm{lb})$ & 0.907 & megagrams (or "metric ton") & $\mathrm{Mg}$ (or "t") \\
\hline \multicolumn{5}{|c|}{ TEMPERATURE (exact degrees) } \\
\hline${ }^{\circ} \mathrm{F}$ & Fahrenheit & $\begin{array}{r}5(\mathrm{~F}-32) / 9 \\
\text { or }(\mathrm{F}-32) / 1\end{array}$ & Celsius & ${ }^{\circ} \mathrm{C}$ \\
\hline \multicolumn{5}{|c|}{ ILLUMINATION } \\
\hline fc & foot-candles & 10.76 & & \\
\hline $\mathrm{fl}$ & foot-Lamberts & 3.426 & candela $/ \mathrm{m}^{2}$ & $\mathrm{~cd} / \mathrm{m}^{2}$ \\
\hline \multicolumn{5}{|c|}{ FORCE and PRESSURE or STRESS } \\
\hline & poundforce & 4.45 & newtons & \\
\hline $\mathrm{lbf} / \mathrm{in}^{2}$ & poundforce per square inch & 6.89 & kilopascals & $\mathrm{kPa}$ \\
\hline \multicolumn{5}{|c|}{ APPROXIMATE CONVERSIONS FROM SI UNITS } \\
\hline Symbol & When You Know & Multiply By & To Find & Symbol \\
\hline \multicolumn{5}{|c|}{ LENGTH } \\
\hline $\mathrm{mm}$ & millimeters & 0.039 & inches & in \\
\hline $\mathrm{m}$ & meters & 3.28 & feet & $\mathrm{ft}$ \\
\hline $\mathrm{m}$ & meters & 1.09 & yards & $\mathrm{yd}$ \\
\hline $\mathrm{km}$ & kilometers & 0.621 & miles & $\mathrm{mi}$ \\
\hline \multicolumn{5}{|c|}{ AREA } \\
\hline $\mathrm{mm}^{2}$ & square millimeters & 0.0016 & square inches & $i^{2}$ \\
\hline $\mathrm{m}^{2}$ & square meters & 10.764 & square feet & $\mathrm{ft}^{2}$ \\
\hline $\mathrm{m}^{2}$ & square meters & 1.195 & square yards & $\mathrm{yd}^{2}$ \\
\hline ha & hectares & 2.47 & acres & $\mathrm{ac}$ \\
\hline $\mathrm{km}^{2}$ & square kilometers & 0.386 & square miles & $\mathrm{mi}^{2}$ \\
\hline \multicolumn{5}{|c|}{ VOLUME } \\
\hline $\mathrm{mL}$ & milliliters & 0.034 & fluid ounces & $\mathrm{fl} \mathrm{oz}$ \\
\hline L & liters & 0.264 & gallons & gal \\
\hline $\mathrm{m}^{3}$ & cubic meters & 35.314 & cubic feet & $\mathrm{ft}^{3}$ \\
\hline $\mathrm{m}^{3}$ & cubic meters & 1.307 & cubic yards & $y d^{3}$ \\
\hline \multicolumn{5}{|c|}{ MASS } \\
\hline g & grams & 0.035 & ounces & $\mathrm{oz}$ \\
\hline & kilograms & 2.202 & pounds & $\mathrm{lb}$ \\
\hline Mg (or "t") & megagrams (or "metric ton") & 1.103 & short tons $(2000 \mathrm{lb})$ & $\mathrm{T}$ \\
\hline \multicolumn{5}{|c|}{ TEMPERATURE (exact degrees) } \\
\hline${ }^{\circ} \mathrm{C}$ & Celsius & $1.8 \mathrm{C}+3$ & Fahrenheit & ${ }^{\circ} \mathrm{F}$ \\
\hline \multicolumn{5}{|c|}{ ILLUMINATION } \\
\hline Ix & lux & 0.0929 & foot-candles & fc \\
\hline $\mathrm{cd} / \mathrm{m}^{2}$ & candela $/ \mathrm{m}^{2}$ & 0.2919 & foot-Lamberts & $\mathrm{fl}$ \\
\hline & FOF & nd PRESSUR & RESS & \\
\hline $\mathrm{N}$ & newtons & 0.225 & poundforce & lbf \\
\hline $\mathrm{kPa}$ & kilopascals & 0.145 & poundforce per square inch & $\mathrm{lbf} / \mathrm{in}^{2}$ \\
\hline
\end{tabular}




\section{TABLE OF CONTENTS}

TECHNICAL DOCUMENTATION PAGE .................................................................... ii

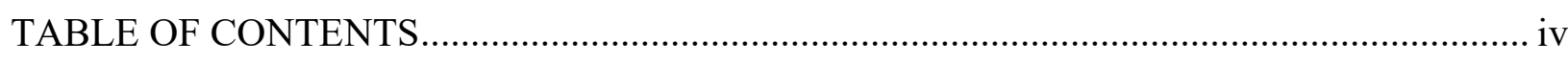

LIST OF FIGURES ………......................................................................................... vii

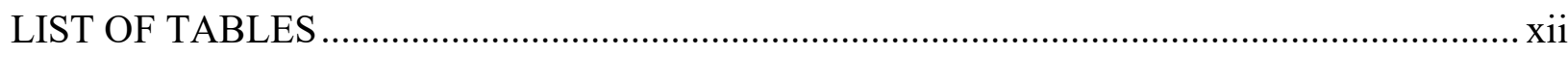

ACRONYMS, ABBREVIATIONS, AND SYMBOLS ……………………………............ xiv

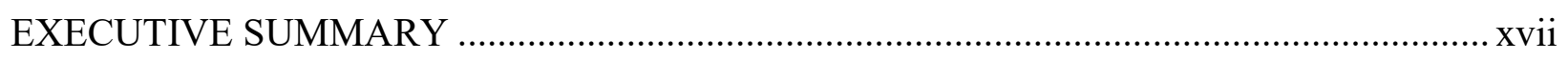

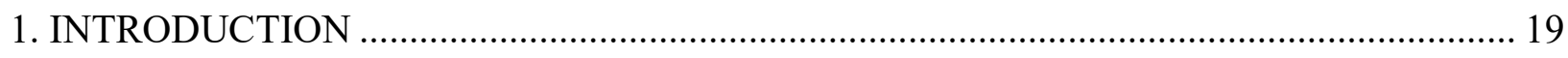

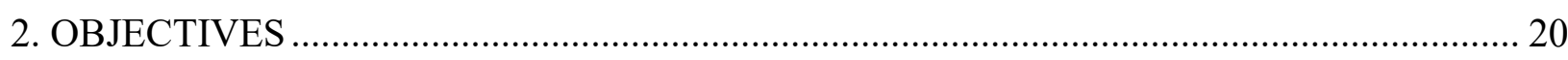

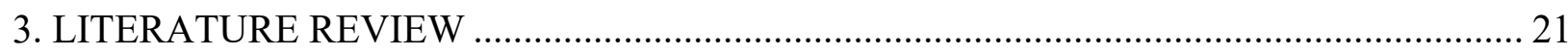

3.1. Development of new intercity and commuter transit services......................................... 21

3.2. Multimodal planning for intercity transit..................................................................... 24

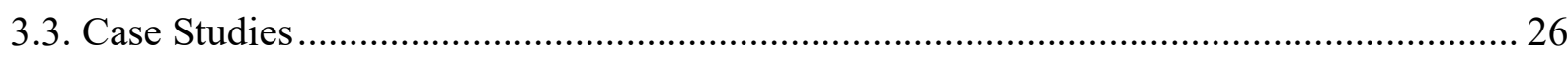

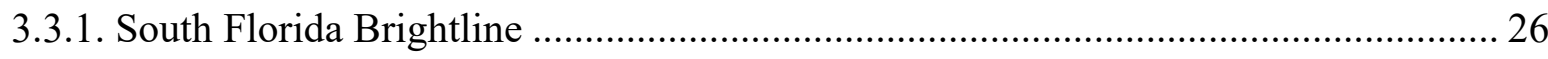

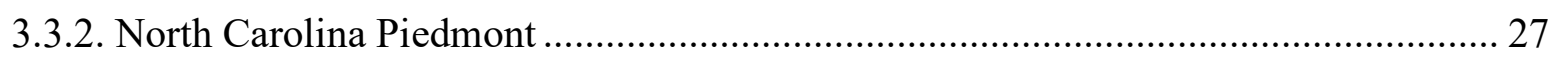

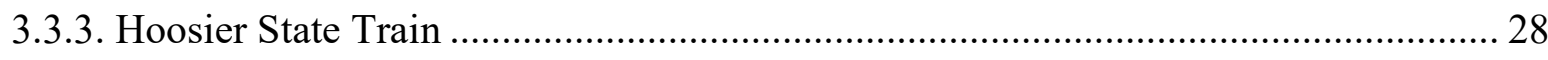

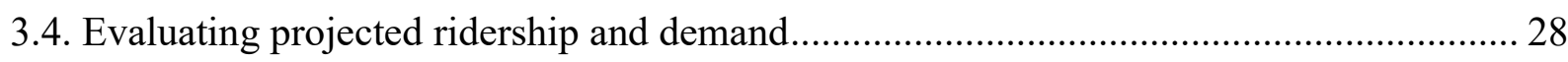

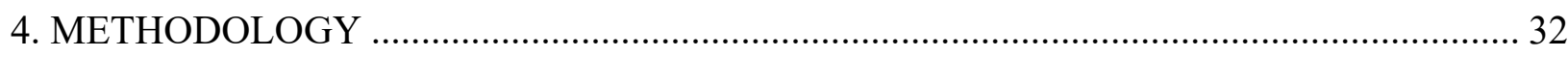

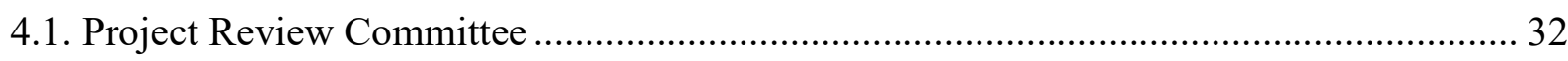

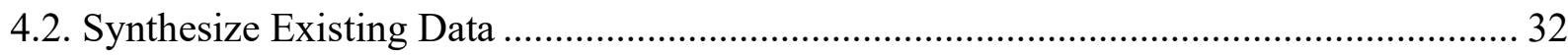

4.3. Identify transit route and terminal evaluation priorities and performance metrics............ 33

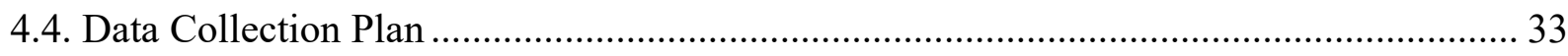

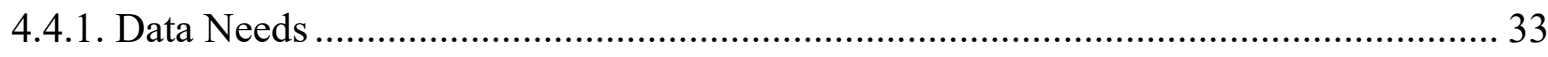

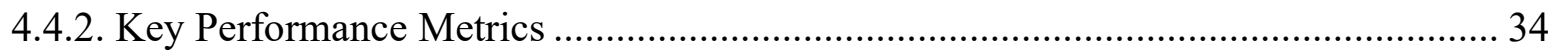

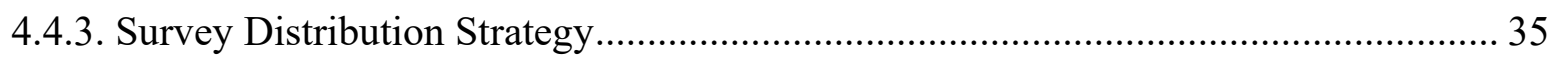

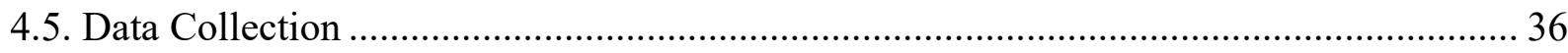

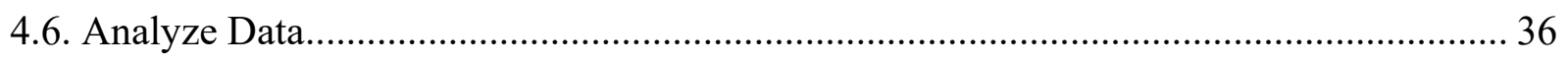

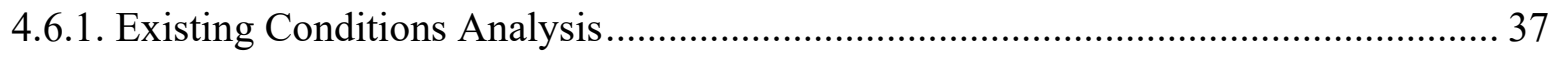

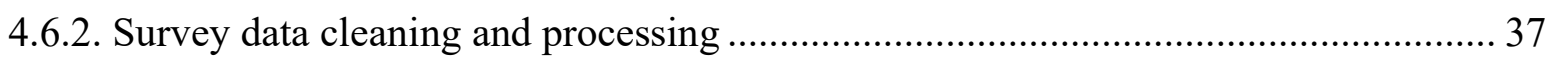

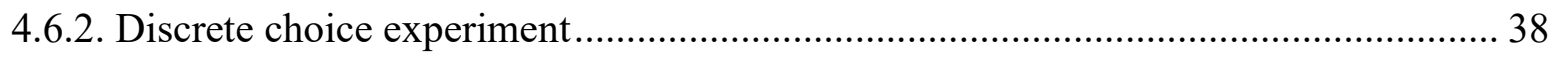


4.6.3. Survey results: descriptive statistics and qualitative analysis ................................... 40

4.6.4. Data inputs for spatial analysis and modeling ........................................................ 40

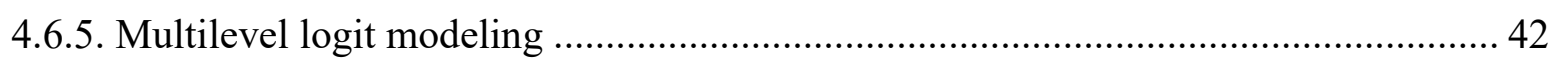

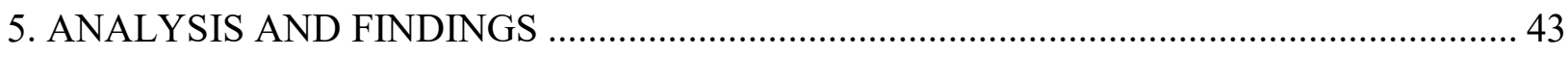

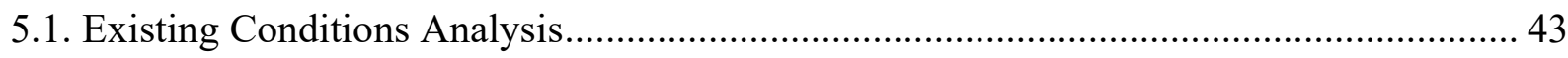

5.1.1. Background and Legislative Context...................................................................... 43

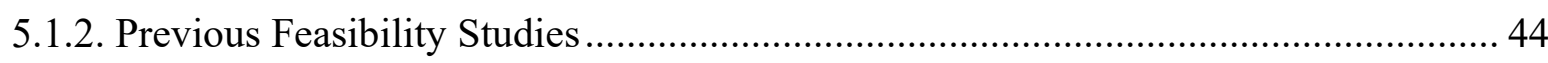

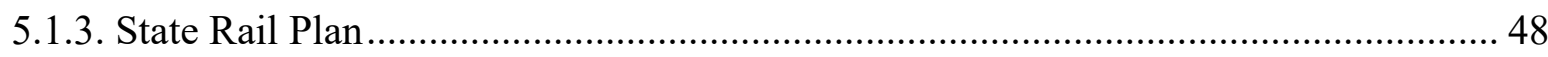

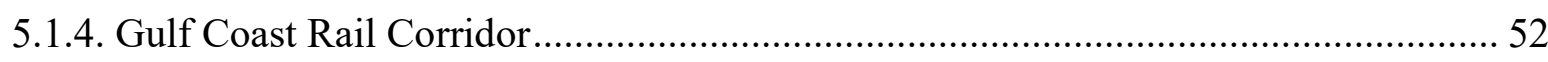

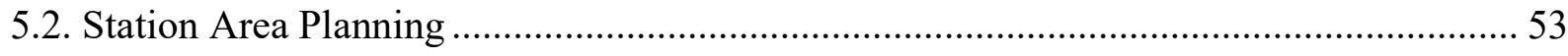

5.2.1. Baton Rouge Downtown Station............................................................................. 53

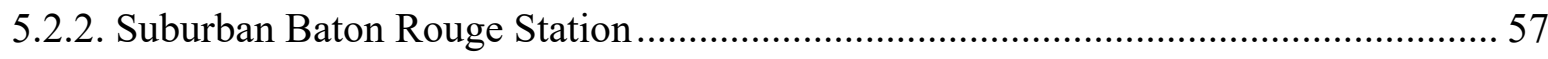

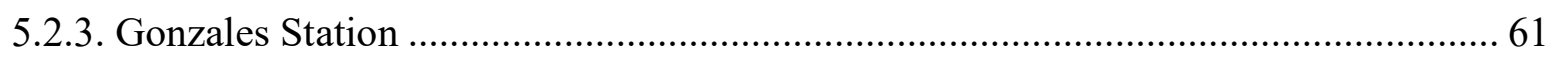

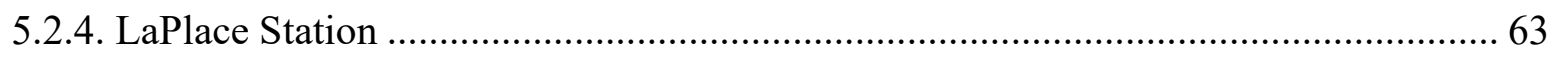

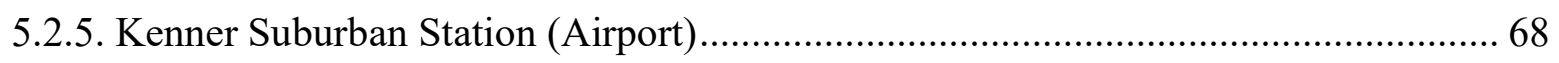

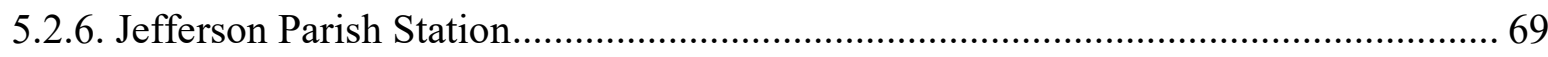

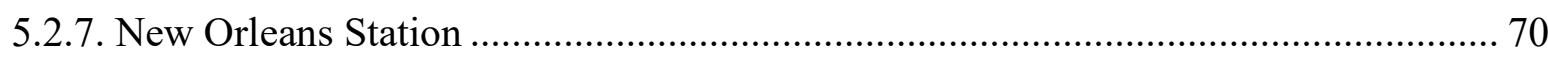

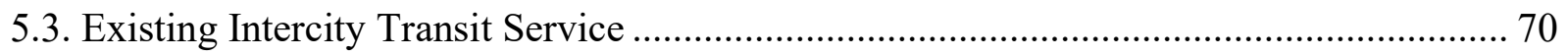

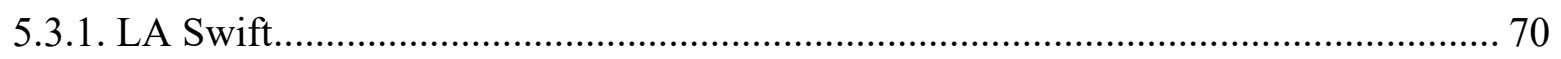

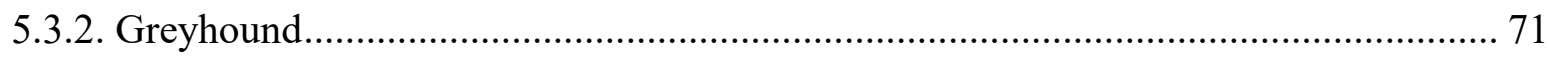

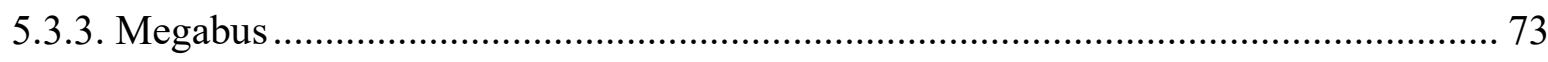

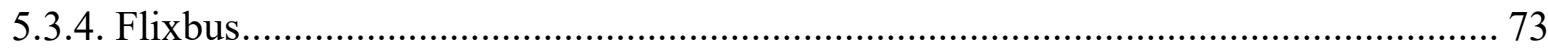

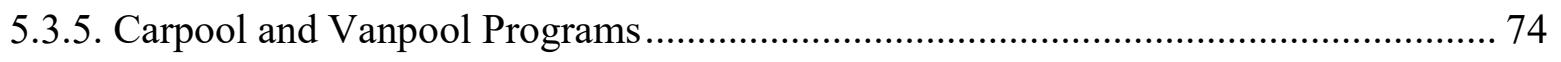

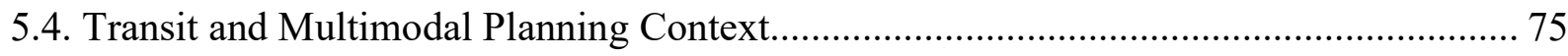

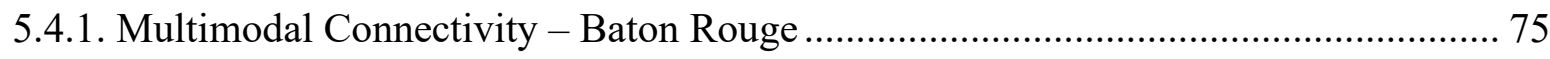

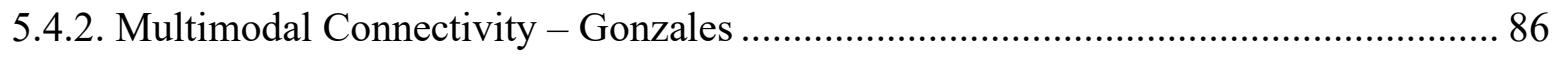

5.4.3. Multimodal Connectivity - LaPlace ……………………………………………..... 88

5.4.4. Multimodal Connectivity - Jefferson Parish .............................................................. 91

5.4.5. Multimodal Connectivity - New Orleans ………………………………………....... 96

5.5. Evaluation of Previously Developed Cost and Ridership Estimates ............................... 100 
5.5.1. Implementation Costs ........................................................................................... 100

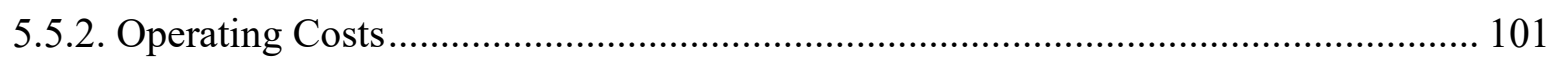

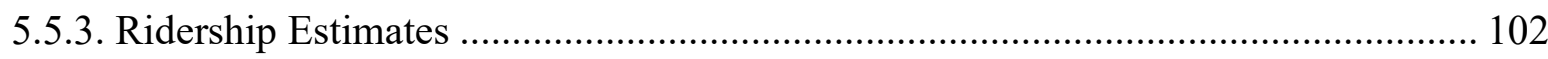

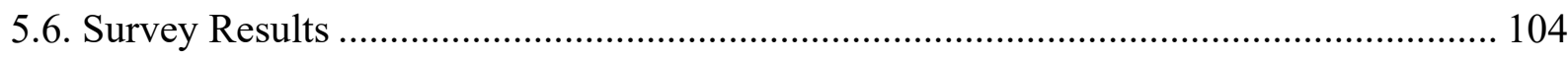

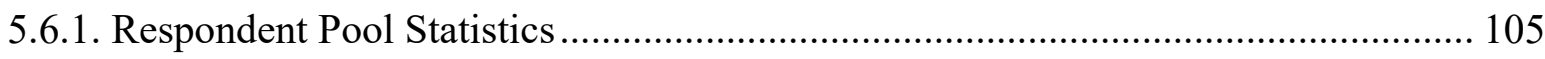

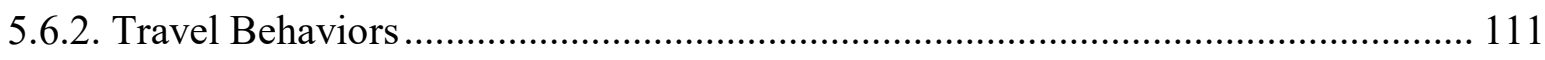

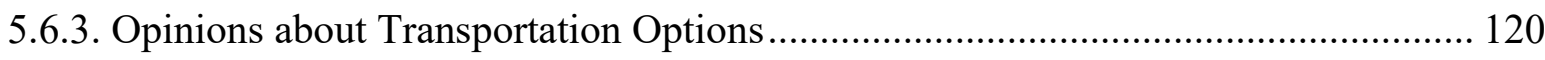

5.6.4. Impacts of COVID-19 on Travel Behavior ………….......................................... 127

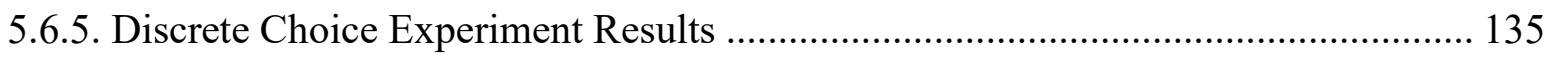

5.6.6. Cohort-based DCE Findings ............................................................................... 140

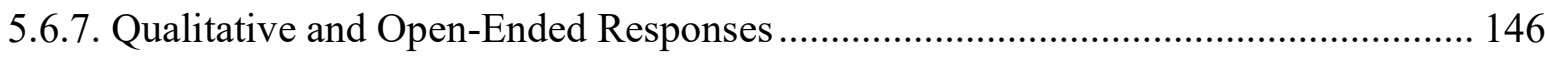

5.6.8. Spatial Distribution of Select Variables and Survey Responses................................ 148

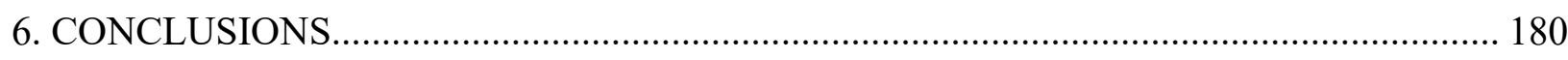

6.1. Existing and Future Conditions ................................................................................ 180

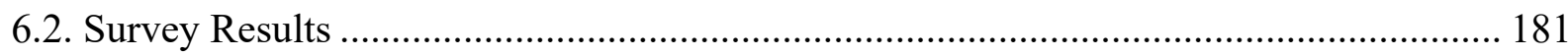

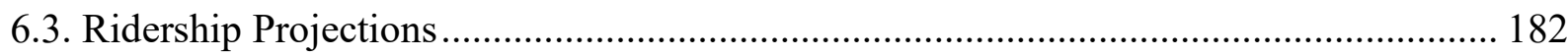

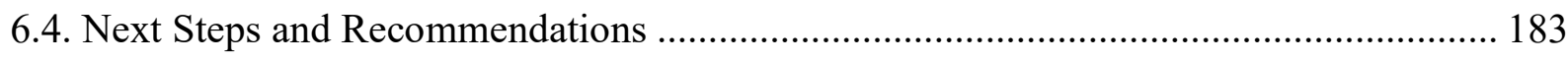

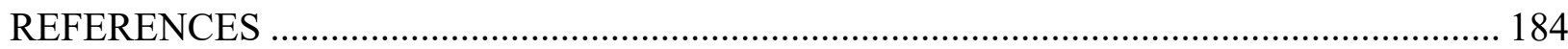

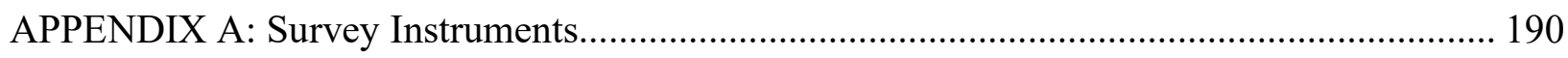

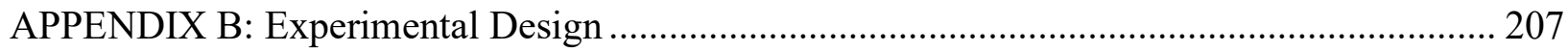

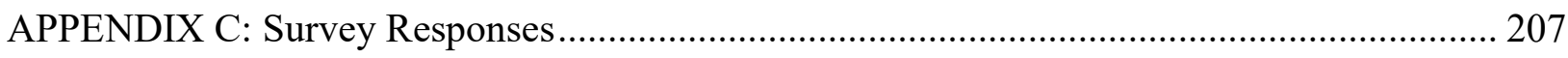

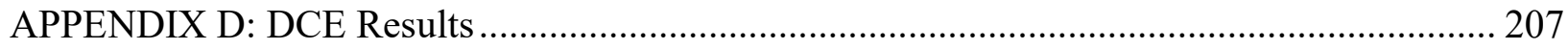

APPENDIX E: Open-Ended Responses (Queried)_................................................................ 207 


\section{LIST OF FIGURES}

Figure 1. Discrete choice experiment experimental design development stages (23).............. 31

Figure 2. Example format of the discrete choice survey as viewed by end user...................... 40

Figure 3. Proposed rail station locations, Baton Rouge - New Orleans Intercity Passenger Rail

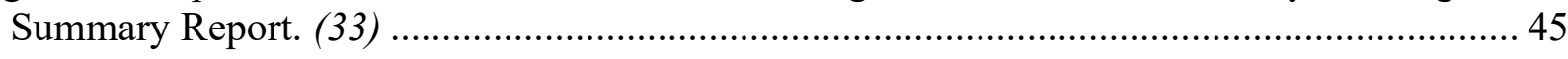

Figure 4. Original Gulf Coast high-speed rail corridor map. (33) ......................................... 45

Figure 5. Map of proposed rail station locations, 2014 HNTB feasibility study. (1) ................. 47

Figure 6. Existing and potential passenger rail routes in Louisiana. (32)............................... 49

Figure 7. Gulf Coast Corridor Existing and Proposed Service. (29) ........................................ 52

Figure 8. Downtown Baton Rouge station area map. (38) .................................................. 54

Figure 9. Downtown Baton Rouge station area population density per acre. (38) .................... 55

Figure 10. Downtown Baton Rouge station area job density per acre. (38) ............................. 55

Figure 11. Density of retail and service destinations. (38) ..................................................... 56

Figure 12. Proposed downtown Baton Rouge station site plan - West of rail tracks. (38).......... 56

Figure 13. Suburban Station site options and site context. (38) ................................................ 57

Figure 14. Suburban Baton Rouge station population density per acre. (38) .......................... 58

Figure 15. Suburban Baton Rouge station job density per acre. (38) ....................................... 59

Figure 16. Suburban Baton Rouge station density of retail and service destination. (38)........... 59

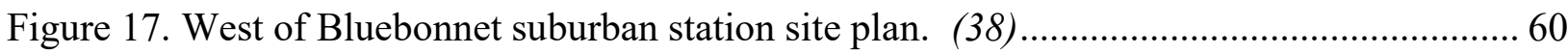

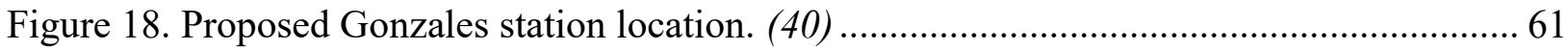

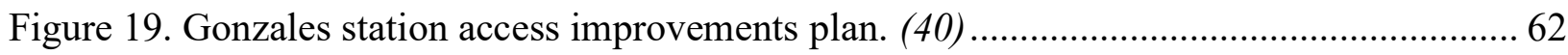

Figure 20. Potential site area redevelopment scenario. (40) ….............................................. 63

Figure 21. LaPlace Airline and Main proposed transportation center and redevelopment scenario.

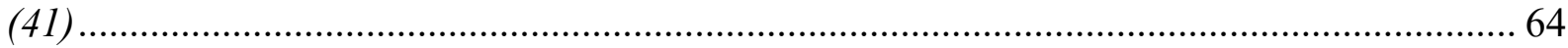

Figure 22. LaPlace station plan survey findings: key station features. (41) ............................. 65

Figure 23. LaPlace station plan survey findings: station area amenity preferences. (41) ........... 66

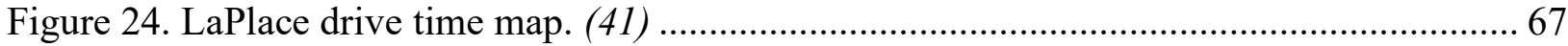

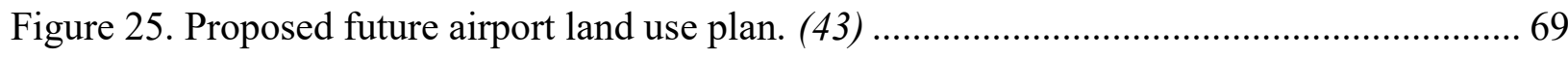

Figure 26. Location of Greyhound stations in NO-BR corridor............................................ 72

Figure 27. Government Street proposed station transit access. (38) .................................... 76 
Figure 28. Downtown Baton Rouge proposed station site plan. (38) ....................................... 77

Figure 29. Downtown Baton Rouge proposed station site plan - ingress detail. (38)................ 77

Figure 30. East Baton Rouge parish latent demand for biking and walking. (50)..................... 79

Figure 31. Bike network plan detail: downtown and mid-city Baton Rouge. (50).................... 79

Figure 32. Tiger Trails Garden District route map - mid-city detail. (54) ............................... 80

Figure 33. Baton Rouge Suburban Station site plan. (38) ....................................................... 81

Figure 34. Baton Rouge Suburban Station entrance layout. (38) …...................................... 81

Figure 35. Proposed medical district transit circulator shuttle route. (39)................................ 82

Figure 36. Suburban Baton Rouge Station area existing transit access. (38) ............................ 82

Figure 37. CNT Transit Performance Index - Suburban Baton Rouge Station. (38).................. 83

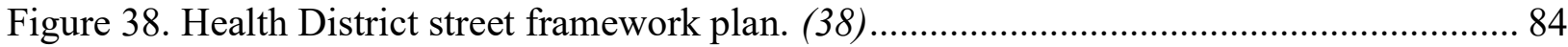

Figure 39. BREC Health Loop trail system. (39) ................................................................... 84

Figure 40. Proposed Baton Rouge BRT route - downtown detail. (59) .................................. 86

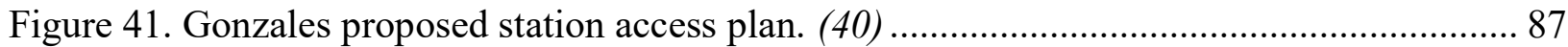

Figure 42. Proposed East Roosevelt St complete street cross section. (40) .............................. 87

Figure 43. Proposed Airline Highway RPTA fixed transit route. (41) ..................................... 89

Figure 44. Proposed LaPlace loop RPTA fixed transit route. (41) ......................................... 89

Figure 45. LA Safe Airline Highway proposed cross section. (41) ....................................... 90

Figure 46. Proposed LaPlace rail station and connecting bicycle routes. (41) ......................... 90

Figure 47. Jefferson Parish estimated bicycle demand. (62) ................................................ 92

Figure 48. Jefferson Parish proposed bikeways. (62) ........................................................ 93

Figure 49. New Orleans metro area transit propensity index. (64) ........................................ 95

Figure 50. Proposed Kenner/Elmwood JeT bus routes. (64) ................................................. 95

Figure 51. New Orleans downtown transit center primary and secondary site locations. (66) .... 96

Figure 52. Existing downtown New Orleans transit service. (64) .......................................... 97

Figure 53. Proposed downtown New Orleans transit service. (64) ........................................ 98

Figure 54. Existing and proposed bikeways, downtown New Orleans. (67)........................... 99

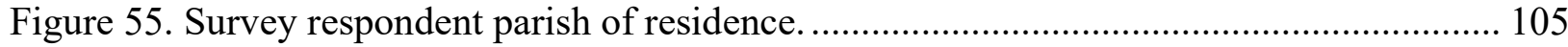

Figure 56. Respondent employment status. ................................................................ 106

Figure 57. Gender distribution of survey respondents.................................................... 107 
Figure 58. Gender distribution of survey respondents by parish..................................... 107

Figure 59. Age distribution of survey respondents.................................................... 108

Figure 60. Age distribution of survey respondents by parish. ........................................... 108

Figure 61. Survey respondent race distribution. ............................................................ 109

Figure 62. Survey respondent race distribution by parish. ................................................. 109

Figure 63. Income distribution of survey respondents. ................................................ 110

Figure 64. Income distribution of survey respondents by parish....................................... 110

Figure 65. Survey respondent usual work location...................................................... 111

Figure 66. Survey respondent household vehicle access. ................................................. 112

Figure 67. Survey respondent Pre-COVID commute mode(s) .......................................... 113

Figure 68. Survey respondent frequency of travel within New Orleans - Baton Rouge corridor.

Figure 69. Survey respondent frequency of travel within New Orleans - Baton Rouge corridor by

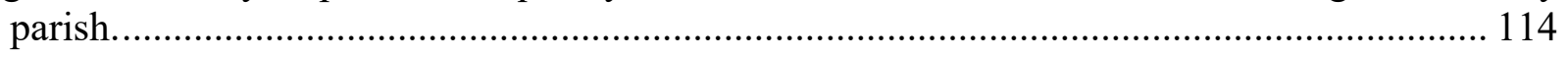

Figure 70. Survey respondent intraregional travel behaviors by parish. ............................... 115

Figure 71. Survey respondent purpose of travel within corridor....................................... 116

Figure 72. Survey respondent typical travel mode within corridor. ..................................... 117

Figure 73. Survey respondent typical travel mode within corridor by parish. ....................... 117

Figure 74. Survey respondent typical travel days within corridor....................................... 118

Figure 75. Survey respondent typical travel days within corridor by parish......................... 118

Figure 76. Survey respondent typical travel start times within corridor................................ 119

Figure 77. Survey respondent typical travel end times within corridor................................. 119

Figure 78. Survey respondent support for proposed rail service. ........................................ 120

Figure 79. Survey respondent support for proposed rail service by parish. .......................... 121

Figure 80. Survey respondent assessment of local public transit quality. ............................. 121

Figure 81. Survey respondent assessment of local public transit quality by parish. ................ 122

Figure 82. Survey respondent assessment of local bicycle infrastructure quality................... 123

Figure 83. Survey respondent assessment of local bicycle infrastructure quality by parish. ..... 123

Figure 84. Survey respondent assessment of walking environment in community................. 124

Figure 85. Survey respondent assessment of walking environment in community by parish.... 124 
Figure 86. Survey respondent preferred long-term solution for I-10 congestion. ...................... 125 Figure 87. Survey respondent preferred long-term solution for I-10 congestion by parish. ...... 125

Figure 88. Survey respondent likely mode of access to rail station............................................ 126

Figure 89. Survey respondent likely mode of access to rail station by parish........................... 127

Figure 90. Survey respondent commute mode before, during, and after (anticipated) COVID-19 (modal groups) ..................................................................................................... 128

Figure 91. Survey respondent anticipated return to pre-COVID travel behaviors. .................... 132

Figure 92. Survey respondent anticipated return to pre-COVID travel behaviors by parish. .... 133

Figure 93. Impact of COVID-19 on survey respondent transit use. .......................................... 134

Figure 94. Impact of COVID-19 on survey respondent transit use by parish. .......................... 134

Figure 95. Relative importance of attributes (all respondents).................................................... 141

Figure 96. Relative value of levels - all respondents.............................................................. 142

Figure 97. Marginal willingness to pay - all respondents......................................................... 143

Figure 98. Walk/bike potential capture area and population: Baton Rouge proposed stations. 149

Figure 99. Transit potential capture area and population: Baton Rouge proposed stations. ...... 150

Figure 100. Walk/bike potential capture area and jobs: Baton Rouge proposed stations............ 151

Figure 101. Transit potential capture area and population: Baton Rouge proposed stations. .... 152

Figure 102. Walk/bike potential capture area and population: Gonzales proposed station........ 153

Figure 103. Walk/bike potential capture area and jobs: Gonzales proposed station. ................. 154

Figure 104. Walk/bike potential capture area and population: LaPlace proposed station.......... 155

Figure 105. Walk/bike potential capture area and jobs: LaPlace proposed station. ................... 156

Figure 106. Walk/bike potential capture area and population: Jefferson Parish proposed stations. 158

Figure 107. Walk/bike potential capture area and jobs: Jefferson Parish proposed stations...... 159

Figure 108. Walk/bike potential capture area and population: NOUPT..................................... 160

Figure 109. Walk/bike potential capture area and jobs: NOUPT.............................................. 161

Figure 110. Transit potential capture area and population: NOUPT.......................................... 162

Figure 111. Transit potential capture area and population: NOUPT........................................ 163

Figure 112. Survey respondent distribution within corridor parishes........................................ 164

Figure 113. Overall support for proposed passenger rail service: Baton Rouge. ....................... 166 
Figure 114. Overall support for proposed passenger rail service: Gonzales. ......................... 167

Figure 115. Overall support for proposed passenger rail service: LaPlace ........................... 168

Figure 116. Overall support for proposed passenger rail service: Jefferson and Orleans Parish. 169

Figure 117. Ease of walkability to destinations of interest in community: Baton Rouge. ........ 170

Figure 118. Ease of walkability to destinations of interest in community: Gonzales............... 171

Figure 119. Ease of walkability to destinations of interest in community: LaPlace................. 172

Figure 120. Ease of walkability to destinations of interest in community: Jefferson Parish...... 173

Figure 121. Ease of walkability to destinations of interest in community: New Orleans. ......... 174

Figure 122. Anticipated mode of travel to future rail station: Baton Rouge. .......................... 175

Figure 123. Anticipated mode of travel to future rail station: Gonzales. .............................. 176

Figure 124. Anticipated mode of travel to future rail station: LaPlace. ................................. 177

Figure 125. Anticipated mode of travel to future rail station: Jefferson Parish........................ 178

Figure 126. Anticipated mode of travel to future rail station: New Orleans. .......................... 179 


\section{LIST OF TABLES}

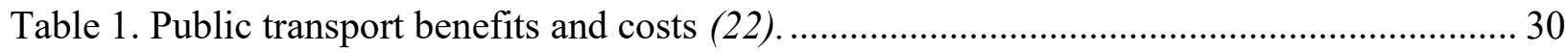

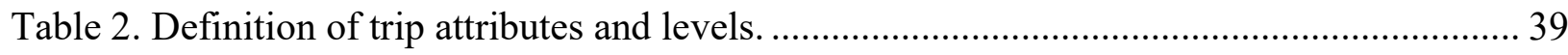

Table 3. Sociodemographic and built environment variables...................................................... 41

Table 4. Proposed service design, 2010 BKI Report. (33) ............................................................ 46

Table 5. Anticipated operating costs, 2010 BKI Report. (33) .................................................... 46

Table 6. Proposed service design, 2014 HNTB feasibility study. (1).......................................... 48

Table 7. Total Rail Activity Impacts. (32) ……………............................................................. 49

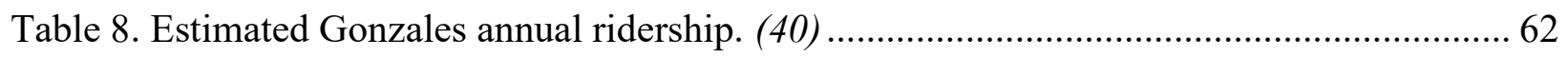

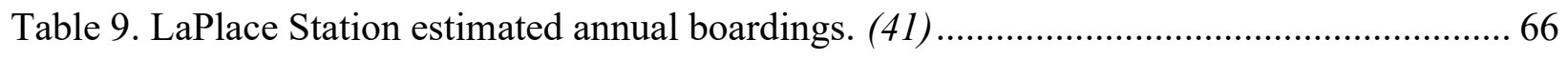

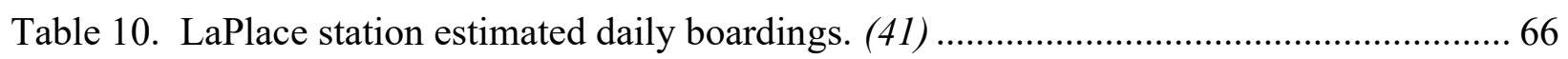

Table 11. Baton Rouge to New Orleans (NOUPT) scheduled trips - Greyhound .......................... 72

Table 12. New Orleans to Baton Rouge scheduled trips - Greyhound.......................................... 73

Table 13. Estimated 2014 feasibility study capital costs (in millions of 2013 dollars). (1) ....... 100

Table 14. 2010 Feasibility study estimated operating costs. (33)............................................. 101

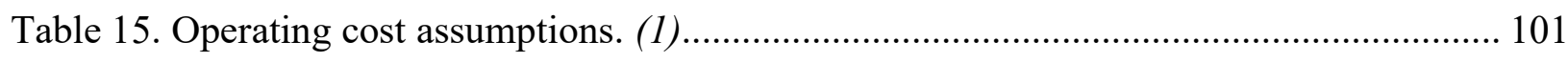

Table 16. Total operating costs, revenue, and projected subsidy. (1) ......................................... 101

Table 17. New Orleans - Baton Rouge projected ridership and ticket revenues. (33)............... 102

Table 18. Annual attendance for special events in New Orleans. (1) .......................................... 103

Table 19. Estimated total annual ridership, 2010 vs. 2014 projections. $(1,33)$......................... 103

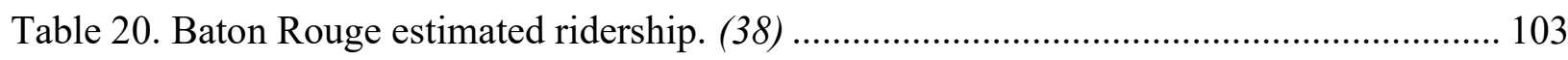

Table 21. Gonzales estimated ridership. (40) ....................................................................... 104

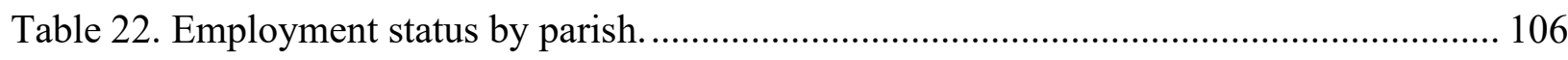

Table 23. Survey respondent usual work location by parish. ................................................... 111

Table 24. Survey respondent household vehicle access by parish............................................. 112

Table 25. Survey respondent pre-COVID commute mode(s) by parish..................................... 113

Table 26. Survey respondent intraregional travel behaviors by parish...................................... 115

Table 27. Survey respondent purpose of travel within corridor by parish................................. 116

Table 28. Survey respondent commute mode before, during, and after (anticipated) COVID-19

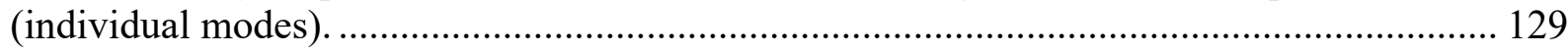


Table 29. Survey respondent commute mode before, during, and after (anticipated) COVID-19 (individual modes) by parish. ......................................................................................... 130

Table 30. Respondent commute mode share before, during, and after (anticipated) COVID-19:

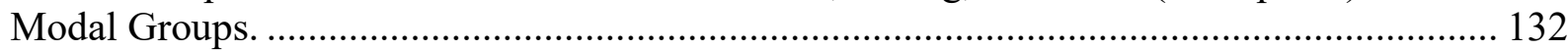

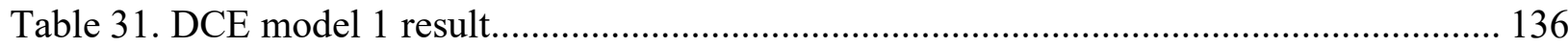

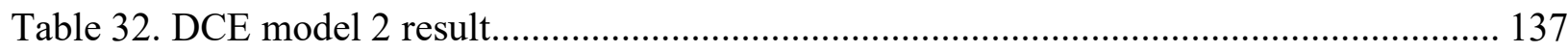

Table 33. Ridership estimates: calculation of daily interparish trips (step a)............................. 138

Table 34. Ridership estimates: calculation of daily interparish trips (step b)............................. 139

Table 35. Ridership estimates: calculation of potential daily and monthly ridership................. 139

Table 36. Relative importance of attributes by parish. ................................................................ 141

Table 37. Relative value of levels by parish........................................................................ 142

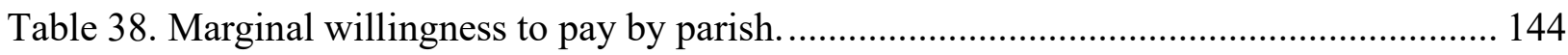

Table 39. Relative importance of attributes by gender, race/ethnicity, income, and vehicle access.

Table 40. Relative value of levels by gender, race/ethnicity, income, and vehicle access......... 145

Table 41. Marginal willingness to pay by gender, race/ethnicity, income, and vehicle access.. 146

Table 42. Open-ended responses: number of references by keyword/theme. ............................ 147 


\section{ACRONYMS, ABBREVIATIONS, AND SYMBOLS}

ABS

ACS

ADA

ARRA

ARRF

BID

BRAF

BREC

BRRA

BRT

BUILD

CATS

CBA

$\mathrm{CN}$

CPEX

CRISI

CRPC

CTPP

DCE

DOT

EPA

FAST

FRA

FTA

GIS

GTFS

HLM

IRB

KCS
Automatic Block Signals

American Community Survey

Americans with Disabilities Act

American Recovery and Reinvestment Act of 2009

Aggregate Rail Ridership Forecasting

Business Improvement District

Baton Rouge Area Foundation

Recreation and Park Commission for the Parish of East Baton Rouge

Baton Rouge Redevelopment Authority (aka Build Baton Rouge)

Bus Rapid Transit

Better Utilizing Investments to Leverage Development

Capital Area Transit System

Cost Benefit Analysis

Canadian National Railway

The Center for Planning Excellence

Consolidated Rail Infrastructure and Safety Improvements Program

Capital Region Planning Commission

Census Transportation Planning Package

Discrete Choice Experiment

Department of Transportation

Environmental Protection Agency

Fixing America's Surface Transportation Act

Federal Railroad Administration

Federal Transit Administration

Geographic Information System

General Transit Feed Specification

Hierarchical Modeling

Institutional Review Board

Kansas City Southern Railway 
LADOTD

LANOIA

LASAFE

LEHD

LODES

LSRRA

MLM

NEPA

NORG

NORPC

NOUPT

OTP

PUD

PRIIA

PRC

RPTA

ROW

RRIF

RTA

SLD

SRC

STOPS

TAZ

TDM

TDR

TIF

TIFIA

TIGER

TOD

TRB
Louisiana Department of Transportation and Development

Louis Armstrong International Airport

Louisiana Strategic Adaptations for Future Environments

Longitudinal Employer-Household Dynamics

LEHD Origin-Destination Employment Statistics

Louisiana Super Region Rail Authority

Multilevel Modeling

National Environmental Policy Act

New Orleans Gateway Program

New Orleans Regional Planning Commission

New Orleans Union Passenger Terminal

On-Time Performance

Planned-Unit Developments

Passenger Rail Investment and Improvement Act of 2008

Project Review Committee

River Parishes Transit Authority

Right-Of-Way

Railroad Rehabilitation \& Improvement Financing

New Orleans Regional Transit Authority

Smart Location Database

Southern Rail Commission

Simplified Trips-On-Project Software

Transportation Analysis Zone

Travel Demand Management

Transfer of Development Rights

Tax Increment Financing

Transportation Infrastructure Finance and Innovation Act

Topologically Integrated Geographic Encoding and Referencing

Transit-Oriented Development

Transportation Research Board 
UNO

UP

VMT
University of New Orleans

Union Pacific Railway

Vehicle Miles Traveled 


\section{EXECUTIVE SUMMARY}

This study aims to evaluate the multimodal linkages to and opportunities for proposed terminal sites for a potential future passenger rail connection between Baton Rouge and New Orleans, Louisiana. A broad coalition of stakeholders, including local and regional governmental entities, economic development organizations, and advocates support the development of this connection, and several feasibility studies and station area plans have been developed in anticipation of possible future funding for implementation.

However, the effectiveness of the proposed project as a means to expand employment opportunity for Louisiana residents and promote economic growth within rail corridor communities, to mitigate traffic congestion and support corresponding environmental benefits, and to provide efficient access to goods, services, and destinations is contingent upon the convenient provision of multimodal transportation facilities and services connecting the proposed intercity rail service to the surrounding communities.

This study supports an improved understanding of the dynamics of likely ridership through the following key activities:

- a comprehensive evaluation of existing transportation networks connecting proposed rail terminal sites

- distribution of a survey aimed at understanding the potential for passenger rail ridership and the needs of likely users

- identification of transit priorities and opportunities to maximize connectivity of intercity rail to employment destinations

- development of methods to model rider preferences and exploratory methods of estimating projected and/or potential ridership, including non-work trips

Overall, we find the following broad conclusions and recommendations with implications for transportation planning within the Baton Rouge-New Orleans super region as pertains to the proposed passenger rail corridor:

$>$ Recently completed station area plans and local transit/streets enhancement project have created a robust blueprint for future service. Implementation of these plans will position local jurisdictions to substantially improve multimodal accessibility and provide key connections for future rail service users to connect to and from their final destinations.

$\checkmark$ Recommendation: Additional work is needed to advance similar planning activities where such plans have not yet been developed, as well as to identify funding sources to implement proposal recommendations.

$>$ The survey, which drew in over 4600 completed responses (primarily from parishes which would be directly served by the proposed rail service), found strong support regionwide for passenger rail as well considerable interest in multimodal travel locally. However, corridor residents are not necessarily currently interested in using active modes of transport or public transportation to access the train, indicative of current deficiencies in these networks and reflecting the region's relatively dispersed, auto-oriented development patterns.

$\checkmark$ Recommendation: There are many plans, but as-yet limited cohesive multimodal networks. If planners and stakeholders wish to prioritize non-automobile modes of accessing the train and maximize station area development potential, considerable 
work and investment is needed to continue to improve local connections: most respondents simply do not see these as viable options at present.

$>$ Although interest exists among commuters who work across parish lines to use the train for work trips, most potential riders would not expect to utilize passenger rail for work trips; instead, it is viewed as a vital means of accessing the region's many cultural, recreational, sporting, and entertainment events, as well as connecting families.

$\checkmark$ Recommendation: existing ridership models may be based on faulty assumptions that overestimate commute trips and underestimate trip purposes. Additional research is needed to further investigate and model the types of trips most likely to be captured by the proposed rail service.

$>$ COVID-19 has impacted residents' travel behaviors and patterns but may have also increased exposure to and comfort with walking and bicycling: survey respondents indicate an interest in incorporating active modes of travel into their lifestyles even beyond the pandemic. On the other hand, telecommuting has increased dramatically in 2020, and these impacts are expected to linger long term.

$\checkmark$ Recommendation: build upon the increased interest in walking and bicycling experienced regionally in 2020 by continuing to promote policy, programs, and projects that support use of public space and $R O W$ for recreation and active transportation, to improve public perception of existing transportation options.

$>$ Modeling of survey responses, including a Discrete Choice Experiment (DCE) aimed at analyzing rider sensitivities and preferences as well as extrapolation of reported interparish trip frequencies. The data showed consistent preferences across neighborhoods, parishes, and demographic groups, and indicate that potential demand, if scheduled appropriately and not constrained by supply of service, could exceed previously estimated ridership projections.

$\checkmark$ Recommendation: Additional research is needed to address gaps in the survey sample and target underrepresented user groups. In addition, model results were inconclusive and require further exploration and analysis. A full update of the ridership estimation model (including utilization of the FTA's STOPS software and analytic tools) is recommended to reflect changes in the state's changing population and travel patterns over the last decade. However, continued exploration of methods to better plan for non-work trips and special user groups is also imperative.

This project seeks to inform future transit, passenger rail, and multimodal planning processes and advance the implementation of projects through outreach and technology transfer to local, regional, and state-level stakeholders and promote efficient, effective transportation investments. For the proposed rail service to be successful and meet revenue targets, it must be designed to meet the needs of those most likely to ride it. This study provides new insight into the preferences and perceptions of the route's target audience, in order to inform implementation. 


\section{INTRODUCTION}

The prospect of resuming a passenger rail connection between New Orleans and Baton Rouge, Louisiana, discontinued in 1969, has periodically surfaced as a transport priority and subject of study at intervals over the last thirty years, from an early feasibility study completed in advance of the 1984 World's Fair (1) to a rail station master plan for a proposed interim stop location in Gonzales, Louisiana, completed in 2018 (2).

Broad support from economic development organizations and local and regional governments has been garnered for the project, in order to better connect the "Southeast Louisiana Super Region," home to over 2 million people and almost 1 million jobs (3). Advocates in the seven parishes along the corridor have formed the Louisiana Super Region Rail Authority (LSRRA), a collaborative entity authorized by the state legislature allowing municipal and parish governments to form a compact focused on reinvigorating the feasibility of passenger rail between Baton Rouge and New Orleans.

However, the project has faced significant challenges in advancing toward implementation $(4,5)$ most notably over concerns about ongoing operating costs not covered by projected fare revenue. At least two opportunities to seek federal funding to implement the project have been passed over, first due to opposition from former Governor Bobby Jindal (6), and most recently due to a lack of interest (and matching funds) from neighboring states in advancing a broader proposal to return passenger rail to the Gulf Coast, including the New Orleans-Baton Rouge connection (7).

A broad coalition of stakeholders, including local and regional governmental entities, economic development organizations, and advocates support the development of this connection, and several feasibility studies and station area plans have been developed in anticipation of possible future funding for implementation. However, the effectiveness of the proposed project as a means to expand employment opportunity for Louisiana residents and promote economic growth within rail corridor communities, to mitigate traffic congestion and support corresponding environmental benefits, and to provide efficient access to goods, services, and destinations is contingent upon the convenient provision of multimodal transportation facilities and services connecting the proposed intercity rail service to the surrounding communities.

Previous research (1) asserts that the proposed rail service using predominantly existing, freightrail tracks, could be developed incrementally to serve seven possible stations, including the Louis Armstrong Airport, at an initial annual operating subsidy requirement as low as $\$ 6.7$ million, substantially lower than previous iterations of the project put forth as feasible. This estimate, however, is contingent upon the proposed service meeting ambitious ridership targets.

A key determinant of whether the rail connection could meet those targets is how effectively the rail service connects riders to their final destinations in order to reduce friction and costs associated with travel via public transportation relative to personal automobiles. In order to ensure that the proposed service, if developed, can successfully serve its potential users, and to understand which factors (in terms of access, potential rider characteristics, and connecting service scenarios) are most likely to result in achievement of projected ridership targets, additional research is needed to identify state and local actions that will maximize station connectivity and best support the development of a successful service that realizes purported economic benefits to the New OrleansBaton Rouge super region. 


\section{OBJECTIVES}

This study aims to address the gap in our understanding of how the proposed rail terminals relate to their immediate and regional context by evaluating multimodal connectivity and accessibility at the proposed terminals, New Orleans, Baton Rouge, and points in between, and to identify recommendations for maximizing ridership of the proposed rail service, if developed, by

promoting convenient, efficient connections from intercity rail terminals to key destinations and communities.

Specifically, this research addresses the following key objectives:

1. Conduct an evaluation of the connections between proposed and potential rail terminals in New Orleans and Baton Rouge and the existing public transportation systems to which this service would connect Louisiana residents to economic centers within the region.

2. Model dynamics of likely ridership and identify recommendations for proposed terminal sites and multimodal linkages that will optimize intercity transit service utilization, thereby maximizing congestion reduction, environmental impact, and economic opportunity expected to result from the proposed service.

The output of this project is a set of survey findings and model results illuminating how service design, station placement, and planning can be expected to impact ridership for the proposed New Orleans-Baton Rouge rail link under different planning scenarios, and a series of recommendations for maximizing the overall utility, feasibility, and economic potential of the proposed connection, in order to address gaps in previous planning efforts which have hindered momentum toward project implementation. 


\section{LITERATURE REVIEW}

As a recent Congressional Research Service Report notes (p.2), "The federal government has been involved in preserving and improving passenger rail service since 1970, when the bankruptcies of several major railroads threatened the continuance of passenger trains. Congress responded by creating Amtrak - officially, the National Railroad Passenger Corporation-to preserve a basic level of intercity passenger rail service, while relieving private railroad companies of the obligation to maintain a business that had lost money for decades (8)." Currently, New Orleans is the starting point for multiple long distance Amtrak routes, including The City of New Orleans route, which stops in 18 cities along the way to major transportation hubs such as Jackson, Memphis, and Chicago, and the Sunset Limited which links New Orleans to Houston and Los Angeles, respectively the fourth and second most populated American cities. The 1,377-mile Crescent connecting New Orleans to New York City via Atlanta is another example of a long-distance route linking major cities, with frequent stops connecting smaller, rural communities to larger transit networks.

Growing interest in passenger rail between Baton Rouge and New Orleans follows a trend shifting towards multimodal and transit-oriented development within and between metropolitan regions. Louisiana is geographically fortunate in that the state's capitol, Baton Rouge, is less than 80 miles away from its most populous city, New Orleans. Despite the proximity of these two major cities, there are few transportation options available to travel between the two cities that are practical and affordable for occupational commuters and those without vehicles. As observed by Gatien (9), "Cities are laboratories... They offer an endless variety of contexts for finding out what works and what doesn't (p.5)." The geographic, political, social, and ecological contexts within southern Louisiana present a unique challenge for development of public transit infrastructure in the deltaic super region, therefore potential peer case studies were reviewed in order to inform this project's inquiry and provide guidance and suggestions based on the lessons learned through similar undertakings. This literature review outlines best practices in the development of intercity and commuter transit services generally, and multimodal planning related to station area and rail development specifically, as well as documented limitations and areas of concern. Finally, this section reviews overall methods of projecting ridership as part of service development and evaluates practices for estimating economic impacts.

\subsection{Development of new intercity and commuter transit services}

Passenger rail can be divided into three major general categories: light rail (serving passengers within a relatively constrained urban area with a system extent of 20 miles or less and station spacing of $1 / 2$ to 1 mile, and typically powered by overhead electrical wires), commuter rail (heavy rail serving suburbs of larger metropolitan areas with a total system extent of up to 75 miles and with stations spaced further apart (up to 5-10 miles), and intercity rail, for longer distance routes between metropolitan areas, with greater spacing between stations. The proposed New Orleans to Baton Rouge passenger route is technically an intercity route, although with some characteristics of commuter rail due to the relatively close distance of the two cities and the proximity of intermediate stops to major urban centers. Literature pertaining to both "commuter" and "intercity" rail service typologies is included in this review.

Implementation of transit-oriented development strategies, such as multimodal hubs and intercity commuter rail lines, can help to connect communities to resources and destinations that may not 
be accessible due to financial, physical, or temporal limitations. These techniques have demonstrated the possibility of creating a sense of community and place or revitalizing existing communities that have systematically been cut off from access to resources, by supporting economic development near transit lines, reducing transportation costs for residents, and improving access to jobs for households of all incomes. Environmentally, implementation of intercity rail reduces automobile trips, vehicle miles traveled (VMT), and greenhouse gas emissions, while promoting public health through increased opportunities for active transit such as walking or biking. Fiscally, transit-oriented development can reduce infrastructure costs comparatively considering the immense maintenance costs required to support sprawling growth, while increasing transit agency revenues through increased ridership (10).

About $15 \%$ of Amtrak's total ridership comes from travelers on long distance routes, however it is becoming increasingly popular for passengers to ride shorter portions of these long-distance routes seeing as they often travel the same rails as regional and commuter rail, effectively increasing the frequency of shorter runs. Linking proximate regions, such as New Orleans and Baton Rouge, provides an alternative to increasingly overcrowded intercity highways and airspace, and ridership on regional routes has increased by $72 \%$ in the last decade. Today, these routes account for just under half of all Amtrak ridership, though it should be noted that regional rail transport is also supported by the individual states' infrastructure (10).

Long distance routes have historically been well-utilized by senior citizens and passengers with disabilities who may not be physically comfortable with the constraints of airline travel. Additionally, traveling by rail has massive advantages for improving accessibility and desirability of destinations for residents who are differently abled or non-neurotypical and averse to the challenges of traveling by air. Considerations of physical space and mobility have taken on a new context in the age of COVID-19. What may have once been considered specialized considerations are now shared by the majority of the nation's population in response to the COVID-19 pandemic, where physical proximity to others and allotted personal space are issues of public safety as well as matters of comfort in our transit decisions (10). Although the impact of COVID-19 on transit preferences cannot be properly examined until the pandemic has ended, it is already clear that the ways that we travel throughout the world will be fundamentally changed by this viral event.

Klein et al. (10) cite that 42 of the nation's 60 large and medium hub airports are located within 10 miles of Amtrak stations, with 21 of those 42 airports within five miles of an Amtrak station. With over $35 \%$ of the United States' major airports located within five miles of a rail station, it is notable that we do not see more connectivity between local and regional/intercity transit infrastructure. Experts claim this is a result of institutional barriers, like the limited nature of existing intercity rail networks limiting service and connectivity to other transportation modes, as well as financial barriers preventing speculative development (11).

Connecting transit hubs such as train depots, bus stations, and airports with popular enddestinations, such as college campuses, business districts, and recreational spaces provides opportunity to increase short-distance ridership by getting the passenger closer to their final destination safely and cost effectively, as well as increasing long-distance ridership by connecting passengers to more destinations (12). Inherently, the draw of regional rail connectivity is that one mode of transportation can bridge geographic as well as accessibility gaps by utilizing a variety of transit modes to provide services from the first mile to the last mile of their rider's journey, while 
consolidating resources and maintenance costs by fulfilling the needs of both short and longdistance travelers simultaneously.

No matter what metrics are being used to measure the success of a rail line or station, ridership is the final determinant of whether a station and service meet a community's needs. As indicated in the Hoosier State Rail case study discussed below, evaluation of residents' needs occurred too late, and ridership continued to decline even as the service providers researched avenues for improvement (13). In order to prevent this outcome, community surveys and needs assessments should be conducted during the preliminary stages of project development. Although they may not be traditionally considered as such, the potential riders of any rail service are the biggest stakeholders in that potential development seeing as they are the direct beneficiaries of the public service provided by the rail line. Community visioning processes should engage a wide audience with differing viewpoints to develop a clear picture of the spectrum of viewpoints held by the broad clientele of a public transportation service. While a public entity may need to facilitate the process, there should be equal authority afforded to all participants whether they be city staff, elected officials, or a member of the general public. The visioning process should work towards developing consensus and support for a common goal incorporating feedback from a variety of departments, agencies, community groups, and business interests. As Gatien states (9), "municipal agencies rarely have all the resources they want or need and choices have to be made" (p.6). Providing the community with access to the decision-making process makes the needs of each party transparent and provides insight as to why certain choices are made. "Assessing those choices by evaluating how they impact the most vulnerable in the community, those with reduced mobility, or those who can least afford an increase in transit fares or an increase in their commute times, is a central aspect of any effective integration policy. Particularly when improving accessibility for vulnerable groups might be as simple as filling in a gap in the sidewalk network" $(9, p .6)$

In order to develop consensus between disparate groups with varying amounts of power and conflicting interests, a mutual understanding of goals, responsibilities, and expectations of each other, and of the visioning process, should be clearly defined early in the activity. Kline et al. (10) propose that the process should emphasize long-term planning with near-term results and milestones, and aim to produce viable feedback such as:

- "A clear statement of what the community wants stations and TOD planning to bring to them. (New development? Preserve the existing character? A combination of each? Etc.)

- Direction to create standards for new development, or broad statements about the type and scale of new investment, i.e., densities, building heights, setbacks, etc. For example, to create places that will be centers of activity and economic drivers, buildings should be oriented toward sidewalks.

- A broad sense of the timeline for implementation and the role of the public sector in funding catalytic projects." (10)

While the processes detailed above are undoubtedly useful and scalable, challenges with designing transit around a community's needs are increased as project scope grows from serving a community to a region. While transit-oriented development provides tools, resources, and templates for local partners to implement programs tailored to specific community needs, infrastructural development at the state and federal levels present new coordination and consensus building challenges that increase exponentially as the size of the project footprint grows (14). In a report to Congress entitled Improving Intercity Rail Service in the United States, Ben Goldman writes (p.22): 
"Rail planning in the United States is not centralized, relying on project sponsors (usually states) to formulate their own plans. Congress and several presidents have, at times, identified corridors as investment priorities or set out trip time goals for certain routes, but these have usually not been backed by any financial commitment or implementation plan. The lack of reliable funding for passenger rail capital projects and operations is one obstacle to rail planning, as some states may not wish to invest time and resources into a plan that may not be achievable without additional federal support." (8)

Funding for intercity passenger rail often comes from multiple sources. Typically, passenger fares cover more than half of total operating expenses, including operating trains, paying salaries, and maintaining infrastructure. State and Federal governments often provide some additional funding, especially for capital expenditures, but the annual federal appropriations process can lead to fluctuations in funding year-to-year, which negatively impacts the ability to plan for long-term planning developments. Additionally, political forces and economic conditions greatly influence this funding - this congress may have one vision for intercity passenger rail within the nation's overall transportation system, and the next elected official may completely disagree (10).

With that said, the last decade has seen a renewed interest in intercity and high-speed rail passenger trains on the part of the federal government. As part of the American recovery and Reinvestment Act of 2009 (ARRA), the Federal Railroad Administration dispersed $\$ 8$ billion in funds to 24 states who submitted project proposals for improving local passenger rail services. Feinsod (15) continues,

"In 2011, an additional \$2 billion was appropriated by the U.S. Department of Transportation for use in transportation projects, including HSR projects. These funds, and their related programs, have created a large body of new research, plans, designs, and construction projects that will improve intercity passenger rail services by adding capacity, increasing speeds, improving freight and passenger line coordination, removing congestion points, and accomplishing related projects" (p.5).

Unfortunately, funding for these projects dissolved in 2015. A new Rail Title was included in the five-year Transportation Authorization bill, which passed the House and the Senate and was signed into law by President Obama in December of 2015. This bill enabled intercity passenger rail improvement grants to flow to states and a newly reformed Amtrak (15).

Additionally, the Federal Transit Administration's "5311" program offers subsidies for service to populations under 50,000. Funding is set to increase from $\$ 577$ million in 2018, to $\$ 591$ million in 2019. State governments have added new services on over a dozen routes using this funding, in concert with creative arrangements where states provide matching funds "in kind" in order to facilitate expansion (15).

\subsection{Multimodal planning for intercity transit}

Providing multiple points of access as well as flexible services are considered two determinants of a successful transit option, and therefore designing the Baton Rouge - New Orleans rail connection should place multimodality of stations and destination hubs as an integral aspect of the project's design. Klein (10) describes multimodal stations as such:

"Multimodal stations are those that can easily be accessed by walking, biking, local and regional transit, vanpools and shuttles, taxis, and private car. Ensuring that all of these 
are viable options is especially important for intercity rail stations because those stations serve a variety of people taking trips for many different reasons. Multimodality also supports higher ridership for the trains. Making intercity rail stations into local transit hubs increases the service area for the intercity rail and the ridership potential, while reducing the localized traffic and parking impacts (p.20)."

To make a station multimodal, it should be envisioned from its origin as a transit hub, connecting intercity rail and existing local transit infrastructure in order to mutually grow ridership. Peak demands should always be met, especially when attracting riders from smaller communities. This means demand needs should be prioritized for sports games, concerts, local events and festivals, in addition to the routine commuter's workday needs (10). Stations and surrounding areas should be designed with the multimodal rider in mind, meaning that high occupancy infrastructure should be properly connected with active transportation routes supporting walkers and bikers, safe and sufficient bicycle parking should be provided, and surrounding blocks should be scaled to pedestrian use with complete sidewalks and pedestrian amenities (14). Using the Complete Streets model sets an ideal standard of accessible design that incorporates the needs of all riders, regardless if they want to walk, bike, car-share, take the bus, or drive to their destination (10).

While supporting bicycle travel requires specific developmental considerations, the benefits greatly outweigh the costs. In order for bicycles to be considered a viable means of transport, planning for placement of protected bike lanes, clear and consistent wayfinding signage, determining pathways with low grade elevation changes, specialized bicycle parking and locations of bikeshare hubs should be conducted early in the planning process. Investment in bicycle travel can greatly increase rail ridership in suburban, auto-oriented locations by providing an alternative to single-occupancy travel and connecting the first and last mile gap. Regarding this phenomena, Gatien (9) observes:

"Suburban bikeshare users were far more likely to report increased transit use. These findings indicate that suburban bikeshare users widely use bikeshare to access transit, but are much less likely to use bikeshare to replace transit journeys. This suggests that integrating bikeshare into new suburban transit projects from the outset can provide ridership benefits. Locating bikeshare stations at transit facilities benefits both modes by providing a wider range of mobility options" (p. 43).

Connecting rail stations with bus depots and providing onboard bicycle storage can provide an efficient means to extend bus routes and overall transit connectivity in suburban areas as well (14). Finally, customer empowerment and education will increase the knowledge and capacity of cyclists and will encourage ridership for those who may be averse or afraid of commuting by bicycle. Sauraci suggests offering workshops on how to use bike racks onboard public transit, providing resources regarding bikeshare, and information on navigation and parking accessibility (14).

"The consequences of not making a station area multimodal are cumulative," Kline notes (10): "When a station is surrounded by parking, its placemaking potential is diminished. Parking acts as a barrier for pedestrian access to stations, and the lots themselves take up precious real estate near the station that might otherwise be developed into active, tax-generating uses (p. 20)." Although parking for vehicles, busses, and bicycles must be considered within any functional transit plan, however, there is great disagreement on developing metrics to quantify exactly how much parking is needed. Sauraci (14) asserts: 
"Given the relative cost of bicycle parking compared with other amenities, transit agencies should provide as much bike parking as possible. Many transit agencies set a quantitative metric for bicycle parking based on peak transit ridership. These numbers typically include a factor for existing ridership and a percentage for anticipated growth. While this formula based on percent capacity plus percent for growth has been adopted across several North American transit agencies, the precise percentage of ridership should be tailored to match the station's context. If detailed data is available specifically for cycling to transit, that may be a better dataset to inform decision-making" ( $p$. 27).

Sauraci (14) continues: "Bicycle parking is also the most flexible tool for capacity-building in response to increased demand, and it can offset demand for bicycles onboard transit vehicles." (p.27). Parking for vehicles is costly, spatially and financially. Parking structures cost on average $\$ 40,000$ per space, while a park-n-ride garage can cost upwards of $\$ 118,000$ per space. Comparatively, a bicycle locker costs approximately $\$ 3,000$ to store multiple bicycles (9). Bicycle parking can consist of bike racks, sheltered bike racks, bike cages, bike lockers or lock-up rooms. No matter what form it takes, bicycle parking:

- Should be well maintained and monitored

- Should minimize crowding using regular tagging and removal of abandoned bicycles

- Should have adequate lighting and visibility

- Should be located near station entrances or within stations if space permits

Despite ample evidence of the improved accessibility, affordability, and safety of travel by rail for urban residents in the age of COVID-19, research shows that many urban commuters still prefer the convenience of ride-share service and single occupancy vehicles for short distance travel (13). To provide a competitive option, multimodal alternatives to single occupancy vehicles need to connect public transportation networks to neighborhoods, and rail services need to incorporate new technologies that are modeled to provide comparative benefits to ride sharing. E-ticketing, dynamic pricing, stratified services, and flexible schedules are highly valued services for rail-based transportation in 2020 because these services are designed to meet the user's expectations by providing services that match the convenience and cost of single passenger transit options. Advancements in cellular app technology allowed for the rise of on-demand car services, such as Uber and Lyft, therefore established methods of transit such as commuter rail must adapt processes to accommodate a new technology and changing clientele needs and values. Electronic ticketing, dynamic pricing and stratified services allow passengers to purchase the option that best suits their needs and their budgets, all from the convenience of their phones, making a short distance rail trip economically competitive and just as convenient as ordering a car from an app (12).

\subsection{Case Studies}

This section highlights two recent commuter/intercity regional rail initiatives which provide useful insight into service development, station area planning, and intermodal connectivity for users, as well as highlighting implementation or operational challenges or areas of concern which may be instructive for Louisiana.

\subsubsection{South Florida Brightline}

The economic development potential in areas proximate to rail stations with vibrant designs and necessary amenities can be seen in the Brightline rail development connecting Miami to Fort 
Lauderdale and West Palm Beach in Florida. This service debuted in January of 2018 and runs approximately 11 high speed trips per day. In the few years since its origin, this rail line has lured ample high-occupancy residential, commercial, and recreational development surrounding stations in Miami and Fort Lauderdale, with an expected seven acres of downtown development within Fort Lauderdale in years to come. Some aspects that have made this project a success are the vehicle and pedestrian connection between the Brightline station in West Palm Beach and Clematis Street, a popular pedestrian shopping area with newly built 24-story residential tower overlooking the station and SkyBike bike-share services. The Miami station boasts an attached office tower with retail space including a grocery store and a gym, as well as two newly constructed residential towers. Fort Lauderdale's station is still being designed, and Mayor Dean Trantalis expects residential and office space as well as a government center within walking distance of the station.

Although the neighborhoods immediately surrounding Fort Lauderdale are in the process of being revitalized, brightly color-coded pathways have been painted along sidewalks to direct riders to popular destinations and cultural sites. All three stations on the Brightline route have Avis rental cars and designated ride-share pickup areas on site, and West Palm Beach goes as far as offering free shuttle service from the station to popular destinations in the area to ensure that riders are connected from the Brightline to their final destination. The strategic initiatives deputy executive director of Broward Metropolitan Planning Organization, James Cromar, says the area has untapped potential for even more transit development. Fort Lauderdale's station is across the street from a stop on the city's Sun Trolley route, as well as a city bus stop. Miami's station is already a depot for other rail lines, including Metromover and Metrorail, with service from Tri-Rail in development.

The Brightline is a prime example of a successful multimodal connector bringing people throughout the Miami super region safely, effectively, and affordably. According to riders' testimonies, this route has opened up new occupational opportunities by providing a cheaper, faster, and easier alternative to commuting by car, while simultaneously increasing access and connectivity between residents, amenities, and recreational attractions throughout the region. As the Brightline train pulls into each station, an announcement is made saying "We hope you enjoyed your care-free, car-free ride" (16). Despite its popularity and plans for expansion, Brightline service has been suspended since March 2020 due to COVID-19, with no reopening date announced as of November 2020 (17).

\subsubsection{North Carolina Piedmont}

While access to amenities and destinations can lure development, the quality of the service provided as a mode of transportation is the primary driver behind increasing ridership and making a rail endeavor successful. Metrics for quality rail service typically are based on punctuality of trains, frequency of service, and flexibility in pricing and traveling options. The "Piedmont" passenger train service, a croute connecting two of the Raleigh and Charlotte in North Carolina has been improved in recent years, increasing top train speed from 59 to 79 miles per hour and rivaling travel time in a single occupancy vehicle. Station improvements and replacement of rail crossings with bridges have generated development within the downtown areas, and younger generations as well as college students who are less likely to own vehicles largely account for the 450,000 travelers along this route each year (18).

Despite promising ridership quotas and increasing investment through federal grants, the Piedmont rail service has faced issues due to the COVID-19 pandemic. In addition to obvious public health 
concerns associated with mass transit during a viral outbreak, many commuters now work from home, and those who previously had the resources to travel for leisure are less inclined to do so due to economic hardship. As of May 2020, the North Carolina Department of Transportation (NCDOT) has eliminated two of the three daily round trips for the Raleigh-Charlotte route, while the state and Amtrak have suspended the Carolinian train connecting Charlotte with New York City. Cutting this state route saves the NCDOT approximately $\$ 13,000$ per day, which offsets the estimated $\$ 300$ million loss in expected revenue from March through May of 2020 as a result of the pandemic (19).

\subsubsection{Hoosier State Train}

In a case study with regional similarities to the New Orleans / Baton Rouge super region, the Indiana DOT, Iowa Pacific Holdings, and Amtrak formed a public-private partnership in order to improve the success of their regional high speed rail line, the Hoosier State Train (HST), connecting Indianapolis to Chicago with four small town stops along the way. This partnership measured success by examining on-time performance and reliability of their trains and sought to develop solutions after identifying a gap in first and last mile travel options for HST riders. The "first and last mile" issue refers to the lack of accessible, affordable, and practical options for riders to travel the first mile from the start of their journey to the rail line, as well as the last mile from the train to their destination. This is a common problem in designing mass transit that has to be solved case by case based on the specific environment of the station and the preferences of specific riders. In this scenario, researchers identified the implementation of micro-transit, such as bus services or short line rail, and improvement of existing and new park-and-ride facilities to attract riders from counties that lacked a nearby rail station (13).

In order to solve the first and last mile issue, planners sought to integrate multi-modal services and active transportation corridors to connect urban stations to residential neighborhoods and decrease the number of single-occupant car trips (9). Unfortunately, the challenges of implementing these remedial measures were overshadowed by steadily declining ridership numbers, and the Hoosier State Train concluded thirty years of service in June of 2019, although Amtrak's Cardinal line still runs between Indianapolis and Chicago three days a week. This example underscores the importance of designing transit options based around the existing and anticipated needs of riders, so that new services are implemented with the specific needs and preferences of riders already known and anticipated, rather than requiring remedial efforts to make an existing service successful.

\subsection{Evaluating projected ridership and demand}

In their study of international high-speed rail, Feinsod (15) defines the qualitative and quantitative parameters that determine a rail station's success based on their study of the views and opinions of riders. The location of a station is exceptionally important, along with the density of the area surrounding it and the perceived amount of activity occurring. Activity can also be measured quantitatively, by determining the number of modes of transport available, the available lines by mode, the average service frequency at peak hours, and the number of additional stops and stations within the city or region. Connection to other transit options through bus terminals or airport shuttles are sought by users and can greatly improve the functionality and the success of a station in fulfilling a community's needs (15). Importantly, the quality of the station area is likewise critical: most active transportation trip segments will be generated by housing, employment, retail, 
and services within a short distance of the station and constitute an important determinant of ridership, as well as of the overall vibrancy and place-making contributions of rail stations (10).

In the report Metropolitan Travel Forecasting: Current Practice and Future Direction, the Transportation Research Board (20) outlines their process for estimating future travel demand and modeling the impacts of alternative transportation investment. These simulations are used to predict how proposed facilities, services, and policies will affect mobility of residents, which in turn allows planners and policymakers to make informed decisions relating to the transportation system. Forecasting such as this is also used to monitor air quality and other environmental factors in order to make sure regional transportation programs conform to State Implementation Plans and national environmental quality and environmental justice standards.

The basic approach to modeling transit demand is a four-step process by which the number of daily trips is calculated and distributed among origin and destination zones. This figure is then divided according to transit mode, and then assigned to highway and transit networks. In smaller metropolitan regions, there may be little or no public transit development, and therefore the modeof-travel step can be omitted. This approach has been utilized since the 1950 s to aid in the decision process for determining the location and scale of major highway investments. More advanced models that consider tours of travel in addition to single trips, include joint transportation-land use models, or incorporate human activity into their analysis framework, providing a better representation of actual travel behavior. These increasingly granular approaches are more appropriate for modeling policy alternatives and traffic operations that will have an impact at the local, neighborhood level as well as at a regional scale (20).

While these forecasting techniques have been utilized for over half of a century, they are unable to represent dynamic conditions for the transportation system. Conventional models make use of highway and transit network data that is represented by averages over an extended period, and cannot represent conditions that would influence how, when, and where an individual travel. Additionally, traditional modeling techniques fall short in factoring in non-motorized travel options, freight and commercial vehicle movements, as well as temporally variant traffic volumes and speeds. Lack of comprehensive data that can be adequately compared state to state, or region to region, and a resulting lack of systematic statistical analysis have made it difficult for projections to be made (21).

Another method of measuring the potential of a rail project is to formulate a cost benefit analysis (CBA), or a financial risk assessment. In order to perform a simple assessment, Flyvbjerg (21) suggests a method that plots projected and actual costs against projected and actual traffic. Their method is detailed below:

"For all projects the difference between forecasted and actual construction costs is calculated as actual costs minus forecasted costs in percent offorecasted costs. Forecasted costs are defined as estimated costs at the time of decision to build. This baseline is the international standard for calculating cost development. Actual costs are defined as real, accounted costs determined at the time of completing a project. All calculations are in constant prices. Thus a positive figure of, say, 25 6/37 indicates a cost escalation of 25 percent in constant prices. A negative figure similarly indicates a cost saving of that amount. Zero indicates that forecasted costs were correct and thus equal to actual costs" (p. 5).

Flyybjerg (21) continues: 
"For all projects the difference between forecasted and actual traffic is calculated as actual traffic minus forecasted traffic in percent of forecasted traffic. A completely accurate traffic forecast registers as zero. A positive figure of, say, 15 indicates actual traffic for a project was 15 percent higher than forecasted traffic, whereas a negative figure indicates actual traffic was that much lower than forecasted. Traffic is forecasted and counted for the opening year or the first full year of operations. The basis for calculating the difference between forecasted and actual traffic is the forecast at the time of decision to build the project. Again this baseline for calculations is the international standard" (p. 6)

Holistic assessment of the costs and benefits of a proposed transit investment may also incorporate metrics across several different mobility, economic, and land use dimensions not always captured by traditional forecasting or CBA, which tends to focus primarily on vehicle speeds and operating costs, as shown in Table 1 (22).

Table 1. Public transport benefits and costs (22).

\begin{tabular}{|c|c|c|c|c|}
\hline & Improved Transit Service & $\begin{array}{l}\text { Increased Transit } \\
\text { Travel }\end{array}$ & $\begin{array}{l}\text { Reduced Automobile } \\
\text { Travel }\end{array}$ & $\begin{array}{l}\text { Transit-Oriented } \\
\text { Development }\end{array}$ \\
\hline Metrics & $\begin{array}{l}\text { Service Quality (speed, } \\
\text { reliability, comfort, safety, } \\
\text { etc) }\end{array}$ & $\begin{array}{l}\text { Transit Ridership } \\
\text { (passenger-miles or } \\
\text { mode share) }\end{array}$ & $\begin{array}{l}\text { Mode Shifts or } \\
\text { Automobile Travel } \\
\text { Reductions }\end{array}$ & $\begin{array}{l}\text { Portion of } \\
\text { Development with } \\
\text { TOD Design Features }\end{array}$ \\
\hline $\begin{array}{l}\text { Potential } \\
\text { Benefits }\end{array}$ & $\begin{array}{l}\text { Improved convenience } \\
\text { and comfort for existing } \\
\text { riders } \\
\text { - Equity benefits (since } \\
\text { existing users tend to be } \\
\text { disadvantaged) } \\
\text { - Improved operating } \\
\text { efficiency (if service } \\
\text { speed increases) } \\
\text { - Improved security } \\
\text { (reduced crime risk) }\end{array}$ & $\begin{array}{l}\text { - Mobility benefits to } \\
\text { new users } \\
\text { - Increased fare } \\
\text { revenue } \\
\text { - Increased public } \\
\text { fitness and health } \\
\text { (by stimulating } \\
\text { more walking or } \\
\text { cycling trips) } \\
\text { - Increased security } \\
\text { as more non- } \\
\text { criminals ride } \\
\text { transit and wait at } \\
\text { stops and stations }\end{array}$ & $\begin{array}{ll}\text { - } & \text { Reduced traffic } \\
\text { congestion } \\
\text { - }\end{array}$ & 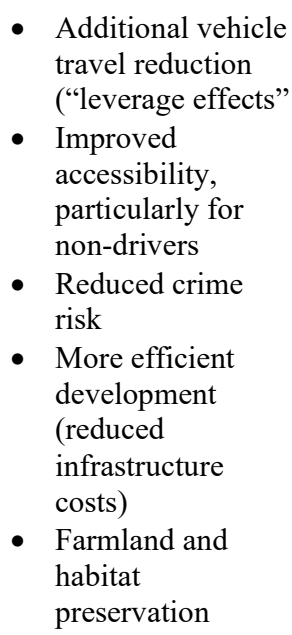 \\
\hline $\begin{array}{l}\text { Potential } \\
\text { Costs }\end{array}$ & $\begin{array}{l}\text { - Higher capital and } \\
\text { operating costs, and } \\
\text { therefore subsidies } \\
\text { - Land and road space } \\
\text { - } \quad \text { Traffic congestion and } \\
\text { accident risk imposed by } \\
\text { transit vehicles }\end{array}$ & $\begin{array}{l}\text { - Transit vehicle } \\
\text { crowding }\end{array}$ & $\begin{array}{l}\text { - Reduced automobile } \\
\text { business activity }\end{array}$ & $\begin{array}{l}\text { Various problems } \\
\text { associated with } \\
\text { more compact } \\
\text { development }\end{array}$ \\
\hline
\end{tabular}

In order to move from general travel forecasting to specific models for predicting ridership on a specific service and identifying factors likely to influence that ridership, statistical modeling methods must be employed that take into account. Soliciting preferences of potential riders across a range of alternative scenarios is frequently achieved through deployment of a discrete choice experiment (DCE), which is a technique frequently used in the social sciences when collection of 
revealed (observed) preference data is not feasible (23). Binary choice models would facilitate evaluation of a proposed scenario or service design or a null alternative but fail to consider a large range of varying alternatives, for which a multinomial logit model provides a more useful analytic framework for hierarchical, "nested" data involving multiple levels of variables $(24,25)$. Modeling of choices as a DCE, relying on statistical software to display choice tasks in a user-friendly way, facilitates experimental design that allows users to review a reasonable number of meaningful choice tasks that highlight key trade-offs and subsets/levels to reliably estimate parameters of interest, e.g., Figure 1 (23).

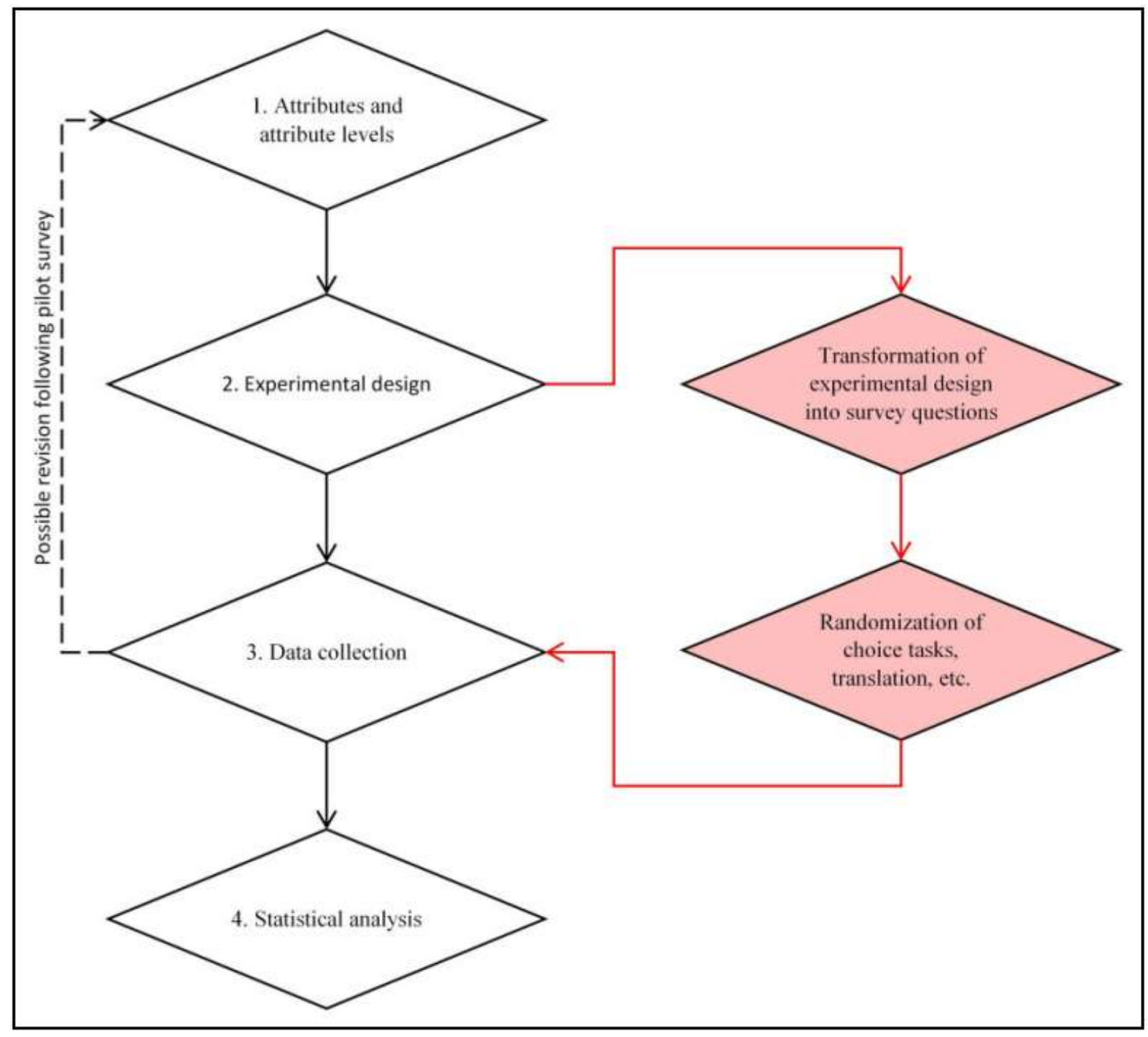

Figure 1. Discrete choice experiment experimental design development stages (23).

The best statistical approach for nested data is hierarchical modeling (HLM), also called multilevel modeling (MLM). The essence of HLM/MLM is to isolate the variance associated with each data level. HLM partitions variance between the choice level (Level 1), individual level (Leve 2), and the census block group level (Level 3), and then seeks to explain the variance at each level. Individual and census block group variances are captured in the random effects term from the Level 2 and Level 3 equation. In the model estimation, only the intercept is allowed to vary across 
Level 2 and Level 3 units. All the regression coefficients at Level 1 are treated as fixed. This is referred to as a random intercept model (26). This type of modeling has been specifically used to model residential housing preferences (25) as well as transit-oriented development (27). Meng et. al (27) further elaborate on different types of discrete choice/multinomial logit models with potential applications for transit and TOD planning, including latent class models, random parameter models, and error component models, applying various models, alternatives, attributes, and levels to optimize experimental design efficiency to answer questions around how, when, and why residents in an Australian rail corridor use different modes of transportation, demonstrating the potential to obtain meaningful explanations from among designed hypothetical choices (i.e., which variables are the most significant contributors to station access mode choice). This technique is directly applicable to the development of parameters to predict potential rail service ridership under varying hypothetical scenarios.

\section{METHODOLOGY}

This research provides a qualitative and quantitative evaluation of the proposed connections between the intercity rail link terminals in Baton Rouge and New Orleans, Louisiana, including the following key activities:

\subsection{Project Review Committee}

A project review committee (PRC) was established consisting of state and regional agency leaders and academic partners involved in passenger rail development and/or workforce development, to assist the project team in identifying previously completed studies, models, and data pertaining to the project, to refine the scope of the research and appropriate study area/communities of focus, and to advise in key metrics to be included in this evaluation.

An initial PRC meeting was held on October 15, 2019 to discuss the scope of the project and review proposed tasks and anticipated outputs. From this meeting, it was determined that the analysis and data collection should include intermediate stops of the proposed rail route (in Jefferson, St. Charles, St. John the Baptist, and Ascension parishes) as well as the primary termini in New Orleans and Baton Rouge.

\subsection{Synthesize Existing Data}

The initial phase of research included collection and evaluation of all available information and data related to the proposed rail connection from previously published studies and reports, including but not limited to:

- Previous feasibility studies for regional intercity rail service

- Previous rail station and station area plans and studies within the corridor

- Route and ridership data for existing and former intercity bus services, as well as local transit services within the study area

- National best practice and peer case study research relevant to development of new intercity or commuter rail services, as well as transit demand and ridership projection methodology (see section 3. Literature Review) 
In addition, phone and email interviews were conducted with key stakeholders familiar with one or more of the above topic areas in order to summarize the history of and current landscape for intercity passenger transit within Southeast Louisiana.

\subsection{Identify transit route and terminal evaluation priorities and performance metrics}

The project team identified research and data collection priorities pertaining to connections between proposed terminals and local transit networks and services, as well as key performance metrics by which to evaluate potential rail link effectiveness. This included the following key activities:

- Discussion or collaboration with Capital Area Transit (CATS), New Orleans Regional Transit Authority (RTA), and River Parishes Transit Authority (RPTA) to identify and evaluate existing and future plans that impact or may be developed to accommodate proposed rail linkages

- Discussion or collaboration with New Orleans Regional Planning Commission (NORPC) and Capital Area Planning Commission (CRPC) to identify plans and programs relating to transit and/or carpool/vanpool/employer-based transportation services which may affect or inform passenger rail viability

- Analysis of existing and/or proposed transit service and recommended priorities for proposed terminals to connect rail users more effectively to employment opportunities and civic, institutional, educational, or recreational destinations

- A draft list of performance metrics for station and transit service analysis was identified during the initial PRC meeting to guide background research, model development, and data collection design.

\subsection{Data Collection Plan}

The project team developed a methodology and instruments for quantitative and qualitative data collection reflecting findings from tasks 2 \& 3. Data collection design centered on the dissemination of two survey instruments: one for statewide distribution incorporating a robust Discrete-Choice Experiment (DCE) component to facilitate spatially disaggregated ridership modeling and projection development, and a smaller, targeted survey focusing on identifying specific needs and concerns of individuals already utilizing intercity transit to reach regional destinations. The latter survey instrument was, by necessity, deferred and ultimately abandoned due to the impacts of COVID-19 on both transit service and the team's ability to conduct in-person field interviews with this highly specific population (see additional discussion in Section 5 about methodology modifications as a result of COVID-19). For additional details including survey instruments, data collection protocols, and Institutional Review Board (IRB) review, see Appendix A.

\subsubsection{Data Needs}

In addition to survey responses themselves, the analysis required aggregation and integration of various spatial and tabular datasets to inform the ridership model.

The data collection component of this project will require the following key datasets: 
- Geocoded survey results from online-based survey targeting study area (Orleans, Jefferson, St. Charles, St. John the Baptist, St. James, Ascension, and East Baton Rouge Parishes) providing direct insight into opinions and preferences about existing transportation options and connections, current and anticipated travel behaviors within the study corridor, as well as geospatial and demographic characteristics for classification purposes.

- 10 records per respondent for DCE Analysis

- 1 record per respondent for non-DCE questions/variables

- In-person intercept surveys targeting current users of existing intercity transit services between New Orleans and Baton Rouge evaluating opinions and preferences about existing transportation options and connections, current and anticipated travel behaviors within the study corridor, and demographic characteristics for classification purposes.

- Spatial data mapping locations of existing and proposed future rail stations and complementary development.

- TIGER shapefiles for study area: Census Tracts, Census Block Groups, parishes, and road network files

- GIS data for computing built environment "D variables" (25):

- Density: population (as the smallest census unit as available)

- Employment (LEHD/ LODES O-D data - census block)

- Design: TIGER primary and secondary roads - statewide; Shapefiles of existing and proposed pedestrian and bicycle facilities, where these exist

- Diversity (land use): parcel level land use data (residential, commercial-office, retail, etc., public-government, school, library, etc.)

- Distance to transit: Spatial data for locations of fixed-route transit stops (intra and inter-city); also include alternative fixed-location transportation options (e.g., Tiger Trails, park-and-ride locations)

- All: Variables at block group level computed and compiled in EPA Smart Location Database (walkability index score, street intersection density, land use mix, etc.)

\subsubsection{Key Performance Metrics}

The purpose of this study is to better understand potential employer-based transit linkages and define a roadmap to successful service and maximum ridership, as relates to where people live and work within the study area corridor. To that end, this evaluation shall look at changes to existing station area plans and/or connecting transportation networks that would best optimize service utility in order to recommend actions for local and regional stakeholders. This research also seeks to identify employment centers and regional destinations for which local transit connections are needed to optimize intercity rail effectiveness and assess whether existing or proposed transit networks meet these needs.

Key metrics defining "success" of the proposed rail service include:

- Ridership

- Operating Subsidy

- Speed of service/competitiveness with driving

- Access to jobs

- Congestion mitigation 
- Multimodal access/connectivity (how many people can access service via walking, biking, transit, and park-and-ride)

To evaluate these metrics, data pertaining to travel behaviors and modal preferences (access to and egress from stations), cost and trip duration sensitivity are needed, as are spatial datasets identified above to relate survey findings to existing conditions.

\subsubsection{Survey Distribution Strategy}

To evaluate multimodal linkages for proposed New Orleans - Baton Rouge rail service and identify scenarios and actions to understand the needs of likely users and maximize potential ridership by enhancing connectivity of terminals to employment destinations. The goal of this survey is to better understand which key variables will make travelers more likely to choose intercity transit over driving in order to make recommendations for planning and implementation.

The survey was structured to include the following question types:

- Travel behavior background and respondent geolocation

- Discrete choice experiment to assess responses under different scenarios

- Stated Preference/Attitude statements

The audience of the survey included anyone who lives or works in the New Orleans-Baton Rouge Super Region and travels between destinations within this corridor. A target was set of at least 300-500 responses, including 100+ Baton Rouge, 100+ New Orleans, plus 20 in-person intercept respondents (prior to COVID-19 precluding in-person data collection activities).

Participants were recruited primarily through online solicitation through partner organizations, including local government agencies, economic development organizations, transit agencies, advocacy organizations, chambers of commerce, and other non-profits interested in regional connectivity and/or potential rail development. An email invitation/press release was developed and distributed to a compiled list of stakeholder organizations within the study area, with request to distribute to their contact lists (newsletter, email, social media) and/or to publish in news media (See Appendix A).

A small subset of data (excluding DCE Experiment) was intended to be collected through a targeted intercept survey at intercity rail/bus stations and/or onboard transit vehicles pending permission from operating entities, soliciting voluntary participation from current regional transit users. These surveys were to be completed by the PI and a trained graduate student assistant wearing easily identifiable University of New Orleans-branded shirts and completed via google form loaded to a tablet computer, with paper surveys available as a backup. The data collection team developed a protocol wherein surveyors would themselves as UNO staff/students and introduce the study topic (using the draft Press Release outreach copy as a script) and ask potential participants to sign a consent form to participate. The surveyor would then verbally conduct the intercept survey and input all responses on either the Google form or paper survey form. Participants would be permitted to choose not to respond to any questions asked. As noted above, this portion of the data collection plan was deferred and ultimately cancelled due to restrictions resulting from COVID-19.

Data collection was completed in accordance with University of New Orleans IRB-approved human subject research protocols, including the following guidelines: 
- All survey participants will be informed that their participation is voluntary, no personally identifying information will be collected, and that their responses are for planning purposes only.

- Age range of participants included in study: $18+$

- Participants from protected groups (minors, cognitively or psychologically impaired individuals, prisoners or parolees, specific medical populations, elderly, pregnant women, minority populations, and UNO students and employees) will not be specifically recruited for participation.

- The surveys are expected to be collected in March 2020.

- This survey falls under the category of requiring only "cover letter consent" (anonymous) adult participants. The UNO standard cover letter for questionnaires will be utilized for both online and in-person survey distribution (see below).

- Aggregated study may be used for conference presentations and publications, as well as released to the sponsoring agency/organization. No personally identifying or sensitive information will be collected. Informed consent/assent records of the participants must be kept for at least three (3) years after the completion of the research.

- See Appendix A for UNO IRB Approval Memo

\subsection{Data Collection}

Data collection occurred from February through June 2020 in accordance with the data collection plan (excluding a 3-month delay as a direct result of COVID-19 and other modifications discussed below), and included the following key activities:

- Collection of tabular and spatial datasets pertaining to existing population, demographics, and distribution of households and jobs within the study area

- Collection and integration of spatial data reflecting built environment characteristics and transportation network features including transit networks, active transportation facilities, and major activity generators

- Distribution of a specialized survey instrument developed in Conjoint.ly web-based software within the focus area through a broadly disseminated, voluntary online-based survey targeting residents within the study corridor (but open to all Louisiana residents). The survey incorporated socio-economic variables, as well as an embedded discrete choice experiment (DCE) and various supplemental questions aimed at better understanding regional travel patterns and opportunities for regional rail, including questions focused on changes in behavior (realized or anticipated) related to the COVID-19 pandemic (see Appendix B for full survey experimental design). The survey was disseminated by multiple local and regional news organizations as well as various stakeholder groups, resulting in a total sample size of over 4,600 valid and substantively completed responses (Appendix C).

- Collection and synthesis of data resulting from concurrent local and regional planning and data collection efforts, including the New Links regional comprehensive operations analysis in New Orleans, planning efforts around potential development of fixed-route transit in St. John the Baptist Parish, and other local and regional planning initiatives.

\subsection{Analyze Data}

In alignment with the performance metrics established in Tasks $3 \& 4$, data was evaluated to analyze anticipated impacts of a proposed New Orleans to Baton Rouge intercity service under 
differing proposed scenarios to determine optimum transit service design for maximizing ridership, economic viability of long-term rail service operations, and key findings about regional travel that may inform local and regional multimodal transportation planning and operation.

\subsubsection{Existing Conditions Analysis}

A desk study of existing conditions was undertaken to assess the extent of existing transportation facilities within station areas, as well as to identify planned or proposed multimodal enhancements which may be anticipated in the event of service implementation. This review included the following key resources:

- Previous rail service feasibility studies

- State and local government GIS data

- Transit agency GTFS data

- Local comprehensive/master plans

- Station area plans

- Existing intercity service schedules and information

- Pedestrian and/or bicycle plans

- News articles documenting developments in station area planning and/or service development

Each of these documents were reviewed to identify information pertinent to the analysis of potential future ridership. Spatial datasets were integrated to facilitate calculation of Euclidean walk/bikesheds and transit service presence within proposed station areas, etc. These datasets were then incorporated into survey modeling.

\subsubsection{Survey data cleaning and processing}

Cleaning and processing of raw survey results required significant effort in order to provide spatially disaggregated response data as well as to remove incomplete, suspected fraudulent, and geographically irrelevant (i.e., out of state) responses.

Automated data review processes in Conjoint.ly software were utilized as an initial screening. Of a total of 10,208 initiated surveys, 4,699 were accepted by the software's algorithm as substantively complete and unlikely to reflect fraudulent results (e.g., insufficient survey duration indicating likely lack of thoughtful responses). From this subset, the research team manually reviewed the participant list and identifying characteristics (IP address where available as well as stated location information) to remove respondents who do not live and/or work in Louisiana. All responses with IP addresses outside of the United States were removed automatically, and all IP addresses within the United States but outside of Louisiana were manually reviewed to assess whether the respondent is a Louisiana resident currently traveling outside the state or, as is increasingly common, using a VPN (virtual private network) to mask the respondent's location. In these cases, both multiple-choice and free-response survey questions (e.g., address as well as openresponse fields) were scanned to determine legitimacy. Overall, a total of 4,641 survey responses were included in analysis (Appendix C).

Survey responses were geocoded using ESRI's geocoding engine to determine relative latitude and longitude for the work and home addresses of survey respondents. Participants were asked to provide their work and home addresses in short answer, as well as the parish from which they were 
reporting from a drop-down list. In addition, the IP addresses of respondents were recorded. When reviewing the data, it became clear that participants provided different scales of information regarding their home addresses, ranging from some that provided their full addresses to others that only provided the name of their street. In order to provide enough information for ESRI to correctly geocode our data, we devised a method with which to sort responses with full addresses from those that were less precise. Using Microsoft Office Excel, responses for home addresses that had less than 24 characters, presumably short responses such as "oak street" or "lafayette LA" for example, were selected using the Conditional Formatting feature. Next, the IP information for the respondent's city, parish, and zip code were appended to the end of the participant's written response for their home address using the formula:

[=CONCATENATE(B2,", ",E2, ", ",D2," Parish ",G2]

Where B2 is the participant's original response, E2 is the city related to the IP address, D2 is the IP associated Parish, and G2 is the IP associated zip code.

This information was copied and pasted into a new spreadsheet using the "paste only values" function to remove all formulas from our dataset. Columns containing the information used in the formulas, including the original unaltered participant response, were retained within the new spreadsheet. This new spreadsheet was exported as a .csv and geocoded using ESRI ArcGIS's "Geocode Addresses" tool. The "address" value was input as the concatenated value including the participants response with appended IP addresses. When running the tool, the prompts for "city" and "county" were determined as the columns of data that contained the city and parish associated with the response IP address. This method produced favorable results, therefore all records that were geocoded with less than $90 \%$ accuracy, as determined by ArcGIS, were culled using a filter to sort the accuracy of results from lowest to highest. All scores below 90 were cleared of contents, and then a macro was run upon the spreadsheet in order to delete all rows with no data. The culling process was repeated for all geocode results that shared geographic location with four or more other respondents. Although more than four people can live in one home, and certainly more than four respondents may live or work in one census tract and/or zip code, we believed that using 4 as a threshold would remove responses that were too vague and therefore overrepresented a possible cause of skewed data.

This process was repeated using the same workflow for work addresses. When culling work addresses, responses that appeared more than four times were retained, while those with less than 90\% confidence in accuracy were removed using the clear contents tool in Excel as well as a macro to delete all rows with empty cells in column A. Finally, a manual scan of all geocoded addresses, as well as a review of failed geocodes, was conducted to identify any anomalous data as well as to correct obvious typographical errors preventing successful geolocation of input addresses. A total of 4,054 addresses were successfully geocoded to a high degree of confidence for use in the spatial modeling described below.

\subsubsection{Discrete choice experiment}

A discrete choice experiment was included in the survey, where respondents were asked to choose pairs of travel choice sets between New Orleans and Baton Rouge. Each respondent was presented with 10 choice sets and asked to choose the alternative they most preferred. Alternatives were defined by various levels of attributes. It is assumed that the respondents assessed the trade-off between different travel attributes. 
The choice sets differed in terms of travel mode, cost, and time to the station at both origins and destinations and cost of the trip between New Orleans and Baton Rouge. These attributes and the related levels are shown in Table 2. The survey layout is shown in Figure 2.

Table 2. Definition of trip attributes and levels.

\begin{tabular}{|c|c|c|}
\hline Attribute & Description & Level \\
\hline \multirow{4}{*}{ How you get to the station } & \multirow{4}{*}{$\begin{array}{l}\text { The mode used to get to the station and } \\
\text { associated cost }\end{array}$} & Drive and Pay to Park \\
\hline & & take Local Transit and pay transit fare \\
\hline & & Walk or Bike (free) \\
\hline & & pay for a Taxi/Uber/Lyft \\
\hline \multirow{3}{*}{ Travel Time } & \multirow{3}{*}{ The travel time to get to the station } & 15 minutes or less \\
\hline & & $15-30$ minutes \\
\hline & & $30+$ minutes \\
\hline \multirow{2}{*}{ Vehicle/Mode } & \multirow{2}{*}{$\begin{array}{l}\text { The mode for the trip between New } \\
\text { Orleans and Baton Rouge }\end{array}$} & Coach Bus \\
\hline & & Passenger Train \\
\hline \multirow{4}{*}{$\begin{array}{l}\text { How you get from station to } \\
\text { final destination }\end{array}$} & \multirow{4}{*}{$\begin{array}{l}\text { The mode used to get to the final } \\
\text { destination from the station and } \\
\text { associated cost }\end{array}$} & Drive and Pay to Park \\
\hline & & take Local Transit and pay transit fare \\
\hline & & Walk or Bike (free) \\
\hline & & pay for a Taxi/Uber/Lyft \\
\hline \multirow{3}{*}{ Travel Time } & \multirow{3}{*}{ The travel time to get to the station } & 15 minutes or less \\
\hline & & $15-30$ minutes \\
\hline & & $30+$ minutes \\
\hline \multirow{4}{*}{ Total One-Way Trip Cost } & \multirow{4}{*}{$\begin{array}{l}\text { The total cost from the origin to the } \\
\text { destination }\end{array}$} & $\$ 10$ \\
\hline & & $\$ 15$ \\
\hline & & $\$ 20$ \\
\hline & & $\$ 30$ \\
\hline
\end{tabular}


Imagine you are traveling in the New Orleans - Baton Rouge Region.

Which option would you choose to make the trip?

(You will review ten pairs of scenarios)
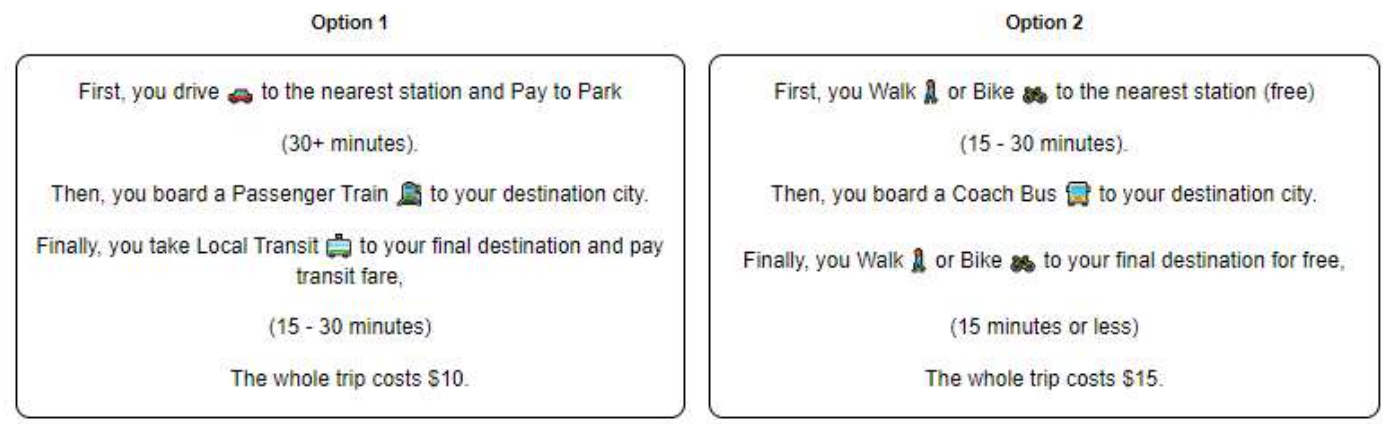

Figure 2. Example format of the discrete choice survey as viewed by end user.

\subsubsection{Survey results: descriptive statistics and qualitative analysis}

All survey questions excluding the DCE choice set were reviewed in Excel to provide summary statistics for all in-state responses, as well as responses for each study area parish to evaluate geographic variation in responses. The sociodemographic characteristics of the respondent pool are summarized, along with descriptive statistics summarizing the respondents' stated travel behaviors and preferences, opinions about existing and proposed transportation options in their community and impacts of COVID-19 on travel behavior.

In addition, open-ended responses to several questions were captured, sorted, and coded by keyword/theme to extract qualitative data documenting questions, strong opinions, concerns, and ideas of the respondent pool. These responses are tallied by category, with select examples extracted to illustrate major themes.

\subsubsection{Data inputs for spatial analysis and modeling}

DCE results, geocoded as described above and joined to spatial datasets in ArcGIS (i.e., TIGER shapefiles to append census tract and block group data), form the foundation of modeling activities to understand regional preferences.

Other factors that were also tested in the analysis include sociodemographic from the survey and built environment variables from Smart Location Database (SLD). The details about these variables are shown in Table 3. 
Table 3. Sociodemographic and built environment variables.

\begin{tabular}{|c|c|c|}
\hline Category & Description & Source \\
\hline \multicolumn{3}{|c|}{ Sociodemographic variables at Individual level } \\
\hline Employment & $\begin{array}{l}\text { The employment status of the respondent in three groups: employed (both full time } \\
\text { and part time); students; not employed (such as retired, unemployed, homemaker, etc.) }\end{array}$ & Survey \\
\hline Commuting mode & $\begin{array}{l}\text { The typically commuting mode to work in five groups: drive; public transit; walk or } \\
\text { bike; Uber/Lyft/taxi; other }\end{array}$ & Survey \\
\hline Vehicle access & Own or have regular access to a vehicle. Dummy variable: $1=y e s ; 0=$ no. & Survey \\
\hline Age & Age in six groups: Age 25 34; Age 35 44; Age 45 54; Age 55 64; Age 65+ & Survey \\
\hline Female & Dummy variable: $1=$ female; $0=$ male & Survey \\
\hline Race & Race in three groups: black, white, other & Survey \\
\hline Income & $\begin{array}{l}\text { Household annual income in four groups: Income_low (less than } \$ 35,000) \text {; } \\
\text { Income_medium }(\$ 35,000-\$ 75,000) ; \text { Income_mediumhigh }(\$ 75,000-\$ 150,000) \text {; } \\
\text { Income high (more than } \$ 150,000)\end{array}$ & Survey \\
\hline \multicolumn{3}{|c|}{ Built environment variables at census block group level } \\
\hline Population density & Gross population density (people/acre) on unprotected land & SLD \\
\hline Employment density & Gross employment density (jobs/acre) on unprotected land & SLD \\
\hline Activity density & Gross activity density (employment + HUs) on unprotected land & SLD \\
\hline Job-population balance & $\begin{array}{l}\text { Standard calculation based on population and total employment: Deviation of CBG } \\
\text { ratio of jobs/pop from regional average ratio of jobs/pop }\end{array}$ & SLD \\
\hline Land use mix & $\begin{array}{l}\text { Employment and Household entropy (based on vehicle trip production and trip } \\
\text { attractions including all } 5 \text { employment categories) }\end{array}$ & SLD \\
\hline Road density & Total road network density & SLD \\
\hline Intersection density & Street intersection density & SLD \\
\hline Distance to transit & Distance from population weighted centroid to nearest transit stop (meters) & SLD \\
\hline $\begin{array}{l}\text { Transit accessibility } \\
\text { quarter mile }\end{array}$ & Proportion of CBG employment within $1 / 4$ mile of fixed-guideway transit stop & SLD \\
\hline $\begin{array}{l}\text { Transit accessibility } \\
\text { half mile }\end{array}$ & Proportion of CBG employment within $1 / 2$ mile of fixed-guideway transit stop & SLD \\
\hline Auto accessibility & $\begin{array}{l}\text { Proportional Accessibility to Regional Destinations - Auto: Employment accessibility } \\
\text { expressed as a ratio of total MSA accessibility }\end{array}$ & SLD \\
\hline
\end{tabular}




\subsubsection{Multilevel logit modeling}

The data contain, for each of the 4,054 individuals, 10 repetitions of the choice between alternative 1 and alternative 2. Alternatives are represented by the bundle of attributes contained in a set of independent variables denoted $\mathrm{x}_{i j, t}$. The subscripts represent $i$ for individual $i, j=1$ or 2 for the two choices in the choice set, and $t=1,2,10$ for the 10 repetitions of the choice task. There is also a dependent variable, $\mathrm{y}_{i j, t}$, which equals 1 if individual $i$ chooses alternative $j$ in repetition $\mathrm{t}$, and 0 if not. Note that for each pair of choices $\mathrm{x}_{i l, t}$ and $\mathrm{x}_{i 2, t}$, exactly one of the $\mathrm{y}_{i j, t}$ values will equal 1 , and the other will equal 0 .

How can we represent this using an appropriate model? It is not appropriate to use a familiar binary choice model to model each of the 20 choices made as if each were a separate choice. In so doing, one would be assuming that each of the 20 choice outcomes represents a discrete choice between that specific outcome and not. But, in fact, there are only 10 choice situations for each person: Each choice is made between the two offered alternatives, not between each offered alternative and the rest of the universe. An appropriate model for data such as these is a multinomial logit model $(24,25)$.

The data in this analysis is also hierarchical, with choices "nested" within individuals and individuals "nested" within census block groups. The choices that were made by the same individual share the same sociodemographic characteristics of the individual. The individuals that live in the same census block group share the built environment of the census block group. The best statistical approach for nested data is hierarchical modeling (HLM), also called multilevel modeling (MLM). The essence of HLM/MLM is to isolate the variance associated with each data level. HLM partitions variance between the choice level (Level 1), individual level (Level 2), and the census block group level (Level 3), and then seeks to explain the variance at each level. Individual and census block group variances are captured in the random effects term from the Level 2 and Level 3 equation. In the model estimation, only the intercept is allowed to vary across Level 2 and Level 3units. All the regression coefficients at Level 1 are treated as fixed. This is referred to as a random intercept model (26).

Multilevel logit models were estimated by using maximum simulated likelihood. Survey findings and supplementary data sources facilitate identification of factors that determine whether a person would take rail or not, in order to identify optimal service design to capture as many potential riders as possible and identify the threshold of travel time by transit within the city to get to the rail terminal that people are willing to accept to make trips by rail. The results are shown below in Section 5.6. 


\section{ANALYSIS AND FINDINGS}

\subsection{Existing Conditions Analysis}

This section summarizes feasibility studies developed relevant to the proposed intercity passenger rail service, including station and station area plans, the legislative context and governing authorities tasked with advancing passenger rail in the region, existing intercity transportation services (including carpool/vanpool programs), existing and proposed local transit networks and associated planning processes and documents, and active transportation connections within proposed station areas. This documentation provides a baseline assessment of work completed relevant to this research to-date and assess the degree to which proposed rail alignment and stations are supported by multimodal transportation options and connected to key regional destinations and activity centers.

\subsubsection{Background and Legislative Context}

Discussions concerning the re-establishment of intercity passenger rail connecting the state's two largest cities and providing additional redundancy and resilience in the state's transportation network date back decades, including efforts to revive a commuter service in advance of the 1984 World's Fair, and as a proposal for which preliminary analysis had been completed within the 2003 Louisiana Statewide Rail Plan (1, 28). After Hurricane Katrina in 2005, congress established the Gulf Coast Working Group, including members from the Federal Rail Administration (FRA), the Southern Rail Commission (SRC), and regional business leaders and elected officials to evaluate opportunities to restore and advance passenger rail within the region (29). In addition to assessing the feasibility of repairing and restoring rail service that was directly disrupted by Hurricane Katrina (i.e. Amtrak's Sunset Limited service from New Orleans to Orlando), stakeholders involved with the working group viewed service expansion as a means to provide a commute alternative to I-10 for workers within the region, expand accessibility for carless households, and provide an additional asset for evacuation in the event of future hurricanes or other emergencies (30).

The Louisiana Intrastate Rail Compact Act (act 858, 2010, RS 48:2170), enacted by House Bill 1410 during the 2010 legislative session, created a legal framework for advancing these ideas, facilitating a means for two or more parishes/municipalities to form a quasi-governmental entity to develop rail, with the authority to negotiate with Amtrak and freight operators. This compact was signed by the mayors of Baton Rouge and New Orleans in 2010, and formed with support from the Center for Planning Excellence to include members representing the City of New Orleans, Ascension Parish, Baton Rouge, East Baton Rouge City-Parish, the Southern Rail Commission, and Jefferson Parish (1). The resulting Louisiana Super Region Rail Authority (LRRA) has the power to raise funds and operate passenger rail services. However, this group has been inactive in recent years, citing a need for clear commitment from the governor in order to continue to advance discussions with freight rail partners (31).

Notably, the Passenger Rail Investment and Improvement Act of 2008 (PRIIA), states are required to provide the funding to support the operation of short-distance intercity passenger rail routes of less than 750 miles (which would include the proposed rail link between Baton Rouge and New Orleans), whereas Amtrak has the financial responsibility for the operation of trains on longdistance routes of 750 miles or more in length (32). 


\subsubsection{Previous Feasibility Studies}

Since 2010, two major feasibility studies and various technical and policy analyses have been completed in support of reestablishing this rail link between the state's two largest cities and metro regions, including the Baton Rouge - New Orleans Intercity Passenger Rail Service Development Plan prepared by Burk-Kleinpeter, Inc. (33) for the Southern Rail Commission in 2010, and a 2014 study and strategic business plan $(1,34)$ commissioned by LSRRA, in partnership with the New Orleans Regional Planning Commission (NORPC), the Capital Region Planning commission (CRPC), and the Baton Rouge Area Foundation (BRAF). This section summarizes methods and findings from these previous planning efforts.

Baton Rouge - New Orleans Intercity Passenger Rail Summary Report (2010)

This planning process and report (33), prepared for the Southern High Speed Rail Commission (SHSRC) by BKI and HDR with funding from FRA and Southern High Speed Rail Commission (SHSRC) grants awarded in 2008, included an initial proposal and feasibility study for passenger rail within the New Orleans-Baton Rouge corridor, including the following six stops (Figure 3):

- Baton Rouge Terminal Station - East Baton Rouge Parish (1500 Main St, new facility)

- Baton Rouge Suburban Station - East Baton Rouge Parish (I-10/Bluebonnet Rd near Mall of Louisiana, new facility)

- Gonzales Town Center - Ascension Parish (E. Cornerview between S. Irma Blvd and N. Edenborne St, new facility)

- LaPlace - St. John the Baptist Parish (Southwest of Main St/US 61, new facility)

- Kenner Suburban Station - Jefferson Parish (Kenner Ave between George St and Duncan St, new facility)

- New Orleans Union Passenger Terminal - Orleans Parish (1001 Loyola Avenue, Existing Facility) 


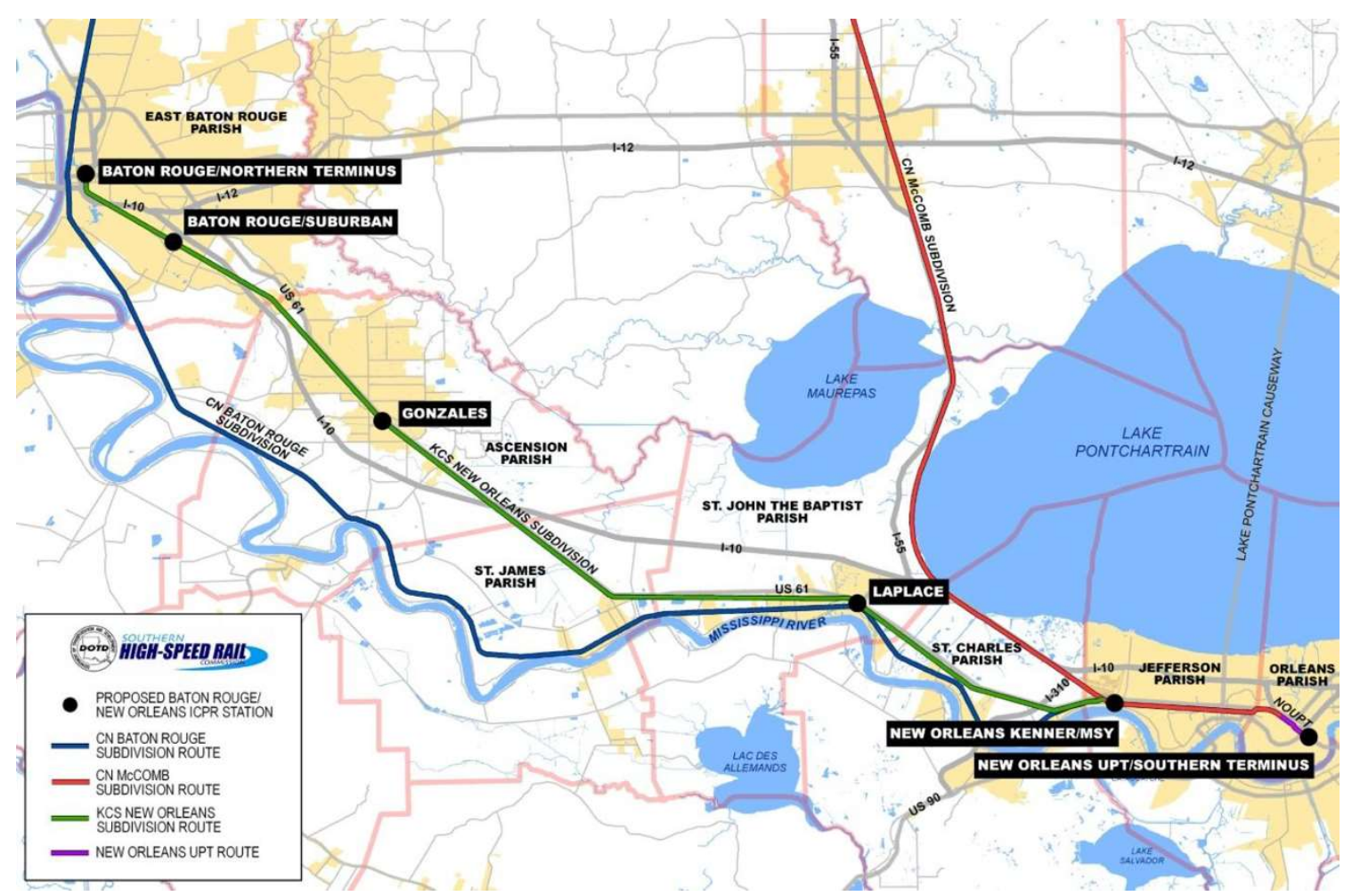

Figure 3. Proposed rail station locations, Baton Rouge - New Orleans Intercity Passenger Rail Summary Report. (33)

The proposed service was intended to connect into a larger vision of the Gulf Coast High Speed Rail Corridor from Houston to Atlanta (formally designated as one of 11 high speed corridors by the US DOT in 1998, figure 4). The service was in part intended to also serve to provide additional capacity during hurricane evacuations.

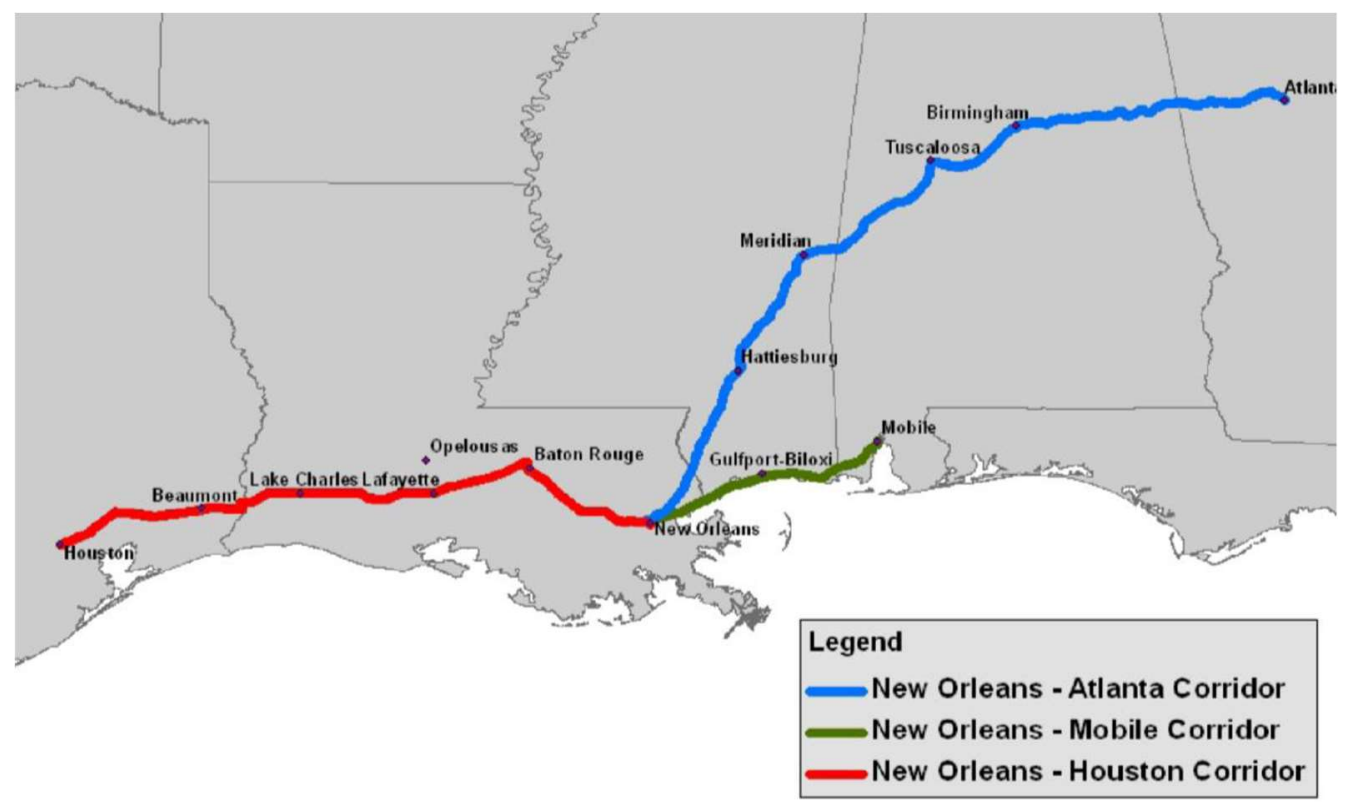

Figure 4. Original Gulf Coast high-speed rail corridor map. (33) 
The proposed service design in the 2010 study (33) envisioned three phases, outlined by key characteristics of speed, number of trips per day, and fare in Table 4. During the feasibility study process, stakeholders confirmed that Amtrak would be the preferred operator for the service, for reasons of their statutory right to access of freight ROW under the Railroad Passenger Service Act of 1970 (Public Law 91-518), critical as the bulk of the proposed alignment is owned by Kansas City Southern, with smaller segments controlled by Canadian National. Under this law, Amtrak is only required to pay for incremental costs associated with use of the tracks for passenger service, whereas any private operator would be expected to pay much more for access (if allowed at all). Insurance indemnification reasons are also cited for the preference of Amtrak as the proposed operator.

Table 4. Proposed service design, 2010 BKI Report. (33)

\begin{tabular}{|l|l|l|l|l|l|}
\hline Service Phase & Top Speed & $\begin{array}{l}\text { Roundtrips Per } \\
\text { Weekday }\end{array}$ & $\begin{array}{l}\text { Roundtrips per } \\
\text { Weekend }\end{array}$ & Travel Time & One-Way Fare \\
\hline Phase 1 & $79 \mathrm{mph}$ & 4 & 3 & $1: 24$ & $\$ 10$ \\
\hline Phase 2 & $90 \mathrm{mph}$ & 6 & 4 & $1: 11$ & $\$ 11.50$ \\
\hline Phase 3 & $110 \mathrm{mph}$ & 8 & 4 & $1: 13$ & $\$ 13$ \\
\hline
\end{tabular}

The estimated cost of developing the corridor for passenger service, not including rolling stock, was $\$ 390 \mathrm{M}$, including the following critical component features:

- Construction of a new 2-mile bridge across the Bonnet Carré Spillway

- Realignment of track, new switches and signals at East Bridge Junction

- Addition of second track into NOUPT

Anticipated operating costs, contingent on projected ridership targets of 39,000 boardings per month in year 1 (460,000 per year) and 135,000 boardings per month by year 25 (1.5 million per year), are summarized in Table 5 . The consultants estimated that a large majority $-88 \%$ - of trips would be work-related. Additional analysis of ridership and cost projections is discussed in section 5.5 .

Table 5. Anticipated operating costs, 2010 BKI Report. (33)

\begin{tabular}{|l|l|l|l|l|}
\hline Service Phase & $\begin{array}{l}\text { Annual O\&M Cost } \\
\text { (in millions) }\end{array}$ & Annual Ridership & $\begin{array}{l}\text { Annual Revenue (in } \\
\text { millions) }\end{array}$ & $\begin{array}{l}\text { Annual Deficit (in } \\
\text { millions) }\end{array}$ \\
\hline Phase 1 (2013) & $\$ 18.5$ & 461,000 & $\$ 3.9$ & $\$ 15.6$ \\
\hline Phase 2 (2018) & $\$ 23.3$ & 644.200 & $\$ 6.3$ & $\$ 17$ \\
\hline Phase 2 (2023) & $\$ 26.2$ & 886,400 & $\$ 9.9$ & $\$ 16.3$ \\
\hline
\end{tabular}

\section{Baton Rouge - New Orleans Intercity Rail Feasibility Study (2014)}

Four years after the BKI study was completed, a new feasibility study (1) was prepared by the HNTB corporation for New Orleans Regional Planning Commission, Capital Region Planning Commission, and the Baton Rouge Area Foundation, with the expressed aim of "strengthen[ing] the coalition of support for passenger rail service between Baton Rouge and New Orleans and to identify a clearly-defined process for moving the project forward to implementation," in recognition of the stalled progress of previous efforts. The effort included the development of a 
technical memorandum and a strategic business plan, as well as an updated capital and operating plan.

The study reviewed previous planning efforts, the development of the rail compact, progress on New Orleans Gateway (NORG) Program (which aims at addressing reduce rail congestion, highway crossing delays, etc.), NOUPT improvements, updates to the Louisiana State Rail Plan, as well as current federal policy and grant opportunities as well as other funding and financing options. Finance options discussed include tax sources, federal grants, value capture strategies (e.g., TIF, development impact fees, BIDs, etc.), bonds and TIFIA/RRIF programs, in addition to fare box revenues and other state and local sources. In particular, value capture options were identified as likely to be critical in the financing of the proposed service, particularly in intermediate stations with significant opportunity for station area development.

An extensive stakeholder outreach effort was conducted to "continue developing a broad base of support" for the proposal, with the explicit goal of building stakeholder support for the proposed service and further developing the rail service plan. This process took a multi-pronged approach, simultaneously working on project development and outreach, station area planning and economic development with transit agencies, airports, and development authorities, and institutional issues involving railroad stakeholders.

The HNTB study modifies the previously proposed service design in terms of both scope and siting, recommending shifting the downtown Baton Rouge terminal approximately one mile to Government Street in order to shorten the route (therefore eliminating necessary bridge and track improvements necessary to access the Main St location), and shifting the suburban Baton Rouge station closer to Essen Lane, where a portion of the alignment is already double tracked (Figure 5). Other technical adjustments to the alignment are proposed, including additional siding near Siegen Lane in East Baton Rouge to facilitate train passing movements at Essen Lane. In addition, a seventh stop is proposed in Jefferson Parish, along Airline Highway

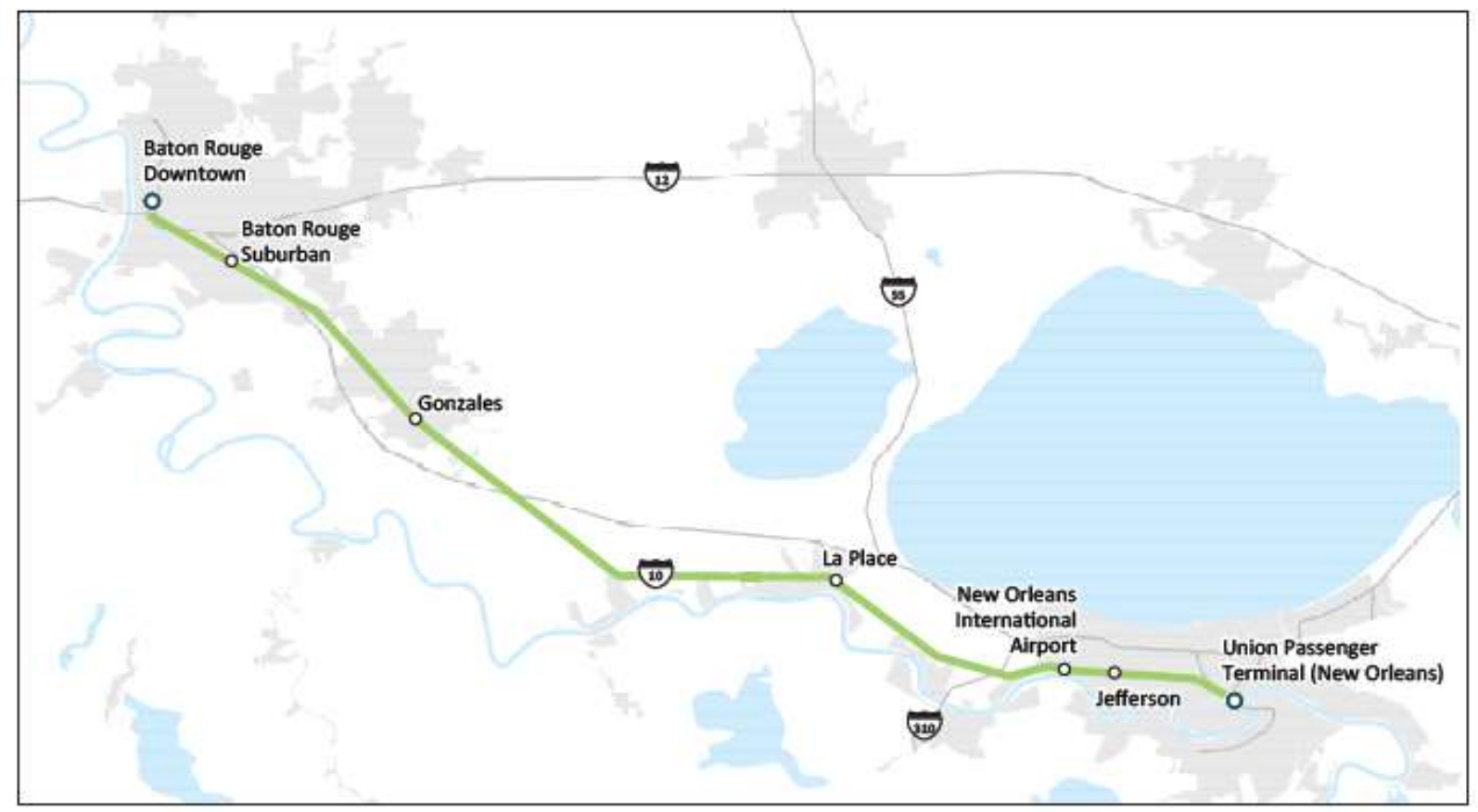

Figure 5. Map of proposed rail station locations, 2014 HNTB feasibility study. (1) 
In addition, the proposal significantly scales back the scope of service operations, and, consequently, projected operating costs, advocating an incremental approach to service development that minimizes the focus on increasing travel speeds beyond the previously proposed "Phase 1" maximum of $79 \mathrm{mph}$ and limits service to two round trips per day (one AM, one PM), with assumed 365-day service and additional trips to be added only as dictated by ridership demand (Table 6). The reduction in top speed facilitates a reduced initial capital cost, while the significantly scaled-back service proposed allows for the calculation of a much lower operating cost $(\$ 250 \mathrm{M}$ compared to $\$ 390 \mathrm{M}$ ) and operating subsidy $(\$ 6.7 \mathrm{M}$ compared to $\$ 14.5 \mathrm{M})$. As with the 2010 study, Amtrak is presented as the presumed operator of the service. Service under this scenario is expected to result in an anticipated one-way travel time of 1:35 (calculated using the Train Performance Calculator and assuming recommended track improvements), compared to 1:24 for Phase 1 under the 2010 scenario (reflecting the addition of a seventh station).

Table 6. Proposed service design, 2014 HNTB feasibility study. (1)

\begin{tabular}{|l|l|l|l|l|l|}
\hline Service Phase & Top Speed & $\begin{array}{l}\text { Roundtrips Per } \\
\text { Weekday }\end{array}$ & $\begin{array}{l}\text { Roundtrips per } \\
\text { Weekend }\end{array}$ & Travel Time & One-Way Fare \\
\hline Initial & 79 & 2 & 2 & $1: 35$ & $\$ 10$ \\
\hline
\end{tabular}

Given this service design, HNTB projects annual ridership of 210,000 per year at a fare of $\$ 10$ per trip (one way.) Notably, the HNTB study, which developed ridership projections using the FTA's Aggregate Rail Ridership Forecasting Model, asserts that ridership projections previously conducted fail to account for the significant number of non-work trips that might be anticipated within the region, given New Orleans' many festivals and events, as well as government functions and sporting events in both New Orleans and Baton Rouge.

The 2014 Feasibility Study also provides a detailed strategy to implement the proposed service, including finance strategies and structures aligned with estimated capital and operating costs.

\subsubsection{State Rail Plan}

The University of New Orleans recently engaged in an analysis of passenger and freight rail systems that will be used to guide future investments, including a benefit/cost analysis of system expansion to inform the work of state transportation planners by exploring economic development opportunities, identifying key corridors for investment, and highlighting areas of safety and/or congestion concern (35). This plan frames the current freight and passenger rail systems in the state of Louisiana (Figure 6), the latter consisting of three long-distance Amtrak routes which terminate in New Orleans at New Orleans Union Passenger Terminal, serving over 212,000 passengers per year across seven Louisiana stations as of 2018 , over $85 \%$ of whom boarded or alighted at NOUPT (32). Growth in passenger rail activity of over $50 \%$ is projected over the next 20 years (32). 


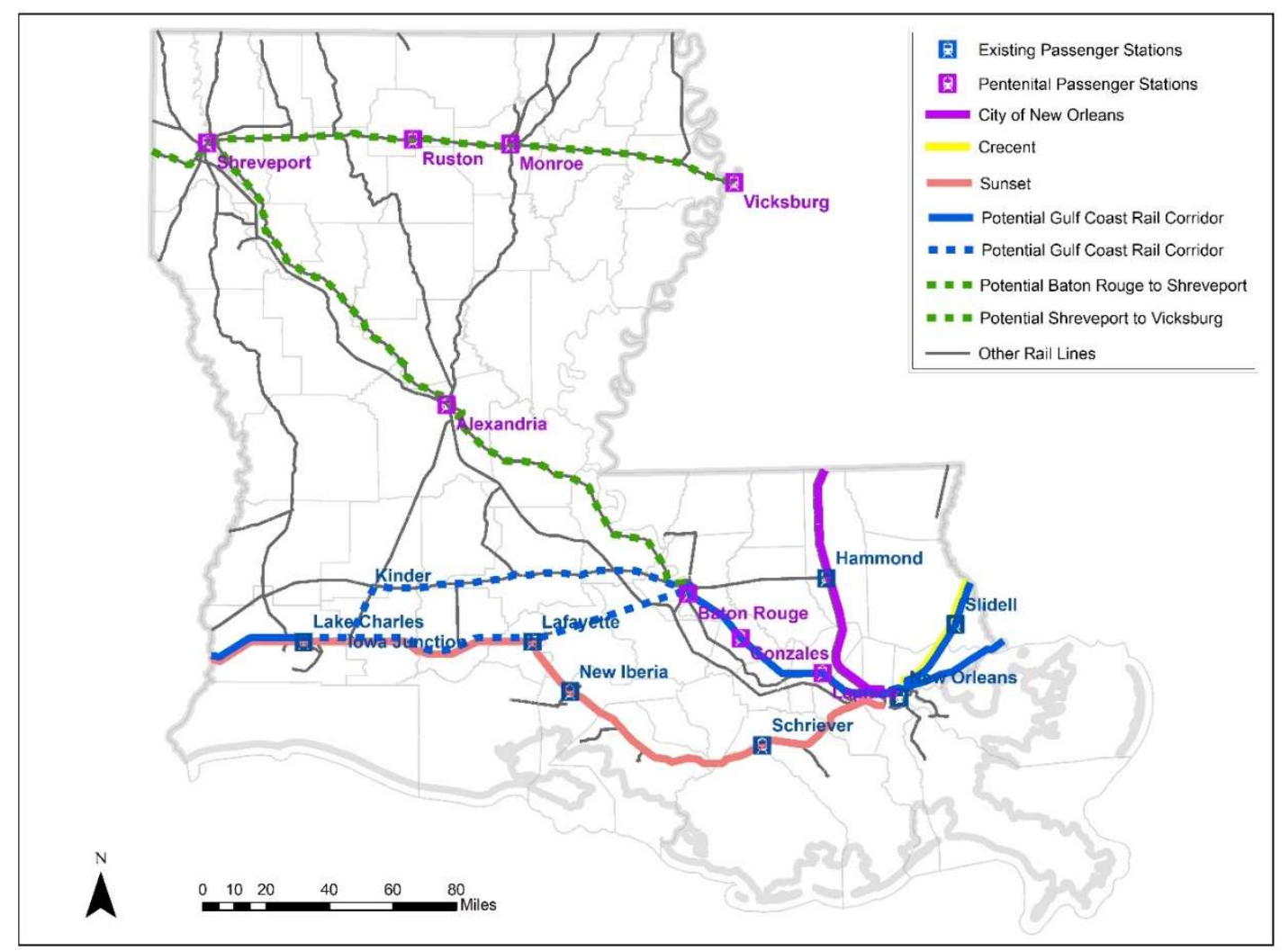

Figure 6. Existing and potential passenger rail routes in Louisiana. (32)

The economic impact of freight and passenger rail is significant (Table 7), with a total yield of $\$ 729$ million in income generated, or a total economic output of \$1.925 billion (32). As the Rail Plan notes, "Amtrak intercity passenger rail service connects major urban areas, which is important given the limited air service in the state. Passenger train travelers generate income not only for rail operations, but also for restaurants, hotels, and other visitor service establishments. Furthermore, passenger stations have the potential to increase economic development around the station areas" (p. 2).

Table 7. Total Rail Activity Impacts. (32)

\begin{tabular}{|l|l|l|l|l|}
\hline & Direct & Indirect & Induced & Total \\
\hline Output $^{\mathbf{1}}$ & $\$ 1,091$ & $\$ 357$ & $\$ 476$ & 1,925 \\
\hline Value Added $^{\mathbf{1}}$ & $\$ 686$ & $\$ 173$ & $\$ 272$ & $\$ 1,131$ \\
\hline Labor Income $^{\mathbf{1}}$ & $\$ 528$ & $\$ 78$ & $\$ 123$ & $\$ 729$ \\
\hline Indirect Business Tax $^{\mathbf{1}}$ & $\$ 18$ & $\$ 15$ & $\$ 29$ & $\$ 62$ \\
\hline Employment $^{2}$ & 3,528 & 1,723 & 3,612 & 8,863 \\
\hline
\end{tabular}

Source: IMPLAN ${ }^{1} \$$ in Millions of 2017 Dollars ${ }^{2}$ Number of Jobs 
In addition, the Rail Plan notes socio-environmental and livability impacts associated with rail transport, citing the potential for a New Orleans-Baton Rouge rail corridor to spur economic development, support evacuation needs, and mitigate congestion without necessitating ROW acquisition.

Moving forward, the state's objectives for passenger rail include:

- Enhancing existing services - maintain and improve existing stations

- Engaging the freight railroads in new passenger rail planning initiatives

- Continuing outreach to stakeholder

- Developing funding strategies for passenger rail initiatives

- Encouraging multimodal integration, and

- Continuing with Amtrak station upgrades.

Toward those objectives, the Plan proposes additional study of intercity service along the KCS/UP line between Shreveport and Baton Rouge to connect to the proposed Baton Rouge - New Orleans service and the new Gulf Coast service linking New Orleans to Baton Rouge. The need to identify opportunities for connecting local transit services (as well as possible Thruway bus services) is emphasized.

The rail plan outlines ongoing initiatives led by Amtrak to improve service at existing Louisiana passenger rail stations, including track and yard restoration projects. Additional efforts to enhance existing services are recommended, including promotional programs, expanding onboard volunteer docent program partnerships, improved coordination with freight railroads to address on-time performance and capacity issues, and new multi-state partnerships for service.

Lack of a clear funding strategy for implementing proposed enhancements and new services is cited as a key barrier. At the state level, the 2019 Rail Infrastructure Improvement Program ACT 222 (HB 394) authorizes rail infrastructure improvements that extend short line railroad tracks to serve additional industries, but no funding has been allocated to support its implementation. The Rail Plan notes that parish or regional agencies may also lead rail improvement programs, while private funds may be leveraged to develop projects that indirectly advance new service development by reinforcing the foundation of existing trackage and terminals (while also improving freight service). Importantly, any such efforts would need to explicitly include contractual language referencing future passenger rail capacity (32).

The rail plan identifies multimodal integration and transit-oriented development (TOD) as key factors in service development or enhancement. The placement of terminals in downtown locations within easy walking distance of nearby destinations and, where applicable, transit connections is cited as an asset.

Notably, the current poor on-time performance (OTP) of current Amtrak services in Louisiana is identified as a critical limitation of success: largely due to train interference delays (primarily freight) and signal delays. Amtrak has made reliability a priority system-wide by negotiating and incentivizing passenger train scheduling priority with the freight railroad companies. This has resulted in several years of improved on-time performance for all trains. However, poor reliability continues to hinder ridership growth. 
Finally, the State Rail Plan cites numerous benefits associated with passenger rail provision, especially in urban areas, to "function as local connection points for other feeder modes and create downtown transportation hubs for the community" (p. 71) when supported by pedestrian-friendly development patterns, supportive development initiatives, and multimodal connections through active transportation and public transit. New Orleans' NOUPT is cited as an example of these synergistic effects, wherein the development of new light rail (streetcar) service has corresponded to the development of a new mixed-use neighborhood including 1000 luxury apartments and condos, and 200,000 sf of commercial space (32).

In addition to supporting local economic development goals, the Plan cites a need for mitigating VMT growth as a key impetus for passenger rail development, as statewide, vehicular travel is forecast to grow to 179 million weekday Vehicle Miles of Travel (VMT) by 2044, and a significant proportion of those miles $(30 \%)$ is likely to occur on the state's interstate system (32). "Without expanded transportation capacity," the Plan cites (p.111), "Louisiana's competitive position in the transportation marketplace will deteriorate and the costs for business, manufacturing and trade will increase." Provision of intercity rail service between New Orleans and Baton Rouge is identified as a key strategy to address this need, with a presumption that commuters headed to or from downtown job centers would make up a dominant share of ridership.

Regarding the proposed NO-BR service specifically, the Rail Plan reiterates needed improvements to pilings on the Bonne Carré Spillway and other bridges, and improvements to the 157 at-grade highway crossings within the corridor. In addition, the Automatic Block Signals (ABS) on KCS segments of the proposed route, which require manual alignment, and speed limits within certain portions of the route as areas of concern for project development.

The plan tallies the number of freight trains that currently utilize the proposed track (between four and six between Baton Route and Frellsen Junction; about 1- per day between Frellsen Junction and Orleans Junction, 12 between Orleans Junction and CN's Mays Yard, plus two passenger trains, and about 30 per day from Mays Yard to Southport Junction connecting to NOUPT's facilities), highlighting the challenges of ensuring smooth integration of passenger and freight operations. Again, New Orleans Rail Gateway project improvements are cited as an important foundation for necessary future passenger rail upgrades.

Shifts in housing employment distribution within the region are noted in the plan, along with increased VMT and congestion within the I-10 corridor, which the authors suggest indicating a major opportunity for commute trips, which they assume to make up 70-80\% of the total ridership. Multiple-trip discount fares are recommended to facilitate usage of the proposed service by commuters. The Plan estimates that shifting some of these commuters to rail could reduce annual VMT by 86 million within the corridor, mitigating 38,299 tons of CO2.

Importantly, the state rail plan identifies the establishment of a dedicated funding source for the Rail Program at LaDOTD (housed within the Office of Multimodal Commerce), as a key objective of the State's Rail Vision in order to focus resources and successfully secure federal funding assistance for key freight and passenger rail goals, including advancement of the NO-BR connection. 


\subsubsection{Gulf Coast Rail Corridor}

In 2015, the Consolidated Rail Infrastructure and Safety Improvements (CRISI) Program was created under Section 11301 of the Fixing America's Surface Transportation (FAST) Act, dedicating funds for new federal rail programs. The Southern Rail Commission was awarded funds under this program in 2018 to restore twice-daily passenger rail service between New Orleans and Mobile, AL and support preliminary engineering and environmental reviews pertaining to the New Orleans-Baton Rouge corridor (36).

The Southern Rail Commission (29) envisions the New Orleans-Baton Rouge link to connect into the broader Gulf Coast Corridor (Figure 7). This connection is focused along the Gulf Coast (first to Mobile, and eventually resuming service to Orlando), but the SRC highlights the potential for the NO-BR connection to both support and be supported by this parallel effort, functionally increasing the potential population for whom each service would be useful significantly.

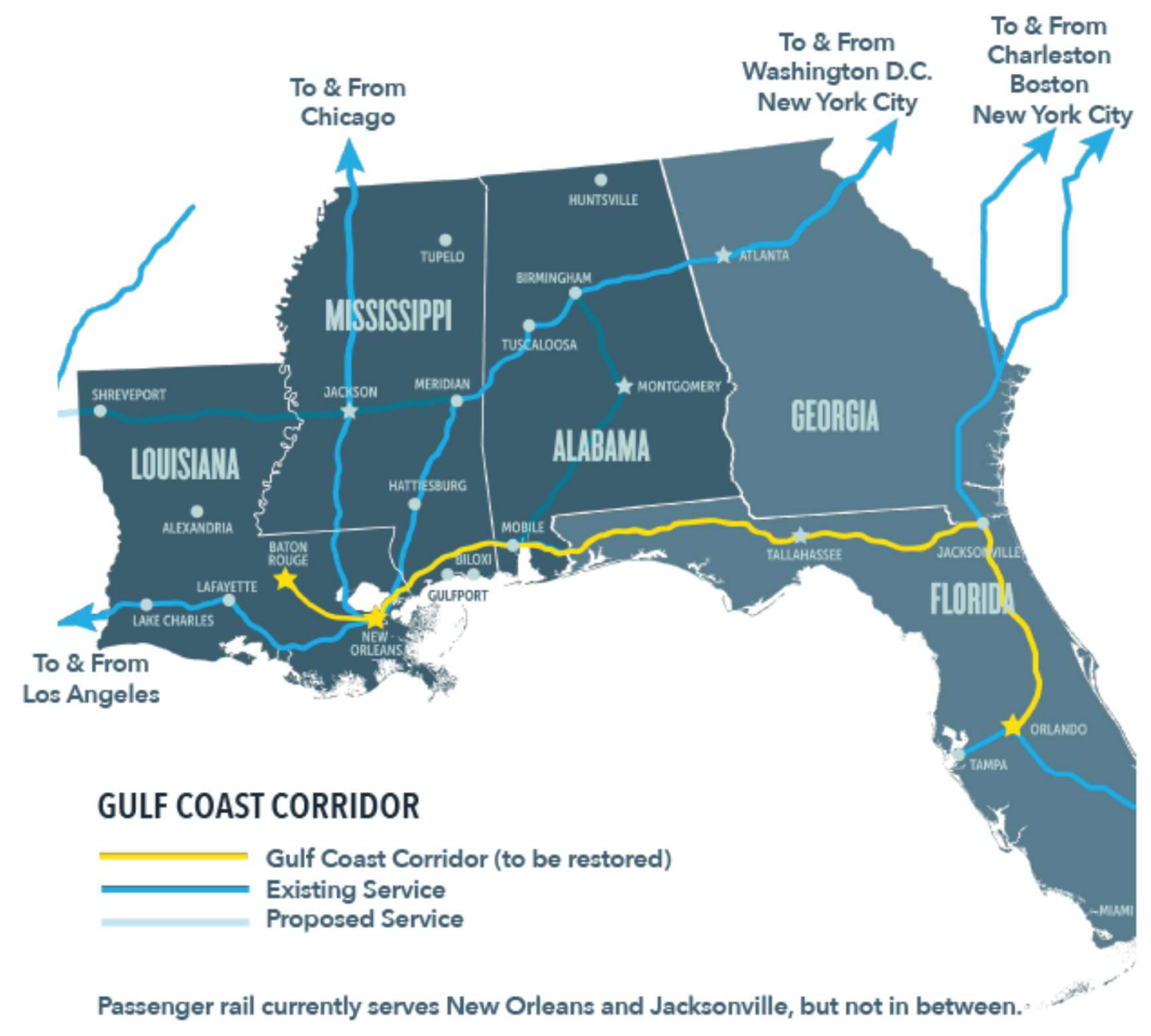

Figure 7. Gulf Coast Corridor Existing and Proposed Service. (29) 
The proposed service would consist of two daily trains and would be intended to serve work travelers as well as promote regional tourism and support evacuation efforts as needed. As part of an FRA grant to implement the service, SRC also requested \$10M to support a NEPA review for the New Orleans-Baton Rouge segment, directly linking these parallel efforts.

\subsection{Station Area Planning}

Station area proposals or plans, at various levels of detail, have been developed in each of the communities potentially served by the proposed rail link. Baton Rouge solicited proposals for downtown and suburban station area development in 2017 with support from the Southern Rail Commission and the East Baton Rouge Redevelopment Authority (37), while LaPlace and Gonzales have published station area plans refining target locations along the rail corridor and outlining strategies for service-supportive development. This section and the following evaluate the locations and plans for development of these terminals relative to local transit networks and supporting multimodal facilities (e.g., trails, bikeways, park-and-ride facilities) to assess the degree to which proposed terminals would adequately meet the needs of potential users and therefore support optimal usage of the proposed intercity service.

The 2014 Feasibility Study (1) proposes that the following qualifications are fundamental to station siting for the proposed service:

- Proximity to diverse residential and nonresidential land uses

- Direct access to regional and local amenities

- Maximum connectivity within existing street grid

- Connectivity to existing greenway systems

- Land available

- Provide opportunities for placemaking

The range of station types and amenities described in the feasibility study is assumed to vary based on land use and community context, from a simple platform and ticket kiosk with an adjacent parking lot to a fully developed station. However, regardless of station size or complexity, it is critical that the station be an asset to its community, tightly integrated into the surrounding neighborhood, with walkable, "complete" streets, and supportive infill development nearby (1).

Strategies to advance the development of effective station areas include overlay zoning, plannedunit developments (PUD), tax districts, development bonuses, or transfer of development rights (TDR) to encourage compact, mixed-use development that supports walkability and transit use (1). This section outlines planning processes and findings regarding the siting and development of potential passenger rail stations within the proposed corridor.

\subsubsection{Baton Rouge Downtown Station}

While the original 2010 proposal identified a station location near Main Street, the 2014 study identified a shift in the preferred location to Government Street in order to facilitate easier CBD access and avoid challenges associated with freight switching movements north of North Boulevard.

The Baton Rouge Redevelopment Authority (now called Build Baton Rouge) advanced a $\$ 450,000$ station area master plan, funded by the FRA with City-Parish matching funds completed by HNTB 
to give local leaders the opportunity to evaluate potential transit-oriented developments, whether or not a rail service eventually materializes (37). The plan identified several sites within the Baton Rouge health district that would include new commercial and/or mixed-use buildings and includes analysis of potential funding opportunities (38).

The proposed options for a downtown station, on the 1500 block of N. Government Street in Mid City (Figure 8), included two alternatives with the station configured either to the east or west of the tracks. Both alternatives identified potential ROW connections including additions to the street grid to facilitate multimodal circulation, as well as a bus terminal for direct CATS access (38).

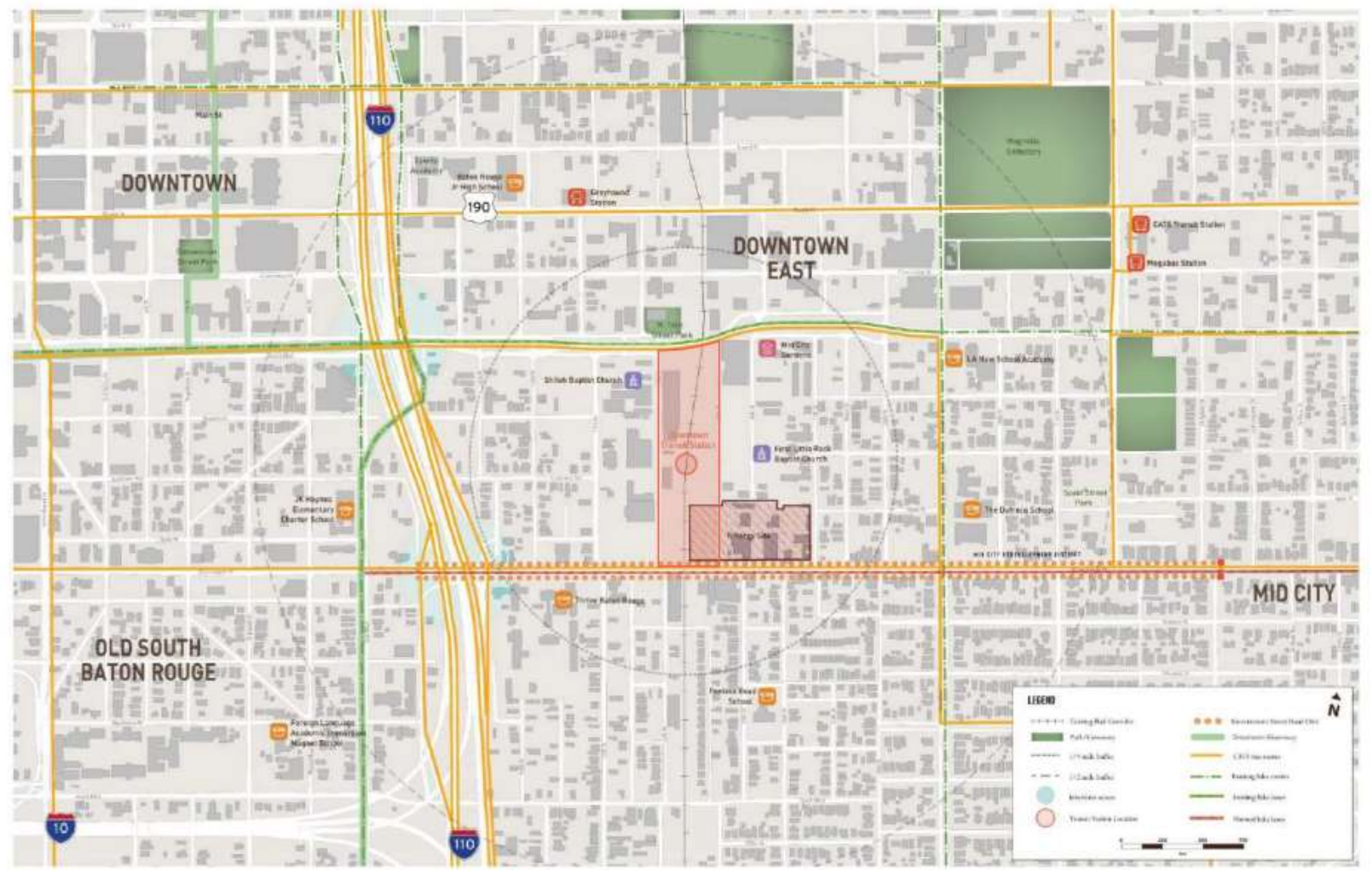

Figure 8. Downtown Baton Rouge station area map. (38)

Future land use plans for this area, as defined by the FUTUREBR Comprehensive Plan, designate the site for a mid-rise, mixed use "Regional Center" intended to provide high quality pedestrian and transit access (38).

Significant development activity has already occurred within the proposed station area, including the acquisition of the 6-acre former Entergy site (now known as the Electric Depot), along with a brownfield grant to support its redevelopment.

However, population and employment density of the site area are currently relatively low, at 4-16 residents per acre within half a mile of the station area (Figure 9) and less than 10 jobs per acre across 236 businesses (Figures $10 \& 11$ ) for a total of 3,300 jobs (38). A small portion (less than $100)$ of the station area's residents is employed within $1 / 2$ mile of the station (38). 
Ultimately, the station area west of the railroad tracks was recommended for development due to reduced development costs and implementation obstacles, as well as opportunities to utilize existing surface parking areas.

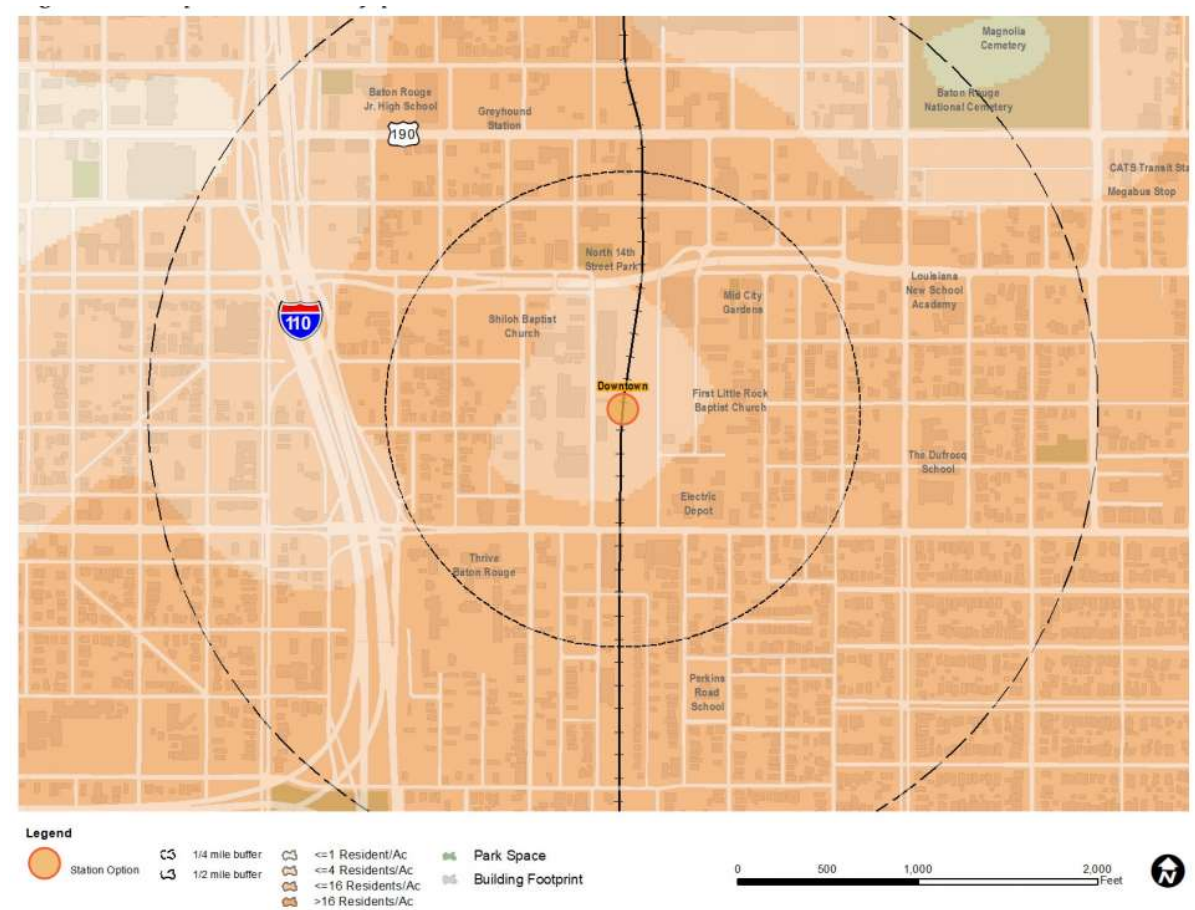

Figure 9. Downtown Baton Rouge station area population density per acre. (38)

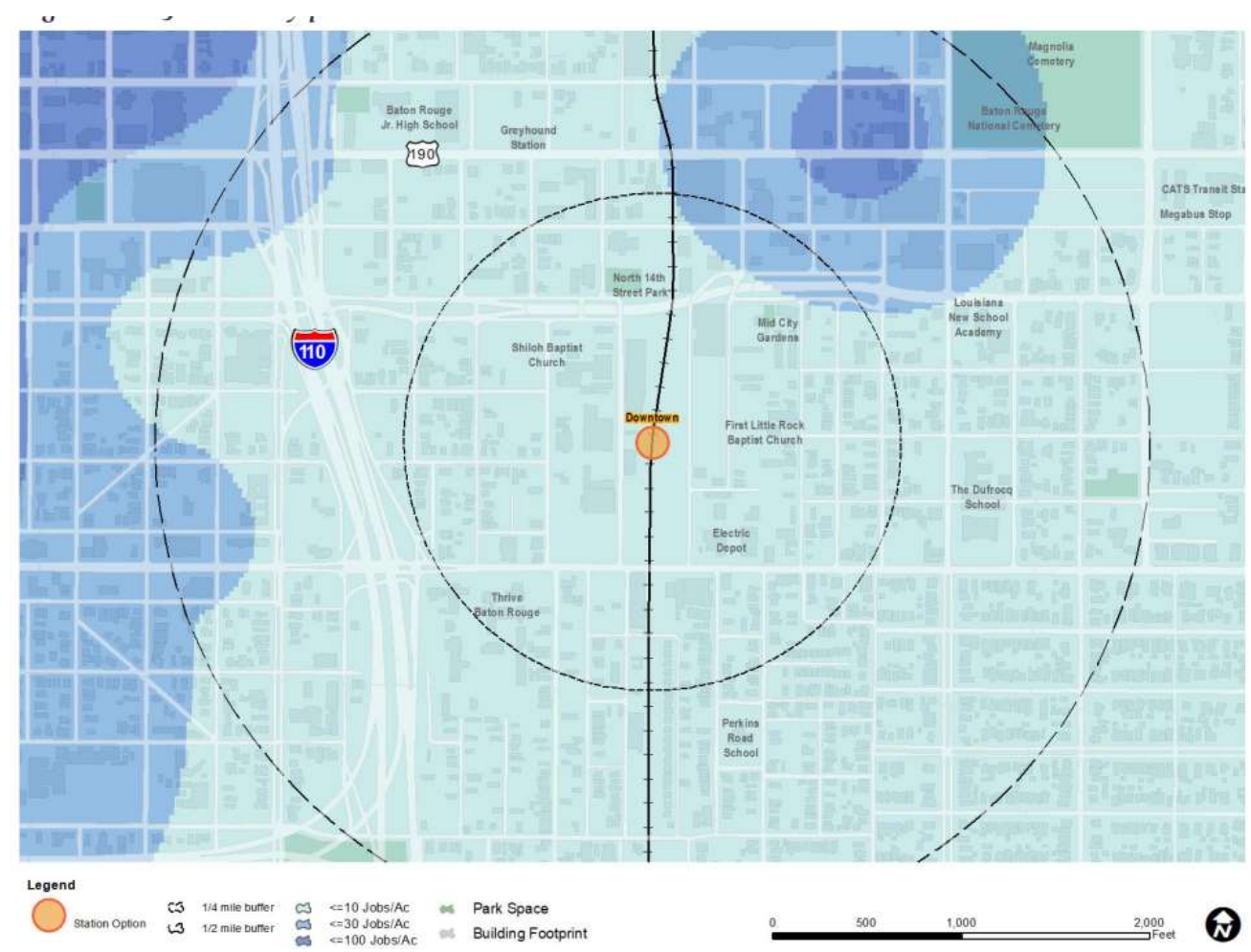

Figure 10. Downtown Baton Rouge station area job density per acre. (38) 


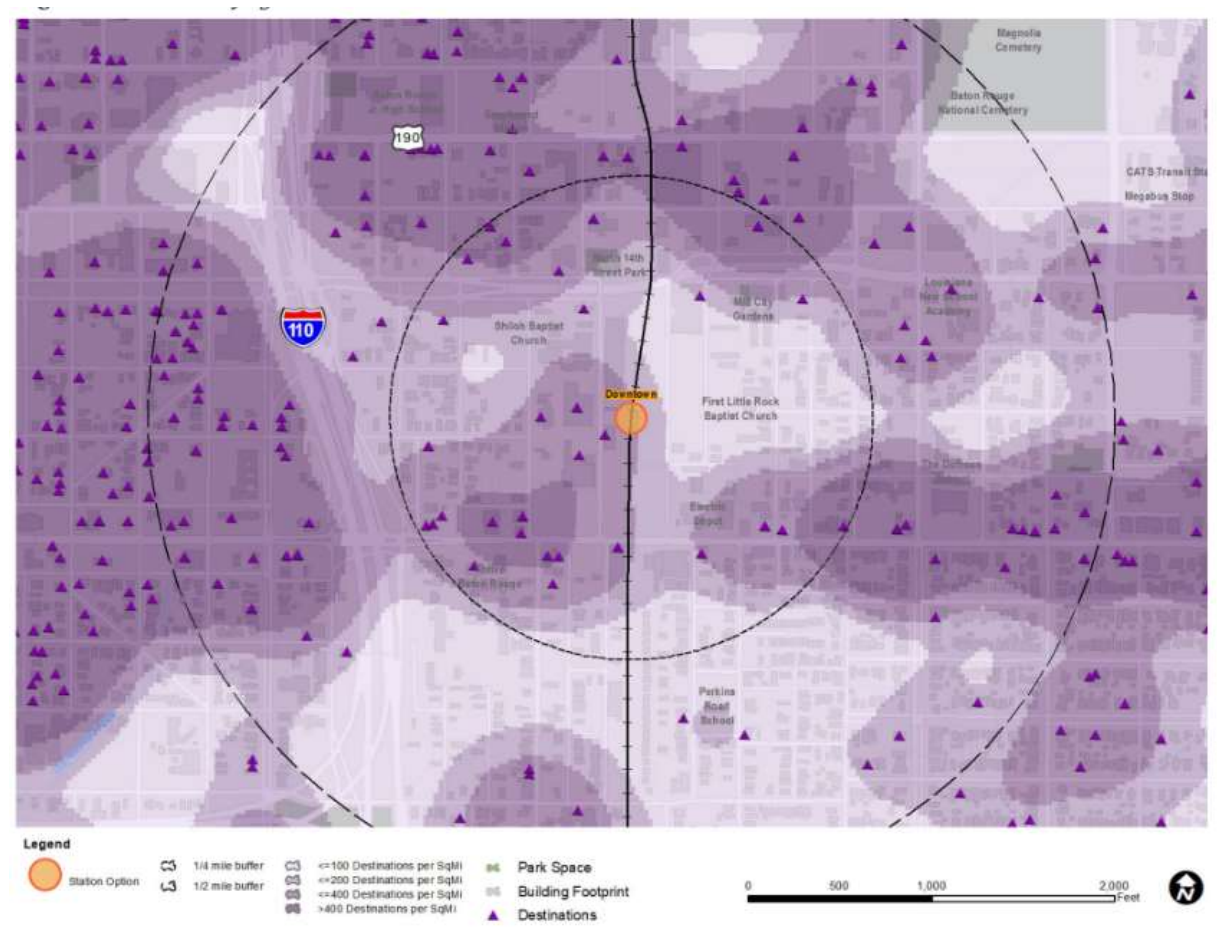

Figure 11. Density of retail and service destinations. (38)

A TOD concept is proposed to further advance redevelopment in the area (Figure 12), including two mixed-use buildings with retail as well as rail station facilities on the ground level and 125 residential units on three floors above, with an estimated development value of $\$ 35 \mathrm{M}$ (38). In addition, the plan calls for "neighborhood TOD" to encourage continued build-out of the station area through new construction and adaptive reuse over time, with opportunity identified for up to 576 new dwelling units, 56,000 sf of retail, and 27,230 feet of office space at a value of $\$ 137 \mathrm{M}$. Affordable housing set asides are recommended for this development, which is expected to require some degree of public-sector investment to realize.
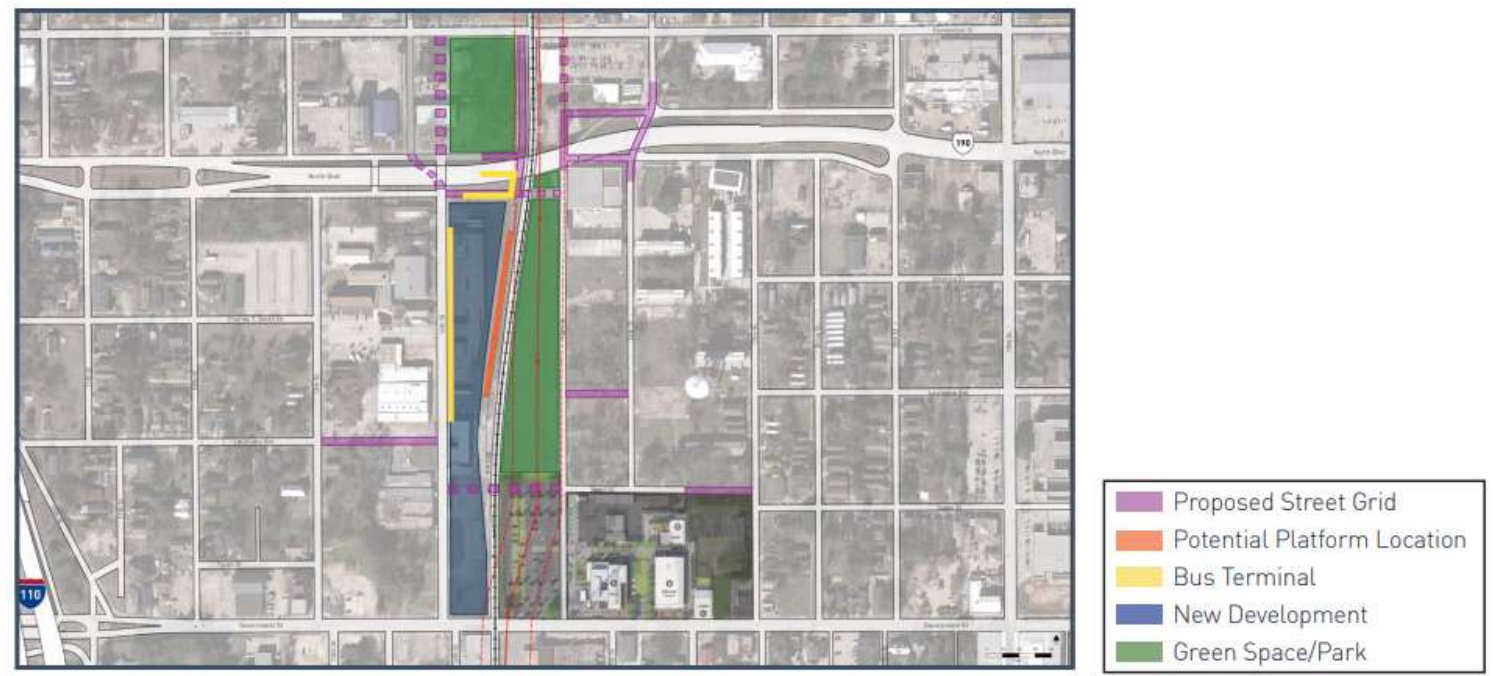

Figure 12. Proposed downtown Baton Rouge station site plan - West of rail tracks. (38) 
Importantly, the plan calls for an emphasis on equity through the TOD development process to ensure benefits are realized by existing residents of the station area, 58\% of whom are African American, and where the median household income is well below the metro area average at $\$ 27,407$ (38).

For both the Downtown and Suburban Baton Rouge station area plans, a phased approach is indicated, with construction anticipated to align with a proposed corridor service initiation in 2025 , with consecutive expansions to build out the proposed intermodal connections, TODs, and stations themselves over the subsequent two decades (38).

Cost estimates for full build out of the Downtown Baton Rouge station total approximately \$29M, with a Phase 1 estimate of \$5.7M (38).

\subsubsection{Suburban Baton Rouge Station}

Similarly, plans for the suburban Baton Rouge rail station site, originally proposed for near Bluebonnet and the Mall of Louisiana, shifted during the 2014 feasibility study process identifying Essen Lane near the Baton Rouge Medical Complex as the preferred station location. The 2015 Master Plan for the Baton Rouge Health District identified three station site options: West of Essen Lane, East of Essen Lane, and East of Midway Boulevard (39). The 2019 Baton Rouge Passenger Rail Station Master Plan added two additional potential stations, West of Midway Boulevard and West of Bluebonnet Boulevard (as originally proposed). These sites were each evaluated for feasibility and functionality for the suburban Baton Rouge Station (Figure 13).

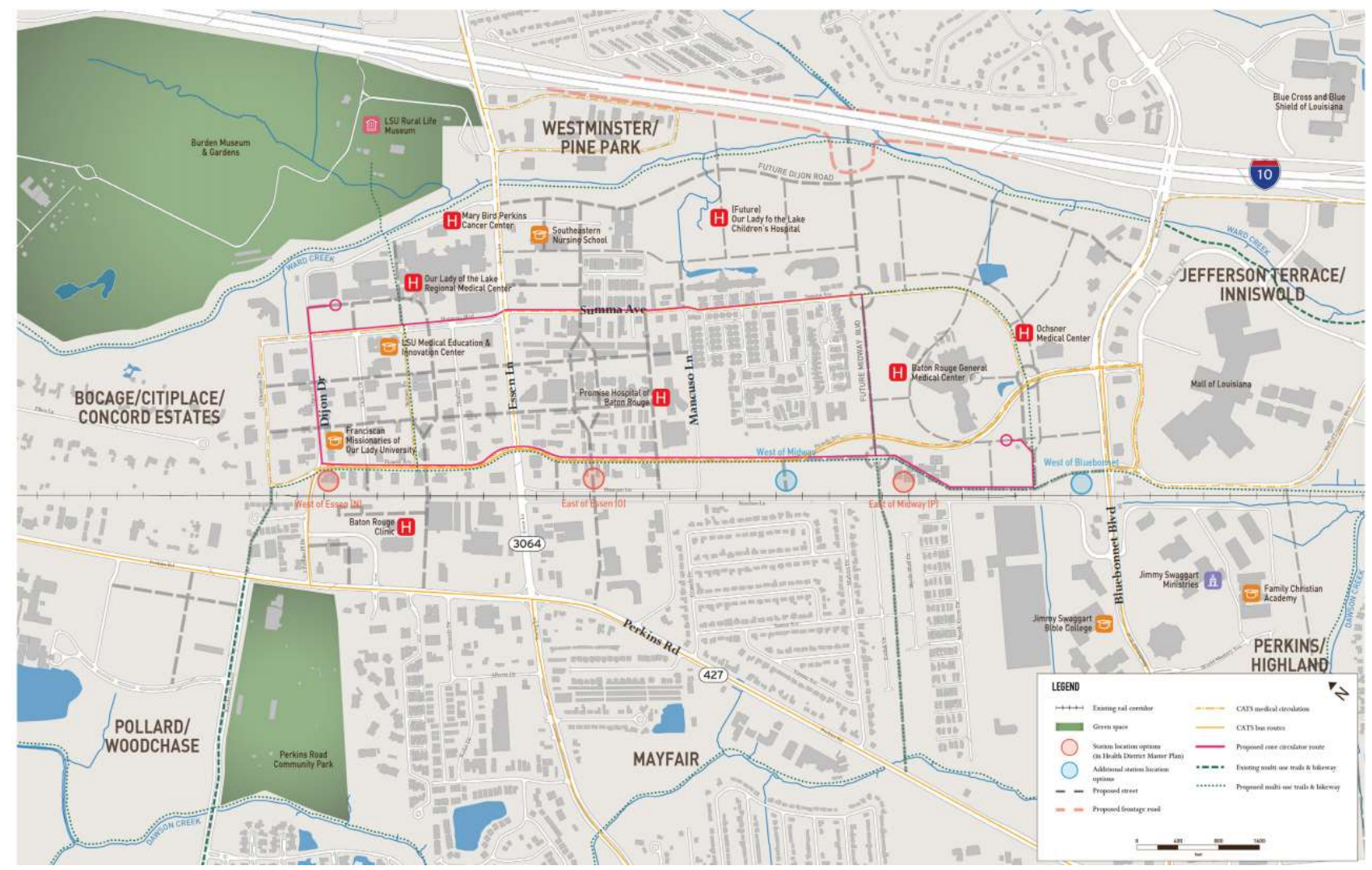

Figure 13. Suburban Station site options and site context. (38) 
Existing and planned land uses are compatible with station development at all sites (excluding an industrial Zoning classification at the West of Midway site), but the degree to which existing development conflicts with proposed station footprints varies, with relocation and demolition of existing businesses and structures required on the three westernmost proposed sites. The sites on the east side of the district, on the other hand, have more undeveloped land available.

Existing multifamily housing is concentrated toward the center of the potential station area (Figure 14), though residential densities are generally low in the area due to its concentration of medical and institutional uses, while job densities, conversely, are clustered toward the western and easternmost sites, adjacent to medical centers and the Mall of Louisiana (Figures 15 and 16).

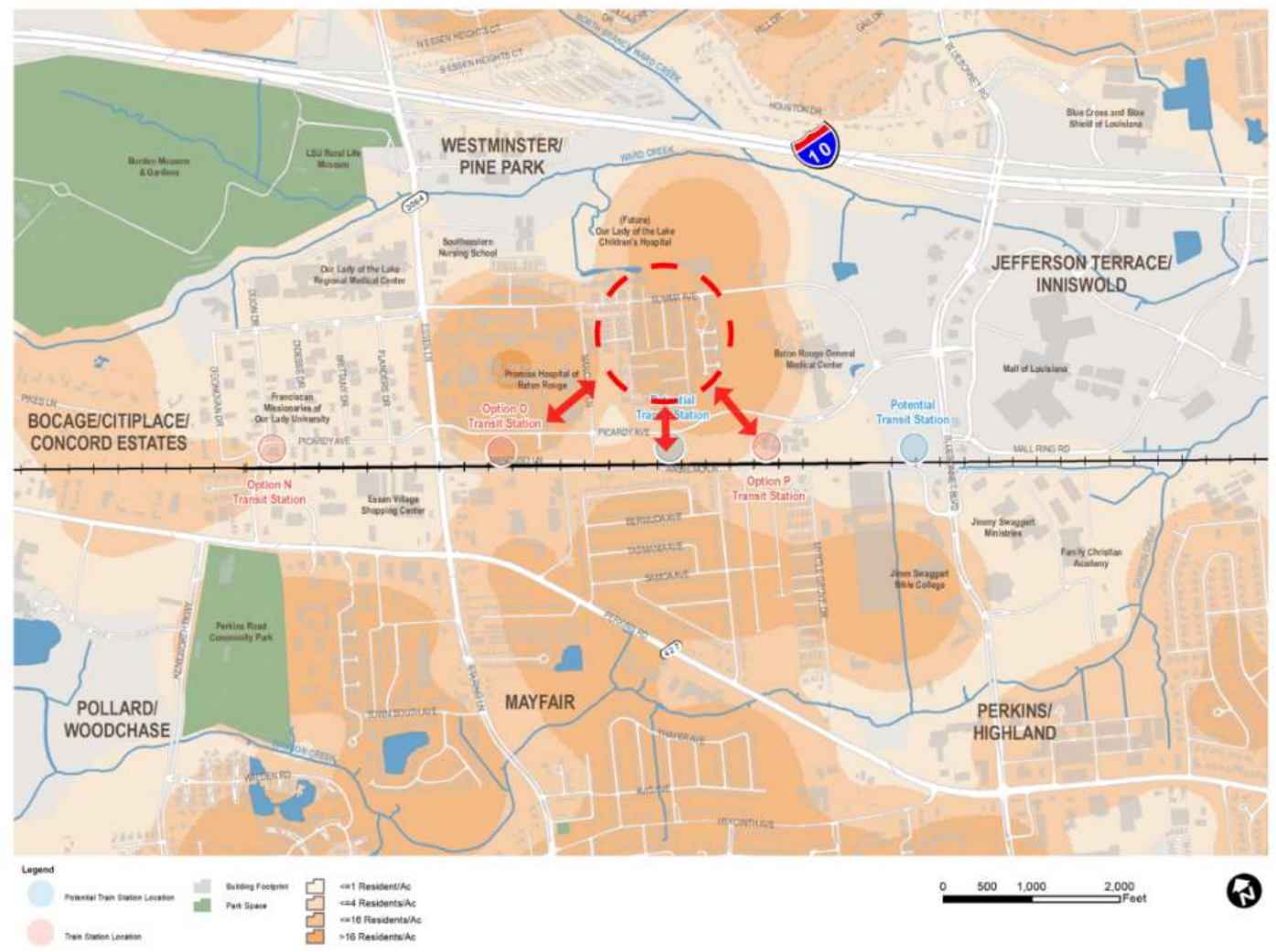

Figure 14. Suburban Baton Rouge station population density per acre. (38) 


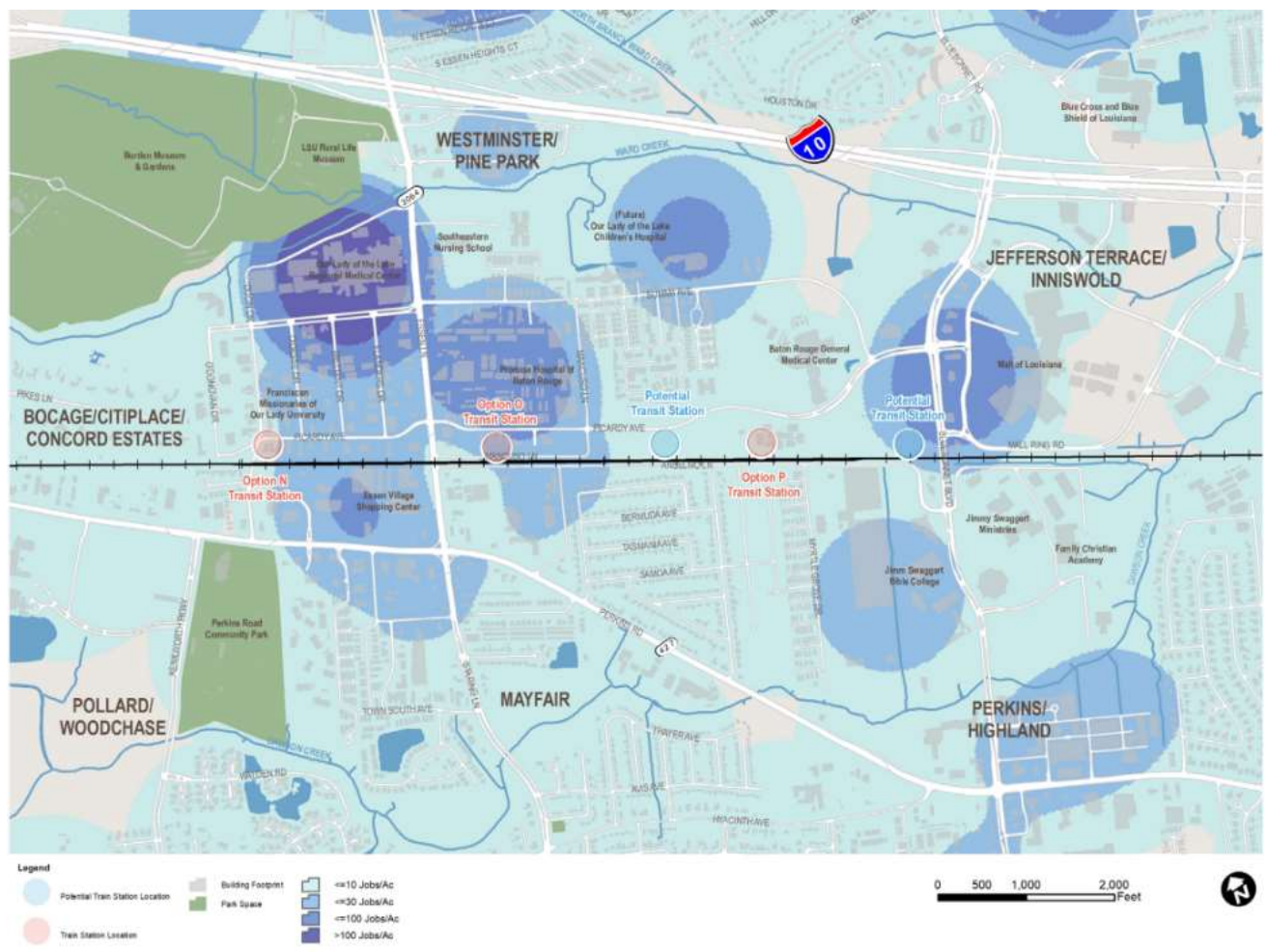

Figure 15. Suburban Baton Rouge station job density per acre. (38)

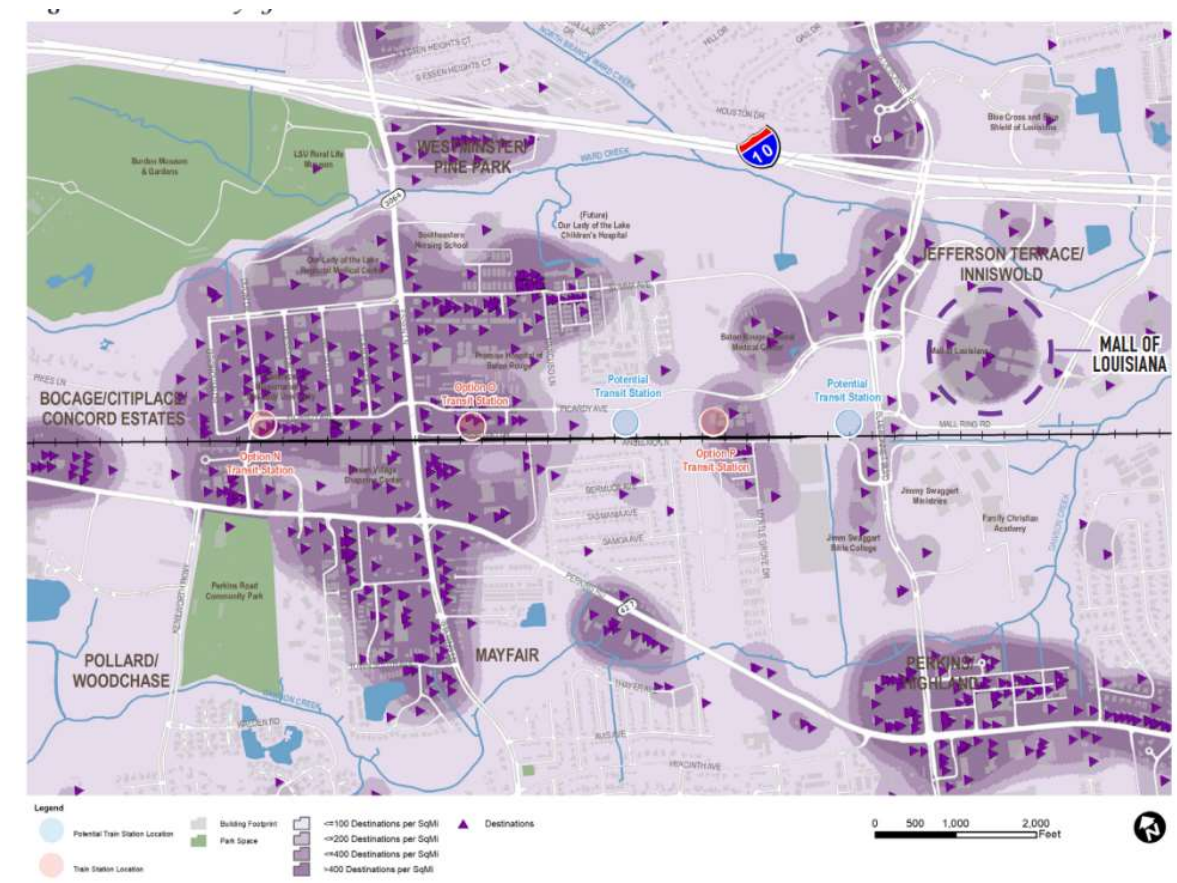

Figure 16. Suburban Baton Rouge station density of retail and service destination. (38)

As a result of these characteristics, as well as logistical considerations for railroad operations, environmental issues, etc., the Master Plan recommends the West of Bluebonnet station site for development due to significant opportunity for TOD, availability of undeveloped land, and 
planned or existing multimodal connections (Figure 17), despite being less centrally located to existing housing and employment centers, and likely necessitating additional track extensions. The West of Midway and East of Midway Boulevard sites also deemed viable for development (38).

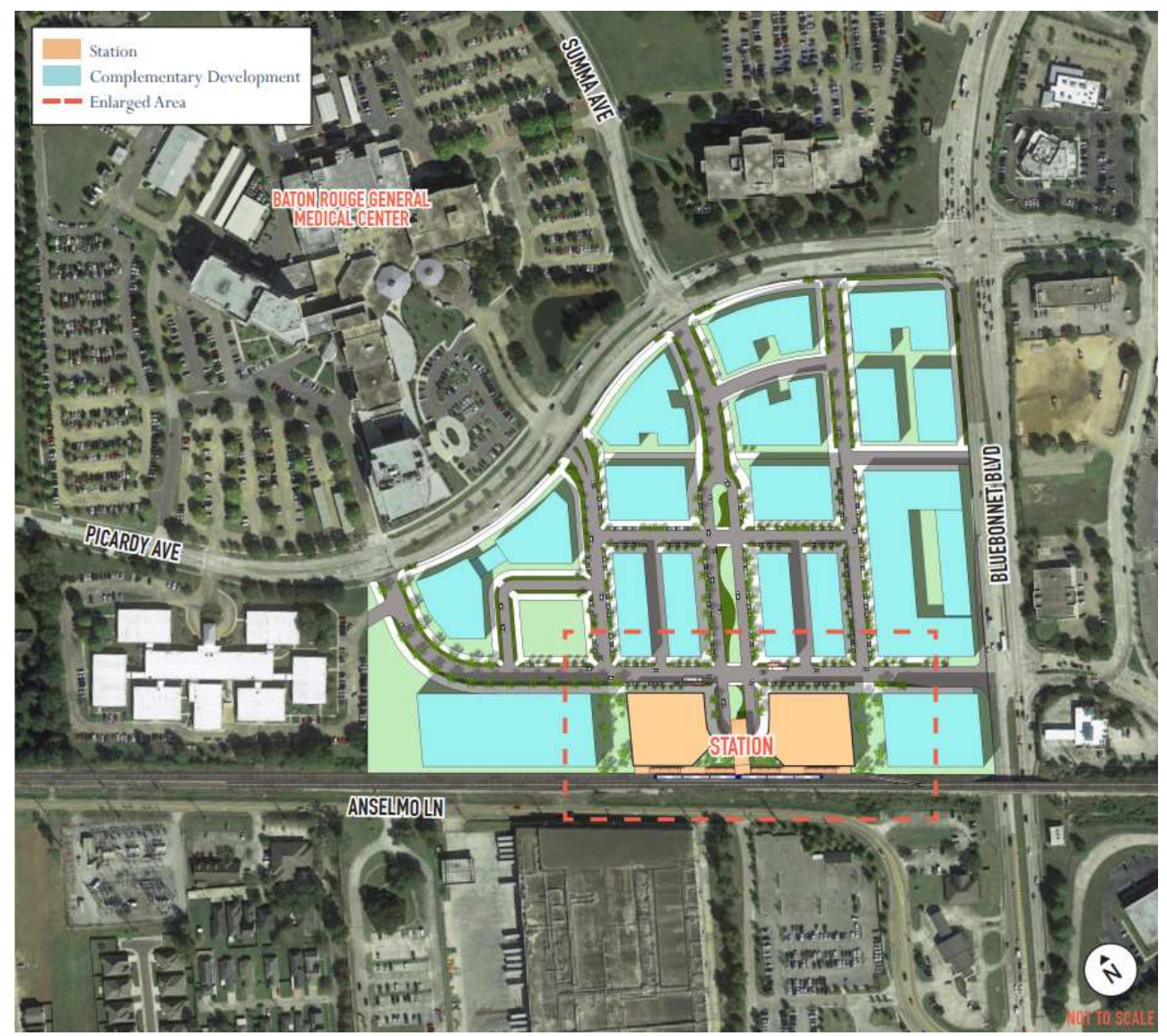

Figure 17. West of Bluebonnet suburban station site plan. (38)

The station is expected to be designed to meet Amtrak Category 2 Medium Station classification, with an option for reduced capacity at startup. The site is designed to interact with over 26 acres of undeveloped surrounding land, with significant opportunity for mixed-use infill development. The Master Plan estimates over 21,000 sf of retail, and up to 77 dwelling units for a $\$ 25 \mathrm{M}$ development value within the station area itself, with up to 424 dwelling units and 77,000 sf of retail, 190,000 sf of medical offices, and 223,000 sf of other office uses within the surrounding neighborhood TDO development, assuming a 5-story maximum design. This neighborhood TOD scenario is expected to generate nearly 1,150 jobs and bring a value of $\$ 248 \mathrm{M}$. Mixed income development with affordable units serving health district employees, along with district-wide parking strategies rather than individual building parking requirements, are encouraged (38).

With over 4,700 jobs within half a mile of the proposed station, and 14,500 jobs within one mile, the station area is a major employment hub, with about $12 \%$ of employees already commuting to work via transit (38). Fewer than $1 \%$ of the area's residents live within the station area, which has a higher median household income than the citywide average. While at present the area is relatively well served by transit (discussed below), walking and bicycling in the area is limited due to the presence of major arterials and the railroad track itself (38). The proposed "Health Loop Trail" 
(39) is intended to expand pedestrian and bicycle connectivity within the area, while reducing traffic pressure from continued development of the medical district.

The Medical District plan also highlights opportunities for the suburban Baton Rouge station in particular to aid in emergency preparedness, with the proposed rail stations intended to serve as assets for evacuation and other local emergencies, including improved hospital access and connectivity (39).

Cost estimates for the Suburban Baton Rouge station total nearly $\$ 23 \mathrm{M}$ for full build out, with an initial phase 1 cost of $\$ 7.7 \mathrm{M}$.

\subsubsection{Gonzales Station}

The City of Gonzales, included in both feasibility studies for connecting service, has also recently completed a Passenger Rail Station Master Plan (40). Gonzales is located 25 miles from Baton Rouge and 57 miles from New Orleans, has a population of approximately 10,000 people, and the city has clearly placed passenger rail service as a desired goal of its 2015 Comprehensive Plan vision. The intent is to use the station as a civic focal point and locus of more intensive downtown development/TOD, as well as a link to regional employment centers, situating Gonzales as a viable "bedroom community" for both Baton Rouge and New Orleans metros.

Both the 2010 and 2014 Feasibility Studies anticipated siting the Gonzales station near City Hall, along East Cornerview Street. However, the City of Gonzales has purchased property for a proposed station along N Bullion Avenue between East Railroad Street and East Ascension Street, the site of a former rail depot and current DMV parking lot. The 2018 Gonzales Passenger Rail Station Master Plan focuses on the development of this site (Figure 18).

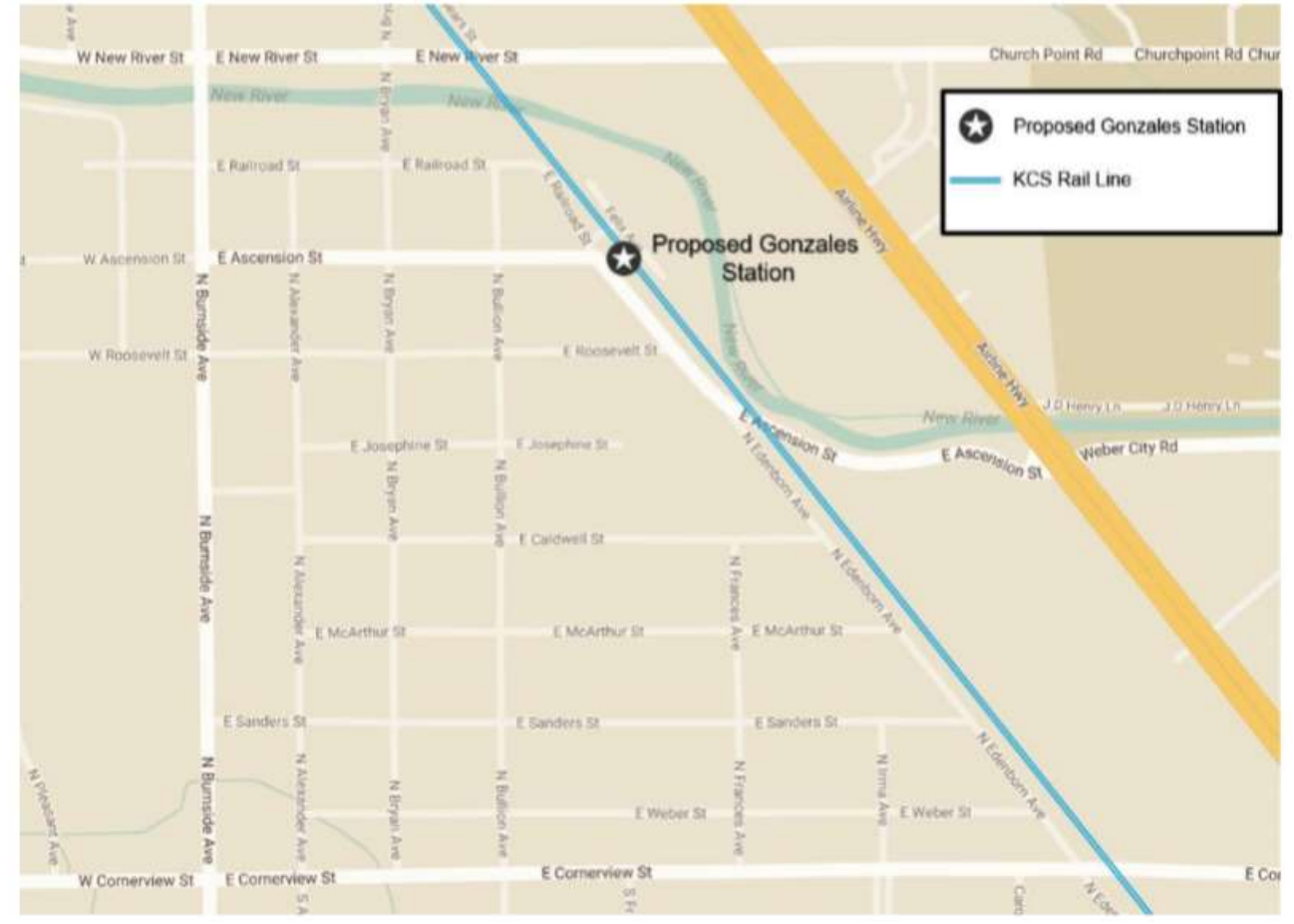

Figure 18. Proposed Gonzales station location. (40) 
The previous service feasibility studies estimate that approximately $25 \%$ of rail boardings would originate from Gonzales, with over 9,400 annual trips at initial ( 2 trip per day) service levels (Table 8). Amtrak's guidelines, based on projected ridership, call for a "Category 4" station, indicating an unstaffed, sheltered platform. However, Gonzales stakeholders have identified that their station also serve as a "gateway to the city" with enhanced amenities and indoor space, in addition to preparing for higher future ridership as services are enhanced and expanded.

Table 8. Estimated Gonzales annual ridership. (40)

\begin{tabular}{|l|l|l|l|}
\hline Round Trips per Day & HNTB 2014 report & Amtrak 2010 report & BKI/HDR 2010 report \\
\hline $\mathbf{2}(\mathbf{4}$ trips) & $9,461^{*}$ & - & - \\
\hline $\mathbf{4}(\mathbf{8}$ trips) & $14,191^{*}$ & 14,887 & 20,745 \\
\hline $\mathbf{6}(\mathbf{1 2}$ trips) & $19,922^{*}$ & 25,605 & 28,989 \\
\hline $\mathbf{8}(\mathbf{1 6}$ trips) & $37,843^{*}$ & 30,870 & 39,888 \\
\hline
\end{tabular}

* values extrapolated assuming 240 seats per train, a 60\% Load Factor, times number of trips per day, and 365 days service

Significant opportunities exist to enhance pedestrian and bicycle access to this site, including connection to the existing pedestrian and bicycle trail along New River west of the proposed station site, and related improvements identified in the Gonzales Comprehensive Plan's Complete Streets Map and Connections Plan Proposal (developed with support from the National Park Service Rivers, Trails, and Conservation Assistance Program). Specific opportunities and preliminary designs for adding complete streets enhancements to roadways connecting the proposed station site to existing facilities and/or downtown areas are outlined for East Ascension Street, East Railroad Street, and North Alexander Street, as well as several local streets cited in the National Park Service Gonzales Connections Plan for additional study to evaluate potential conversions to one-way traffic in order to accommodate complete streets design features (Figure 19). Improvements to existing parking facilities could expand capacity to 78 spaces, with opportunities to provide green infrastructure enhancements and expand parking capacity in future development phases.

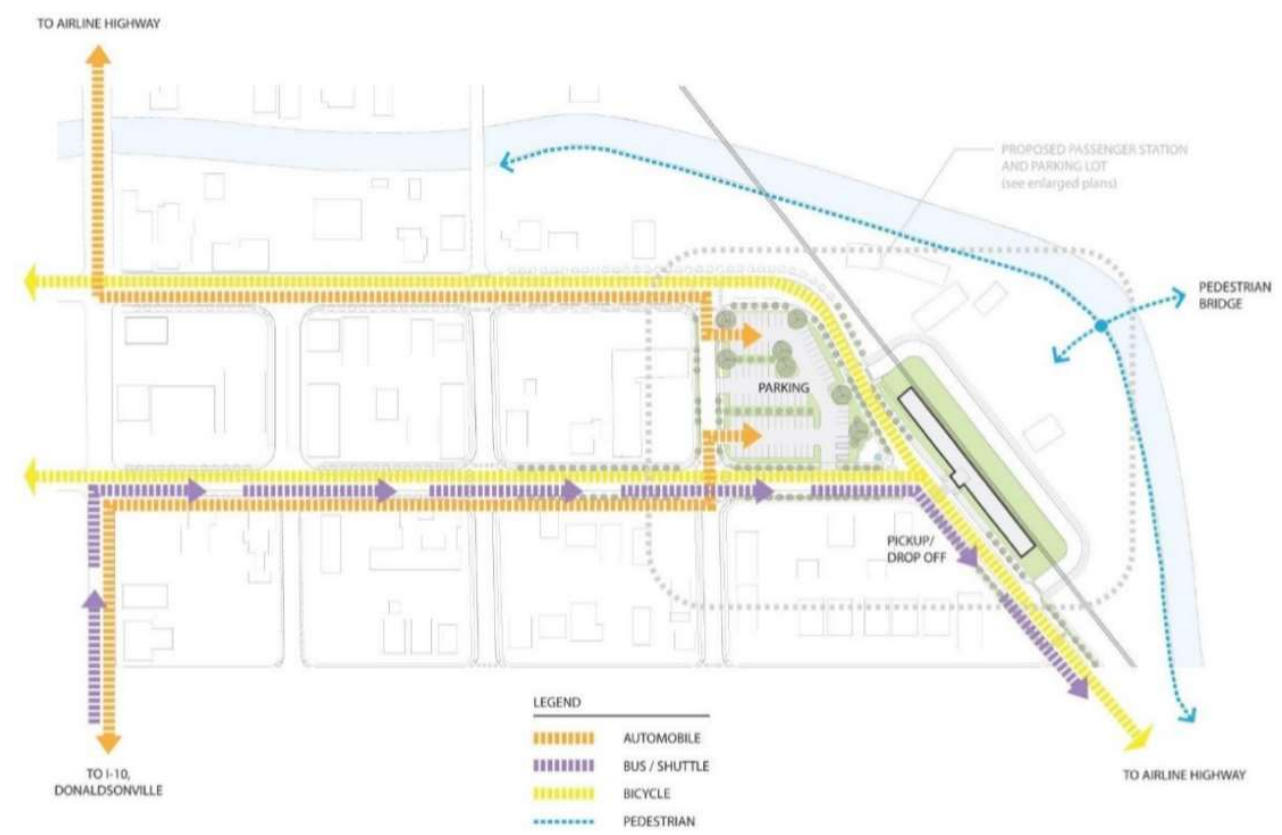

Figure 19. Gonzales station access improvements plan. (40) 
In addition, the station development plan proposes phased development of vacant or underutilized properties in the vicinity of the proposed station. Mixed-use infill development among existing residential and commercial properties is recommended, along with public open space/park enhancements along the New River (40). Additional opportunities for redevelopment abound across the New River, where planners have identified up to 600,000 square feet of commercial and retail opportunity, for which a 3-5 story, "urban village" concept is proposed in accordance with the Gonzales Comprehensive Plan and encouraging ridership (Figure 20).

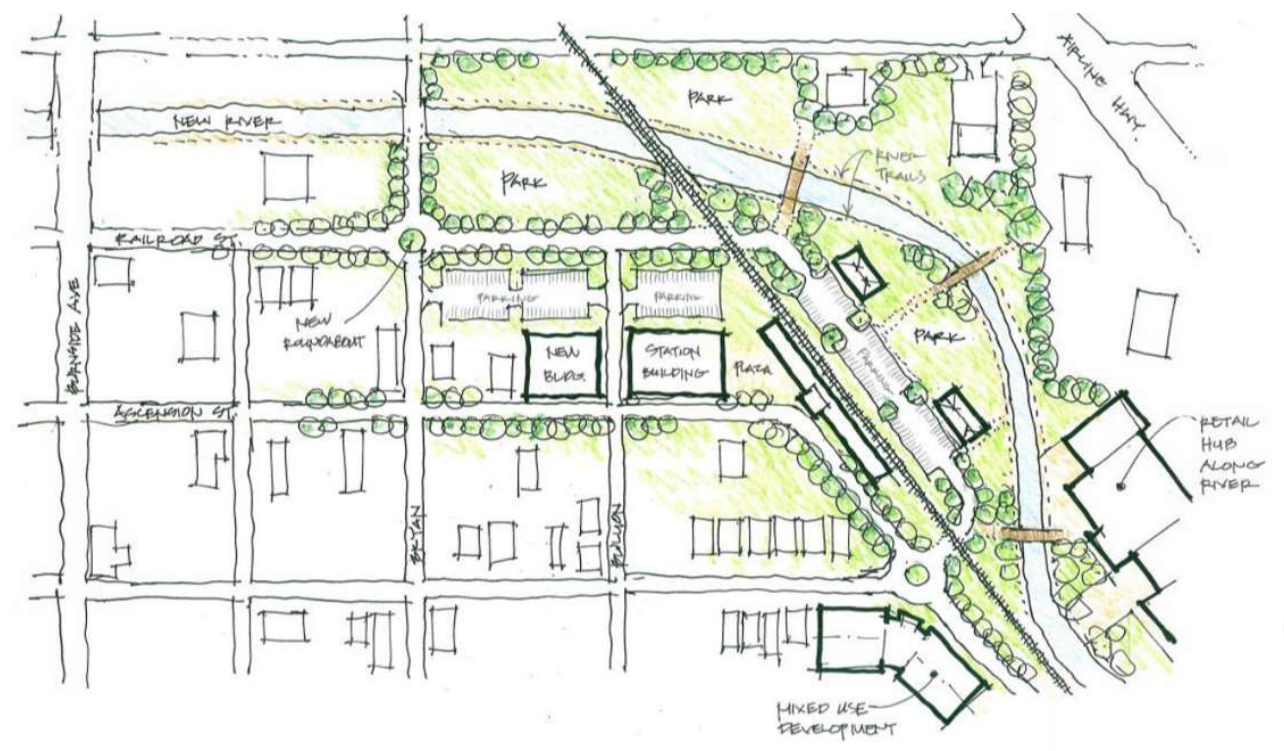

Figure 20. Potential site area redevelopment scenario. (40)

In addition, the Gonzales station is located four miles from the Tanger Outlets and could potentially provide access to the parish's chemical district through future public transit and/or vanpool connections.

Notable barriers to development of the proposed Gonzales station include needing to negotiate with KCS to remove siding track within the station footprint, and the necessity for a phased implementation approach that incorporates creative finance tools and public-private partnerships to achieve the desired "town center" development outcome which would best support ridership growth. Initial implementation steps needed include adoption of proposed future land use and zoning for the site, advancing complete streets connectivity, and initiating the NEPA process (in conjunction with the broader corridor project advancement).

\subsubsection{LaPlace Station}

LaPlace is a largely suburban community of approximately 29,000 residents in St. John the Baptist Parish. Initial feasibility studies proposed siting the LaPlace station near the US 61/US 51 interchange west of Main Street, though other alternatives along Airline Highway have been proposed closer to residential development and employment centers (1). St. John the Baptist Parish's 2014 comprehensive plan further elaborated on the potential of passenger rail and accompanying station area development as an opportunity to improve housing and economic options, as well as transportation, in combination with zoning and policies that promote walkability and mixed-use development (41). A multi-modal transportation center feasibility study and conceptual plan was completed by St. John the Baptist Parish in 2019, with support from the 
Federal Rail Administration and Southern Rail Commission (41). This study expanded and refined the proposed station area to include the historic Main Street corridor between Airline Highway and West $5^{\text {th }}$ Street, with the rail station itself located between Main St and Cardinal St (Figure 21).

\section{Refined Main Street Scenario}

a smaller commercial functions to complement existing context

(b) green pocket park to serve as buffer between residential development and rail line, pocket parks provide visual screening and stormwater management

(c) pedestrian plaza (d) trees along railroad tracks to serve as visual screening

(e) area to serve as phase 1 satellite surface parking using permeable povernent

(f) parking garage to serve town center

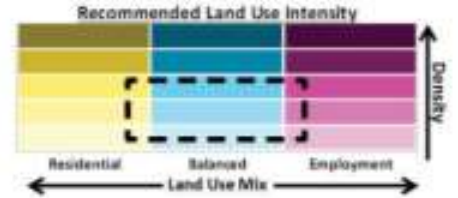

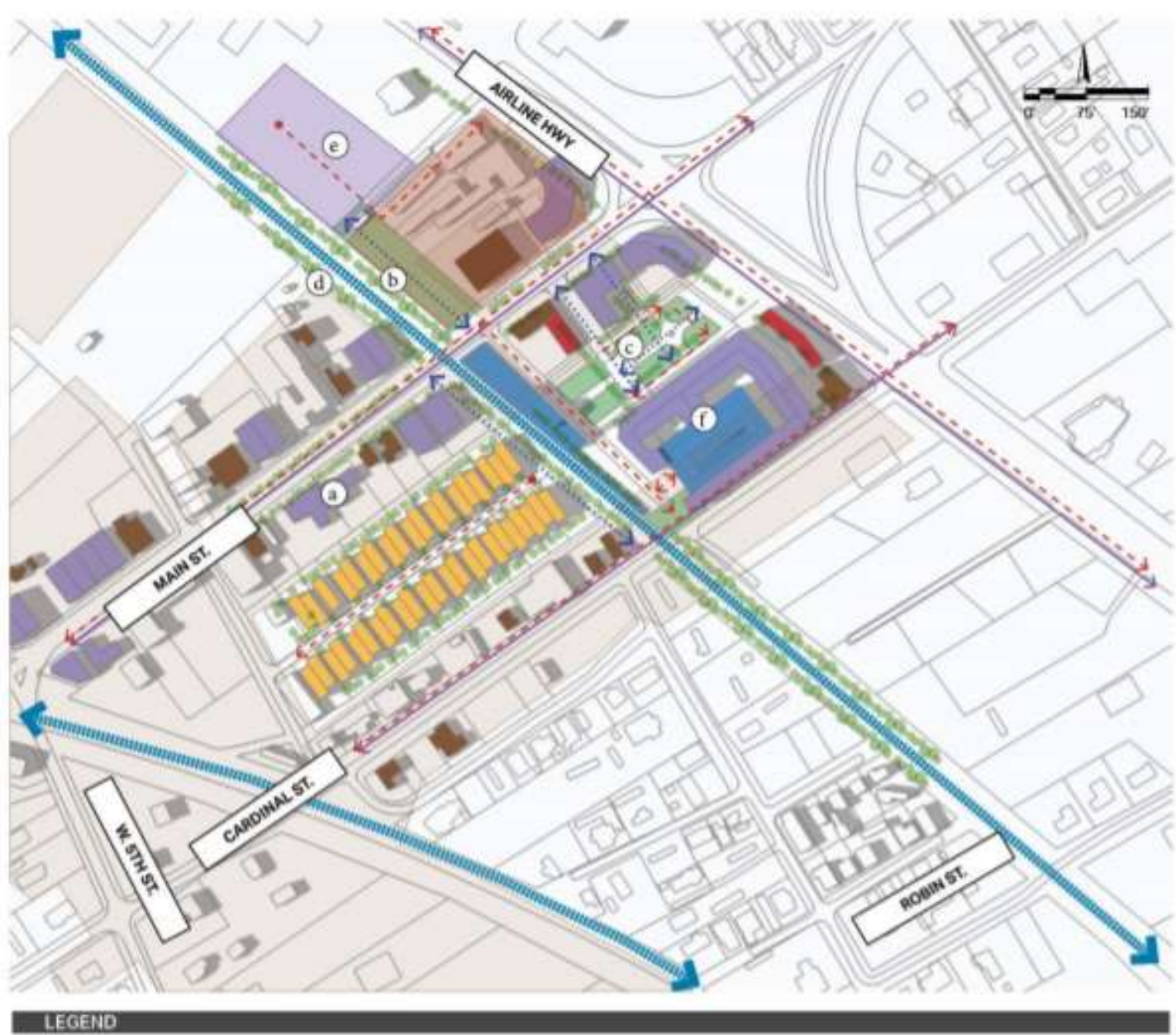

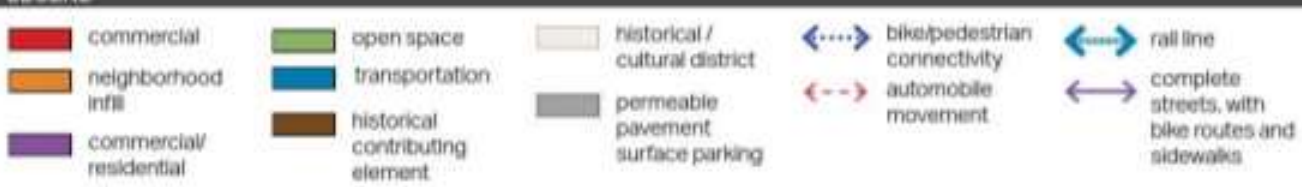

Figure 21. LaPlace Airline and Main proposed transportation center and redevelopment scenario. (41) 
The study and plan describe a transportation center that is intended to serve multiple uses beyond strictly serving the proposed rail service, including civic uses, such as spaces to host public meetings and as a staging area and/or shelter during disaster events. The station area would also integrate with any future fixed-route transit service (see section 5.4) in order to expand multimodal access. The proposed station area is located on relatively high ground and is intended to support ongoing investments in LaPlace's historic district, as well as the Louisiana Strategic Adaptations for Future Environments (LA SAFE) program's complete streets streetscape project, also centered at Airline Highway and Main Street (awarded in 2018 and scheduled to be completed by 2022). This project incorporates pedestrian and bicycle facilities, drainage improvements, and aesthetic/streetscape enhancements to reduce flood risk while achieving transportation and economic benefits to the surrounding community (41).

St. John the Baptist Parish hosted four community meetings and administered an online survey to solicit feedback on the proposed rail station and plan, generating a total of 378 responses (primarily from within LaPlace). The majority of respondents expressed a preference for a station that also serves as a town center, specifically one that includes retail, food service, and community uses, as well as childcare, Wi-Fi, and a variety of transportation connection options including both (ample and free) parking and transit (Figures 22 and 23). Forty-five percent of respondents indicated that their place of work was somewhere that would potentially be served by the proposed rail service.

\section{If you could take a train from LaPlace to work, what features at the LaPlace station would encourage this behavior? Check all that apply.}

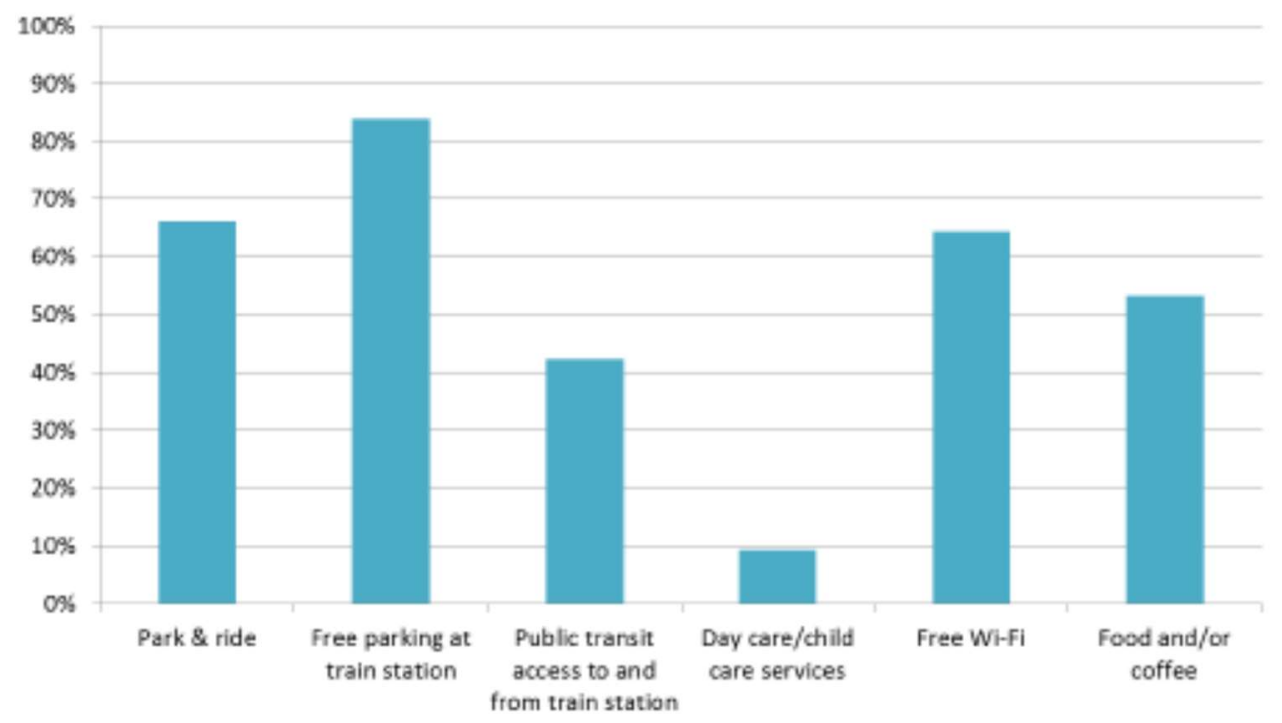

Figure 22. LaPlace station plan survey findings: key station features. (41) 
What would you like to see in and around the station site? Select your top 5 choices.

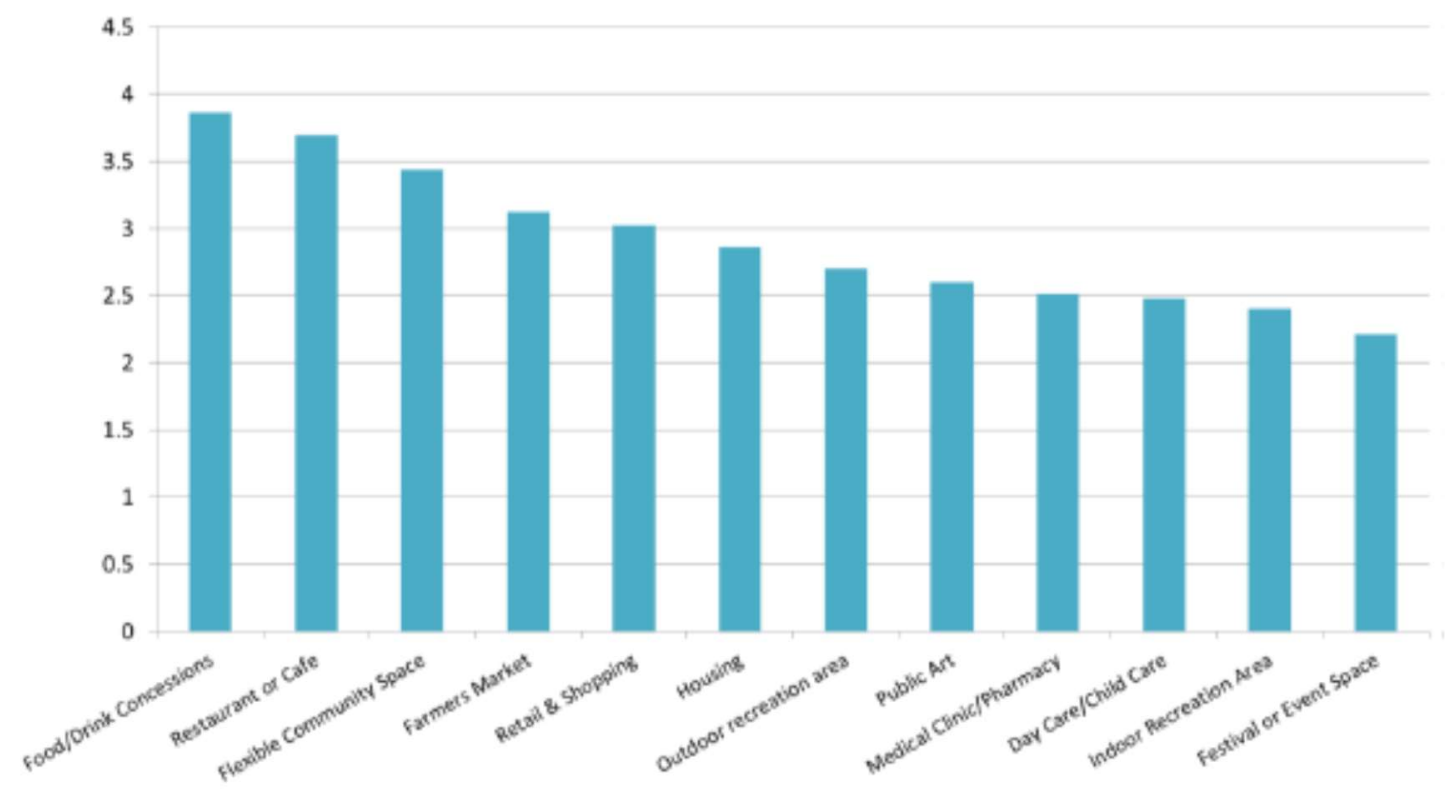

Figure 23. LaPlace station plan survey findings: station area amenity preferences. (41)

Ridership projections were developed as part of this feasibility study (Tables $9 \& 10$ ), based on an assumption of four round trips per day (rather than the two trips per day proposed as an initial service phase in HNTB's study). These projections extrapolate from previous estimates (utilizing FRA ridership projection models) which estimated that approximately $18 \%$ of total boarding's would originate in Gonzales or Laplace, and that based on current population, about $75 \%$ of these would likely originate from LaPlace for a total of 44,631 boardings per year, translating to approximately 165 LaPlace Station boardings per day (based on methodology recommended by Amtrak's Station Program and Planning Guidelines).

Table 9. LaPlace Station estimated annual boardings. (41)

\begin{tabular}{|l|l|l|}
\hline Round Trips per Day & Time Horizon & SHRC (2010) \\
\hline $\mathbf{2}(\mathbf{4}$ trips) & & \\
\hline $\mathbf{4}$ (8 trips) & 4 years out $(2013)$ & 62,235 \\
\hline $\mathbf{6}(12$ trips) & 9 years out $(2018)$ & 86,967 \\
\hline $\mathbf{8}(16$ trips) & 15 years out $(2023)$ & 119,664 \\
\hline
\end{tabular}

* Ridership projections based on opening year of 2013

Table 10. LaPlace station estimated daily boardings. (41)

\begin{tabular}{|l|l|l|l|}
\hline Round Trips per Day & NORPC/CRPC (2014) & Amtrak (2010) & SHRC (2010) \\
\hline 2 (4 trips) & 105 & & \\
\hline 4 (8 trips) & 157 & 165 & 230 \\
\hline $6(12$ trips) & 210 & 254 & 322 \\
\hline $8(16$ trips) & - & 343 & 443 \\
\hline
\end{tabular}

Trade area analysis based on drive times (Figure 24) illuminates the extent to which the proposed station area is readily accessible within a 10-minute drive for the majority of LaPlace residents. 


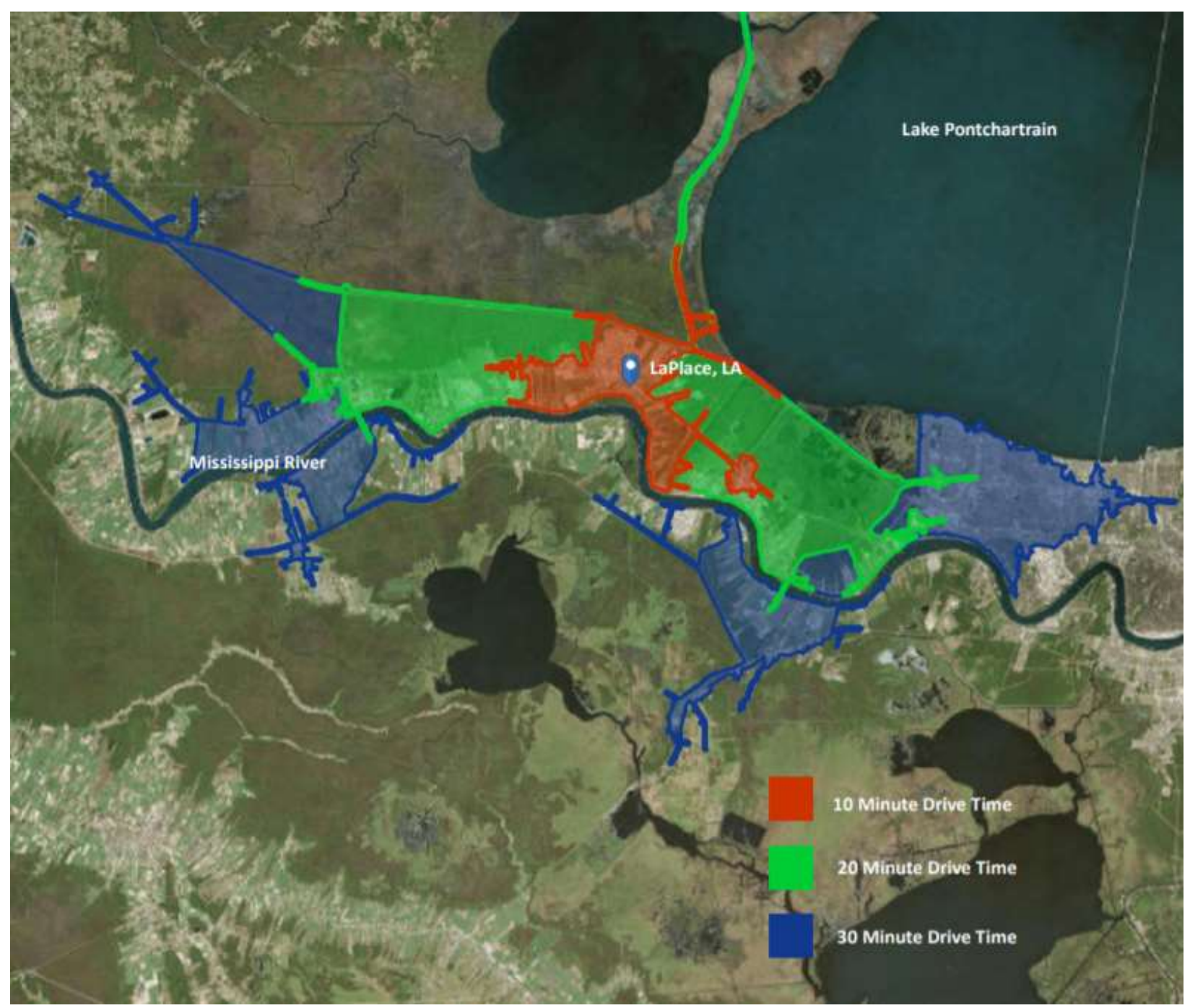

Figure 24. LaPlace drive time map. (41)

Based on estimated ridership figures, the plan proposes an Amtrak Category 3 station, with an indoor waiting room and restrooms, similar to the Amtrak station in Lafayette, Louisiana. The study's market analysis indicates that LaPlace is likely to be primarily a point of origin rather than a destination for passengers from elsewhere in the region, but that the market can support additional commercial development of the station area to meet existing local demand in a variety of market categories. The success of a "town center" or Transit-Oriented Development (TOD) development typology, however, is predicated on the advancement of supportive land use policies and transportation networks (41). Most of the proposed station area is currently zoned for commercial use; proposed future land use includes mixed uses. The study indicates that changes to current zoning codes will be needed to allow higher densities, smaller setbacks, and a mixeduse zoning classification or design overlay in order to facilitate the proposed development typologies.

Different scenarios were presented at the community meetings offering development approaches that balance development intensity, mix of land uses, and housing development within the study area. These scenarios include a focus on a linear "Main Street" area with housing above retail, 
services, and dining; a "Town Center" scenario focusing on the station itself as a hub of community activity and events and mixed-use development nearby, or a "Neighborhood Center" scenario focused on housing within walking distance of the station.

Additional analysis using IMPLAN to evaluate proposed development scenarios and estimate direct, indirect, and induced effects of the proposed project (assuming a "Hybrid Scenario" focused on Main Street development and the train station block area) suggests that the total impact output of implementation at over $\$ 12 \mathrm{M}$ in total construction impacts, $\$ 18 \mathrm{M}$ in commercial impacts, and $\$ 4 \mathrm{M}$ in tax impacts for development of the station block alone (41).

Traffic analysis using Synchro software assessed how the proposed changes would impact Airline Highway, Main and Cardinal Streets, and US-51. Traffic capacity analysis (assuming increased activity generated by train station and related developments) found that with improvements planned under the LASAFE program, the current roadway network can accommodate the additional anticipated traffic from redevelopment of the station area.

Importantly, there are currently no safe pedestrian accommodations within the proposed station area, which was noted as a barrier to implementation at public meetings. The LA SAFE project, as noted above, includes the development of multi-use paths along US-61 and crosswalks and pedestrian signals at Main Street, which will significantly improve non-motorized access to the area. Additionally, feasibility studies have been developed to connect these paths to the Mississippi River Trail near the proposed station area site, creating a network of facilities that permits greater station access by walking and bicycling (41). The study notes additional value capture opportunities to support additional improvements in infrastructure, operations, and maintenance.

\subsubsection{Kenner Suburban Station (Airport)}

The proposed station location along Airline would have provided a direct connection to the old Louis Armstrong International Terminal (LANOIA), however, additional connecting services would be required in order to connect rail passengers to the new terminal, located to the north of the previous facility. The 2014 feasibility study (1) called for this to be addressed in the master plan for the new terminal, then under development, in anticipation of a future rail line.

The 2015 Kenner Comprehensive Plan (42) highlights the opportunity for rail access via commuter rail between New Orleans and Baton Rouge, indicating the potential economic development benefits of station development in Rivertown, as well as potential light rail connection between downtown New Orleans and the Airport. The plan notes that "Kenner has oversight on all permitting, land use, and zoning matters pertaining to the airport property" (p. 35), and highlights community outreach findings indicating that enhanced transit service and passenger rail development are broadly supported by Kenner residents, but does not substantively address how future station area development might proceed, or how a Rivertown station could be effectively connected to seamlessly serve the new airport terminal (42).

The Louis Armstrong New Orleans International Airport Long-Term Infrastructure Development Plan (43) suggests that a new spur could be constructed in the southwest quadrant of the airport complex to connect existing rail lines to an intermodal logistics center (Figure 25), in order to facilitate movement of goods from the airport to and from the Port of New Orleans, but no discussion of potential passenger rail service is included. 


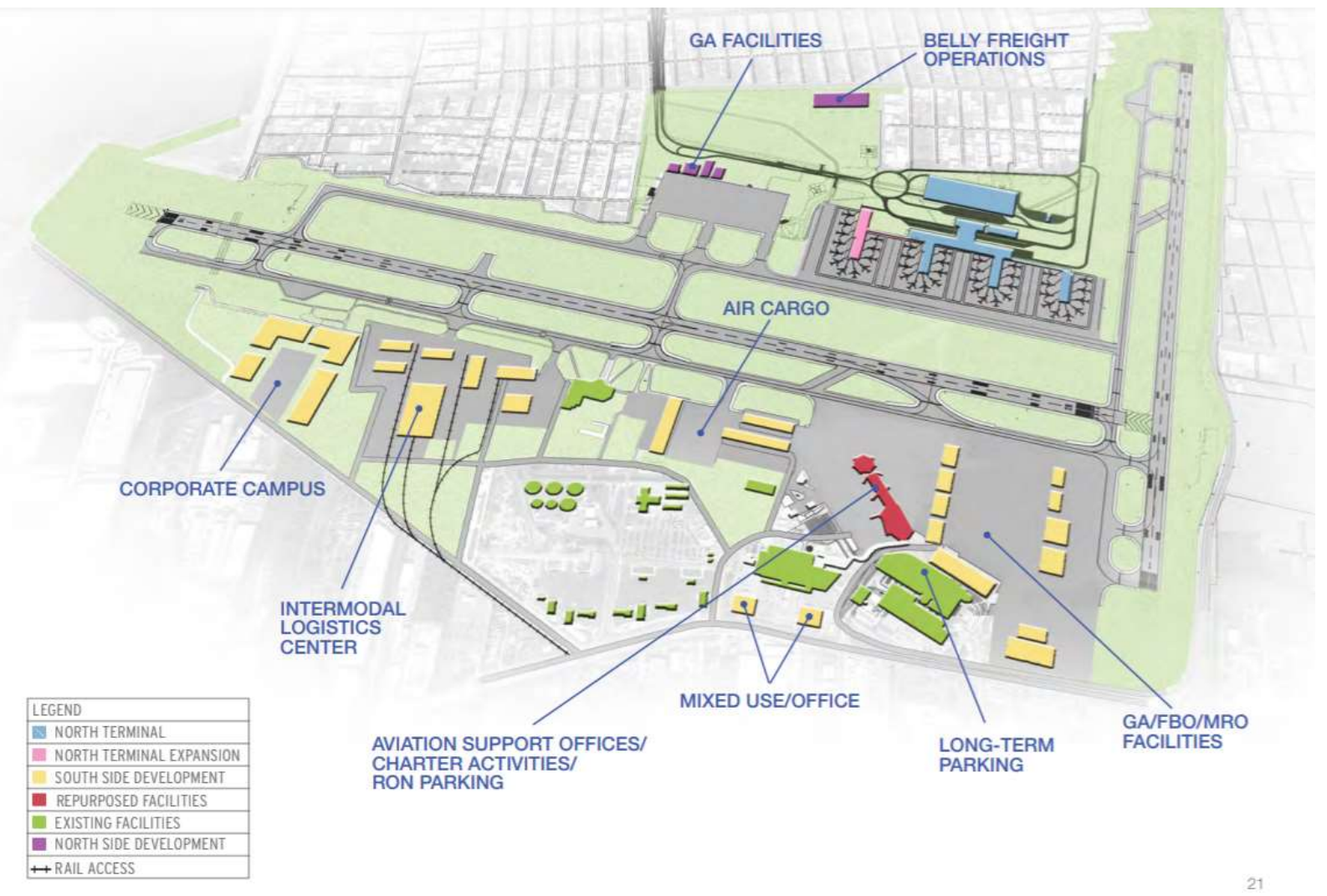

Figure 25. Proposed future airport land use plan. (43)

Meanwhile, the new North Terminal of LANOIA was completed in 2019, with ground transportation accessing the facility from the north via Loyola Drive. Hotel and offsite parking shuttles currently use a dedicated right-of-way on Bainbridge St to connect to the Jerome S. Glazer Airport Access Road serving the former (south) terminal area, which could also be utilized to connect airport customers to the proposed Rivertown station. However, no specific plans have been developed to refine the precise station location, station area development, and/or intermodal connections.

\subsubsection{Jefferson Parish Station}

The 2010 study did not include a Jefferson Parish stop, other than the Kenner/Airport location, but stakeholder discussion during the 2014 outreach effort revealed a consensus for an additional stop, preferably near the activity centers along Airline Drive between Transcontinental Drive and Dickory Avenue, an area which includes the "Shrine on Airline" baseball stadium, the Jefferson Performing Arts Center, the New Orleans Saints' training facility, and Delgado Community College's Jefferson Campus.

Zephyr Field on Airline Drive. This location would serve the baseball park and other key destinations, including the new Performing Arts Center and the New Orleans Saints' training facility, and it would provide convenient access for parish residents.

Jefferson Parish's updated master plan, Envision Jefferson 2040, adopted in 2019 (44), calls for the parish to "Participate in ongoing discussions involving the State, railroads, and other entities 
to create passenger rail from New Orleans to Baton Rouge, including a stop in the unincorporated parish and at the Louis Armstrong International Airport; and update planning with analysis of the economic feasibility of rail stops in coordination with key stakeholders" (p. 95) but does not otherwise discuss specific steps for station area planning or development, nor is a specific station site identified in the Parish's future land use map.

\subsubsection{New Orleans Station}

The existing NOUPT facility is the preferred and obvious terminal for the proposed service in all feasibility studies and documents, due to its downtown location, existing capacity and passenger amenities, and adequate connectivity to multimodal and transit connections. NOUPT currently serves three long-distance Amtrak routes, as well as Greyhound and Megabus intercity busses (including those discussed below serving Baton Rouge).

As an established station, no significant changes to rail alignment or the overall facility are anticipated, however, opportunities to enhance station amenities, access, and utilization of stationadjacent parcels abound. NOUPT's 1994 Master Plan was updated following Hurricane Katrina, with a focus on the station's key role in the proposed New Orleans-Baton Rouge rail link, documenting existing transportation and land use context and opportunities for development of underutilized parcels (32). The New Orleans Master Plan (45) moreover, calls for additional study "to improve multimodal access to and from the Union Passenger Terminal to address comprehensive way-finding signage, high-visibility crosswalks, bicycle and vehicular parking, bicycle routes, ridesharing services, high quality information services, and improved taxi and bus service" (Ch. 11, p. 14).

Over the last decade, several of those parcels have since been redeveloped with new mixed-use developments, including hundreds of new housing units, significantly altering the composition of the surrounding area. In addition, a proposed streetcar connection to NOUPT was realized in 2012.

In 2019, the City of New Orleans announced a $\$ 6.6 \mathrm{M}$ renovation of NOUPT, supported largely by federal grants, to enhance ADA compliance, update major systems, and expand the rail platform canopy (46). The project was intended to support the City-assisted evacuation program (re-fencing and adding a gate for direct connection, trains for evacuation). As of November 2020, however, this project has been deferred indefinitely.

\subsection{Existing Intercity Transit Service}

This section outlines existing and recent (post-Katrina) intercity bus services operating within the study corridor as of March 2020. The long-term impacts of COVID-19 on privately operated bus services are not yet known, but an update on current (November 2020) service operations is provided where available, as some services have been disrupted by the pandemic and resultant reductions in travel.

\subsubsection{LA Swift}

Service on the LA Swift, a connecting service initiated in the wake of Hurricane Katrina to support Louisiana residents commuting between downtown New Orleans and the CATS terminal in Baton Rouge, with intermediate stops in LaPlace, Sorrento, Gonzales, and Highland Road in Baton Rouge was discontinued in July 2013, despite efforts from BRAC, GNO, Inc., Ride New Orleans, the Southeast Super Region Committee, and New Orleans City Council to preserve its operation. 
LA Swift was overseen by DOTD and operated by the Calco-Hotard group. During the final months of its operation, over 12,000 riders used the LA Swift service monthly, with average daily ridership of 250-530 (47).

Initially intended to support commute trips of Louisianans displaced from New Orleans to Baton Rouge by Hurricane Katrina, rider surveys found that, as the years went on, the demographics of riders and their trip purposes shifted somewhat. A 2013 survey of over 300 riders by Ride New Orleans, AARP, and the Center for Planning Excellence (CPEX) found that over $80 \%$ of riders were African American, and 74\% were from families with incomes below \$40,000 per year. Just over half used the service for work trips, while the remainder relied on the LA Swift to see family and friends, access health care, or access colleges or universities in the region. While $32 \%$ of respondents reported not having access to a personal vehicle, the majority chose to use the swift for reasons other than lack of access to a car; notably, 53\% reported that they would have continued to use the service if the price of the fare was increased (47).

At a fare of just $\$ 5$ per trip, this service generated annual revenue of approximately $\$ 761,000$, with the remainder of the service supported by FTA funds (Section 5311 Grants for Rural Areas, as well as ARRA funds) at $\$ 2.3 \mathrm{M}$ per year. As hurricane recovery funds dwindled, the amount made available by FTA decreased to $\$ 1.6 \mathrm{M}$ and a local match of $\$ 750,000$ - excluding fare revenue which goes directly to operator Hotard - was required by FTA in order to extend the service. Despite fundraising efforts, local boosters and supporting organizations were unable to secure the required funds.

\subsubsection{Greyhound}

Greyhound currently operates several routes which serve New Orleans and Baton Rouge, including limited services to intermediary stops in Gonzales and LaPlace.

Greyhound serves NOUPT in New Orleans, and the dedicated Greyhound terminal at 1253 Florida Blvd in Baton Rouge. Select (non-express) schedules also serve a Chevron station at 2915 Highland Rd in Baton Rouge and two sign-only stops in LaPlace (a Pilot Travel Center at 4301 Main St) and Gonzales (2200 W Cabela Pkwy) (Figure 26). 


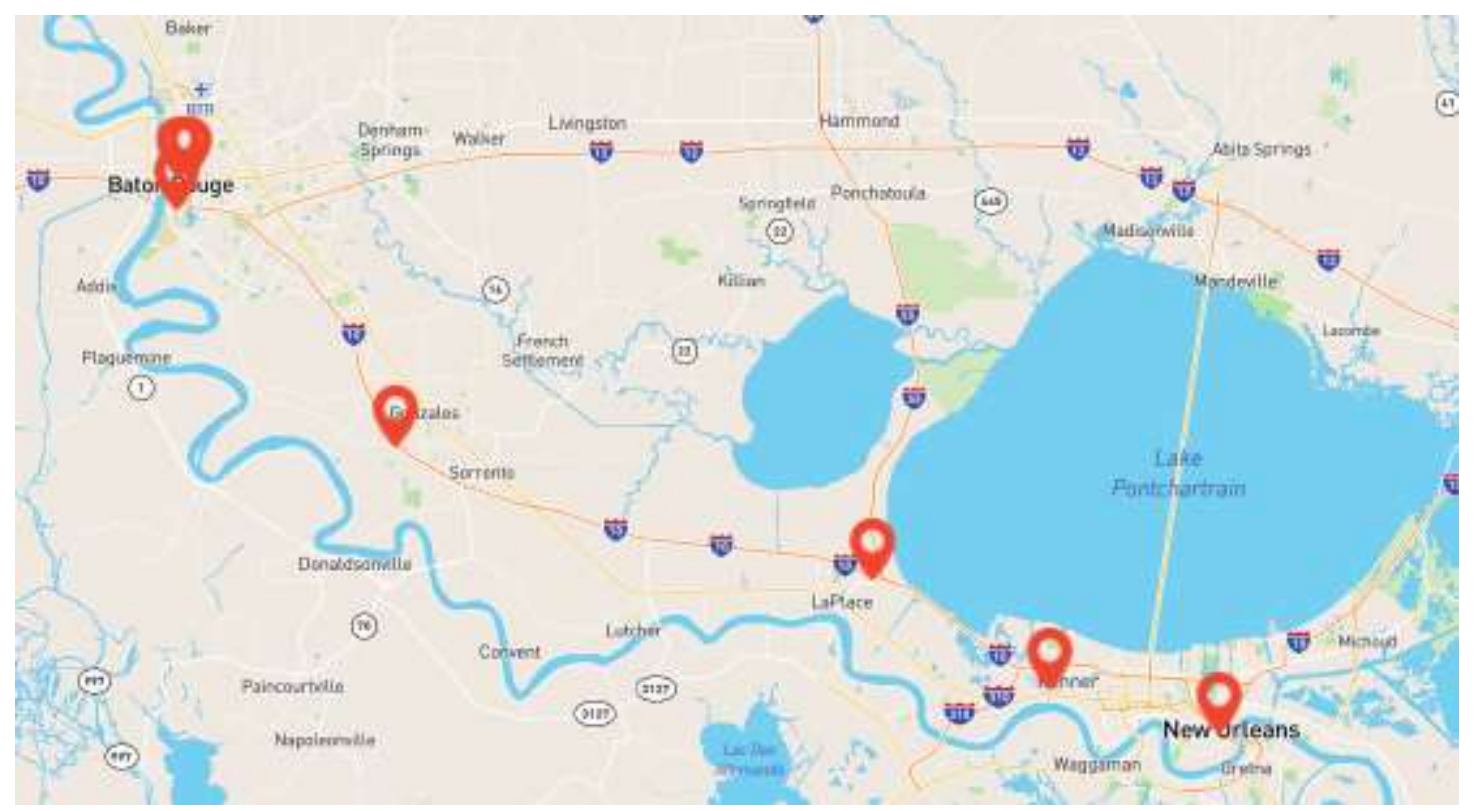

Figure 26. Location of Greyhound stations in NO-BR corridor.

Currently, Greyhound operates approximately six round trips between Baton and Rouge and New Orleans (or vice versa) per day (Tables 12 and 13). In addition, Greyhound served the south terminal of New Orleans International Airport with connections to downtown New Orleans at $1: 40 \mathrm{pm}$ and $8: 40 \mathrm{pm}$, and a once-daily outbound schedule to Houma, Lafayette, Lake Charles, and Ruston, but with no direct link to Baton Rouge. In addition, some incoming busses include a scheduled stop on Poydras street in downtown New Orleans, just prior to arrival at NOUPT. Express routes indicate those also serving additional cities, including Houston, Atlanta, and Shreveport (as well as major points in between). Local routes are supported in part by federal subsidies aimed at supporting job access; these services expanded following the discontinuation of LA Swift in order to maintain some degree of regional transit connectivity.

Table 11. Baton Rouge to New Orleans (NOUPT) scheduled trips - Greyhound

\begin{tabular}{|l|l|l|l|l|l|l|}
\hline Schedule & $\begin{array}{l}\text { Baton } \\
\text { Rouge }\end{array}$ & $\begin{array}{l}\text { BR } \\
\text { Chevron }\end{array}$ & Gonzales & LaPlace & Type & $\begin{array}{l}\text { Weekend } \\
\text { Service }\end{array}$ \\
\hline $\mathbf{1 2 4 6 / 1 2 6 2}$ & $5: 15 \mathrm{am}$ & & & & Express & Yes \\
\hline $\mathbf{3 8 2 3}$ & $5: 45 \mathrm{am}$ & & $6: 25 \mathrm{am}$ & $6: 55 \mathrm{am}$ & Local & No \\
\hline $\mathbf{3 8 3 5}$ & $10: 30 \mathrm{am}$ & & $11: 10 \mathrm{am}$ & $11: 40 \mathrm{am}$ & Local & Yes \\
\hline $\mathbf{3 8 0 5}$ & $1: 10 \mathrm{pm}$ & & & & Express & Yes \\
\hline $\mathbf{3 8 4 1}$ & $5: 00 \mathrm{pm}$ & $5: 10 \mathrm{pm}$ & $5: 40 \mathrm{pm}$ & $6: 10 \mathrm{pm}$ & Local & No \\
\hline $\mathbf{1 2 5 4}$ & $6: 50 \mathrm{pm}$ & & & & Express & Yes \\
\hline $\mathbf{1 5 9 6}$ & $7: 00 \mathrm{pm}$ & & & & Express & Yes \\
\hline $\mathbf{3 8 0 7}$ & $7: 10 \mathrm{pm}$ & & & & Express & Yes \\
\hline
\end{tabular}


Table 12. New Orleans to Baton Rouge scheduled trips - Greyhound

\begin{tabular}{|c|c|c|c|c|c|c|}
\hline Schedule & NOUPT & LaPlace & Gonzales & $\begin{array}{ll}\text { BR } & - \\
\text { Chevron }\end{array}$ & Type & $\begin{array}{l}\text { Weekend } \\
\text { Service }\end{array}$ \\
\hline 1281 & 6:16am & & & & Express & Yes \\
\hline 1563 & 8:50am & & & & Express & Yes \\
\hline 3808 & $10: 15 \mathrm{am}$ & & & & Express & $\begin{array}{l}\text { Weekend } \\
\text { only }\end{array}$ \\
\hline 3824 & $11: 20 \mathrm{am}$ & & $12: 40 \mathrm{pm}$ & $1: 25 \mathrm{pm}$ & Local & No \\
\hline 1259 & $12: 45 \mathrm{pm}$ & & & & Express & Yes \\
\hline 3810 & $4: 30 \mathrm{pm}$ & & & & Express & Yes \\
\hline 3832 & $5: 00 \mathrm{pm}$ & $6: 00 \mathrm{pm}$ & $6: 35 \mathrm{pm}$ & & Local & Yes \\
\hline 1265 & $6: 25 \mathrm{pm}$ & & & & Express & Yes \\
\hline 3836 & $7: 30 \mathrm{pm}$ & $8: 30 \mathrm{pm}$ & $9: 05 \mathrm{pm}$ & $9: 50 \mathrm{pm}$ & Local & No \\
\hline
\end{tabular}

Neither LaPlace nor Gonzales stops are served by morning bus service inbound toward Baton Rouge, prohibiting use of Greyhound service for most commute trip purposes. Surveys of LA Swift riders in 2013 found that Greyhound services connecting New Orleans to Baton Rouge were ill-suited to rider needs: there were insufficient intermediate stops, much higher fares than the LA Swift, and schedules that did not accommodate commute trips (47). Trip fares vary based on demand for individual trips but tend to range between $\$ 10$ and $\$ 20$ for a one-way fare between New Orleans and Baton Rouge.

As of November 2020, most routes and schedules appear to be operating as listed.

\subsubsection{Megabus}

Megabus serves New Orleans from NOUPT, and Baton Rouge from a location at the rear of the CATS Terminal at Convention St and $22^{\text {nd }} \mathrm{St}$, with a drop-off area on convention street, but no parking provided. Busses depart Baton Rouge for New Orleans three times per day, at 4:50am, $12: 45 \mathrm{pm}$, and 7:20pm daily. Busses depart New Orleans for Baton Rouge at 9am, 4:45pm, and $11: 59 \mathrm{pm}$, daily. Fares vary based on demand, ranging from $\$ 2$ to more than $\$ 20$ for a one-way ticket.

As of November 2020, Megabus is only operating four days per week (Friday through Monday) with one-way fares between New Orleans and Baton Rouge of \$25-\$40.

\subsubsection{Flixbus}

Flixbus, a new private transit service which began operating in Louisiana in 2019, offers connections between New Orleans and Baton Rouge as well as to Lafayette and Lake Charles (en route to Houston and Austin). Flixbus boards from a signed stop at 138 Florida Boulevard in downtown Baton Rouge, and from NOUPT in New Orleans. Trips depart Baton Rouge at 5:05am, $12: 25 \mathrm{pm}, 3 ; 25 \mathrm{pm}, 5 \mathrm{pm}, 6: 20 \mathrm{pm}$, and $8: 45 \mathrm{pm}$. Trips depart New Orleans at 8:30am, 10:20am, $12: 20 \mathrm{pm}, 3: 20 \mathrm{pm}, 6 \mathrm{pm}$, and 11:20pm.

Previously, limited additional stops serving the University of New Orleans and Louisiana State University were scheduled, although these appear to have been discontinued post-COVID. Flixbus service in the United States was temporarily discontinued entirely during Spring/Summer 2020, and has been gradually been reinstated in select locations, including limited trips serving New Orleans and Baton Rouge (one trip per day each way, 4-5 days per week as of November 2020). 


\subsubsection{Carpool and Vanpool Programs}

A key opportunity to optimize the proposed rail service to realize its utility as a viable option for regional commuters is the expansion and enhancement of carpool and vanpool programs connecting workers to and from major employment destinations.

Capital Region Planning Commission (CRPC) in Baton Rouge, in partnership with DOTD, has developed a Travel Demand Management (TDM) program called Commuter Krewe of Louisiana (launched 2018) that aims to reduce congestion and single-occupancy vehicle trips by working with employers to develop feasible vanpool and/or telework options, as well as to encourage multimodal transportation generally through bicycling, transit, and walking to meet commuting challenges for their employees, and to take advantage of federal tax programs incentivizing transit and vanpool usage. In planning for this $\$ 1.5 \mathrm{M}, 3$-year program, an inflow/outflow analysis of commutes within the greater Baton Rouge area was conducted, although this did not specifically target New Orleans to Baton Rouge trips. Initial private and public sector partnerships developed included (48):

- Greater Baton Rouge Industry Alliance

- Capital Region Industry for Sustainable Infrastructure Solutions (CRISIS)

- Downtown Development District

- Baton Rouge Health District

- IBM

- Southern University

- Fortis College

- LSU

- BASF

- East Baton Rouge

- West Baton Rouge

- Stantec

- Associated Grocers

- L'Auberge Casino

- Amerihealth Caritas

- DOTD

- Division of Administration

- Office of Disability Affairs

- LA Dept. of Revenue

However, not all of these preliminary partnerships have resulted in defined carpool or vanpool initiatives. The Commuter Krewe program is also partnered with other regional agencies within the state (Acadiana Planning Commission and New Orleans Regional Planning Commissions) to facilitate broad regional solutions to commute challenges. The program replaces the former Geaux Ride carpooling program and provides a social media influenced trip matching software to facilitate connections among users.

Regionally, the Northshore's Pelican Bus service, a private charter bus service between St. Tammany Parish and New Orleans, with daily service from two park-and-ride stops in Mandeville to New Orleans CBD at a rate of $\$ 30$ per day or discounted $\$ 95$ weekly or $\$ 260$ monthly passes (\$255 for government employees) (49). 
Some regional private employers within the region also offer private carpool or vanpool services for their employees, including Chevron, which utilizes Zimride to connect co-workers who live within proximity to one another to the company's Covington-based campus. A key feature of such programs is the inclusion of a "guaranteed ride home" policy, wherein participating commuters can be reimbursed for transportation expenses (taxi, rideshare, rental car, etc) when an emergency situation arises.

In the absence of fast, frequent, and reliable local transit options throughout the region to connect to proposed rail services, carpool and vanpool programs like Commuter Krewe, or private shuttles to and from key employment destinations, can be a critical element of realizing congestion benefits and making rail a viable commute option for those who do not live within close proximity to stations (i.e., most of the region's population). However, obstacles to implementation of carpool and vanpool programs remain, include simple reluctance to ride with strangers or give up the flexibility of a personal automobile. These concerns are likely to be amplified by the lingering impacts of the COVID-19 pandemic.

\subsection{Transit and Multimodal Planning Context}

The 2010 Feasibility Study (33) noted the need to adapt local transit service to connect to the proposed intercity service, acknowledging that "To facilitate increased ridership and provide a more efficient transportation system, local public transit authorities will provide feeder service from their local areas to/from the train stations, providing seamless origin to destination connectivity along the corridor" (p. ES3). This sentiment was reiterated in the 2014 HNTB study (1), which observed that "Connections to the local transportation network are essential for the success of passenger rail service. This includes easy roadway access from major regional corridors, parking, readily-available transit service and bike and pedestrian facilities" (p.6) and that "station area planners should work with transit authorities or private companies to ensure that the needs of rail passengers are met by either public or private transportation services" (p.15).

Currently, only NOUPT in New Orleans is served with "adequate" transit connectivity (1); all other stations would need improved multimodal accessibility, along with the development of station amenities considered in station area plans. Modifications may be needed in local transit routes and/or schedules in order to effectively serve potential train riders and support the ridership targets on which the service's success hinges. In addition to transit availability, supportive station area land uses, accessible active transportation facilities and networks, and overall siting of the rail terminals (discussed above) will significantly impact project performance.

This section discusses transit connectivity for each station area, along with multimodal (biking, walking, and driving) access issues. In addition, the stations are reviewed in the context of the current Louisiana State Rail Plan.

\subsubsection{Multimodal Connectivity - Baton Rouge}

East Baton Rouge Parish has undergone significant planning and implementation centered on increasing access to safe and convenient transportation alternatives in recent years, including the recently completed East Baton Rouge Pedestrian and Bicycle Master Plan (50), the CATS Strategic Plan (51), launch of the Gotcha Bike Share program in 2019, the Plank Road Master Plan (52), and other initiatives and projects aimed at supporting bicycling, walking, and transit while addressing congestion and environmental quality concerns. These initiatives consistently 
reference and/or support future passenger rail development, either by facilitating direct multimodal connections to the proposed station areas, by promoting transit-supportive, walkable development patterns, or both. The current site plan context of each of the two proposed Baton Rouge rail station locations (including siting variations for the suburban station) are discussed below, including planned or proposed infrastructure or planning interventions which would be likely to impact rail service utilization.

Downtown Station: The proposed downtown Baton Rouge rail station, as defined by the 2019 Station Master Plan (38) on Government Street (Figure 27), in the Mid-City neighborhood, identified by East Baton Rouge's Comprehensive Plan, FutureEBR, as a "regional center" conducive to more intensive, transit-supportive future development (53).

The proposed station would be proximate to existing local transit on Government Street (Route 12) and Florida Street (Route 44). In addition, both the existing Greyhound station and CATS main hub/Megabus stop - and a total of 12 CATS routes - are within feasible walking distance $(1 / 2-3 / 4$ mile) (38). In theory, station area residents could access about 35,000 jobs by transit within 30 minutes during peak service ${ }^{1}$, and 39,000 residents could reach the station within the same timeframe at service peaks (38). Currently, however, a much smaller share of the station area's 1400 employed residents (about 100) actually utilize transit to commute (38), suggesting that available service is not perceived as a viable option under current conditions and service levels.

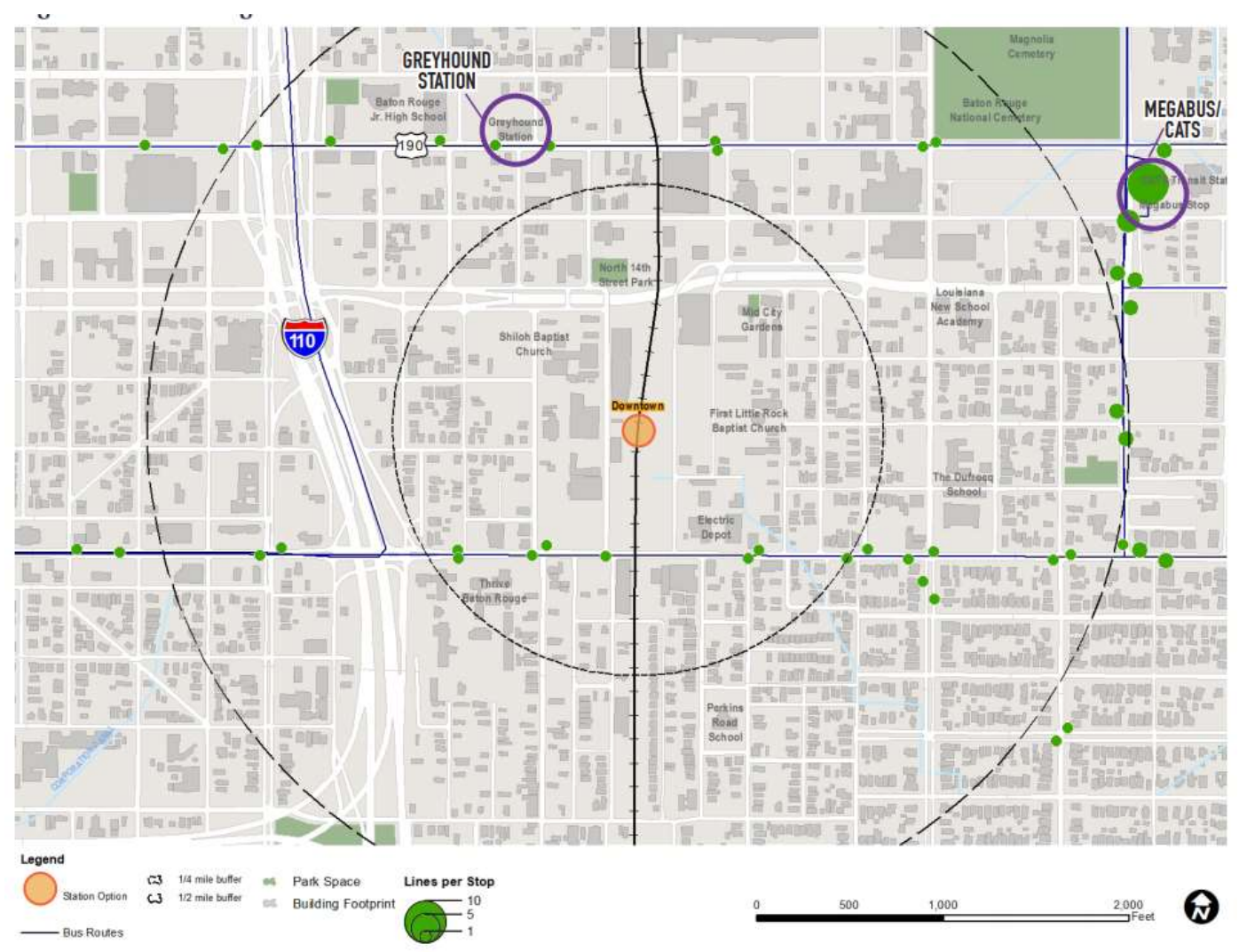

Figure 27. Government Street proposed station transit access. (38)

\footnotetext{
${ }^{1}$ Estimated using the Center for Neighborhood Technology's (CNT) AllTransit ${ }^{\mathrm{TM}}$ tool
} 
The proposed station site plan envisions a future mixed-use TOD and includes a scalable parking area that could accommodate between 130 and 390 vehicles (38). By vehicle, it would be accessible via $14^{\text {th }}$ street, Government Street, and North Boulevard with primary loading and unloading off $14^{\text {th }}$ street (Figure 28). The site plan also includes a dedicated transit lane and up to four bus bays but notes that additional coordination with CATS is needed to refine spatial allocations and access points (38).

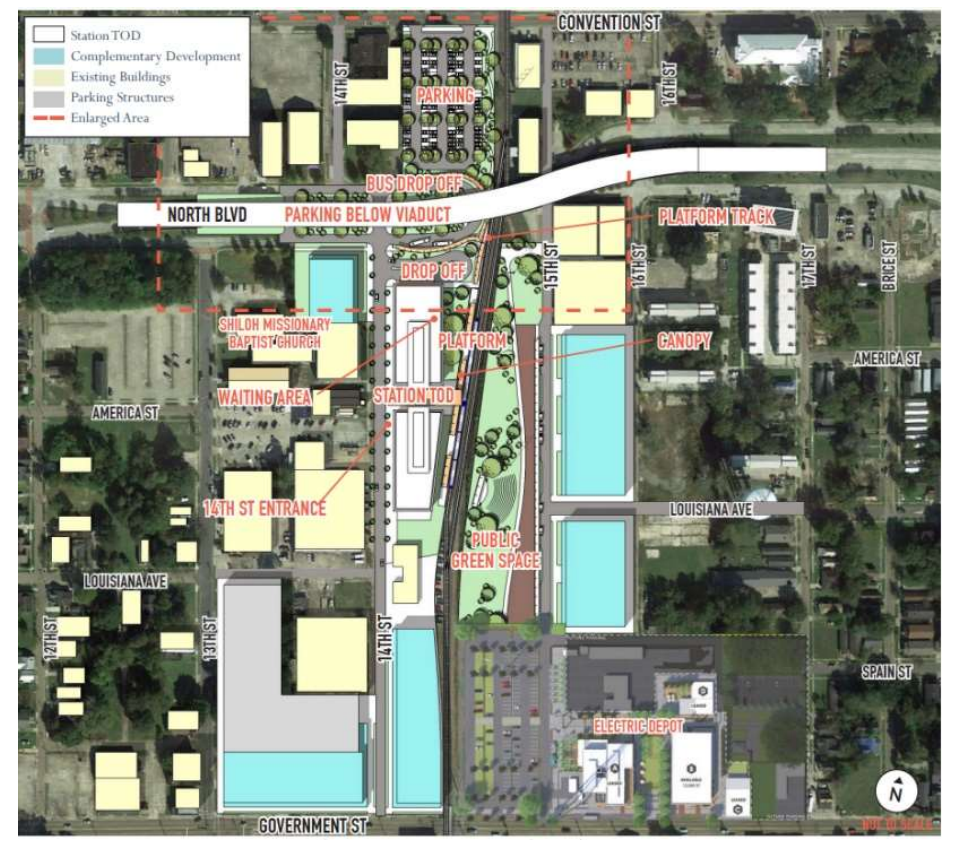

Figure 28. Downtown Baton Rouge proposed station site plan. (38)

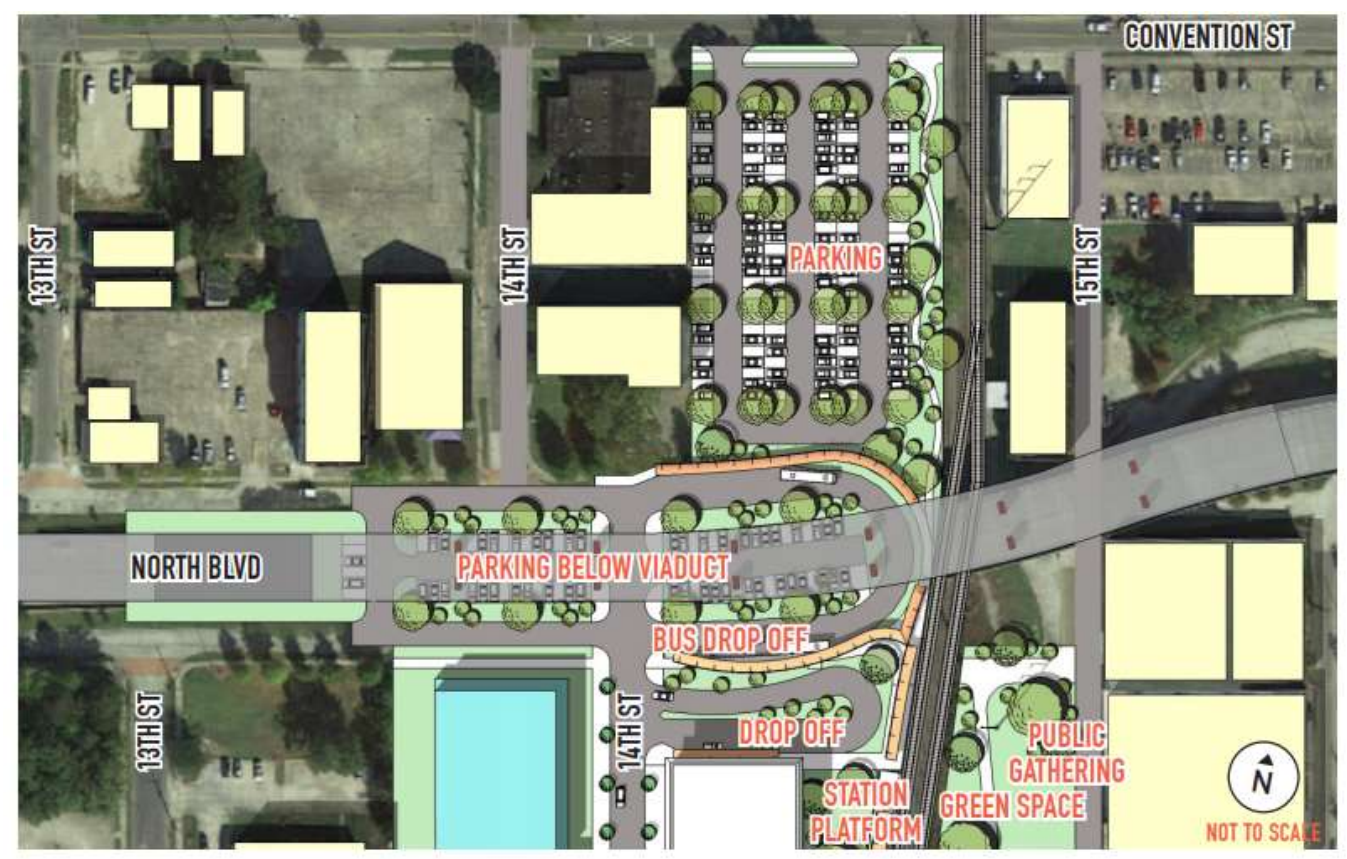

Figure 29. Downtown Baton Rouge proposed station site plan - ingress detail. (38) 
The project is envisioned as a TOD, and as a public-private partnership with the TOD developer, in order to share maintenance and operations costs and generate revenue through parking fees, rents, and possibly sales and/or property tax revenue from a new station area Economic Development District. CATS is also identified as a potential cost-sharing partner if local transit facilities are integrated into final designs as envisioned (38). Connection to a potential bus rapid transit (BRT) route is noted as an important planning consideration, although at the time of plan publication no definitive plans were underway for BRT (38).

Improvements to facilitate improved pedestrian connectivity are noted, such as canopies covering walking routes and bus stops on either side of North Boulevard, new sidewalks along $14^{\text {th }}$ street, a trail connection from Louisiana Avenue to $14^{\text {th }}$ Street, and traffic calming measures to reduce vehicle speeds.

Overall roadway rehabilitation and striping is also indicated for $14^{\text {th }}$ street to accommodate increased traffic volumes for all modes. Additional study is recommended to evaluate whether the intersection of $14^{\text {th }}$ street and Government Street should be signalized (38).

Bike lanes are also indicated as a potential option for $14^{\text {th }}$ street, connecting to the newly completed bike lanes on government street, which recently underwent a $\$ 13 \mathrm{M}$ road diet and redesign to calm traffic and improve safety from East Boulevard to Lobdell Avenue. This project reduced Government Street from four to three lanes and also included development of continuous sidewalks along the corridor, significantly improving pedestrian and bicycle connectivity to the proposed station area.

The closest existing bike facilities to the station site, in addition to the Government Street bike lanes, are a portion of the Downtown Greenway system with segments along North and East Boulevards. The station area is also within the proposed Phase II service area of Baton Rouge's bike share program, Gotcha Bikes, although no stations are currently located within the immediate vicinity (38).

Meanwhile, the Baton Rouge Bicycle and Pedestrian Master Plan (50) conducted an exhaustive evaluation of existing facilities, latent/potential demand for bicycling, and other factors influencing future opportunities to expand bicycling for transportation and recreation. The plan identifies the area surrounding the proposed rail station as an area of moderate demand (Figure 30), as well as proposed on-and off-road projects to facilitate the development of an integrated bikeway network across the city via various funding sources and under the jurisdiction of multiple agencies and/or programs.

Under this plan, separated or buffered bike lanes along Park Blvd, Government Street, and Eddie Robinson Sr Drive, as well as the North Boulevard Greenway and aforementioned Louisiana Avenue trail connection, would provide a network of access points to the proposed station (Figure $31)$. 


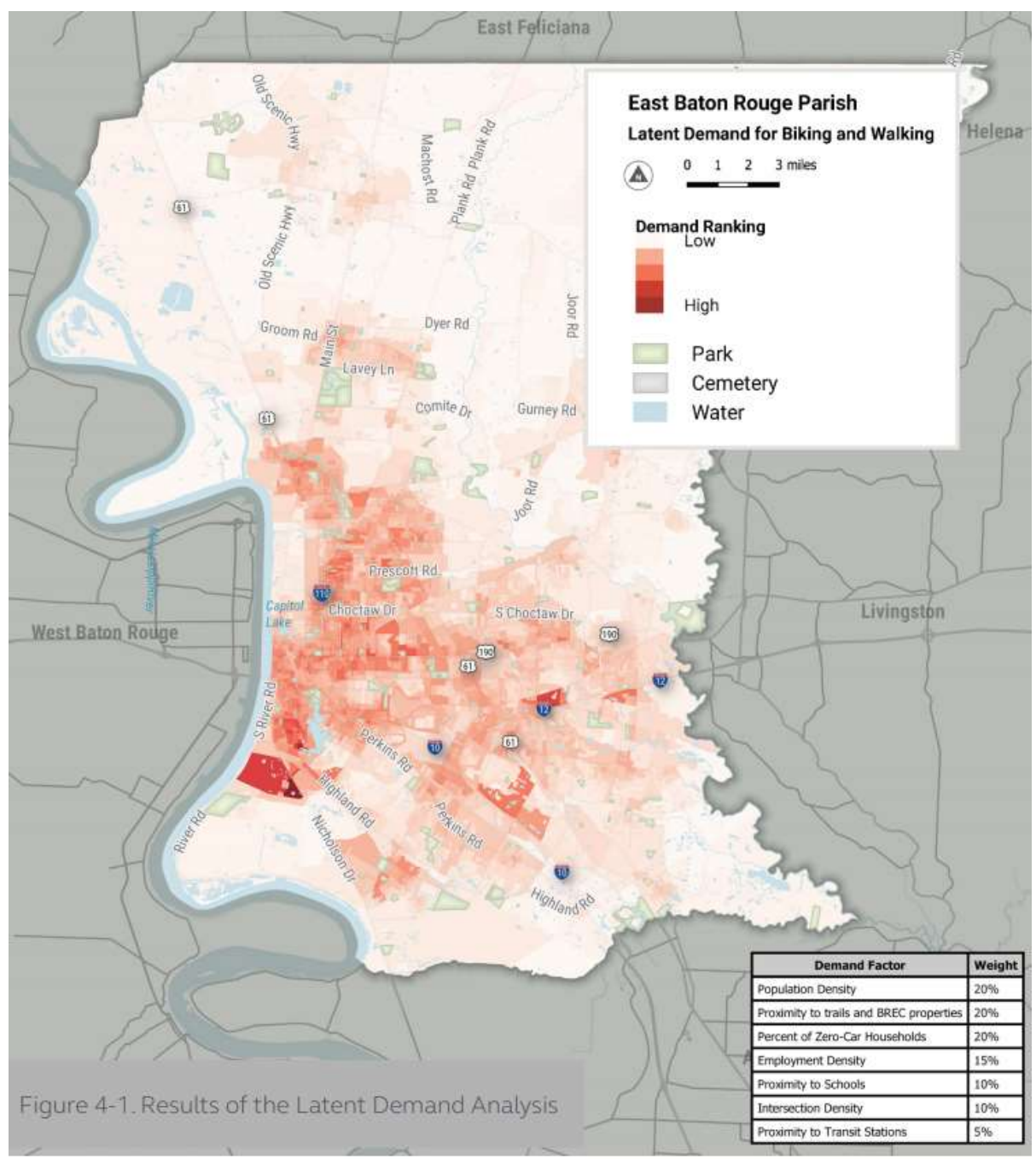

Figure 30. East Baton Rouge parish latent demand for biking and walking. (50)

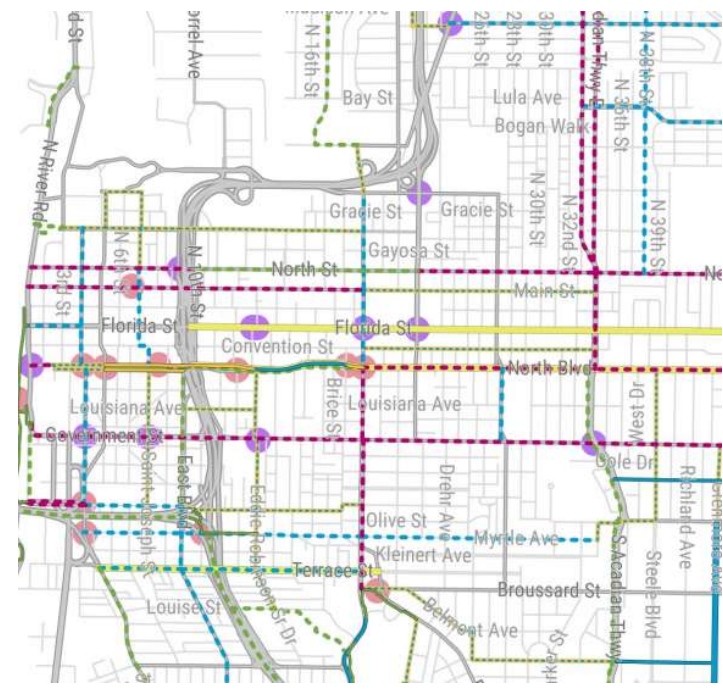

Figure 31. Bike network plan detail: downtown and mid-city Baton Rouge. (50) 
In addition to connections to current CATS routes noted above, the proposed site is also within walking distance of LSU's Tiger Trails transit system (54) serving students as well as the broader LSU community, and which connects to Government Street via $19^{\text {th }}$ street (Garden District route), five blocks away (Figure 32). Adjustment of this route to directly connect to the proposed station, and alignment of the route's schedule to match arrival/departure times, would reinforce access for the greater LSU community to the proposed passenger rail.

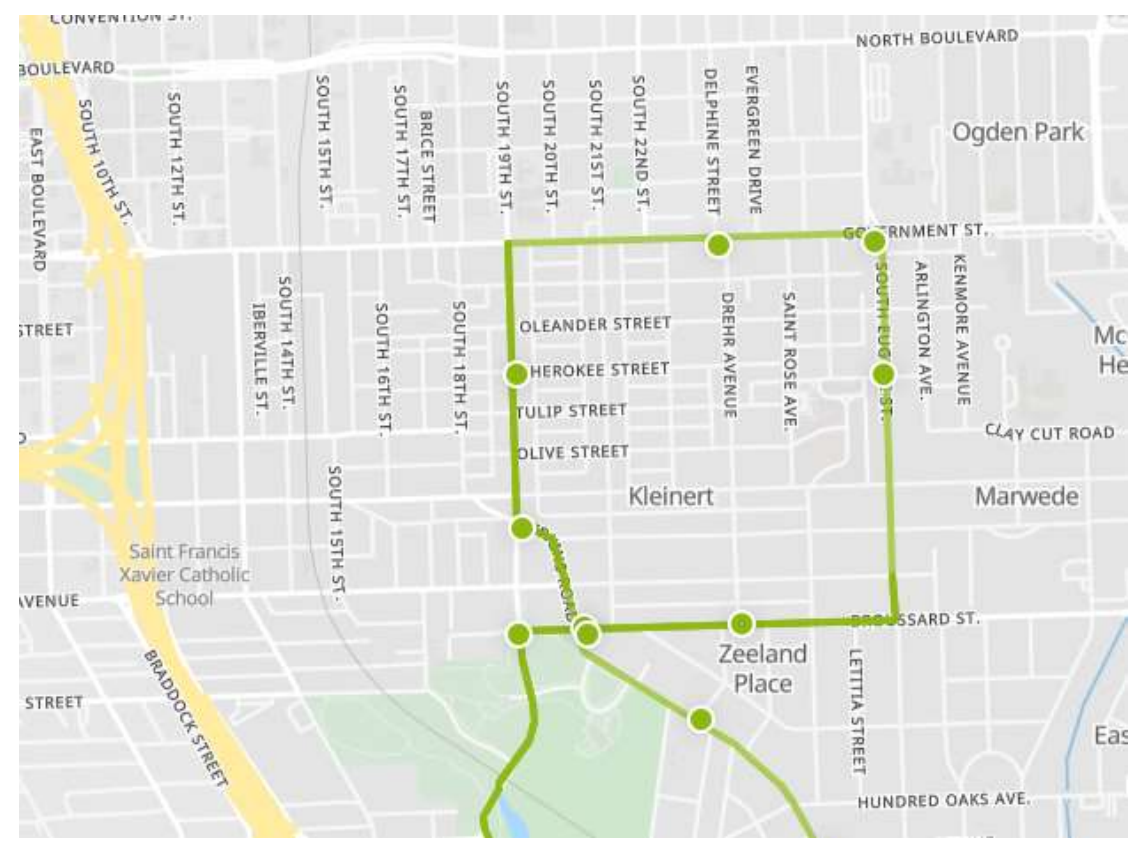

Figure 32. Tiger Trails Garden District route map - mid-city detail. (54)

Overall, the proposed Downtown Baton Rouge station is well-positioned to build on recent and planned investments in multimodal infrastructure connecting Government Street to downtown via new bike and pedestrian facilities, to North Baton Rouge and LSU via the planned Plank Road BRT (as well as an expanding trail network, proposed expansion of the Gotcha bike system, and the LSU Tiger Trails shuttle system), and to future improvements to the CATS terminal. While the number of people who might be expected to access the proposed station area by walking, bicycling, or transit is currently low, recent plans have tended to effectively consider the potential for a future rail connection. Station area planning overall has been robust and thorough. In combination with the implementation of complementary projects and plans which will significantly enhance multimodal access to the site, whether or not rail service is developed, this station has the potential to serve as an effective hub. However, walkability in the broader station area-particularly connecting under the interstate to downtown-remains a systemic challenge. This station would benefit from additional enhancements to reduce barriers to access within the $1 / 2$ mile walkshed.

Suburban Station: The preferred option for the suburban Baton Rouge station, as identified in the East Baton Rouge Plan as the "West of Bluebonnet Boulevard" station site (38), would be accessible from Picardy Avenue via Bluebonnet Boulevard and Essen Lane, with close, direct access to I-10 (Figure 33). New roadways (including a new boulevard extending from the intersection of Summa Ave and Picardy Ave to the station entrance) would be constructed in order to develop the station area as proposed, with the opportunity to include sidewalks and on-street 
bikeways to link the station directly to the BREC Health Loop Trail (38). Passenger pick up and drop off (including taxis and ride share) would take place on the new boulevard (Figure 34), and new on-street bus stops would be included to serve local and regional transit as well as a planned Health District circulator bus (Figure 35) (38).

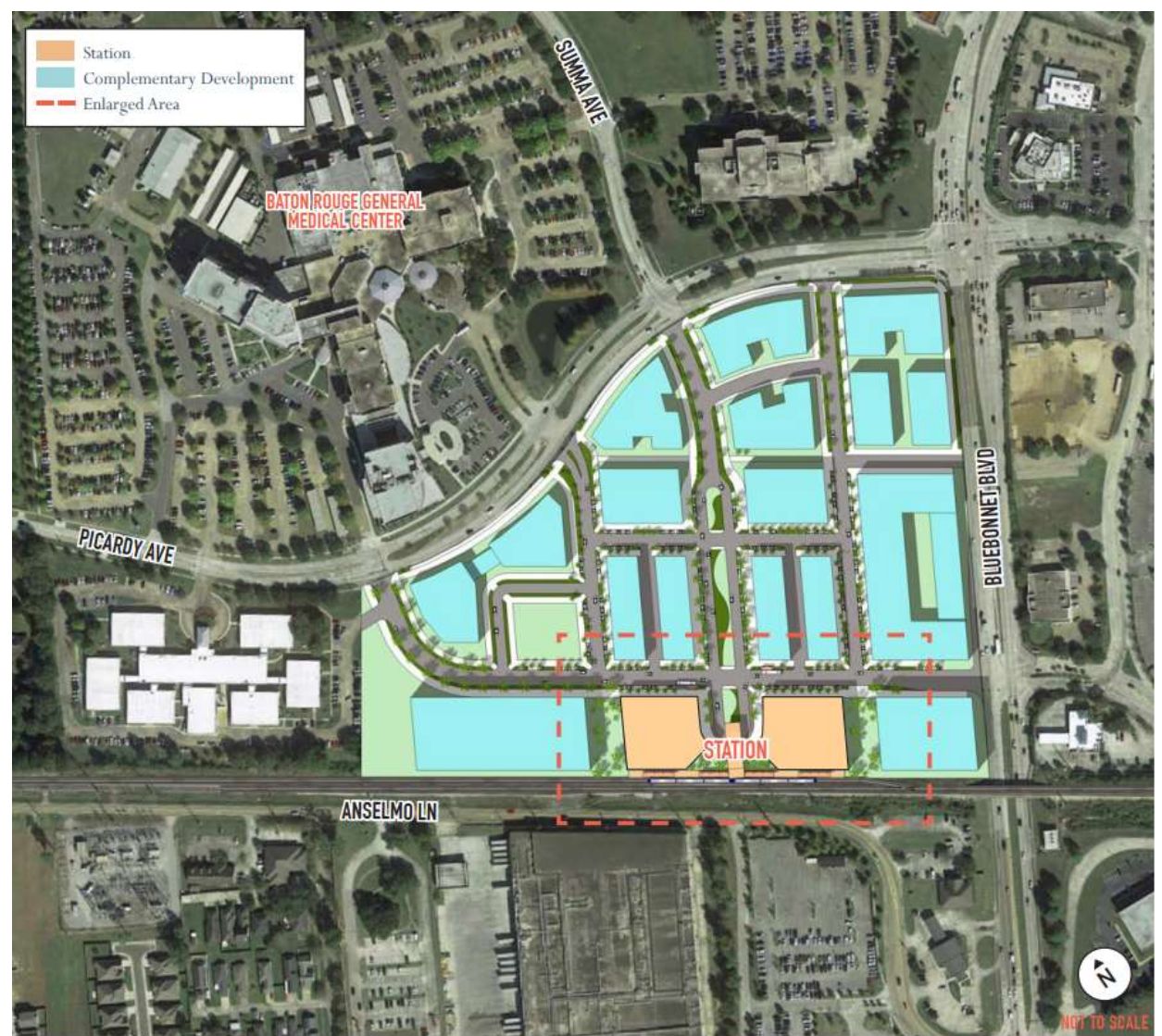

Figure 33. Baton Rouge Suburban Station site plan. (38)
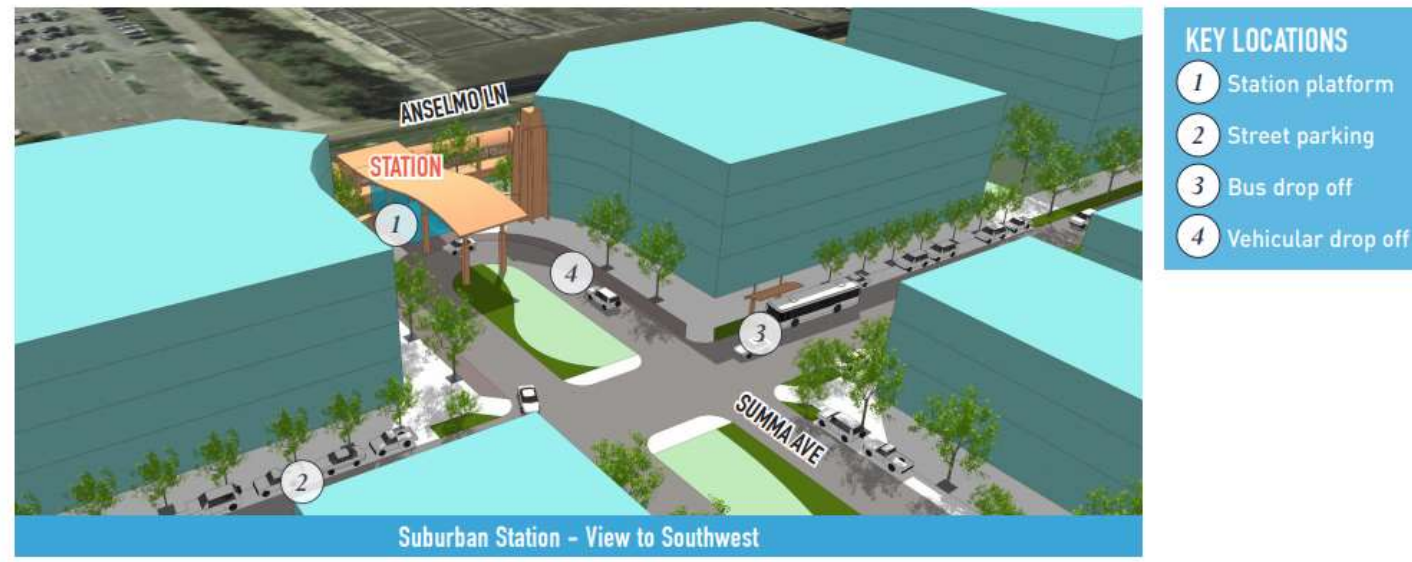

Figure 34. Baton Rouge Suburban Station entrance layout. (38) 


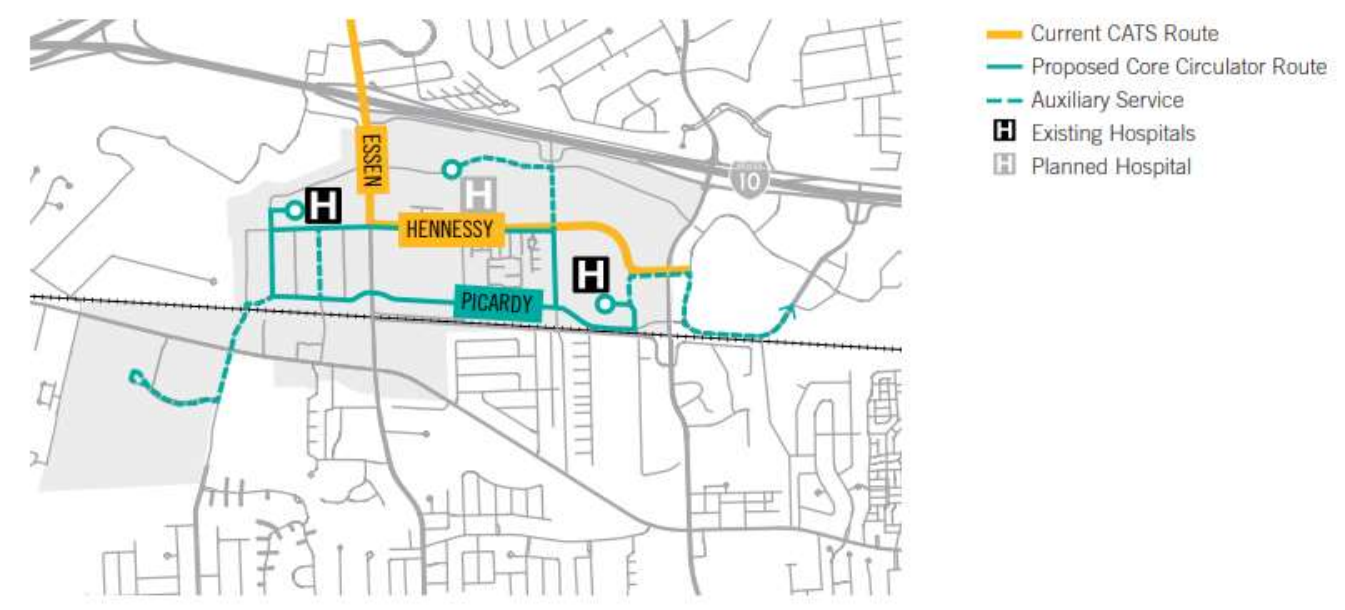

Figure 35. Proposed medical district transit circulator shuttle route. (39)

Current plans call for 240 total parking spaces at the station at 2045 design capacity, with a more limited 50 spaces proposed at service start-up (38). These plans build on recommendations from the 2015 Health District Plan (39), which highlights the need for a multimodal transit center, and provided preliminary diagrams of intermodal connections for each of four proposed station alignments within the corridor, as outlined in the Passenger Rail Station Master Plan (38).

Despite its suburban location, transit service to the Baton Rouge medical district and by extension to the proposed suburban passenger rail station is relatively robust (Figure 36). Approximately 32,000 workers could reach the station area by transit within 30 minutes (38), including links to CATS Routes 60 and 46, with nearby connections to Routes 47, 12, and 17 at the Mall of Louisiana.

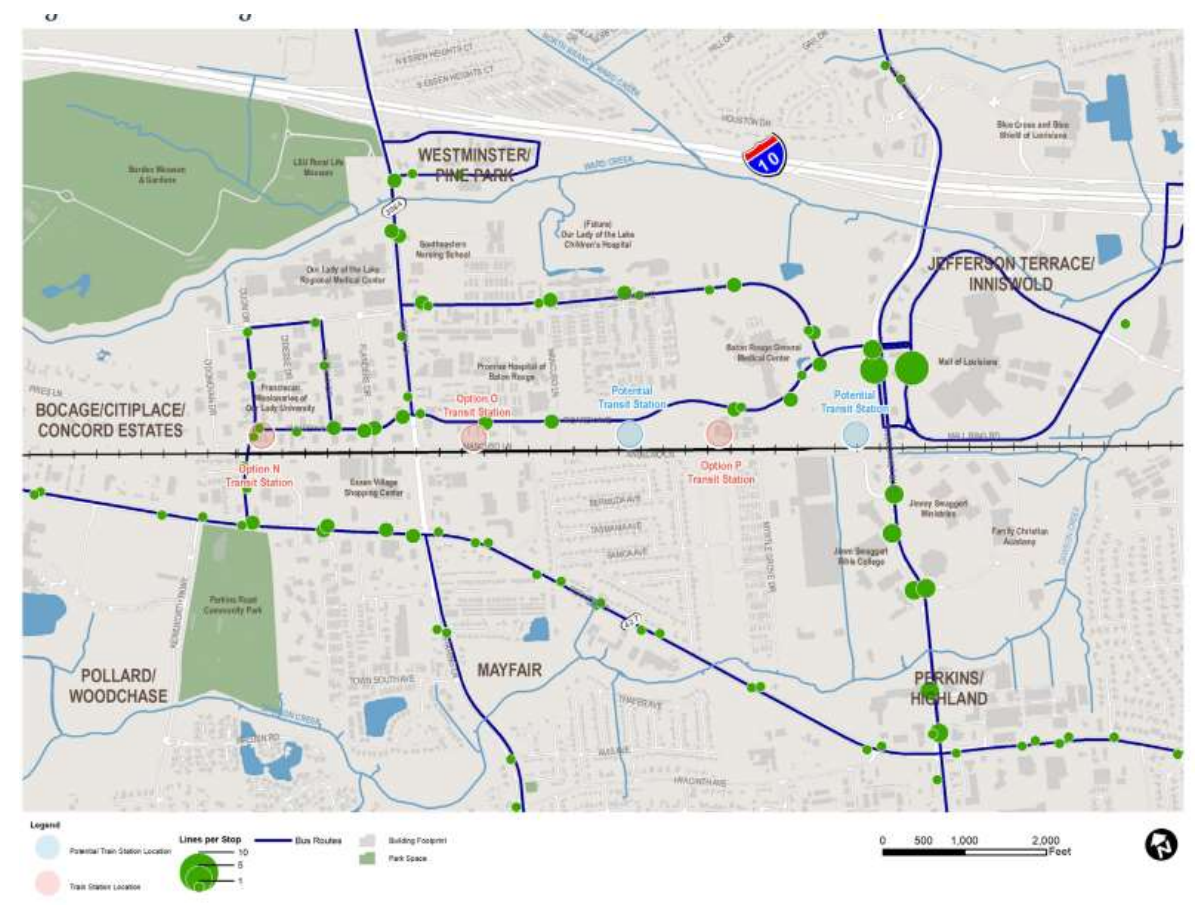

Figure 36. Suburban Baton Rouge Station area existing transit access. (38) 
Moreover, this represents notably better transit access, as defined by the CNT "Transit Performance Index," which indicates that the Health District is better served than most of the Baton Rouge area (38).

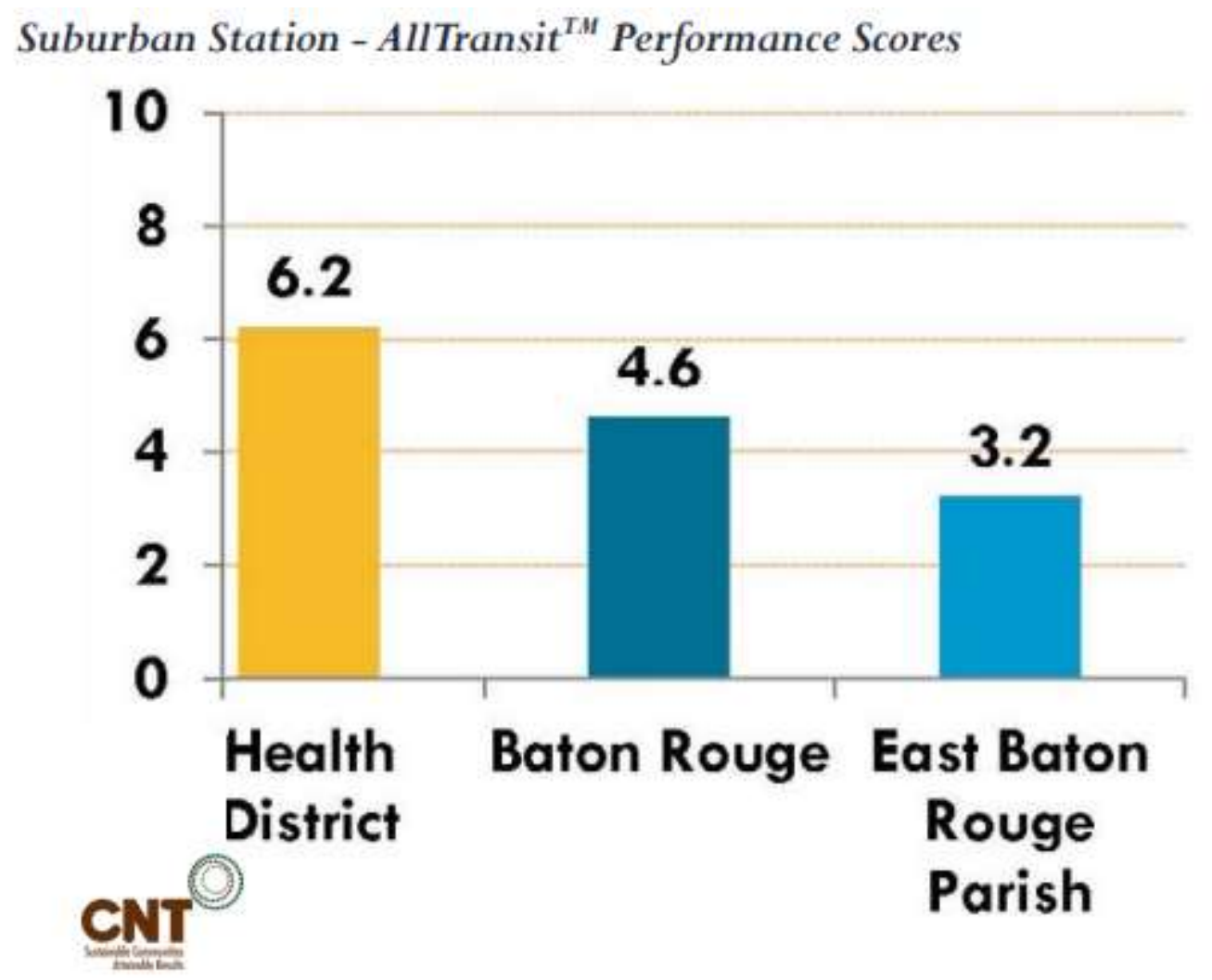

Figure 37. CNT Transit Performance Index - Suburban Baton Rouge Station. (38)

However, lack of street connectivity is currently a limiting factor for transit, walking, and bicycling connections to the area. The Baton Rouge Health District Master Plan (39) recommends several new connections building on recently completed and currently underway roadway projects to enhance these connections through a more integrated street grid, as well as potential new railroad crossings, again providing opportunities for substantially improved access for people walking and bicycling and reconnecting residents south of the Health District who currently lack convenient access to the proposed station area, and for whom the railroad tracks currently serve as a barrier to accessing jobs and services within the health district itself (Figure 38).

Other recommendations for increasing access to the proposed station site include (38):

- Increasing frequency of transit service between downtown and suburban stations as well as to nearby low-income communities

- Explore opportunities for car-share and bike-share

- Add bike lanes and sidewalks to Picardy Avenue north of the station

- Develop safe bike/pedestrian crossings on Essen Lane and Bluebonnet Boulevard 


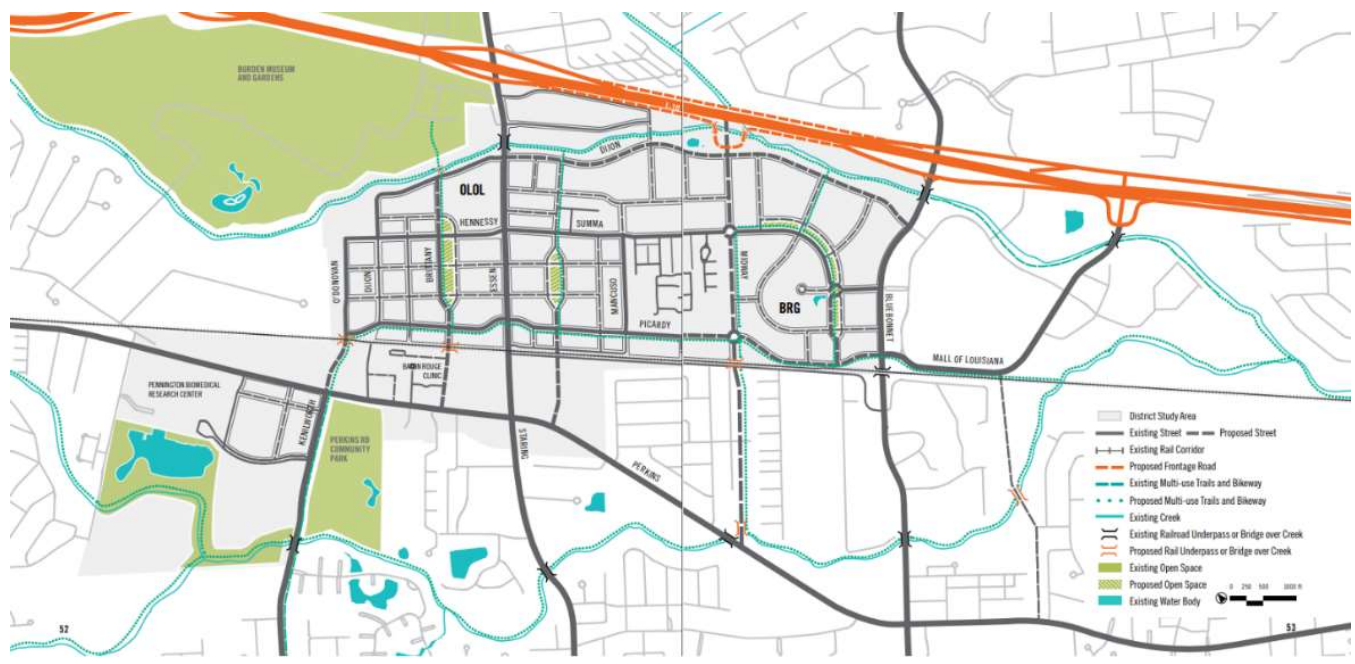

Figure 38. Health District street framework plan. (38)

The Baton Rouge Passenger Rail Station Master Plan (38) acknowledges that future development of the site and rail service could result in increased vehicular trips within the area, and notes that new traffic signals and capacity improvements (e.g., turning lanes and signal timing adjustments) may be needed as traffic volumes increase.

Meanwhile, substantial investments are currently being made in recreational facilities for walking and bicycling within the proposed station area, most notably the BREC Health Loop Trail, a 10mile loop around the Health District connecting existing portions of trail along Ward Creek to newer segments along Perkins/Pennington (Figure 39). The Baton Rouge Bicycle Master Plan (50) promises to connect these trail facilities into a wider network of on and off-street bikeways, both north and south of the railroad tracks.

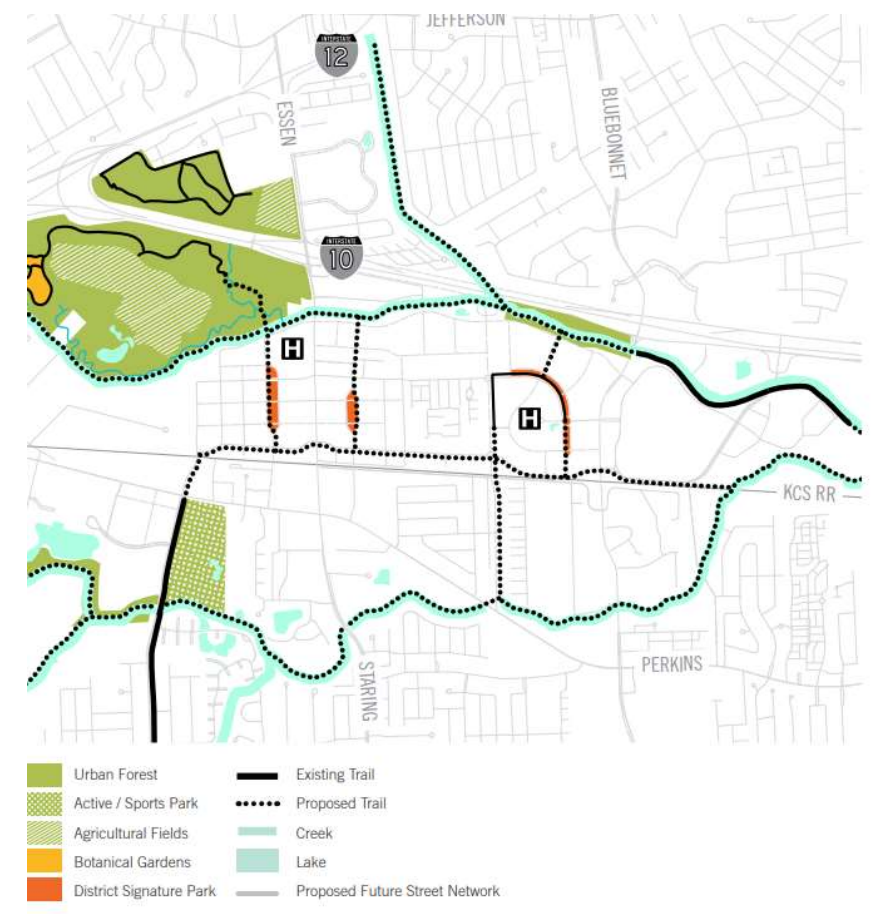

Figure 39. BREC Health Loop trail system. (39) 
The suburban Baton Rouge station represents a clear opportunity and a distinct challenge: the site itself is a relatively "blank slate" which can be designed for multimodal use from the outset, while creating new and much-needed neighborhood connections and optimizing the utility of robust existing transit connections. On the other hand, the urban form of the area, with limited street connectivity/permeability and barriers created by major roadways and the rail line itself, presents a challenge to facilitating non-automobile access to the proposed station. Considerable investment will be needed to implement the recommendations outlined in existing planning documents and reconnect the site to its immediate community as well as the medical and retail facilities within its footprint, to the trail network currently in development, and to other Baton Rouge neighborhoods. Bike share (for first/last mile connections) and fast, frequent transit services (for citywide connections) will be key to facilitating access to and from the station along with rideshare and personal vehicles.

CATS: Finally, multimodal access to both Baton Rouge proposed station locations is closely linked to the city's overall transit network, which theoretically provides access to the station areas for a much broader share of the population than could be possible through walking or bicycling alone. The CATS Strategic Plan (51) calls for regionalized service by 2022, though does not specify precisely where or how this is intended to be developed. The plan identifies goals for service quality, reliability, travel times, ridership, safety, and customer satisfaction among other organizational concerns, but does not identify specific operational changes pertaining to routes, stations, or rider amenities that would impact the proposed rail station(s) in Baton Rouge. The plan also calls for a Comprehensive Operations Analysis (COA) is called for to evaluate these issues in detail. The plan also tasks the agency with implementing at least one regional route outside of the current service area by 2022 .

A complementary 2019 Capital Plan elaborates on the proposed Bus Rapid Transit concept, identifying potential projects on Plank Road, Florida Boulevard, and Nicholson Drive (55). It also identifies seven transit hub projects, most of which are dependent on competitive grant funds for advancement. This list includes a Downtown Multi-Modal Transportation Center, and a South Baton Rouge/Health District Multi-Modal Center, budgeted at approximately $\$ 3 \mathrm{M}$ each, which could be presumed to serve with and/or directly align with proposed intercity rail station sites. However regional rail is not identified as a specific driver in any of the above-noted plan documents.

Also in 2019, CATS overhauled its entire route network, eliminating 145 stops in order to improve service and speed on better-performing routes, and implementing a 6-month rideshare-style "microtransit" pilot project serving residential complexes or major employers in North Baton Rouge and the City of Baker which lack fixed-route transit access (56).

Meanwhile, previous plans for a 3-mile tram linking LSU to downtown (57), which would link to the proposed station area via a proposed Government Street extension, has been set aside in favor of a planned \$40M, 9-mile BRT route between LSU and a future North Baton Rouge hub site near the former Earl K. Long Hospital, concurrent with implementation of the Plank Road Master Plan (52). In 2019, East Baton Rouge Parish announced a \$15M federal BUILD grant to partially fund the BRT project, which would create a north-south connection across the city, as well as connect the existing CATS terminal to downtown via Florida Avenue. The overall Plank Road Masterplan Initiative is also supported by local and state funds as well as \$7M of CATS federal formula funds, and a recently announced \$5M award from JP Morgan Chase's 2020 Advancing Cities Challenge 
(58). The project is expected to be complete by 2023 and would result in frequent (15-minute) service along the route. Available planning documents do not explicitly identify the BRT's relationship to the proposed Government Street passenger rail station, which would be within a short walk of the BRT route (Figure 40) (59).

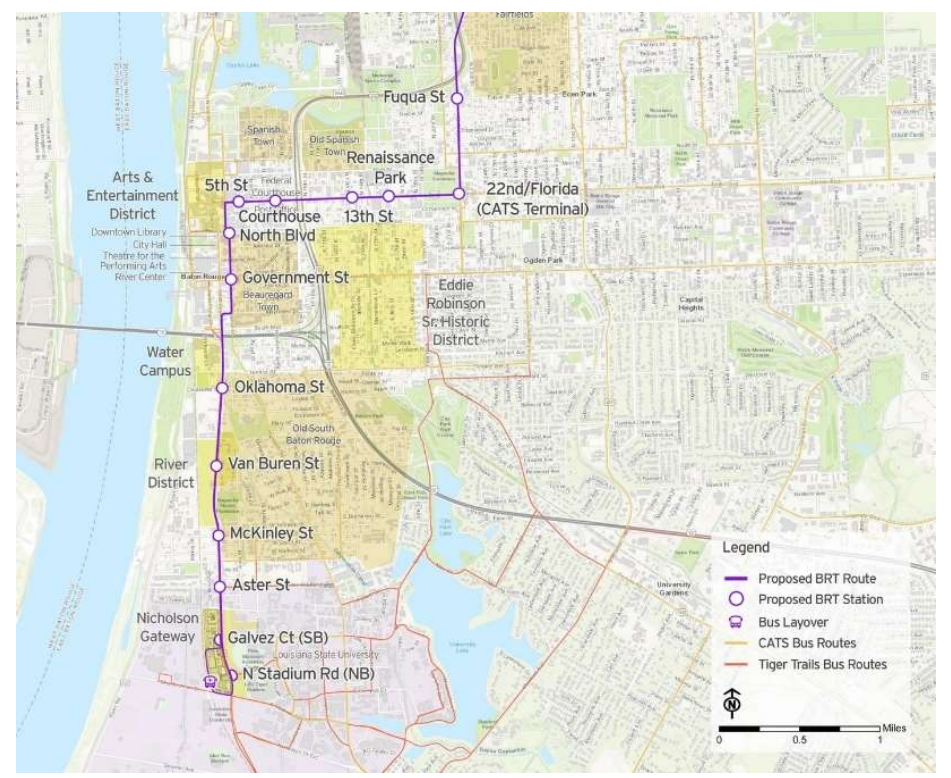

Figure 40. Proposed Baton Rouge BRT route - downtown detail. (59)

Most recently (60), CATS announced an upcoming second update of its strategic plan, expected to conclude in February 2021, which will be used to further refine and guide proposed operations and capital improvements.

Survey findings (Section 5.6) suggest that public confidence in CATS as a viable mode of transportation for everyday use is currently not high. The agency has suffered from historic disinvestment and ongoing budget constraints, although considerable progress has been made in recent years with the provision of real-time transit data, adjustments to routes and schedules to improve reliability and frequency, pilot project development, and planning for future capital investments. These investments indicate promising growth which is essential to future regional rail success. As major projects are implemented, CATS should work to identify opportunities to integrate and leverage the proposed rail service into route planning and scheduling. Importantly, considerable investment in marketing and public information may also be needed to encourage Baton Rouge residents to consider system use.

\subsubsection{Multimodal Connectivity - Gonzales}

Multimodal connectivity for intermediate stations along the proposed routes is constrained by a lack of fixed-route transit and more dispersed land use patterns that limit the number of local residents who can feasibly walk or bicycle to the proposed station. Currently, there are no dedicated bikeways and limited sidewalks within the immediate station area.

The proposed Gonzales station (40) includes vehicular access and parking, as well as bicycle and pedestrian improvements along adjoining streets (as well as across New River), including North Bryan Ave, North Boullion Ave, and East Roosevelt St (Figures 41 and 42). 


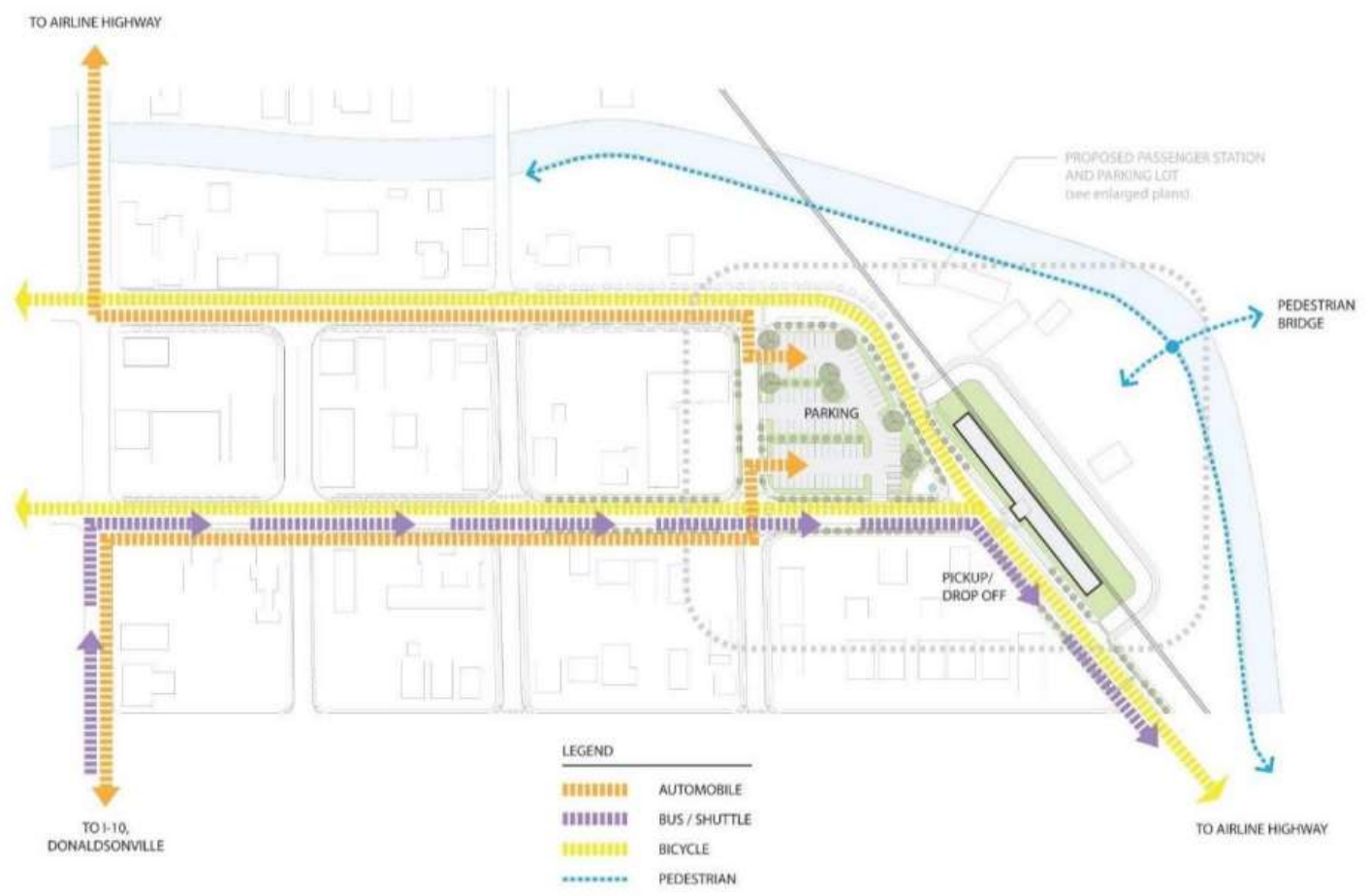

Figure 41. Gonzales proposed station access plan. (40)

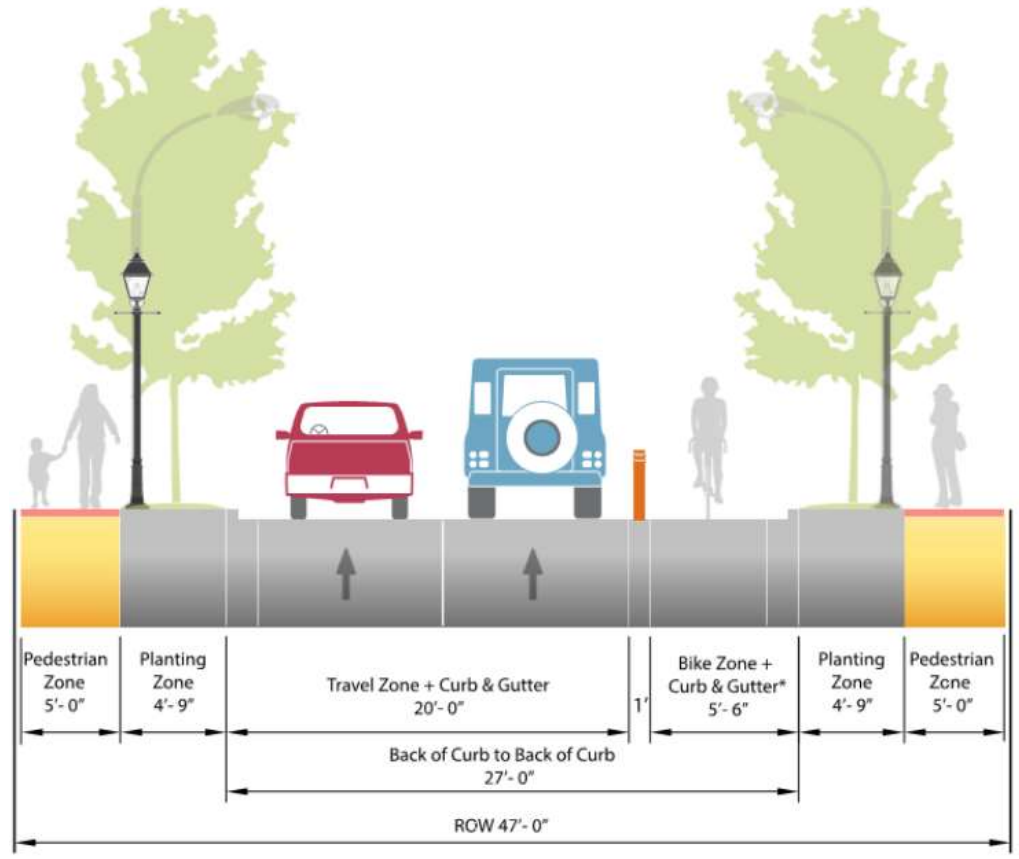

Figure 42. Proposed East Roosevelt St complete street cross section. (40) 
Additional active transportation connections are called for by Gonzales' Comprehensive Plan (61), as well as the National Park Service Gonzales Connections Plan (40), including improved linkages between downtown and Airline highway. In addition, the Station Plan notes that partnerships to provide subsidized transit or shuttle service between the rail station and the chemical district along the Mississippi River should be explored.

Currently, however, no public transit currently exists within Ascension Parish, other than ondemand paratransit service supported by the Council on Aging, which operates for seniors and persons with disabilities on a limited basis. Past initiatives have discussed the need for a transit service (likely park-and-ride based) particularly serving Donaldsonville, Modeste, and Smoke Bend west of the Mississippi River, as well as to support chemical district commute activity.

Gonzales' station area planning process has created a blueprint for an accessible, multimodal station that encourages transit-oriented development and local revitalization. However, it is limited by the overall auto-oriented design of its surrounding context, which will limit the number of potential riders for whom station access by means other than driving would be feasible. Stakeholders observe that coordination of transit services and resources in rural and suburban areas is a persistent challenge; existing demand-response services are typically limited by political boundaries that may not reflect the transportation needs of the region's residents. Regional funding, coordination, and insurance issues inhibit the development of regional services that connect across communities and could also serve to link these communities to regional rail. Additional research is needed to investigate possible solutions to improved regional coordination and to identify resources/funding to meet these needs.

\subsubsection{Multimodal Connectivity - LaPlace}

Similarly, the geography and land use patterns of LaPlace and the surrounding parish limit the potential for non-automobile connections to the proposed station for many residents. Currently, LaPlace is served by River Parishes Transit Authority (RPTA) demand-response service, operated by Transdev, which operates weekdays from $5 \mathrm{am}-7: 30 \mathrm{pm}$ for registered riders.

In 2020 RPTA initiated a Feasibility Study to assess the potential for fixed-route transit service, aimed at maximizing connectivity and job access for riders, increasing system productivity and reliability, and connecting to other transit systems including the proposed Baton Rouge - New Orleans rail service. As of November 2020, the outcome of this feasibility study had not been released to the public. However, initial discussions have included preliminary proposals for a route stretching from the St. James Parish line to Ormond Blvd, with a stop at the planned transportation center, as well as a LaPlace Loop operating locally (Figures 43 and 44). 


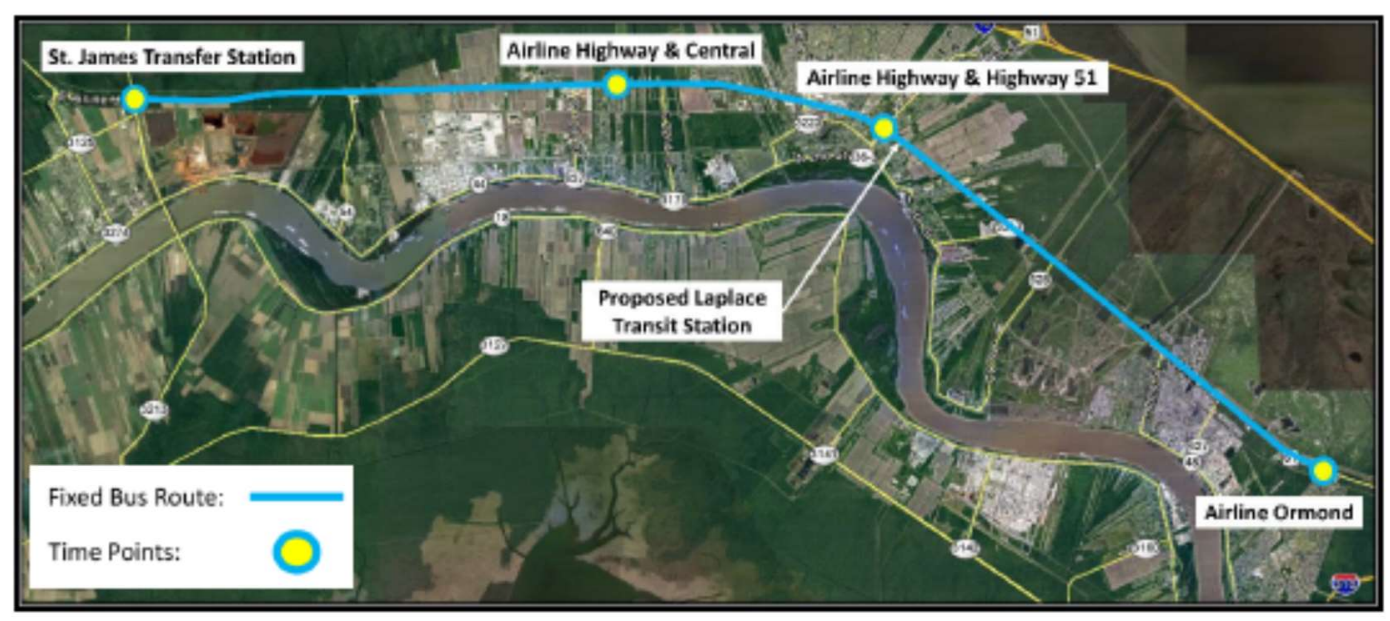

Figure 43. Proposed Airline Highway RPTA fixed transit route. (41)

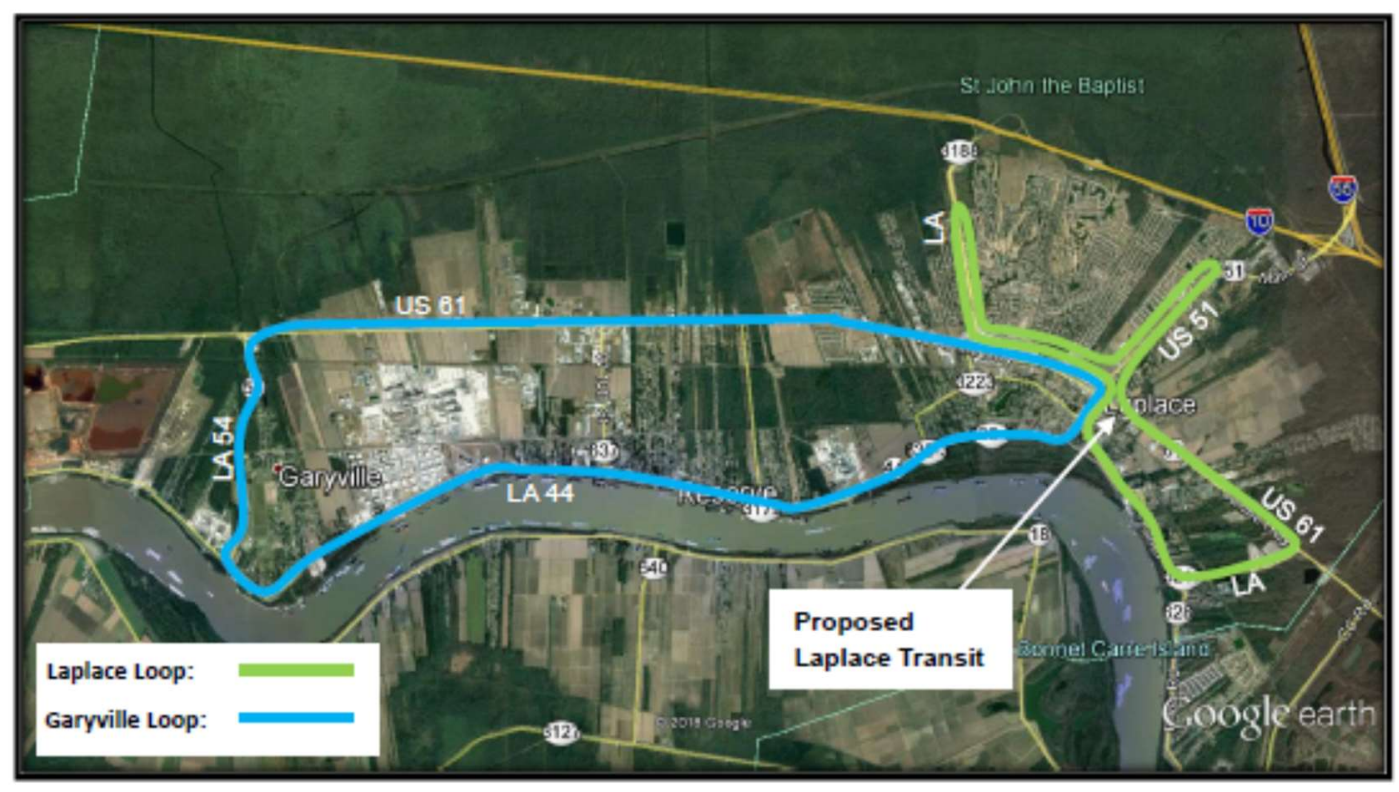

Figure 44. Proposed LaPlace loop RPTA fixed transit route. (41)

Pedestrian accommodations within the station area are limited, and bikeways virtually nonexistent save the Mississippi River Trail which comes within approximately $1 / 2$ mile of the proposed station. Significant improvements to pedestrian and bicycle access to the proposed station site are currently underway, however, with the LA Safe Airline and Main project under construction, bringing 1.6 miles of sidepaths and other pedestrian amenities (e.g., pedestrian signals and crosswalks) to Airline Highway and Main St (Figure 45). Local plans propose new connections to the Mississippi River Trail and development of a network of bicycle and pedestrian facilities to promote station access (Figure 46) (41). 


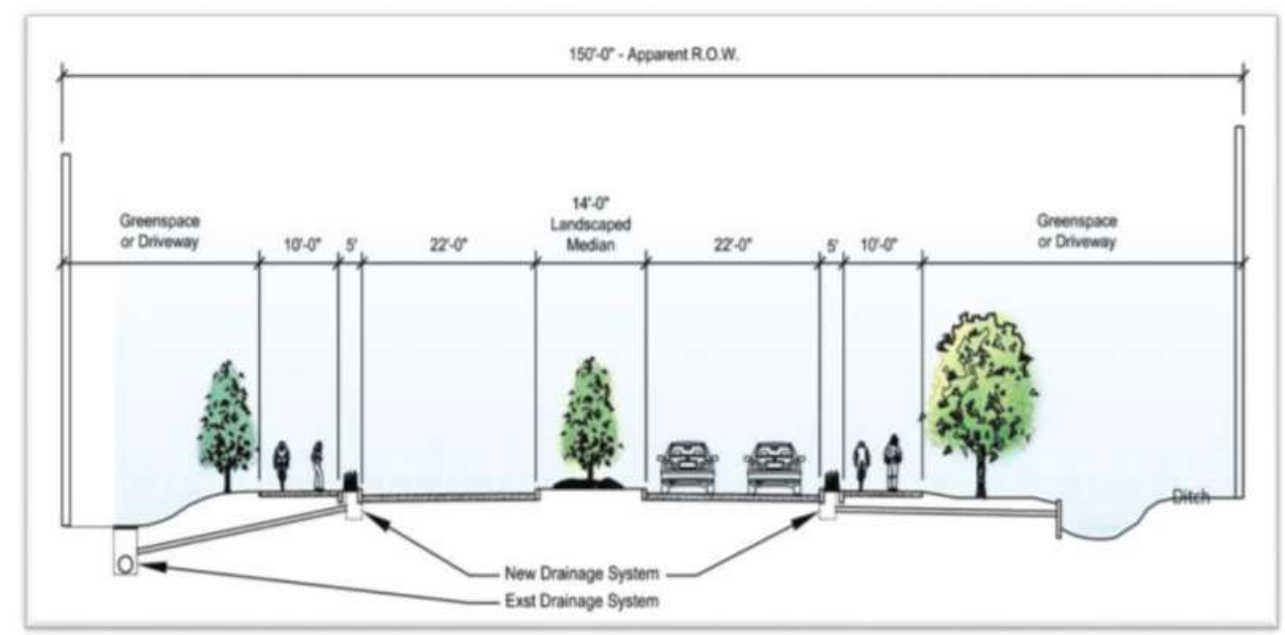

Figure 45. LA Safe Airline Highway proposed cross section. (41)

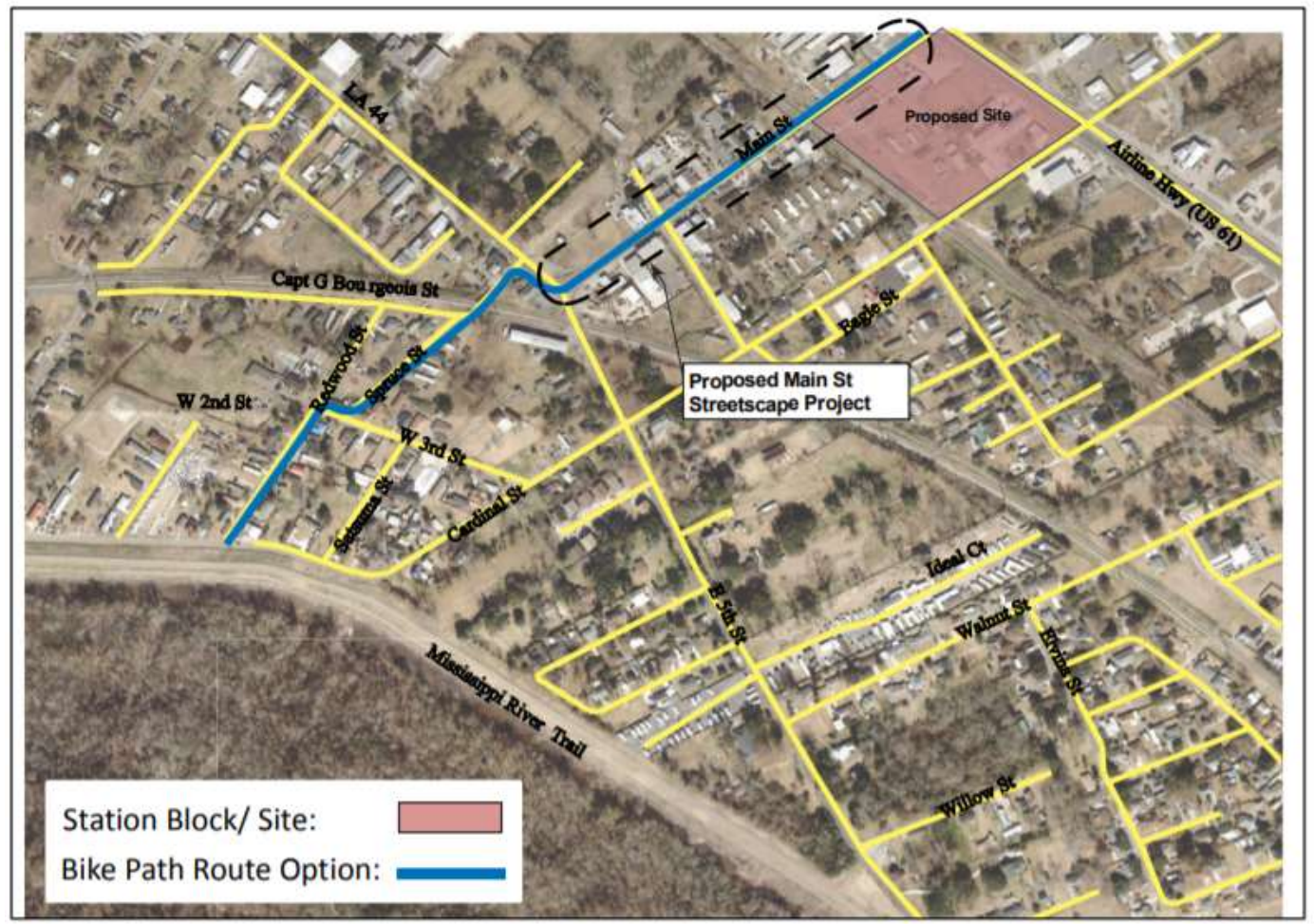

Figure 46. Proposed LaPlace rail station and connecting bicycle routes. (41)

In addition, as part of the LaPlace Transportation Center Plan, analysts used Synchro software to assess how proposed changes stemming from rail station area development and train service would impact traffic, finding no significant impacts (41).

The planned LaPlace Transportation Center estimates demand for up to 350 parking spaces within the project area but emphasizes minimizing parking demand by building up multimodal options and encouraging mixed land uses as part of station area development, as well as constructing a public parking structure and extending Martin Drive to enhance street connectivity (41). 
Like Gonzales, LaPlace has created a strong foundation for future investment in multimodal transportation that reinforces access to the proposed rail service, while also supporting community development that is not contingent upon passenger rail to provide significant transportation and economic benefits. LaPlace is not waiting to improve pedestrian accommodations and is taking steps toward identifying opportunities for transit service development that will significantly enhance the proposed station's connections to its immediate neighborhood and the broader parish. These enhancements are promising indicators of future success should rail service be developed. However, it is important to note that the suburban character of the area and current lack of transit connections to neighborhoods and employment centers means that a plurality of potential riders would still be expected to access the station by driving at this time.

\subsubsection{Multimodal Connectivity - Jefferson Parish}

Suburban areas adjacent to major cities increasingly function as integrated components of the urbanized area economically; in many places, a metropolitan area's residents are as likely to commute from the urban core to employment in adjacent suburbs, and major medical, retail, and other complexes serve a broad, regional community. Unfortunately, political boundaries often serve to sever regional connectivity, while auto-oriented patterns of development reinforce arbitrary divisions between neighborhoods or jurisdictions and limit access to regional employment opportunities and resources. The New Orleans metro area is thus divided, with two separate transit systems, and limited transportation connection points for non-motorized road users between the two parishes.

Suburban Jefferson Parish has taken significant strides toward providing transportation options and recreational opportunities for bicyclists, with the development of the Jefferson Parish Bicycle Master Plan in 2013 (62). This plan provides a vision for active transportation that bridges existing physical and political barriers and provides access to recreation and transportation for people of all ages and abilities. The Master Plan's analysis revealed pockets of high existing or potential bicycle demand, based on sociodemographic characteristics, population and destination density, and other data (Figure 47), finding that the Airline corridor (where both proposed rails stations are located) is a key pocket of high demand. The plan recommends a multi-use sidepath along Airline Highway itself to Williams Boulevard, and then on-street bike lanes from Williams to the parish line, as well as bike lanes along nearby David Drive/Dickory Avenue, which would connect the proposed Metairie station area into the future active transportation network (Figure 48). In addition, north-south connections linking existing levee trails to key destinations (including New Orleans Airport) are planned, although none would directly serve the new MSY north terminal.

Implementation of the Bicycle Master Plan is now underway, creating conditions which make nonmotorized access to the proposed Kenner and Metairie stations more feasible. However, significant impediments to walking and bicycling remain, and future station area planning efforts will need to address both last-mile connections for rail riders accessing major destinations within the immediate station area. The Bicycle Master plan does not explicitly reference the proposed passenger rail service, nor is the integration of bikeways with existing or potential transit service discussed, generally. 


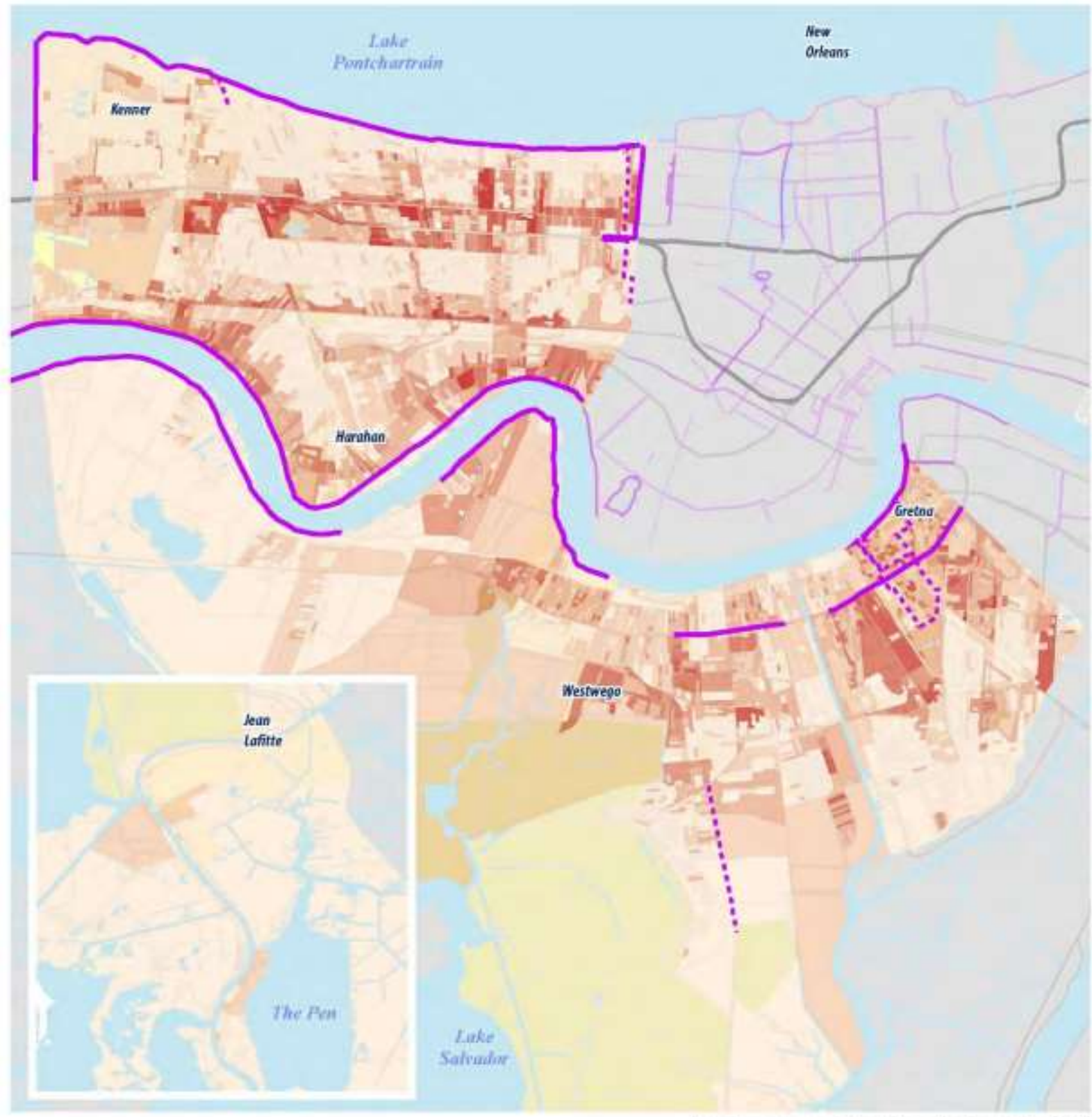

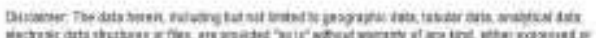

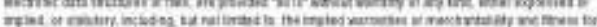

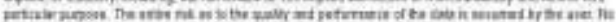

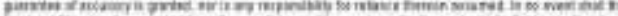

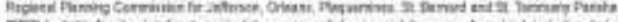

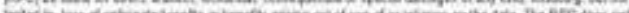

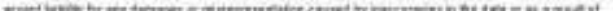

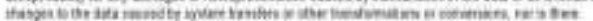

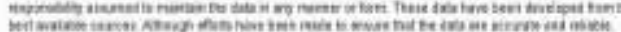

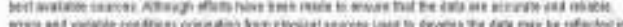

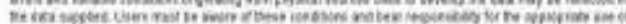

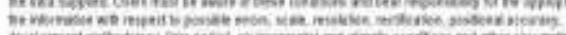

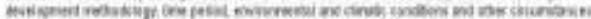

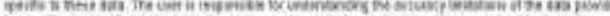

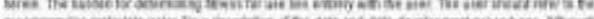
cincar wo

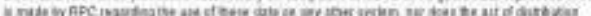

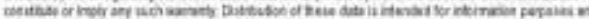

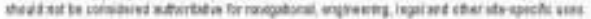

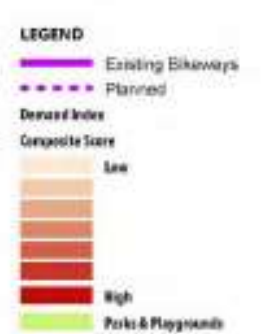

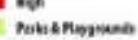

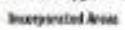

Base layers source: Regional Planning Commission 2012

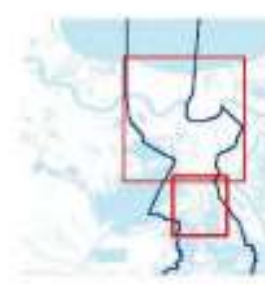

December 26, 2013

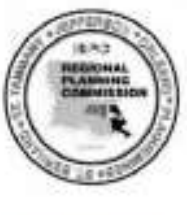

0

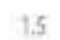
3

Figure 47. Jefferson Parish estimated bicycle demand. (62) 


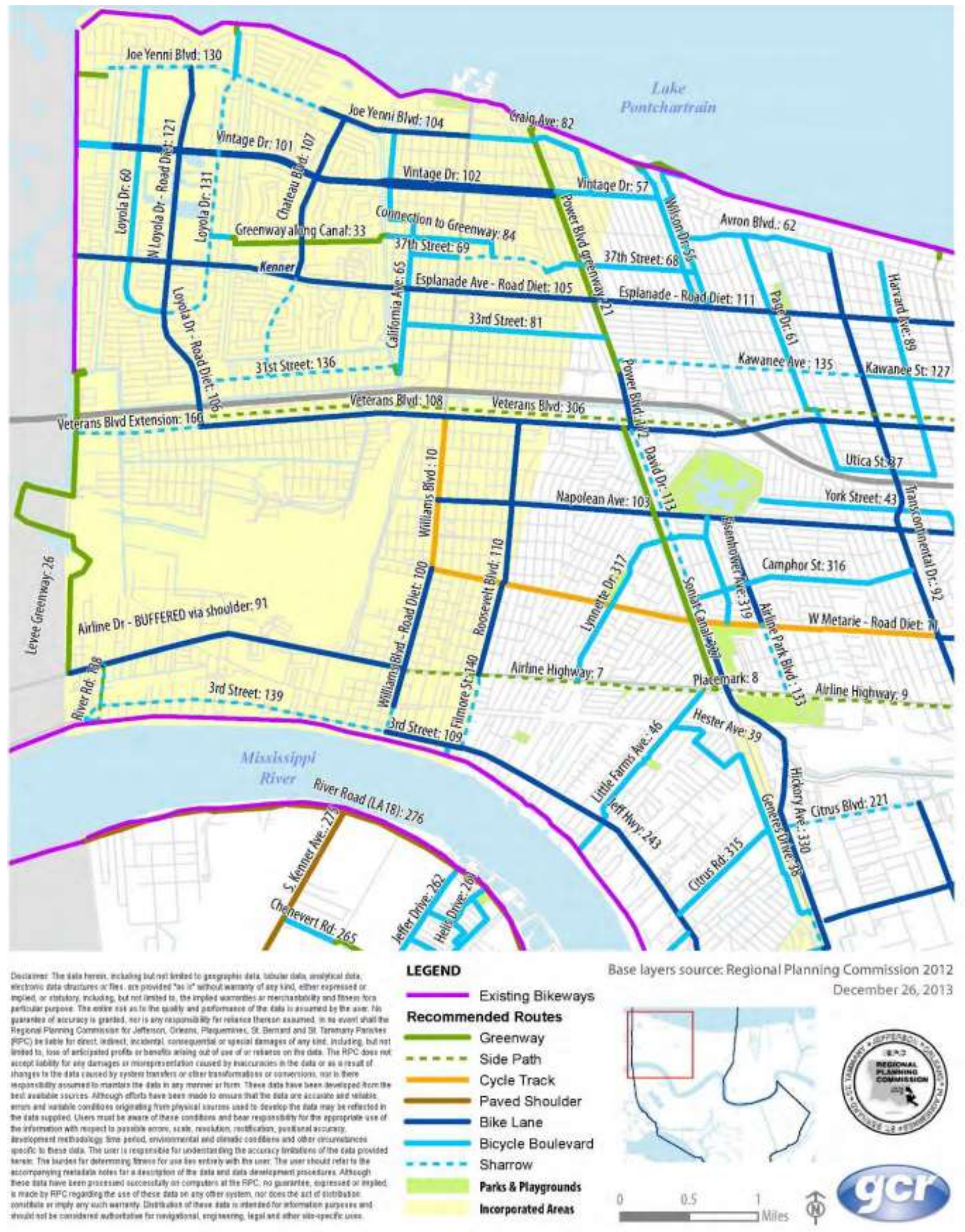

Figure 48. Jefferson Parish proposed bikeways. (62) 
For rail users bound for destinations other than the key activity generators near the proposed stations, multimodal connections are more challenging still. Currently, Airline Highway is served by the E2- Airline bus which connects to downtown New Orleans (weekdays only), while Rivertown is served by the E3- Kenner Local bus which connects to uptown New Orleans at Carrollton and Claiborne. Because definitive station area plans have not yet been developed, it is not clear whether existing transit services would directly serve proposed stations.

The Jefferson Parish Public Transit Strategic Plan (63) outlines goals and objectives for the future of transit in the parish and recognizes the need for improved coordination and collaboration across parish lines to better serve the metro area's residents but does not explicitly discuss connections to regional bus or rail services. The plan also notes that operating expenses currently exceed revenue, and that service cuts are anticipated by 2023 unless changes are made, suggesting the risk that the system's already-infrequent schedules and previously consolidated routes may experience further declines in coverage and/or frequency.

From 2018-2020, JeT participated in the NORPC-led New Links planning process, along with RTA, to develop a proposal for a redesign of regional transit service to better match current and anticipated needs and demands (64). This process included a robust analytic approach to modeling transit propensity/demand, extensive public outreach, and evaluation of multiple data sources to identify optimal service design that maximizes access to jobs and opportunities for regional residents who need or are most likely to utilize such service. Although Jefferson Parish's transit propensity (Figure 49) is notably lower than neighboring Orleans Parish, pockets of high demand exist, most notably along the Veterans Boulevard corridor, as well as just south of the proposed Metairie rail station along Citrus Boulevard.

The proposed transit network redesign would alter the existing Airline Highway route (E2), detouring it off Airline Highway to Citrus Blvd to better serve this pocket of high activity and connect to an enhanced transfer hub in Elmwood (Figure 50). While logical from a demand standpoint, this adjustment would also serve to remove a direct transit connection from the proposed Metairie station. The current Kenner Local (E3) route, meanwhile, would be altered to connect Kenner to West Esplanade via Clearview and Cleary, terminating at East Jefferson General Hospital. These schedule adjustments reflect tradeoffs to better serve Jefferson Parish residents and employees who rely on transit most, but do not appear to consider proposed future regional rail service as a critical factor in determining service allocation in the near term.

Of all the corridor parishes, planning for future passenger rail is least well-developed in Jefferson Parish, with no clearly defined station plans and limited consideration of its potential integration into existing and future multimodal transportation networks among current planning documents. In order for the proposed rail service to adequately serve the major activity generators within its reach, as well as to serve the residents of Jefferson Parish, additional planning is needed to develop local connections. Planned bikeways will enhance overall non-motorized connectivity, while future transit route and schedule adjustments could be made relatively easily in the event that the rail connection is implemented. Overall, however, the sprawling urban form of the Parish and relatively constrained transit service availability will likely indicate continued use of automobilebased modes for most trips; efforts to mitigate demand for parking and maximize ridership into Jefferson Parish will likely center on improving last mile connections to destinations within the immediate walkshed of each station area. 


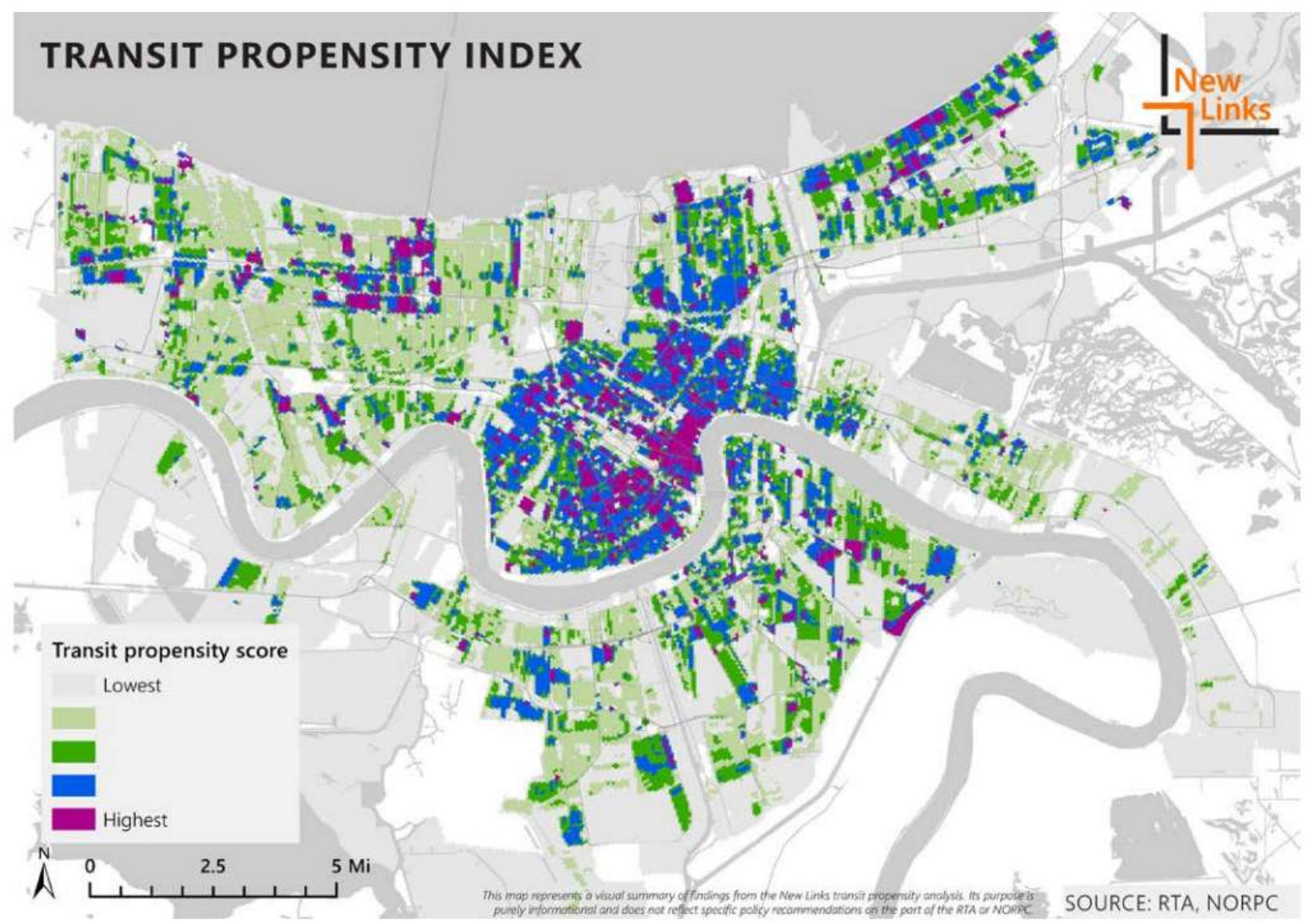

Figure 49. New Orleans metro area transit propensity index. (64)

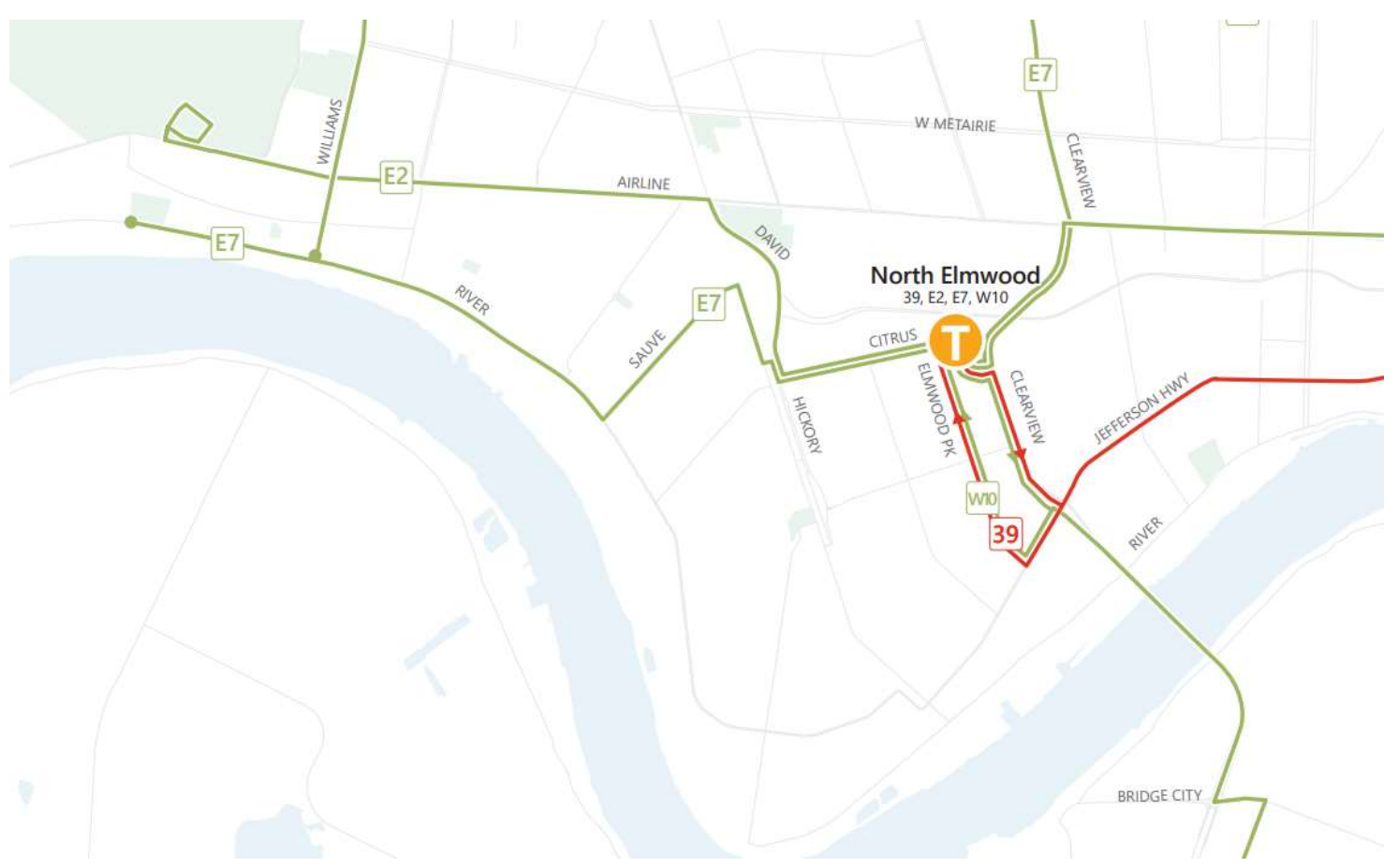

Figure 50. Proposed Kenner/EImwood JeT bus routes. (64) 


\subsubsection{Multimodal Connectivity - New Orleans}

Of all the proposed stations within the NO-BR corridor, the New Orleans station at NOUPT presents the most readily available opportunities to promote active transportation and transit as primary modes of access to regional rail. The terminal is located in downtown New Orleans, with connections to several transit and bicycle routes. In the last decade, the surrounding area has experienced major investments in housing and retail development. These projects have diminished the availability of surface parking, while revitalizing the area and adding hundreds of new housing units within walking distance of the terminal.

New Orleans RTA completed a Strategic Mobility Plan (65) explicitly identifies support for implementation of the Baton Rouge - New Orleans passenger rail project as a component of its goal to "connect to opportunities" and stipulates that the agency will "coordinate with the state" to advance this effort, although this is envisioned as a long-range action within the next 11 to 20 years. NOUPT is not acknowledged directly within the strategic plan, reflecting the findings of a downtown transit center study (66) that ranked it $6^{\text {th }}$ among 12 locations evaluated and relegated it to a secondary/satellite hub for future development in favor of sites more central to downtown employment and/or with greater physical capacity (Figure 51).

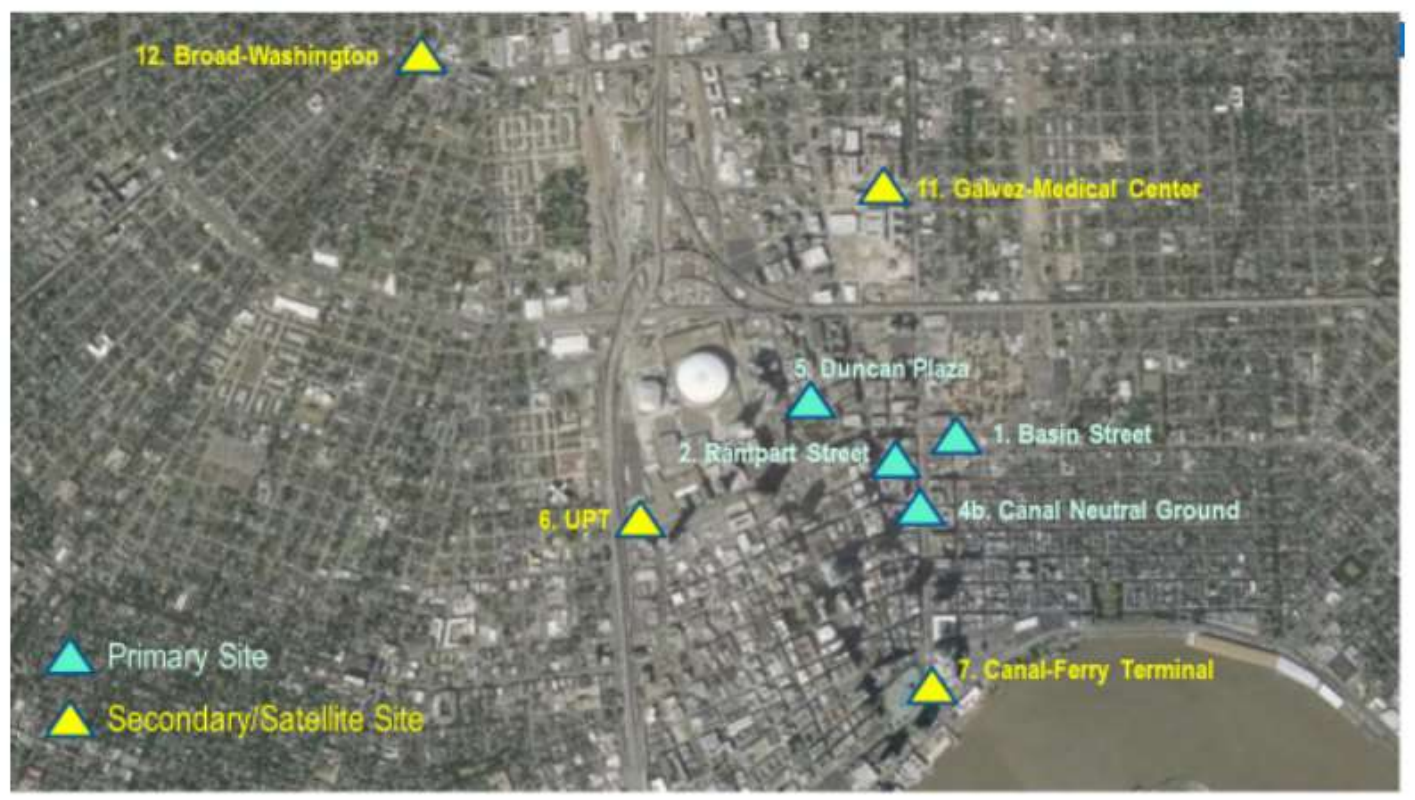

Figure 51. New Orleans downtown transit center primary and secondary site locations. (66)

New Orleans and RTA were also integral partners in the New Links comprehensive operations analysis process (64), which proposes to consolidate the numerous transit routes through New Orleans' CBD onto fewer corridors, in order to facilitate future development of dedicated transitways that can improve bus performance during congested periods. The proposal would reroute most of the bus lines that currently serve NOUPT or pass by on adjacent Loyola Avenue (including several JeT routes serving the Westbank, Figure 52) to S. Rampart St, one block away, leaving only the Loyola/Rampart streetcar and a proposed spur of the Riverfront streetcar directly serving NOUPT (Figure 53). All other downtown-serving routes would be accessible with either a short walk or via the streetcar with a connection at the proposed new Basin St. transfer hub. 


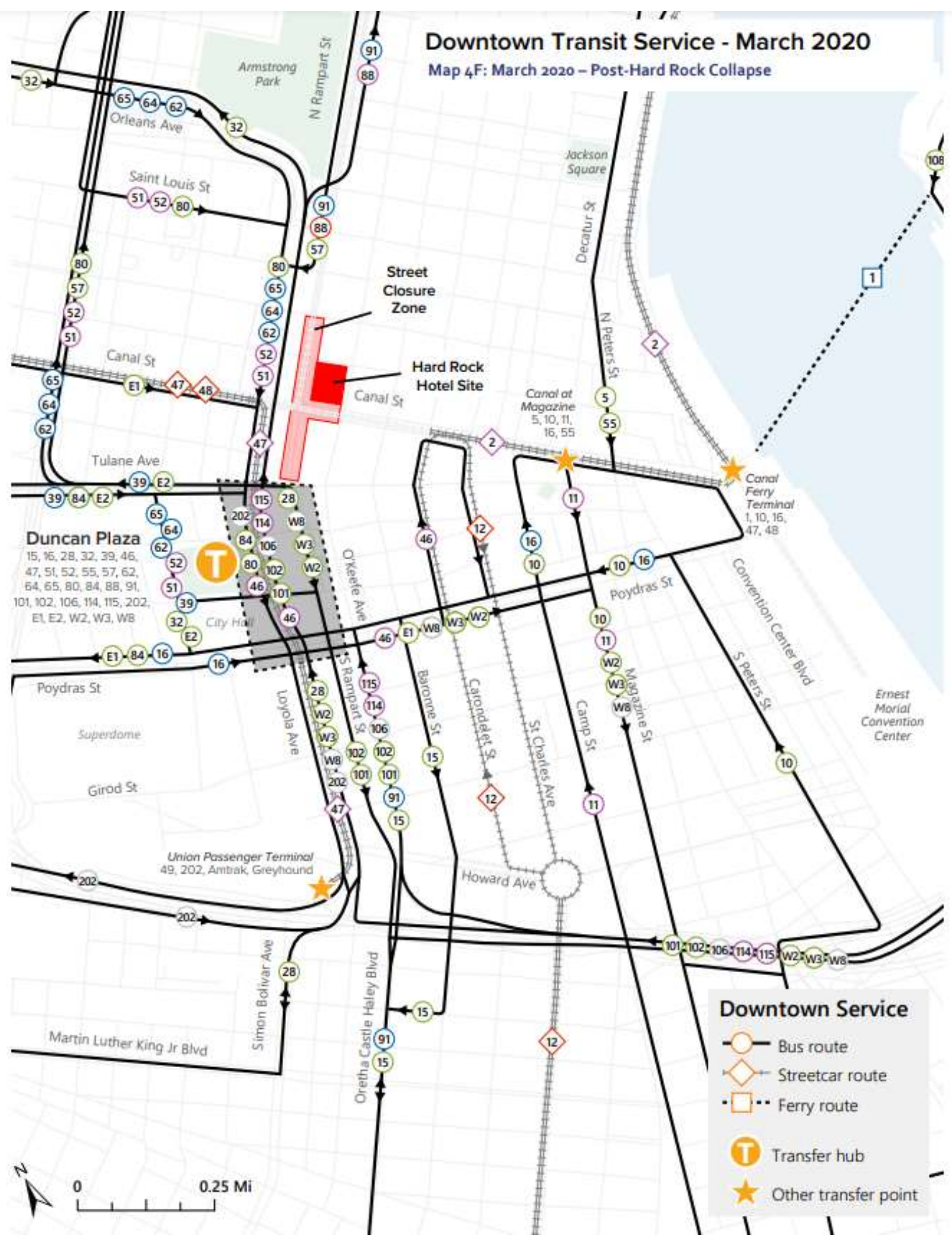

Figure 52. Existing downtown New Orleans transit service. (64) 


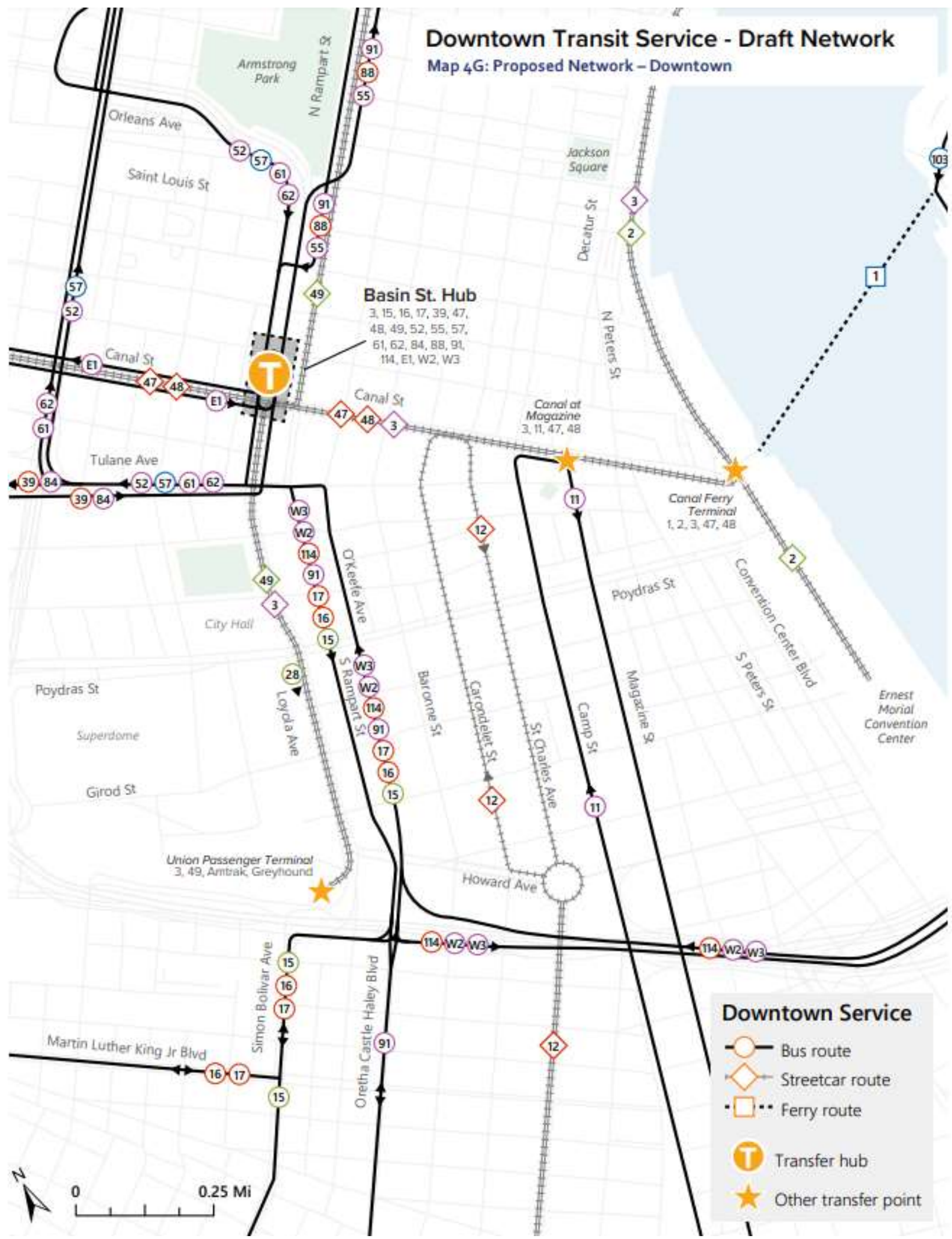

Figure 53. Proposed downtown New Orleans transit service. (64) 
The New Links planning process is expected to be completed in early 2021, with final recommendations delivered to both transit agencies for adoption. The current proposed network, while providing important benefits to frequency and reliability that underpin all effective transit systems, still has notable limitations when it comes to circulation within the downtown area itself, which may be a particular concern for rail service intended to serve downtown commuters as well as special event attendees.

Walking and bicycling connections may be able to effectively address the need for convenient mobility within downtown, particularly if New Orleans succeeds in reviving its Blue Bikes bikeshare program, which was discontinued in April 2020. The Moving New Orleans: Bikes Bikeway Blueprint (67) defines existing and proposed future bikeways, several of which are currently in design or pending construction. This includes new and enhanced bikeways directly linking NOUPT to adjacent Central City and to the CBD and French Quarter via a network of protected bike lanes intended to support cyclists of all ages and abilities (Figure 54). Notably, some gaps and irregularities in the network remain in the proposed plan: conventional (unprotected) bike lanes and shared lanes will be retained on the side of Loyola Avenue closest to NOUPT, and a gap in facilities connecting existing bikeways on Loyola Avenue to proposed bikeways on Simon Bolivar Avenue under the Pontchartrain Expressway-a key barrier for walkability and bikeability—remains.

The area surrounding NOUPT generally has a relatively high degree of walkability, with sidewalks, crosswalks, and pedestrian signals present throughout. Some crossings across Loyola Avenue, as well as under the Pontchartrain Expressway, need improvement to facilitate pedestrian safety. A project aimed at improving access to and within the complex surrounding the Superdome is currently underway, which will extend Howard Avenue past NOUPT and improve pedestrian permeability.

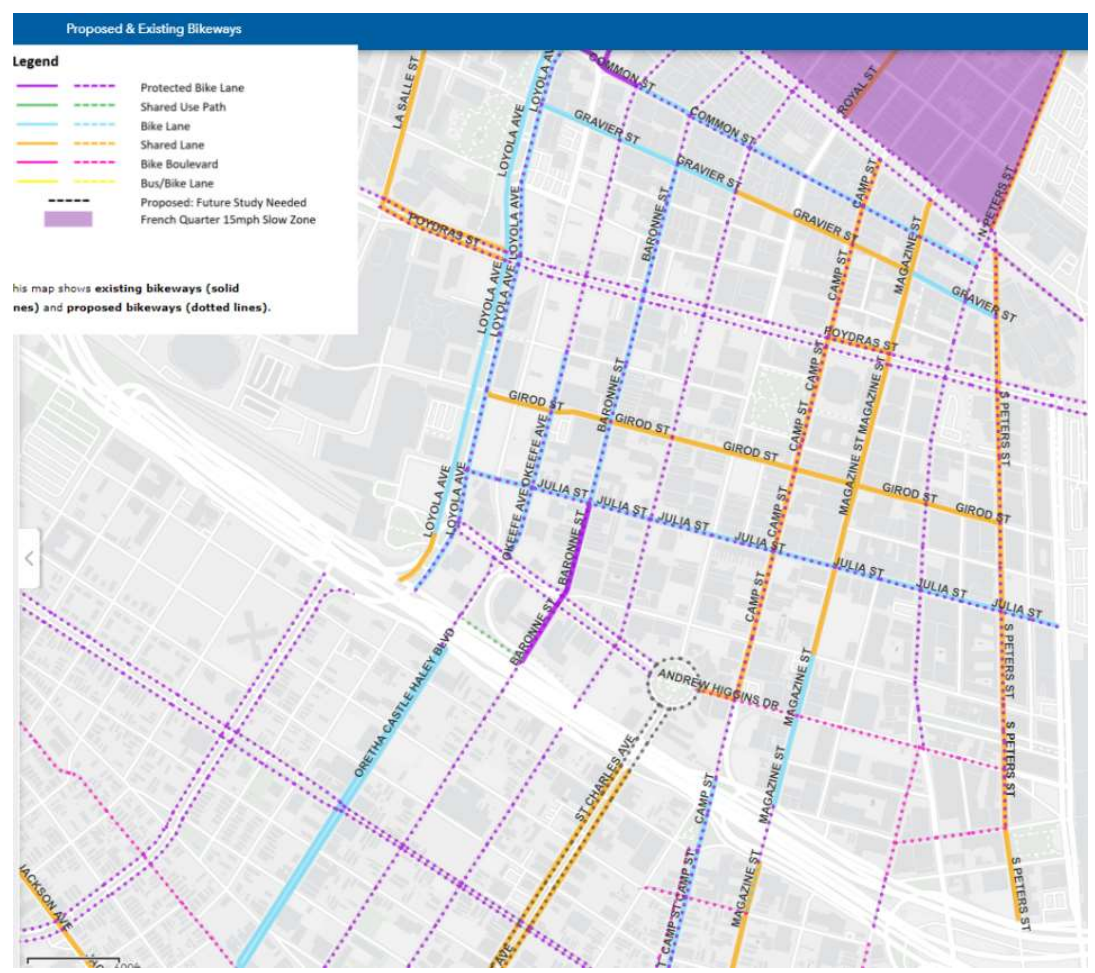

Figure 54. Existing and proposed bikeways, downtown New Orleans. (67) 


\subsection{Evaluation of Previously Developed Cost and Ridership Estimates}

In addition to synthesizing and evaluating previous planning efforts and assessing existing facilities supporting and potential for multimodal access to proposed passenger rail stations, this study includes a limited evaluation of previously developed estimated costs of developing the passenger rail in the Baton Rouge - New Orleans corridor, as well as of anticipated ridership figures, to determine whether modification is needed in order to accurately plan for and successfully fund the proposed service.

\subsubsection{Implementation Costs}

The 2010 Feasibility Study (33) estimated the total cost of implementing the service at $\$ 447.8 \mathrm{M}$ (2010 dollars), plus an additional recommended \$50M East Bridge Junction flyover in part to enhance the utility of the proposed route for evacuation purposes. In 2019 dollars, this would equate to an estimated cost of $\$ 522 \mathrm{M}-\$ 541 \mathrm{M}$ depending on the scope of improvements implemented to increase rail speeds (32).

The 2014 Feasibility Study updated 2010 estimates (Table 13) assuming a more incremental approach with minimal initial capital investments in rolling stock and track improvements, for an overall capital/implementation cost of \$262M (\$284M in 2019 dollars), including \$75M or grade crossing improvements and replacement of the Bonnet Carré Spillway bridge as critical short-term investments (32).

Table 13. Estimated 2014 feasibility study capital costs (in millions of 2013 dollars). (1)

\begin{tabular}{|c|c|c|c|c|c|c|}
\hline Major Cost Item & KCS & $\mathbf{C N}$ & $\begin{array}{l}\text { East Bridge } \\
\text { Junction }\end{array}$ & NOUPT & Corridor & Total \\
\hline Site and Track Work & $\$ 58.96$ & $\$ 37.98$ & $\$ 4.31$ & $\$ 6.54$ & - & $\$ 107.79$ \\
\hline Grade Crossings & $\$ 10.77$ & $\$ 1.85$ & - & - & - & $\$ 12.62$ \\
\hline Structures & $\$ 87.80$ & - & - & - & - & $\$ 87.80$ \\
\hline Signals & $\$ 25.25$ & $\$ 3.83$ & - & - & - & $\$ 29.08$ \\
\hline $\begin{array}{l}\text { Engineering and } \\
\text { Management }\end{array}$ & $\$ 12.79$ & $\$ 3.06$ & $\$ 0.30$ & - & - & $\$ 16.15$ \\
\hline Rolling Stock & - & - & - & - & - & - \\
\hline Stations & - & - & - & - & $\$ 9.00$ & $\$ 9.00$ \\
\hline Total & $\$ 195.57$ & $\$ 46.72$ & $\$ 4.61$ & $\$ 6.54$ & $\$ 9.00$ & $\$ 262.44$ \\
\hline
\end{tabular}

Capital cost estimates do not include the cost of trains, assumed to be leased from Amtrak and therefore included as an operating expense, along with railroad compensation and liability. It is outside the scope of this study to comprehensively evaluate the costs of project implementation. However, since the release of the 2014 feasibility study, key stakeholders (including railway operators) have expressed concern for engineering and safety challenges involving the existing facilities that were not fully reflected in the feasibility report, which may represent a potential risk for capital costs exceeding HNTB's estimates. 


\subsubsection{Operating Costs}

The 2010 report (33) estimated (Table 14), using methodology developed by Amtrak in partnership with the State working group, an annual operating subsidy for the proposed service of $\$ 18.3 \mathrm{M}$ (\$20M in 2019 dollars), whereas the 2014 study revised this, based on a scaled-back service design of only two round trips per day, to $\$ 6.7 \mathrm{M}$ ( $\$ 7.4 \mathrm{M}$ in 2019 dollars).

Table 14. 2010 Feasibility study estimated operating costs. (33)

\begin{tabular}{|l|l|l|l|l|}
\hline Service Phase & $\begin{array}{l}\text { Annual O\&M Cost } \\
\text { (in millions) }\end{array}$ & Annual Ridership & $\begin{array}{l}\text { Annual Revenue (in } \\
\text { millions) }\end{array}$ & $\begin{array}{l}\text { Annual Deficit (in } \\
\text { millions) }\end{array}$ \\
\hline Phase 1 (2013) & $\$ 18.5$ & 461,000 & $\$ 3.9$ & $\$ 15.6$ \\
\hline Phase 2 (2018) & $\$ 23.3$ & 644.200 & $\$ 6.3$ & $\$ 17$ \\
\hline Phase 2 (2023) & $\$ 26.2$ & 886,400 & $\$ 9.9$ & $\$ 16.3$ \\
\hline
\end{tabular}

The 2014 study (1) updated operating costs using an HNTB model, based on the Amtrak Performance Tracking (APT) system. This model assumes an average $60 \%$ load factor, based on typical performance of comparable services.

Table 15. Operating cost assumptions. (1)

\begin{tabular}{|l|l|l|}
\hline Operating Statistic & Total Annual & Calculations/Assumptions \\
\hline Annual Train Miles & 113,800 & 78 miles/trip x 4 trips/day x 365 days \\
\hline Total Car Miles & 341,660 & 3 cars/train x 113,800 annual train miles \\
\hline Train Hours & 2,920 & 2 hours/trip x 4 trips/day x 365 days \\
\hline Ridership & 210,000 & 240 seats/train x $60 \%$ load factor x 4 trips/day x 365 days \\
\hline Total Passenger Miles & $13,140,000$ & 219,000 passengers c 60 mile average trip length \\
\hline
\end{tabular}

Under these assumptions (Table 15), the 2014 study estimates an operating cost at start-up on $\$ 8.8 \mathrm{M}$ (Table 16).

Table 16. Total operating costs, revenue, and projected subsidy. (1)

\begin{tabular}{|l|l|}
\hline Cost Category & Total Costs \\
\hline Host Railroad Payments & $\$ 779,000$ \\
\hline Maintenance of Equipment & $\$ 1,765,000$ \\
\hline Operations & $\$ 1,982,000$ \\
\hline Fuel & $\$ 567,000$ \\
\hline Sales and Marketing & $\$ 393,000$ \\
\hline Stations - Shared (NOUPT) & $\$ 118,000$ \\
\hline Administration & $\$ 1,364,000$ \\
\hline Insurance & $\$ 150,000$ \\
\hline Lease of Equipment & $\$ 1,595,000$ \\
\hline Police and Security & $\$ 169,000$ \\
\hline Total Operating Expenses & $\$ 8,882,000$ \\
\hline Annual Ridership & 210,000 \\
\hline Annual Revenue (\$10/trip) & $\$ 2,100,000$ \\
\hline Net Annual Operating Subsidy & $\$ \mathbf{6 , 7 7 2 , 0 0 0}$ \\
\hline
\end{tabular}

The 2014 study evaluates potential funding opportunities for the proposed service, documenting total sales and use tax revenues for each corridor parish, indicating that operating expenses could be fully covered by a $.25 \%$ sales tax increase, but noting that since sales taxes are already high and use of motor vehicle and fuel taxes in the Transportation Trust Fund is legislatively constrained, value capture options related to station area development, are likely the most 
promising options to cover operating subsidies (along with federal grant programs), particularly for intermediate stations. Millages are also considered as a potential funding option.

\subsubsection{Ridership Estimates}

The proposed rail service has the potential to serve the 2.2 million people and 1 million jobs within the super-region, while reducing congestion in the third-most congested medium-sized urban area in the US (40). However, its impacts to both employment access and congestion mitigation -as well as the service's ability to meet revenue goals - are contingent on accurate ridership estimates that can correctly predict the type and volume of passengers that may be anticipated.

The 2010 Feasibility Study (33) utilized FTA's Aggregate Rail Ridership Forecasting Model, which is based on performance of commuter rail systems with similar characteristics, and the number of potential journey-to-work trips within the service area, in order to forecast ridership. These forecasts assume gradual upgrades in speed of service over the next two decades and the addition of new daily trips, as well as continued development of TOD in station areas, predicting a gradual increase in annual ridership from 461,000 to 1.2 million over 15 years of service (Table 17 ), with a total of $1.5 \mathrm{M}$ riders by the final forecast year of 2038 (34).

Table 17. New Orleans - Baton Rouge projected ridership and ticket revenues. (33)

\begin{tabular}{|l|l|l|l|l|l|l|}
\hline Frequency & Speed & $\begin{array}{l}\text { Forecast } \\
\text { Year }\end{array}$ & $\begin{array}{l}\text { Annual } \\
\text { Ridership }\end{array}$ & $\begin{array}{l}\text { Annual Ticket } \\
\text { Revenue }\end{array}$ & $\begin{array}{l}\text { Avg. Riders } \\
\text { per Train }\end{array}$ & $\begin{array}{l}\text { Tkt. } \\
\text { per } \\
\text { Passenger }\end{array}$ \\
\hline 4 RT & $79 \mathrm{mph}$ & 2013 & 461,000 & $\$ 3,946,200$ & 165 & $\$ 8.56$ \\
\hline 6 RT & $90 \mathrm{mph}$ & 2018 & 644,200 & $\$ 6,339,000$ & 156 & $\$ 9.84$ \\
\hline 8 RT & $110 \mathrm{mph}$ & 2023 & 886,400 & $\$ 9,866,000$ & 165 & $\$ 11.13$ \\
\hline 8 RT & $110 \mathrm{mph}$ & 2028 & $1,205,900$ & $\$ 15,109,000$ & 224 & $\$ 12.53$ \\
\hline
\end{tabular}

Note: *Forecast assumed five additional years of service and Transit Oriented Development around stations.

The 2010 report also looked at non-cash benefits of the proposed service in their overall analysis, including transportation cost savings for users, property value increases in station areas, environmental benefits, and savings realized from reducing (long-since discontinued) LA SWIFT bus service, finding an overall return on investment of \$1.65 in benefits (in 2019 dollars) for every dollar of investment, and a 78\% probability of a positive ROI overall (32).

Importantly, the 2010 study focused heavily on the opportunity of the proposed service to capture commute trips, estimating that $88 \%$ of riders would utilize the train for work-related purposes. Non-work trips were estimated using "a wide range of modal share assumptions" and estimated to make up fewer than $10 \%$ of trips (1). In addition, this study's model assumed continued increases in the price of gas (which has since decreased) and increasing congestion within the I-10 corridor, as well as increased population within the corridor overall.

The 2014 study modified these assumptions, to better account for events and festivals, sporting events, and government functions, outlining the estimated attendance at select various events annually (Table 18) and modifying estimates accordingly. However, HNTB did not update the underlying demand modeling based on capturing commute trips, making the slight adjustment of a $60 \%$ load factor regardless of supply (compared to a 65\% load assumed in 2010), noting that this is likely to be a conservative estimate. This model assumes the same trip fare as the 2010 estimates, at $\$ 10$ each way. 
Table 18. Annual attendance for special events in New Orleans. (1)

\begin{tabular}{|c|c|}
\hline Event & Estimated Attendance \\
\hline R+L Carriers New Orleans Bowl & $40,000-50,000$ \\
\hline Allstate Sugar Bowl & $80,000-100,000$ \\
\hline Zurich Classic PGA Tournament & 100,000 \\
\hline Bayou Classic & 100,000 \\
\hline Mardi Gras & $1.0-1.2$ million \\
\hline French Quarter Festival & 400,000 \\
\hline Jazz and Heritage Festival & $500,000-600,000$ \\
\hline New Orleans Wine and Food Experience & 40,000 \\
\hline Essence Music Festival & 560,000 \\
\hline Voodoo Music Festival & 250,000 \\
\hline Christmas New Orleans Style & $40,000-50,000$ \\
\hline
\end{tabular}

Ultimately, this resulted in reduced overall ridership estimates (Table 19), particularly at the beginning of service with only 2 round trips planned per day.

Table 19. Estimated total annual ridership, 2010 vs. 2014 projections. $(1,33)$

\begin{tabular}{|l|l|l|l|}
\hline Round Trips Per Day & HNTB (2014) & Amtrak (2010) & BKI/HDR (2010) \\
\hline 2 (4 trips) & 210,240 & - & - \\
\hline 4 (8 trips) & 315,360 & 330,600 & 461,000 \\
\hline 6 (12 trips) & 420,480 & 569,000 & 644,200 \\
\hline 8 (16 trips) & 840,960 & 686,000 & 886,400 \\
\hline
\end{tabular}

The 2014 Feasibility Study assigns $65 \%$ of total corridor riders to the two Baton Rouge stations, of which $70 \%$ are expected to board at the downtown station (1). The ridership estimates are calculated using a simple formula developed by Amtrak which divides annual ridership by 270 (intended to account for peak conditions which exceed typical daily ridership during special events and seasonal variations). The Baton Rouge Station Plan (38) further extrapolates these estimates by breaking down annual and daily riders projected for each station, for an estimated 350 daily riders in Downtown Baton Rouge and 150 riders at the Suburban Station at startup (Table 20).

Table 20. Baton Rouge estimated ridership. (38)

\begin{tabular}{|l|l|l|l|}
\hline Corridor Service Level Assumptions & Start-Up (2025) & Mid-Term (2035) & Long-Term (2045) \\
\hline Round Trips & 2 & 6 & 8 \\
\hline Train Speeds & 79 & 90 & 110 \\
\hline Annual Riders & 210,240 & 644,200 & 886,400 \\
\hline Downtown Baton Rouge Station & & & 400000 \\
\hline Annual Riders & 96,000 & 290000 & 1500 \\
\hline Daily Riders & 350 & 1000 & \\
\hline Baton Rouge Suburban Station & & & 173000 \\
\hline Annual Riders & 41000 & 126000 & 640 \\
\hline Daily Riders & 150 & 460 & \\
\hline
\end{tabular}

Similarly, the Gonzales Station Area Master Plan (40) extrapolates estimates to derive daily and annual riders for the Gonzales Station, beginning with just 35 daily riders at onset of service and growing to 140 riders over time (Table 21). 
Table 21. Gonzales estimated ridership. (40)

\begin{tabular}{|l|l|l|l|}
\hline Assumptions & HNTB - 2014 & Amtrak - 2010 & BKI/HDR - 2010 \\
\hline 2 Round Trips Per Day & & & \\
\hline Annual Riders & 9,461 & - & - \\
\hline Daily Riders & 35 & - & - \\
\hline 4 Round Trips Per Day & & & \\
\hline Annual Riders & 14,191 & 14,877 & 20,745 \\
\hline Daily Riders & 52 & 55 & 76 \\
\hline 6 Round Trips Per Day & & & 28,989 \\
\hline Annual Riders & 18,922 & 25,605 & 106 \\
\hline Daily Riders & 70 & 94 & \\
\hline 8 Round Trips Per Day & & & 39,888 \\
\hline Annual Riders & 37,843 & 30,870 & 146 \\
\hline Daily Riders & 140 & 113 & \\
\hline
\end{tabular}

Previous feasibility studies, as well as the station area plans which rely on them to develop cost estimates, do not detail underlying assumptions of the ridership estimate models, or examine in great detail local factors likely to impact the projections. Importantly, as the Baton Rouge station plan notes, ridership estimates will need to be updated during NEPA and preliminary engineering studies, at which time station-level estimates should be updated (38).

It is outside the scope of this study to replicate and/or update the forecasting models previous feasibility studies have employed to estimate anticipated ridership. The FTA forecasting models used, including the Aggregate Rail Ridership Forecasting (ARRF) Model have been calibrated with findings from case study projects (20 relatively recent light and commuter rail projects). These models use Census Transportation Planning Package (CTPP) journey-to-work data, household income, employment density, and other variables derived from publicly available datasets to identify the travel markets served by proposed rail and project unlinked total daily trips for the system as a whole but does not provide detailed spatial information included in a typical regional 4-step travel demand models. Both regional 4-step models and the ARRF model focus on commute trips as the primary driver of travel behavior.

In 2013, the FTA adopted a simplified method for predicting trips for the purpose of preparing grant applications that predicts transit usage for No-build and Build scenarios, weights transitdependent populations, uses predicted change in VMT as a measure of environmental benefit of a proposal (68). This model also depends on worker-flow (commute) data, but also attempts to account for non-work trip patterns based on transit trip attractions in a given transportation analysis zone (TAZ). However, it does not account for trips in special travel markets, e.g., college students, air passengers, or other types of special market travel which may significantly impact ridership. The model is calibrated against a set of existing fixed-guideway light rail and commuter rail transit systems and was intended to be utilized in the development of New Starts and Small Starts grant applications. As a corridor that has the potential to serve a commuter rail function, this may be an appropriate tool for revisiting and updating previously developed ridership estimates. However, the special-market characteristics of the corridor must also be taken into consideration. The results of this study illuminate the degree to which non-work trips are likely to impact ridership.

\subsection{Survey Results}

This section summarizes findings from the primary data collection activity, which consisted of a web-based, opt-in survey with an embedded discrete-choice experiment (DCE) to evaluate travel 
behaviors of people who live and/or work within the study corridor. Summary results are presented for the (cleaned) survey sample as a whole. Responses are generally presented unweighted, to avoid inadvertently masking biases inherent in opt-in surveys, where conventional raking and matching methods for weighting samples have been found to reduce bias very little and risk exacerbating these biases if an incorrect set of weighting variables are applied (69). Instead, the data are first framed in the context of the makeup of the respondent pool, and identification of key dimensions in which this survey does not represent a random, representative sample of the study area population.

These results are also broken down to the parish-level in order to assess notable differences amongst sub-areas within the region. Qualitative and open-ended responses are synthesized to identify key themes that emerge. Finally, the results of the DCE are presented, including segmented results evaluating differences across geographic and demographic groups, along with their application in a projected demand model at the census tract level to provide detailed disaggregated information about likely rail service ridership and characteristics of an optimum service design throughout the study region.

\subsubsection{Respondent Pool Statistics}

A total of 4,641 surveys were substantively completed by Louisiana residents, $91.4 \%$ of whom reside in one of the seven parishes in the NO-BR corridor (East Baton Rouge, Ascension, St. James, St. John the Baptist, St. James, Jefferson, and Orleans). The majority of responses were from residents of East Baton Rouge Parish, followed by Orleans Parish (Figure 55). Because Baton Rouge-based responses dominate the overall sample, this section breaks out responses by the six corridor parishes within the study area for which greater than 25 survey responses were completed (thereby excluding St. James Parish). Unless otherwise indicated, all survey responses from Louisiana residents are included in overall statistics, while only responses from residents of NOBR corridor parishes, minus St. James Parish, are reflected in parish-level breakdowns presented.

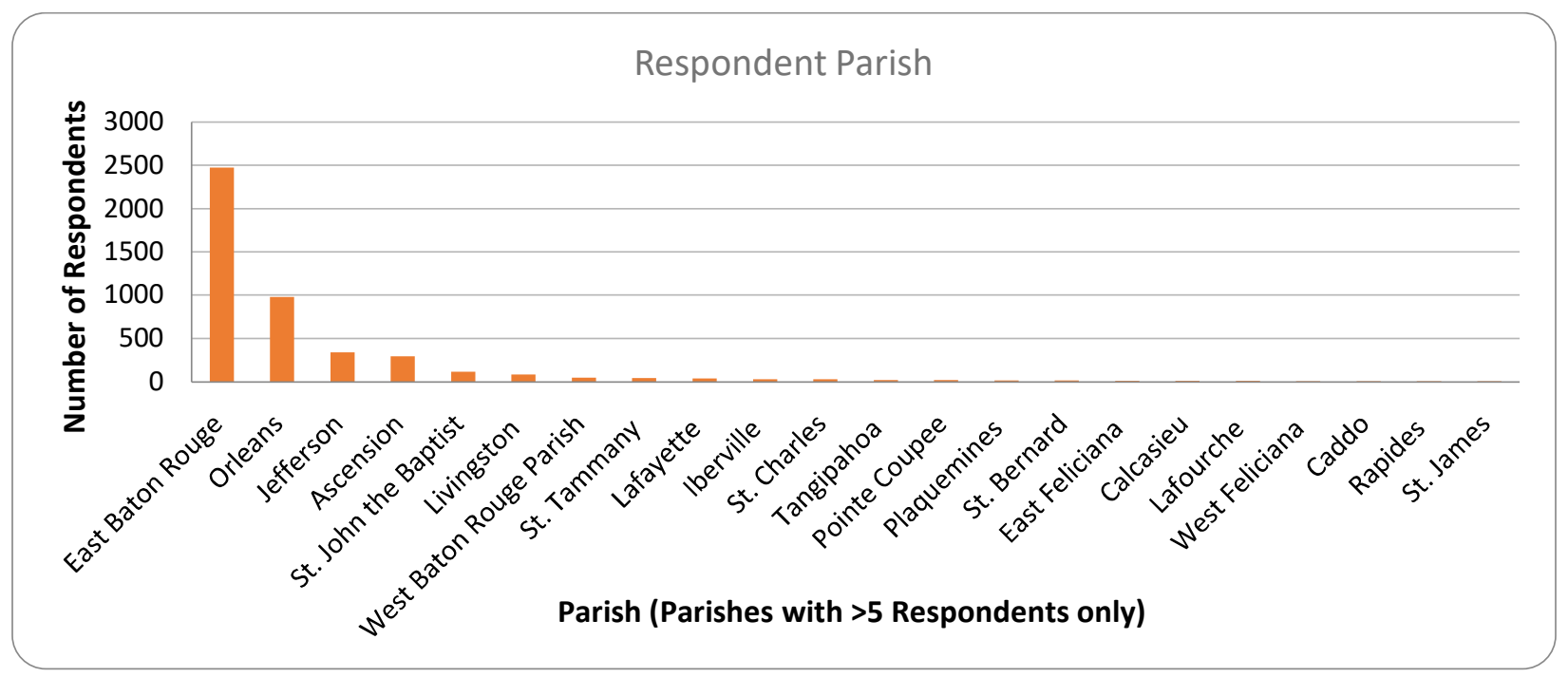

Figure 55. Survey respondent parish of residence.

The majority ( $85 \%$ ) of respondents were employed full-time at the time of the survey (June 2020), with less than $6 \%$ indicating involuntary unemployment, either permanent or as a temporary result 
of COVID-19 (Figure 56). This suggests that Louisianans in more precarious financial circumstances are underrepresented in this survey (as supported by demographic makeup of respondents, discussed below). By contrast, only $60 \%$ of total Louisiana residents 16 years and over were employed as of the 2018 American Community Survey (5-Year estimates), indicating that those outside the labor force are significantly underrepresented by this survey.

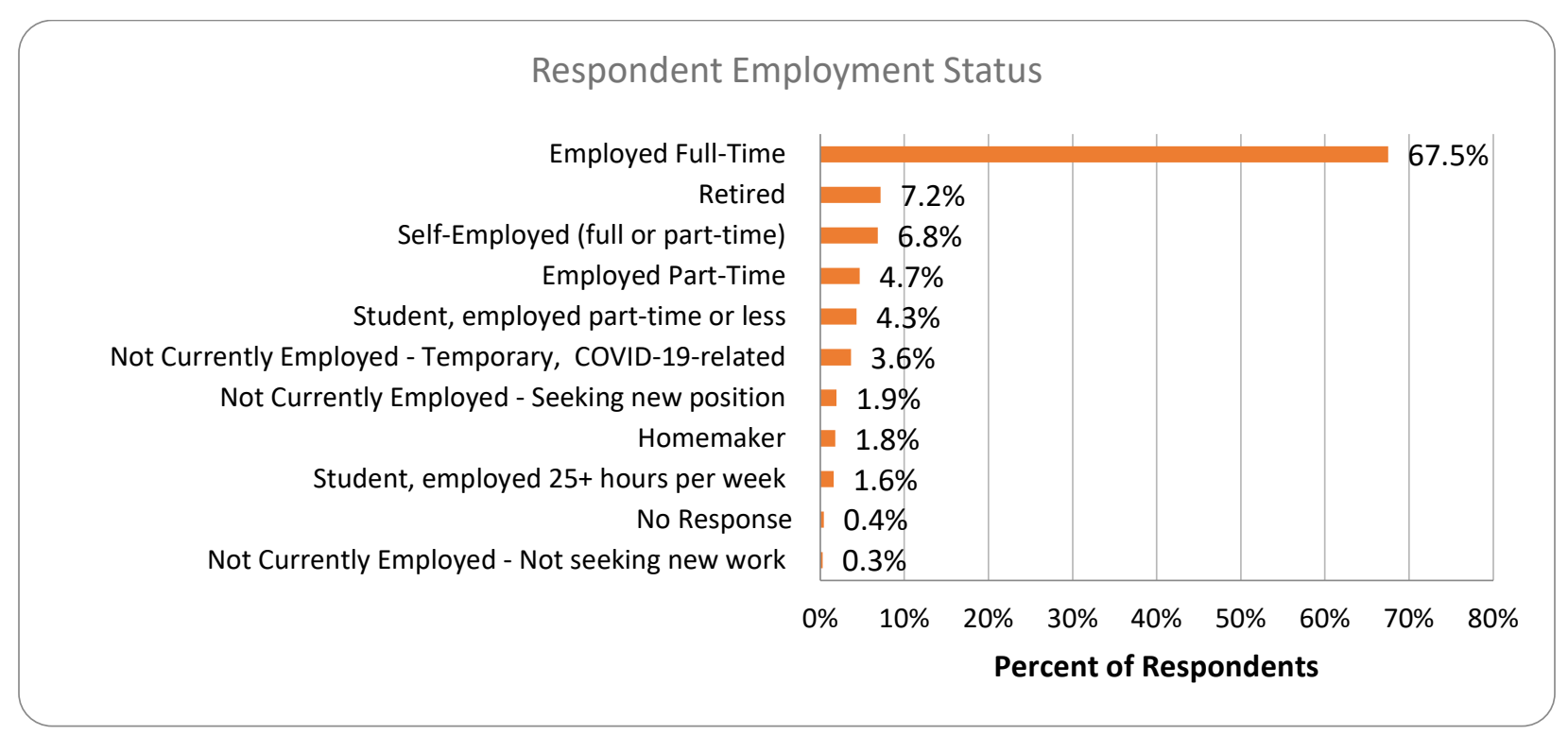

Figure 56. Respondent employment status.

At the parish level (excluding St. James parish, for which the very low number of responses makes response evaluation infeasible), differences emerge in the share of retired respondents (up to $15 \%$ of those residing in St. John Parish), as well those experiencing unemployment due to COVID-19 (highest in Orleans and St. Charles Parishes) (Table 22).

Table 22. Employment status by parish.

\begin{tabular}{|l|l|l|l|l|l|l|}
\hline & Orleans & Jefferson & St. Charles & St. John & Ascension & EBR \\
\hline Employed Full-Time & $68.6 \%$ & $66.6 \%$ & $67.9 \%$ & $66.4 \%$ & $66.3 \%$ & $68.4 \%$ \\
\hline Retired & $3.6 \%$ & $5.0 \%$ & $3.6 \%$ & $15.1 \%$ & $8.2 \%$ & $7.5 \%$ \\
\hline & & & & & & \\
Self-Employed (full or part-time) & $8.9 \%$ & $7.3 \%$ & $3.6 \%$ & $3.4 \%$ & $7.1 \%$ & $6.1 \%$ \\
\hline Employed Part-Time & $3.2 \%$ & $5.0 \%$ & $3.6 \%$ & $2.5 \%$ & $5.8 \%$ & $5.3 \%$ \\
\hline Student, employed part-time or less & $4.9 \%$ & $7.9 \%$ & $7.1 \%$ & $4.2 \%$ & $2.0 \%$ & $4.0 \%$ \\
\hline $\begin{array}{l}\text { Not Currently Employed - Temporary, } \\
\text { COVID-19-related }\end{array}$ & $6.1 \%$ & $3.8 \%$ & $7.1 \%$ & $2.5 \%$ & $3.1 \%$ & $2.7 \%$ \\
\hline $\begin{array}{l}\text { Not Currently Employed - Seeking new } \\
\text { position }\end{array}$ & $2.2 \%$ & $1.5 \%$ & $0.0 \%$ & $0.8 \%$ & $1.4 \%$ & $1.8 \%$ \\
\hline Homemaker & $0.5 \%$ & $0.9 \%$ & $0.0 \%$ & $3.4 \%$ & $4.8 \%$ & $2.0 \%$ \\
\hline Student, employed 25+ hours per week & $1.2 \%$ & $1.2 \%$ & $3.6 \%$ & $0.8 \%$ & $0.7 \%$ & $1.9 \%$ \\
\hline No Response & $0.6 \%$ & $0.3 \%$ & $3.6 \%$ & $0.0 \%$ & $0.0 \%$ & $0.3 \%$ \\
\hline $\begin{array}{l}\text { Not Currently Employed - Not seeking } \\
\text { new work }\end{array}$ & $0.2 \%$ & $0.6 \%$ & $0.0 \%$ & $0.8 \%$ & $0.7 \%$ & $0.2 \%$ \\
\hline
\end{tabular}


The respondent pool skewed slightly female (Figure 57 ), at $54 \%$, compared to $51 \%$ of the state as a whole (2014-2018 ACS 5-year Estimates). Respondents in Ascension, East Baton Rouge, and St. Charles Parishes in particular were overrepresented by women (Figure 58). These disparities are not believed to be substantial enough to have a significant impact on results.

\section{Gender distribution of Respondents}

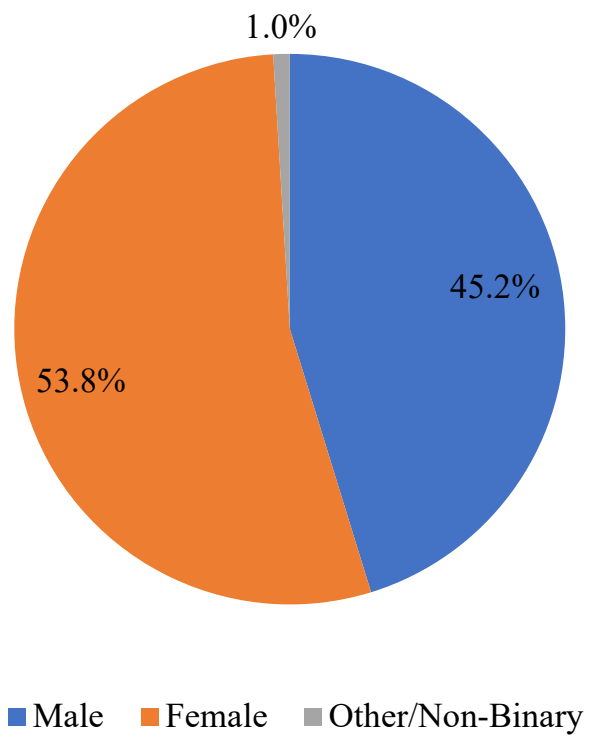

Figure 57. Gender distribution of survey respondents.

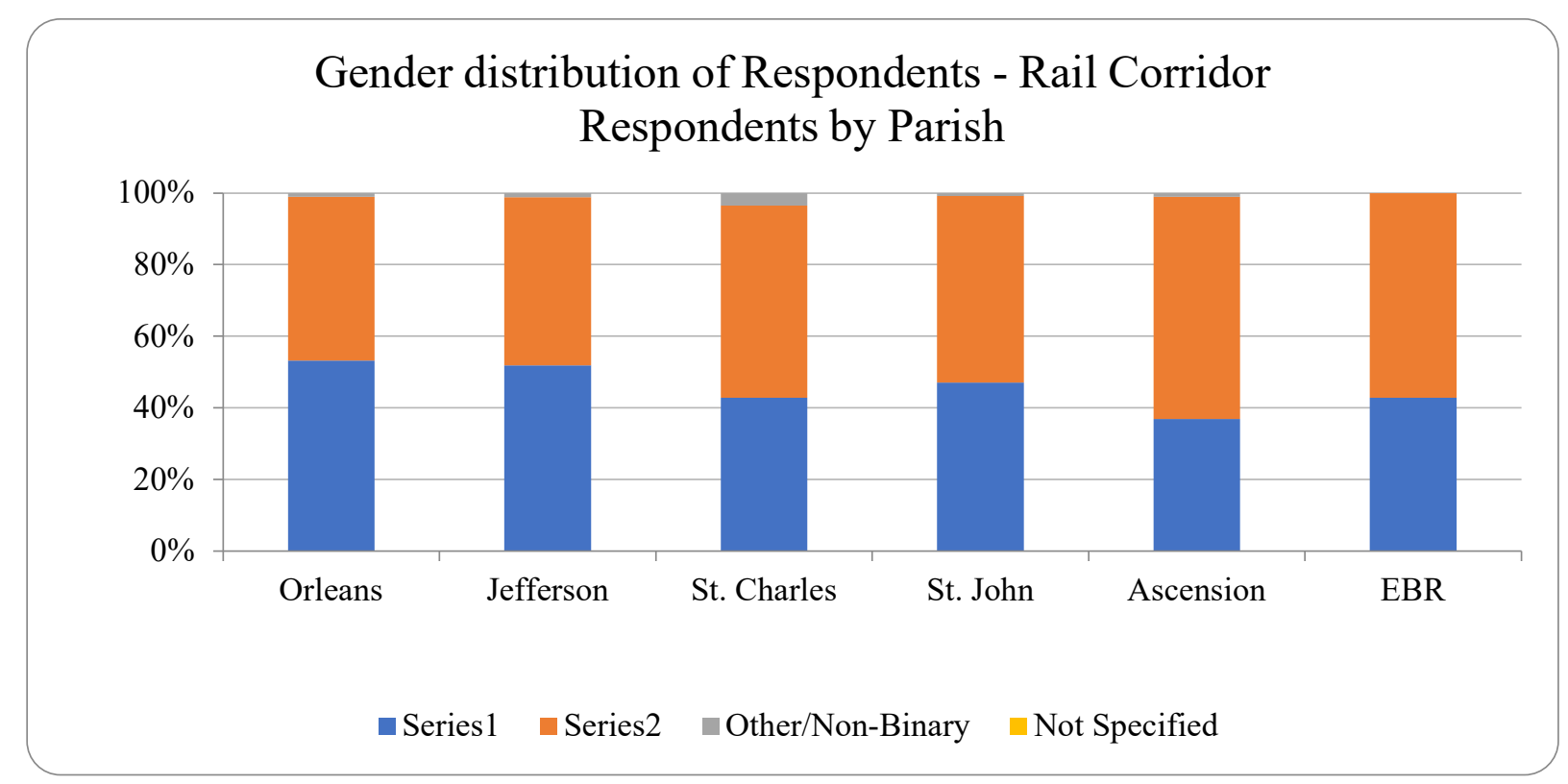

Figure 58. Gender distribution of survey respondents by parish.

The survey instrument did not target children or teenagers; thus, the sample underrepresents these groups relative to the state distribution (Figure 59). In addition, younger adults (25-44) are 
overrepresented relative to the population, while older adults $(65+)$ are underrepresented; unsurprising given the online distribution format. The impact of the sample distribution on overall findings has not been specifically assessed; however previous research suggests that younger demographic groups tend to be more open to alternative modes of transportation including bicycling, walking, and transit.

Respondents in Orleans and Jefferson Parishes, in particular, were more likely to be 44 years old or younger (Figure 60).

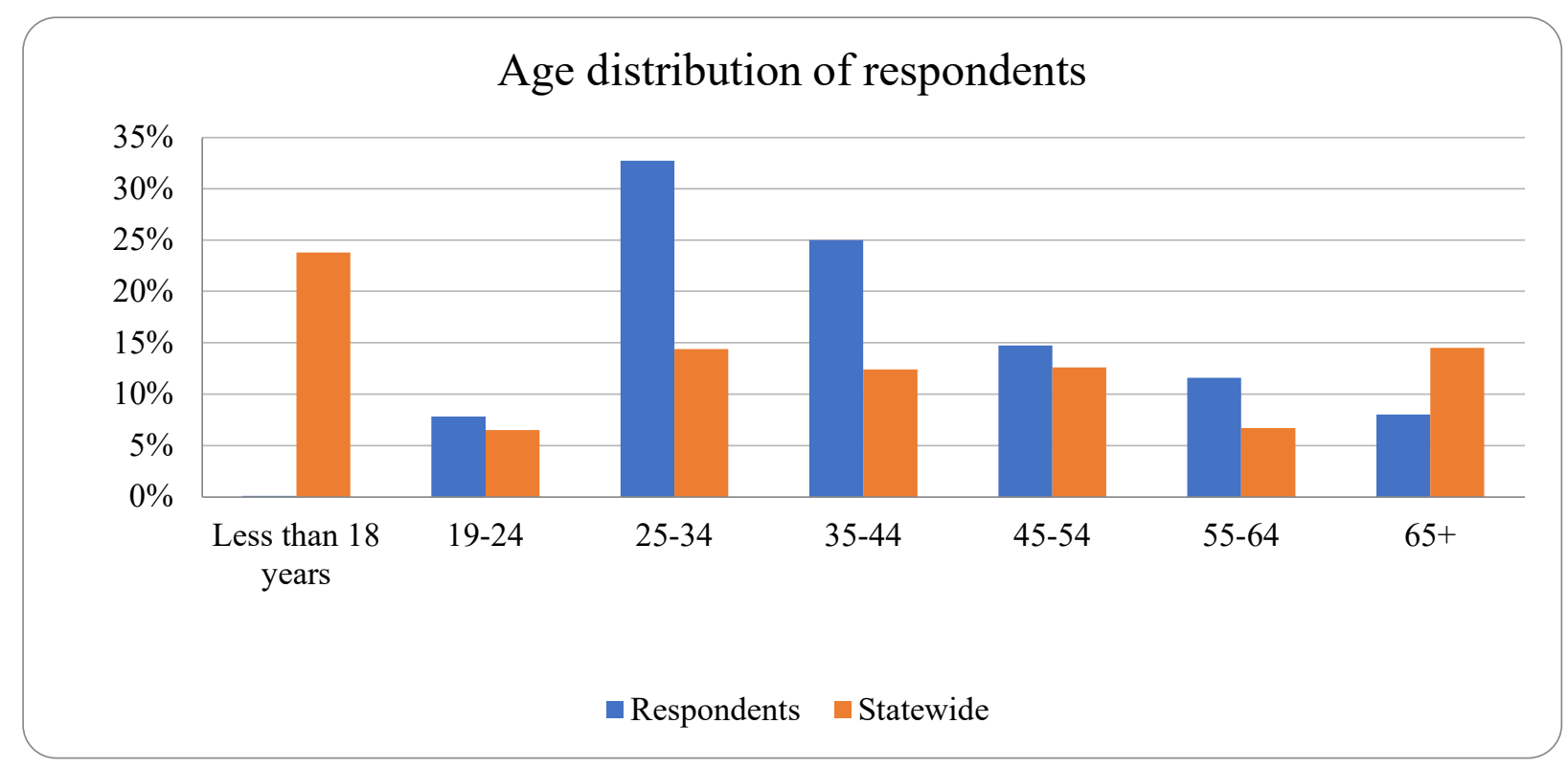

Figure 59. Age distribution of survey respondents.

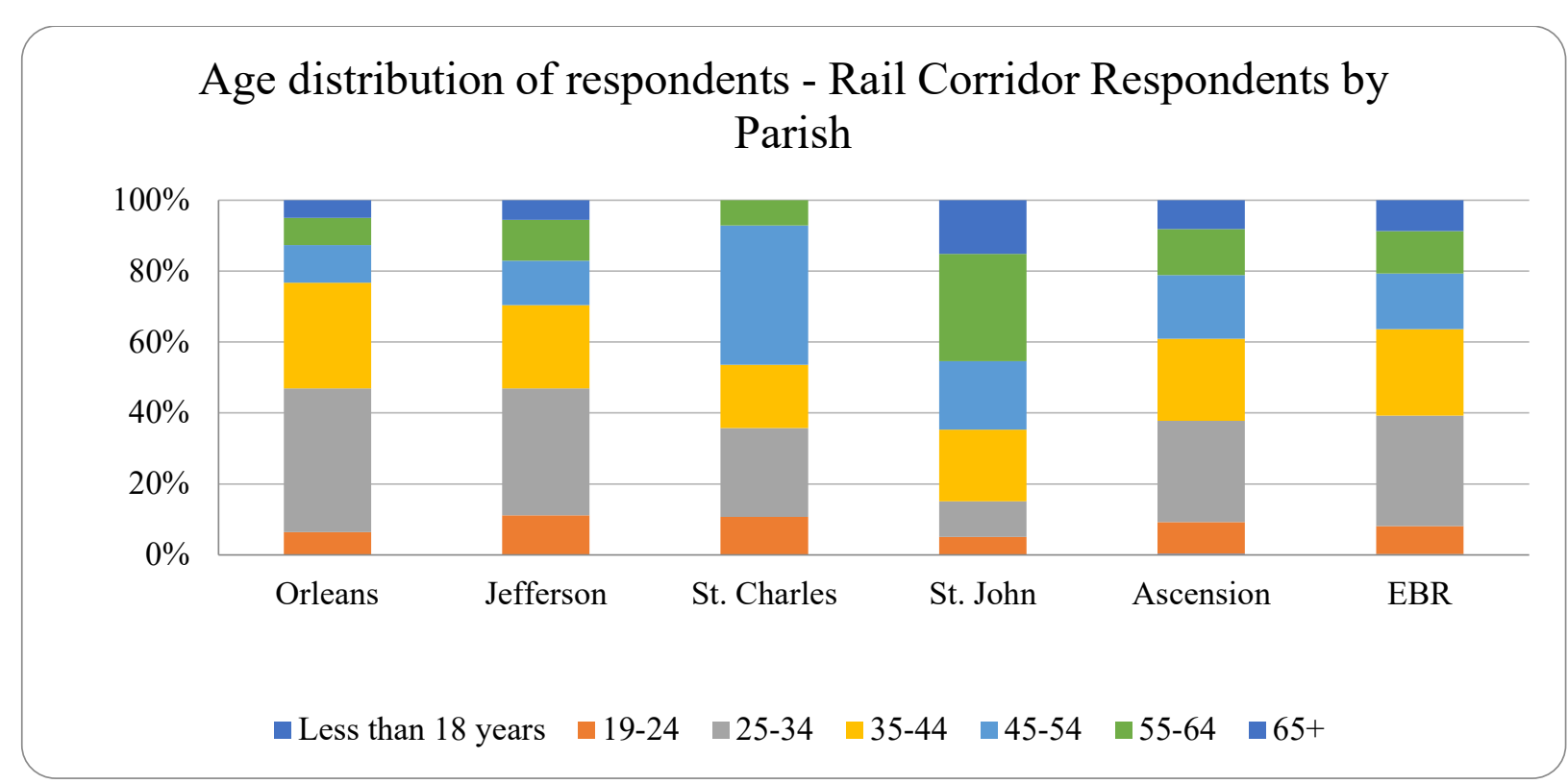

Figure 60. Age distribution of survey respondents by parish. 
Respondents identifying as white are overrepresented in the overall sample, and respondents identifying as Black are significantly underrepresented, making up less than $10 \%$ of the overall sample, but over $30 \%$ of the state's population. This data gap exists in each parish (Figure 61), but is particularly problematic for Orleans and East Baton Rouge Parishes (Figure 62), in which more than half of the population is Black, and suggest a limitation of the data's findings in holistically evaluating the opinions, travel behaviors, and preferences of the populations of these urban areas. See Section 5.6.6 for additional analysis of how segments of the respondent pool broken out by race differ from the analysis of the aggregated survey responses.

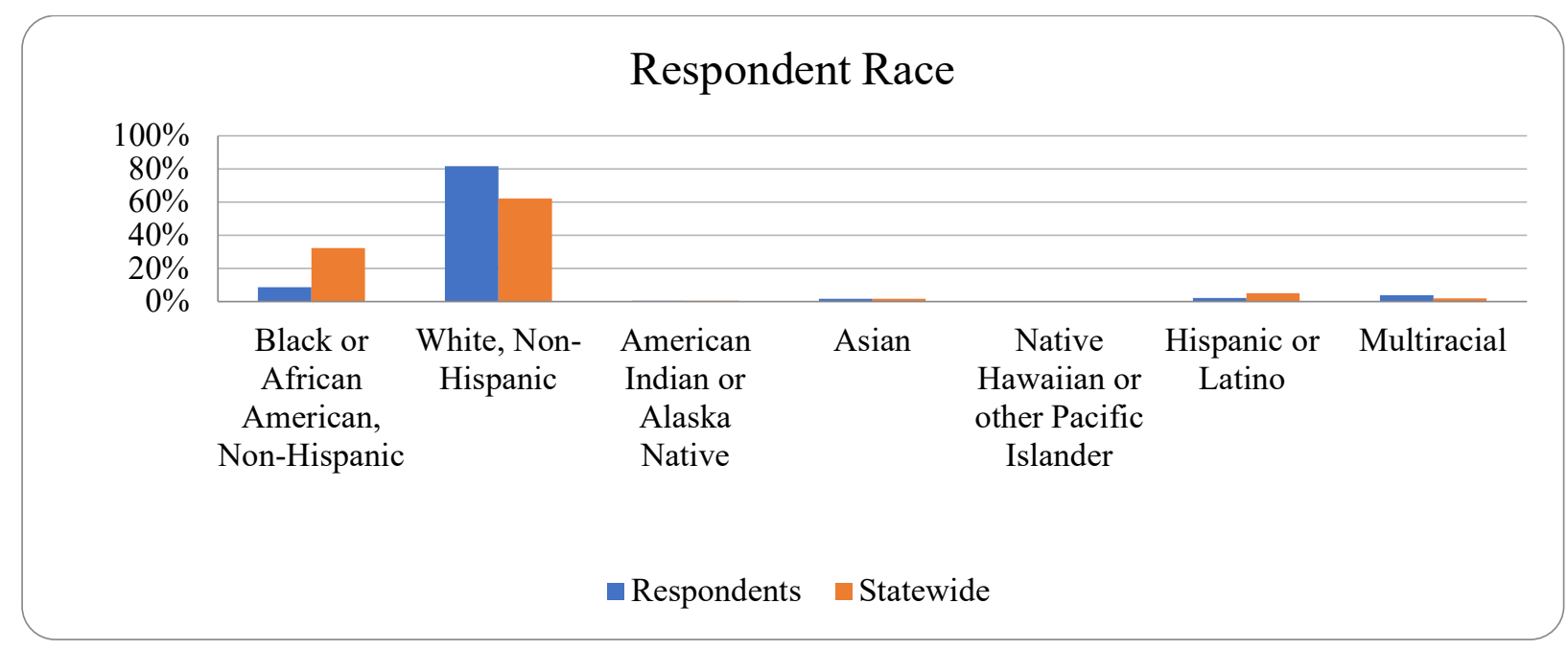

Figure 61. Survey respondent race distribution.

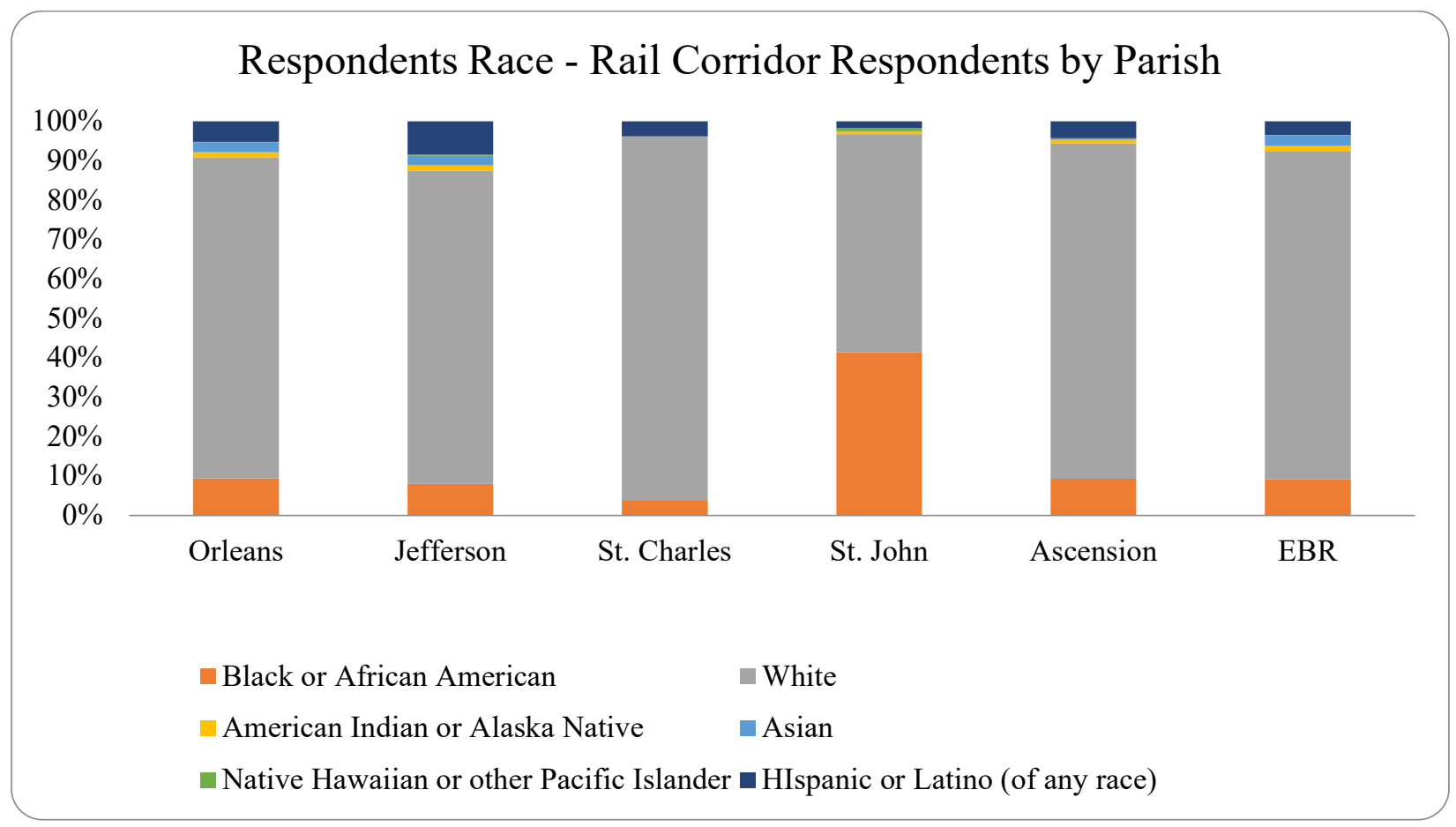

Figure 62. Survey respondent race distribution by parish. 
The incomes of survey respondents (Figures $63 \& 64$ ) distinctly reflect a more affluent group than the state as a whole, with relatively few responses at the lower end of the income spectrum (13\% with a household income of less than $\$ 35,000$ per year, compared to $39 \%$ of the state as a whole), and an overrepresentation of high-income households $(43 \%$ of respondents making more than $\$ 100,000$ per year, compared to $21 \%$ of households statewide). This, along with racial composition of the sample pool, suggests an important caveat to findings, indicating, among other things, that those most likely to use local and regional transit services currently are underrepresented. Disparities in survey outcomes based on race and income are discussed further in Section 5.6.6.

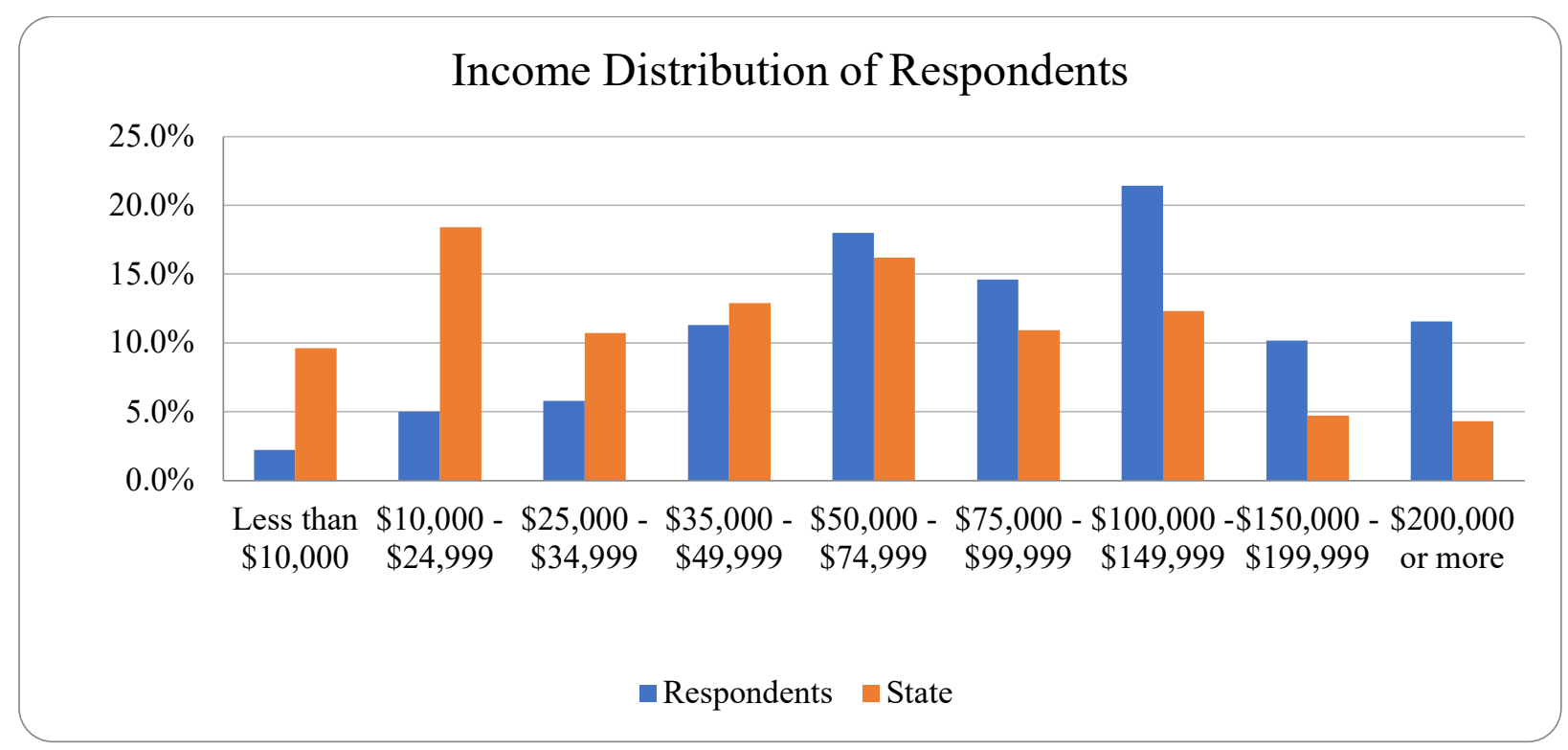

Figure 63. Income distribution of survey respondents.

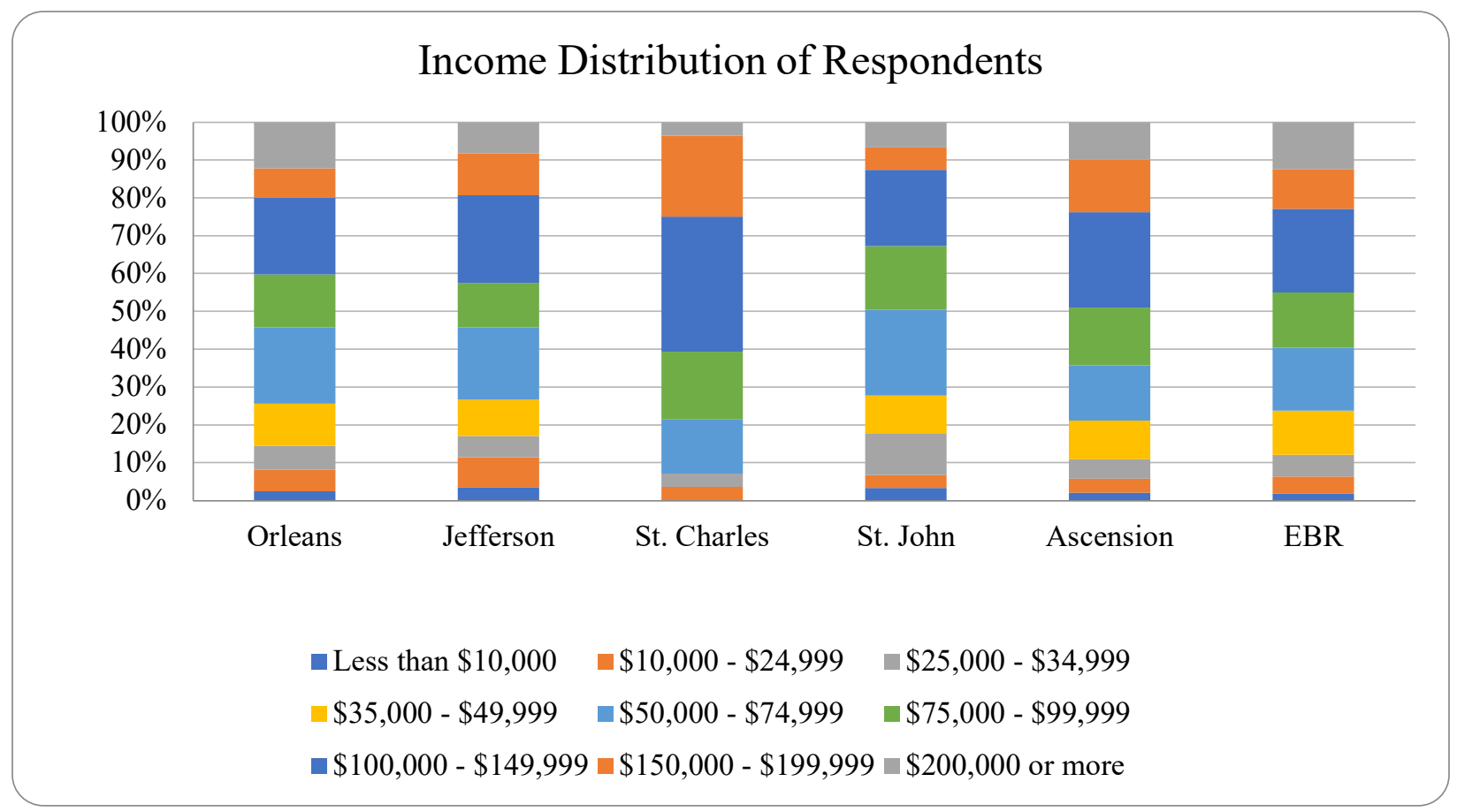

Figure 64. Income distribution of survey respondents by parish. 


\subsubsection{Travel Behaviors}

Among respondents who are employed, $87 \%$ indicated that during typical (i.e., pre-COVID) conditions, they commute to a fixed workplace outside of the home, with $8 \%$ working from home ordinarily and 5\% with variable work locations (Figure 65).

\section{Usual Work Location}

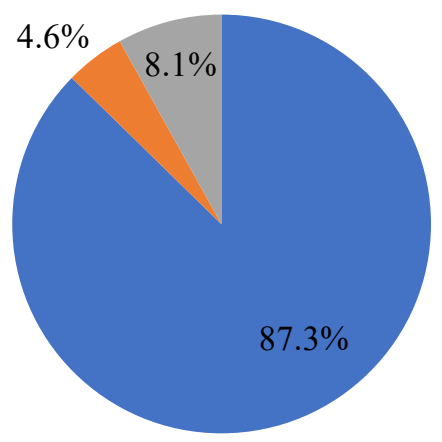

- Fixed location, outside of home Variable location, outside of home

Normally work from home

Figure 65. Survey respondent usual work location.

At the parish level, these trends are relatively consistent, with a higher percent of people who normally work from home (Pre-COVID) in St. Charles Parish and a slightly larger proportion of respondents with variable work locations (including many gig-economy workers) in New Orleans and Ascension Parish (Table 23).

Table 23. Survey respondent usual work location by parish.

\begin{tabular}{|l|l|l|l|l|l|l|}
\hline & Orleans & Jefferson & $\begin{array}{l}\text { St. } \\
\text { Charles }\end{array}$ & St. John & Ascension & EBR \\
\hline Fixed location, outside of home & $82 \%$ & $82 \%$ & $81 \%$ & $71 \%$ & $74 \%$ & $79 \%$ \\
\hline Variable location, outside of home & $6 \%$ & $4 \%$ & $4 \%$ & $3 \%$ & $6 \%$ & $3 \%$ \\
\hline Normally work from home & $8 \%$ & $8 \%$ & $11 \%$ & $7 \%$ & $6 \%$ & $8 \%$ \\
\hline n/a - Retired or Unemployed & $4 \%$ & $6 \%$ & $4 \%$ & $19 \%$ & $14 \%$ & $10 \%$ \\
\hline
\end{tabular}

A total of 264 respondents indicated that they are either full or part-time students, with LSU representing nearly half of those (including main campus in Baton Rouge as well as the LSU Health Sciences Center in New Orleans and other satellite campuses). Tulane University, UNO, and Delgado and Baton Rouge Community Colleges also were strongly represented among the sample.

The overwhelming majority of respondents indicated that they have access to a personal vehicle, again indicating potential underrepresentation of lower-income residents in some areas (Figure 66). 


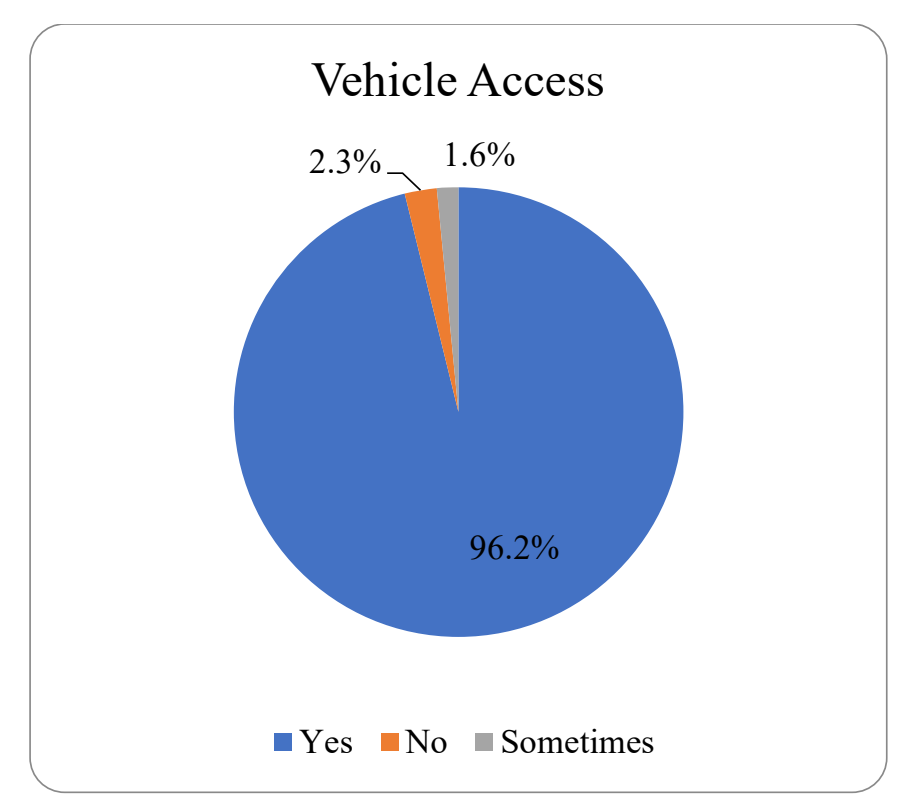

Figure 66. Survey respondent household vehicle access.

Notably, most residents who indicated lack of consistent vehicle access reside in Orleans Parish (nearly $9 \%$ of respondents) consistent with ACS findings that over 17\% of households lack access to a vehicle, but again indicating a sample bias toward better-resourced residents within the region (Table 24).

Table 24. Survey respondent household vehicle access by parish.

\begin{tabular}{|l|l|l|l|l|l|l|}
\hline & Orleans & Jefferson & $\begin{array}{l}\text { St. } \\
\text { Charles }\end{array}$ & St. John & Ascension & EBR \\
\hline Yes & $91.4 \%$ & $96.5 \%$ & $96.3 \%$ & $99.2 \%$ & $99.7 \%$ & $96.9 \%$ \\
\hline No & $5.4 \%$ & $1.2 \%$ & $3.7 \%$ & $0.0 \%$ & $0.0 \%$ & $1.9 \%$ \\
\hline Sometimes & $3.2 \%$ & $2.4 \%$ & $0.0 \%$ & $0.8 \%$ & $0.3 \%$ & $1.2 \%$ \\
\hline
\end{tabular}

Respondents were asked to indicate any modes of transport they used to commute to work (Figure 67). While the vast majority of survey respondents drive alone for all or some of their commute trips, a substantial share also incorporates active modes of transport (bicycling, walking, and/or public transit) into their commute activities at least some of the time, compared to only $5 \%$ of state residents estimated by the American Community Survey to commute via modes other than driving. Notably, the American Community Survey only permits respondents to indicate the mode of transport used most often, which may result in mode share figures that underrepresent active modes. About $11 \%$ of respondents indicate that they work from home, at least on occasion. 


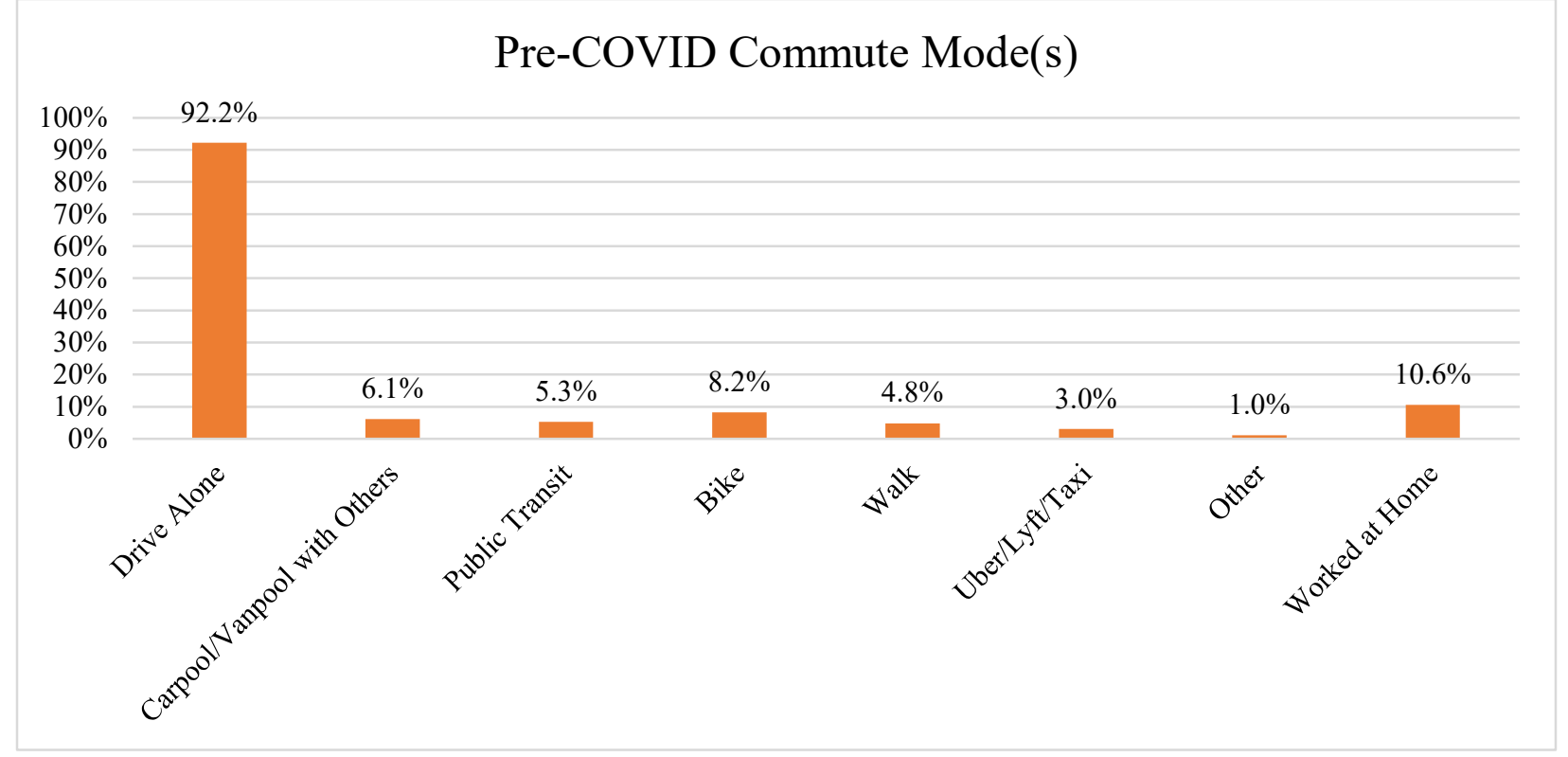

Figure 67. Survey respondent Pre-COVID commute mode(s).

At the parish level, Orleans Parish stands out for having the most diverse transportation options, with over $20 \%$ of respondents indicating that they bike to work some or all of the time, and nearly $14 \%$ indicating that they use public transit (Table 25). The rest of the region reflects a much stronger auto-orientation, with $89-96 \%$ of respondents indicating that they drive alone, with carpooling and bicycling claiming a minority share of work trips. Notably, only $3.1 \%$ of Baton Rouge respondents indicated that they use transit to commute, again indicating a skew in the sample toward more affluent respondents, as well as possibly reflecting perceived deficiencies in the existing transit network.

Table 25. Survey respondent pre-COVID commute mode(s) by parish.

\begin{tabular}{|c|c|c|c|c|c|c|}
\hline & $\begin{array}{l}\text { Orleans } \\
\text { Parish } \\
\end{array}$ & $\begin{array}{l}\text { Jefferson } \\
\text { Parish } \\
\end{array}$ & $\begin{array}{l}\text { St. Charles } \\
\text { Parish }\end{array}$ & St. John Parish & $\begin{array}{l}\text { Ascension } \\
\text { Parish } \\
\end{array}$ & $\begin{array}{l}\text { East Baton } \\
\text { Rouge Parish }\end{array}$ \\
\hline Drive Alone & $78.8 \%$ & $88.8 \%$ & $96.0 \%$ & $95.3 \%$ & $94.8 \%$ & $89.9 \%$ \\
\hline Carpool/Vanpool with Others & $7.2 \%$ & $7.0 \%$ & $4.0 \%$ & $0.9 \%$ & $2.2 \%$ & $5.5 \%$ \\
\hline Public Transit & $13.8 \%$ & $4.0 \%$ & $0.0 \%$ & $0.0 \%$ & $0.7 \%$ & $3.1 \%$ \\
\hline Bike & $20.1 \%$ & $1.8 \%$ & $4.0 \%$ & $3.7 \%$ & $0.0 \%$ & $5.5 \%$ \\
\hline Walk & $9.9 \%$ & $2.1 \%$ & $0.0 \%$ & $0.9 \%$ & $0.0 \%$ & $3.5 \%$ \\
\hline Uber/Lyft/Taxi & $6.9 \%$ & $1.5 \%$ & $0.0 \%$ & $0.0 \%$ & $0.4 \%$ & $2.2 \%$ \\
\hline Other & $1.8 \%$ & $0.9 \%$ & $0.0 \%$ & $0.0 \%$ & $0.7 \%$ & $0.8 \%$ \\
\hline Worked at Home & $13.7 \%$ & $10.6 \%$ & $12.0 \%$ & $7.5 \%$ & $7.0 \%$ & $9.6 \%$ \\
\hline
\end{tabular}


Respondents were asked to identify how frequently they travel within the study corridor (Figure 68). Overall, over half of respondents indicated that they travel outside of their home parish to another destination within the study area at least a few times per month, with nearly $1 / 4$ making trips weekly or more frequently.

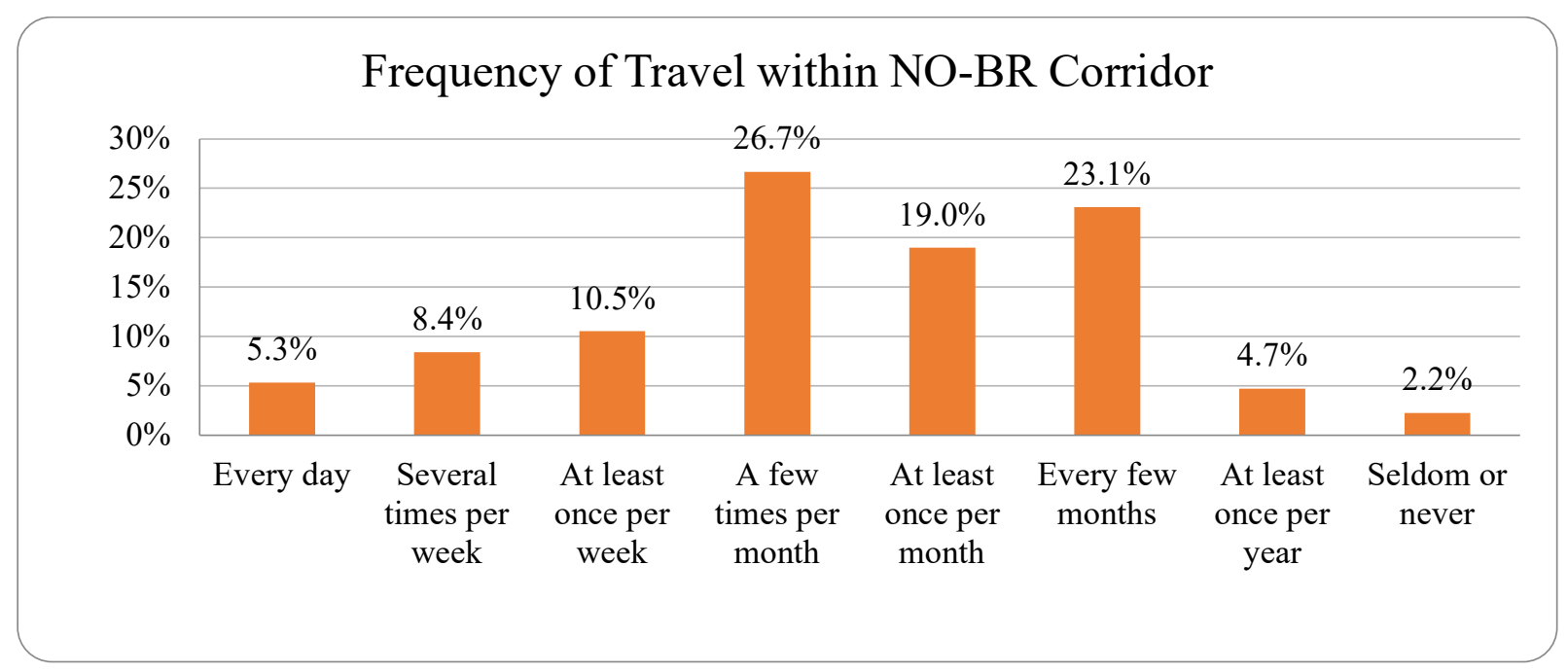

Figure 68. Survey respondent frequency of travel within New Orleans - Baton Rouge corridor.

At the parish level, it becomes clear that while many residents of New Orleans and Baton Rouge tend to stay close to home, with only about $20 \%$ of respondents traveling within the proposed service corridor once a week or more, the residents of intermediate locations tend to travel outside their home parish frequently, led by St. John parish with over $60 \%$ of respondents indicating travel once a week or more (Figure 69).

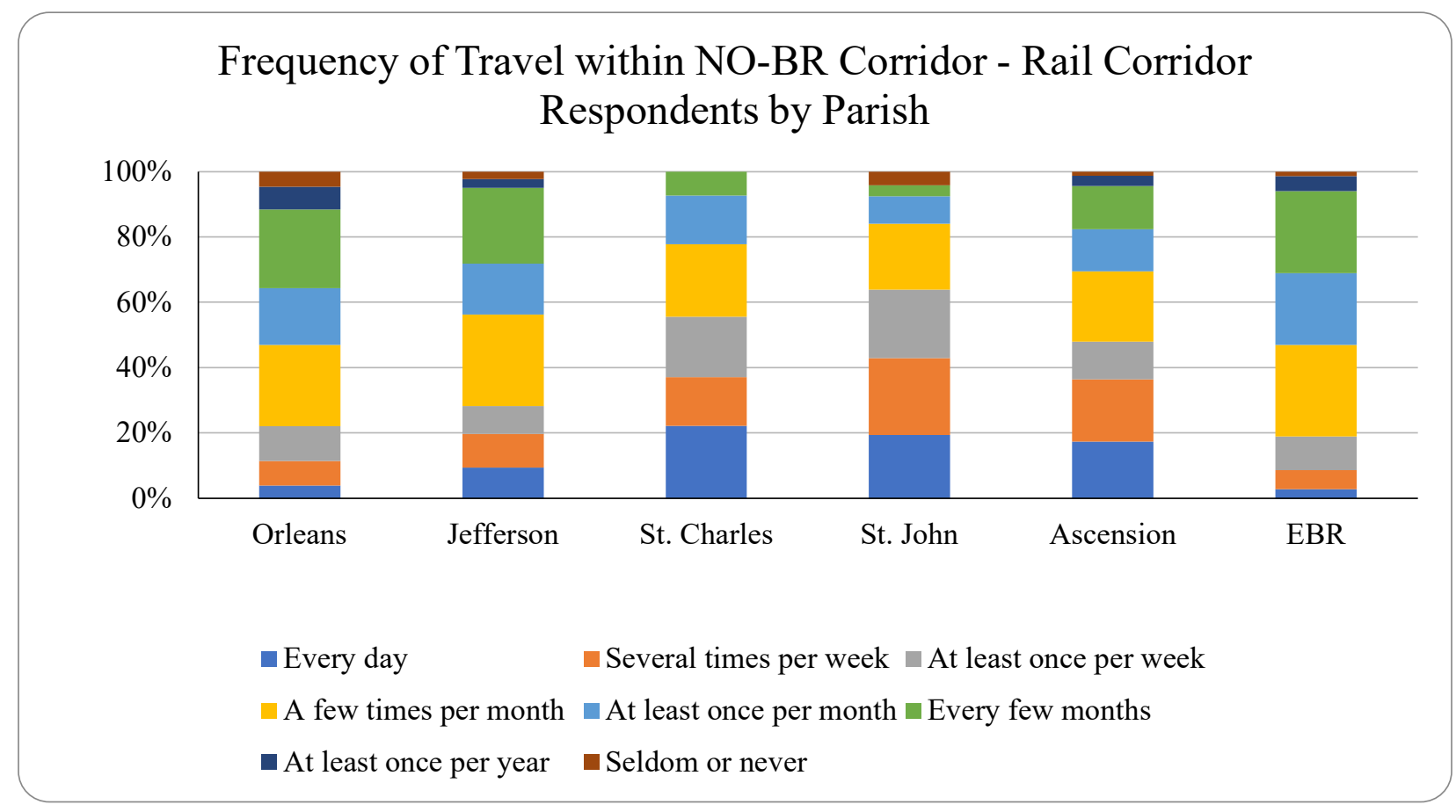

Figure 69. Survey respondent frequency of travel within New Orleans - Baton Rouge corridor by parish. 
Most respondents indicated that they regularly visit multiple parishes within the corridor, with the greatest share indicating travel to the urban centers of New Orleans and Baton Rouge, plus adjacent Jefferson and Ascension parishes, with fewer indicating frequent travel to intermediary stops (Figure 70). Notably, however, this in part reflects the geographic composition and bias of the sample.

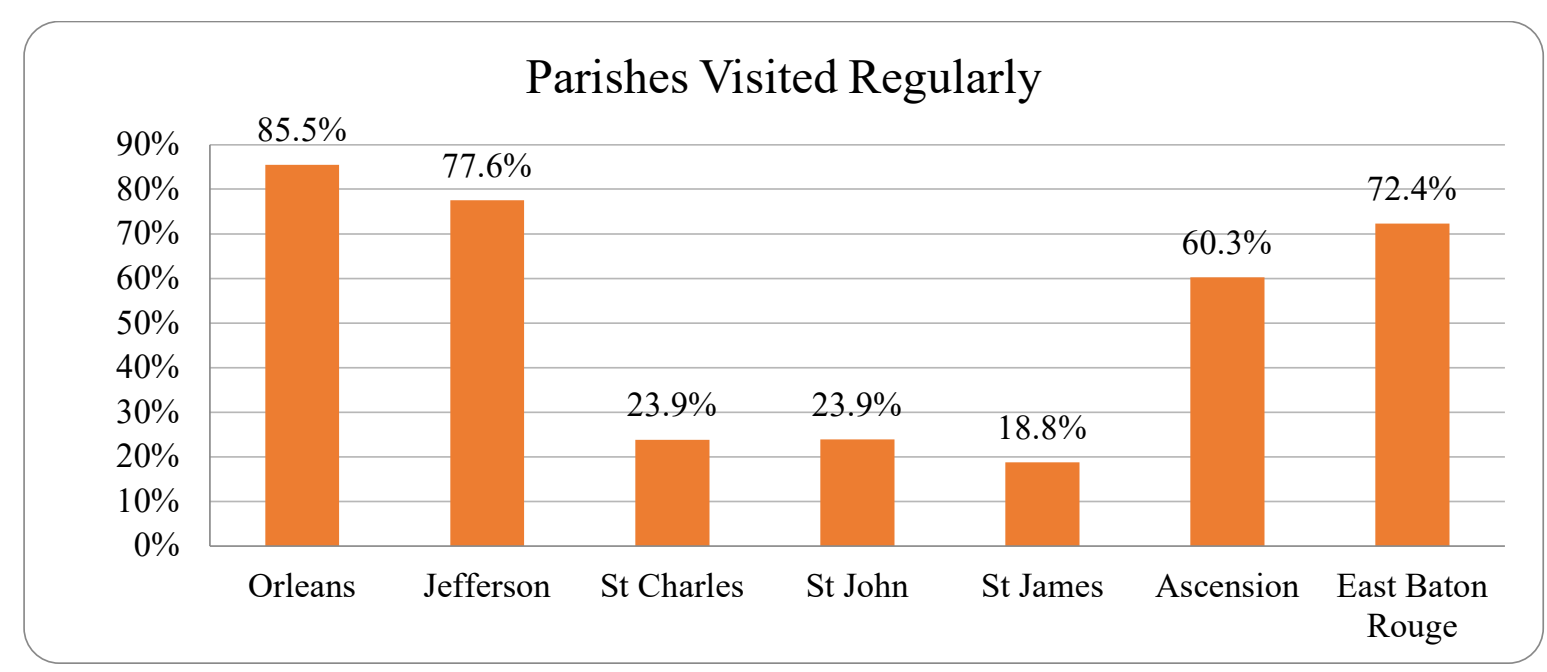

Figure 70. Survey respondent intraregional travel behaviors by parish.

Unsurprisingly, respondents tend to travel most frequently to adjacent parishes. However, as Table 26 indicates, the region's residents travel widely within the corridor, with residents of all parishes traveling to both New Orleans and Baton Rouge regularly, regardless of their residence location. This suggests that, if logistically practical, there could be considerable demand for intermediate stop locations, as well as some degree of unmet demand for transit access to St. Charles and St. James Parishes.

Table 26. Survey respondent intraregional travel behaviors by parish.

\begin{tabular}{|l|l|l|l|l|l|l|}
\hline \multicolumn{7}{|l|}{ Parishes visited regularly within NO-BR Corridor (excluding respondent's own): } \\
\hline & Orleans & Jefferson & St. Charles & St. John & Ascension & EBR \\
\hline Orleans & - & $95.9 \%$ & $88.9 \%$ & $89.1 \%$ & $92.9 \%$ & $96.5 \%$ \\
\hline Jefferson & $92.4 \%$ & - & $92.6 \%$ & $92.4 \%$ & $77.2 \%$ & $73.3 \%$ \\
\hline St Charles & $32.0 \%$ & $48.2 \%$ & - & $77.3 \%$ & $24.5 \%$ & $13.8 \%$ \\
\hline St John & $26.9 \%$ & $45.0 \%$ & $88.9 \%$ & - & $32.0 \%$ & $16.6 \%$ \\
\hline St James & $18.8 \%$ & $20.0 \%$ & $44.4 \%$ & $70.6 \%$ & - & $13.8 \%$ \\
\hline Ascension & $37.9 \%$ & $53.5 \%$ & $74.1 \%$ & $75.6 \%$ & $62.9 \%$ & $68.7 \%$ \\
\hline East Baton Rouge & $87.4 \%$ & $87.1 \%$ & $81.5 \%$ & $73.9 \%$ & $93.2 \%$ & - \\
\hline
\end{tabular}

Critically, only about half of respondents indicated that they travel within the corridor for work trips (Figure 71). A clear majority on the other hand, indicate that they travel to see family or friends, to attend cultural events or activities, or for other recreation or entertainment purposes. This highlights the need and potential of any future intercity transit services to meet the needs of 
non-commute travelers, who are likely to represent a larger share of potential riders than is typically assumed for regional rail travel.

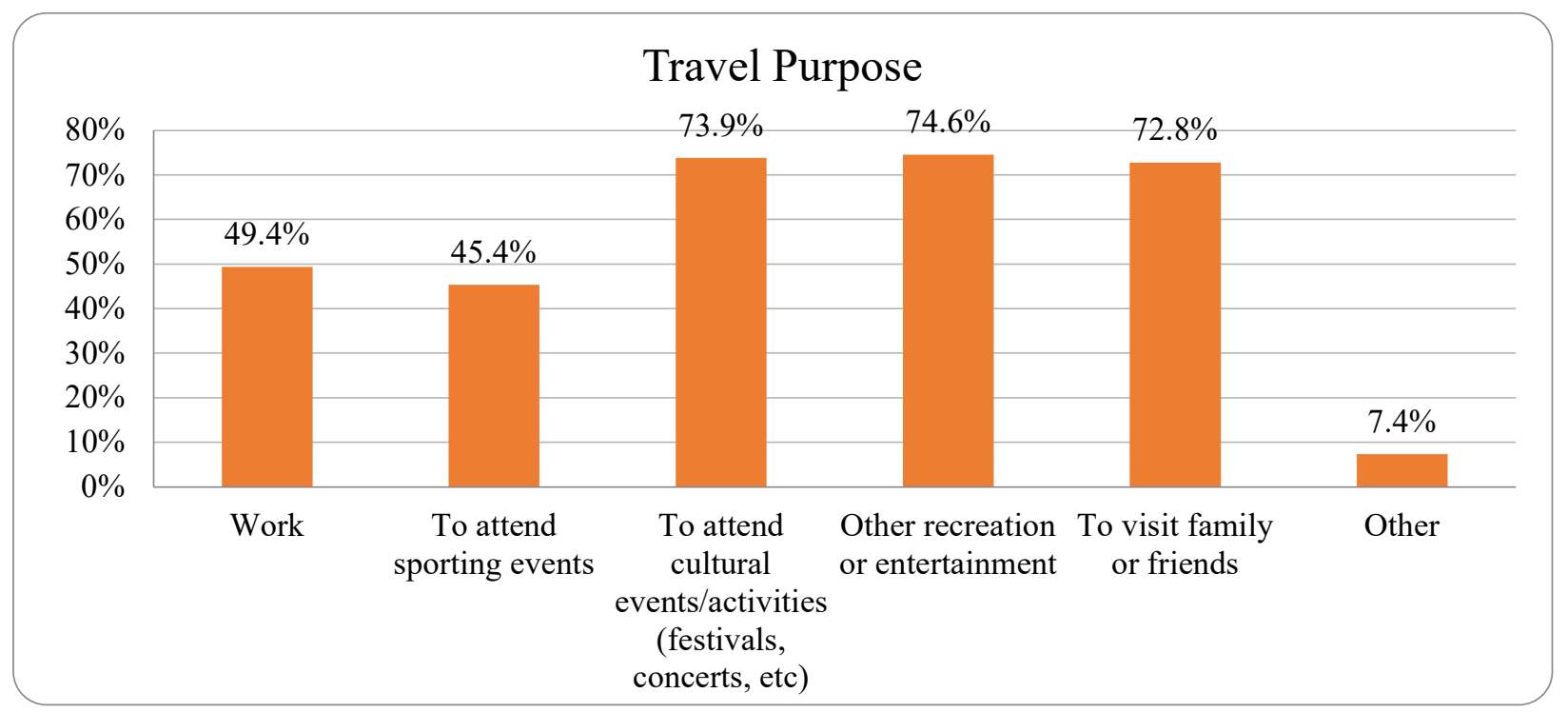

Figure 71. Survey respondent purpose of travel within corridor.

These findings differ somewhat among parishes, with a greater share of St. Charles Parish residents indicating work-related travel, and a smaller share of New Orleanians traveling to sporting events or cultural activities than the rest of the region (Table 27). For all parishes, recreation, entertainment, and/or family and friends make up the dominant drivers of intra-regional travel. Among alternative reasons for travel listed as "other," respondents indicated that education, medical appointments, airport travel, and shopping were the primary additional reasons respondent's cross parish lines.

Table 27. Survey respondent purpose of travel within corridor by parish.

\begin{tabular}{|l|l|l|l|l|l|l|}
\hline & Orleans & Jefferson & St. Charles & St. John & Ascension & EBR \\
\hline Work & $56.3 \%$ & $56.5 \%$ & $66.7 \%$ & $51.3 \%$ & $53.7 \%$ & $44.8 \%$ \\
\hline To attend sporting events & $38.2 \%$ & $47.4 \%$ & $51.9 \%$ & $47.1 \%$ & $58.5 \%$ & $45.8 \%$ \\
\hline $\begin{array}{l}\text { To attend cultural } \\
\text { events/activities (festivals, } \\
\text { concerts, etc) }\end{array}$ & $55.6 \%$ & $60.9 \%$ & $77.8 \%$ & $70.6 \%$ & $82.0 \%$ & $81.8 \%$ \\
\hline $\begin{array}{l}\text { Other recreation } \\
\text { entertainment }\end{array}$ & $58.0 \%$ & $65.3 \%$ & $85.2 \%$ & $75.6 \%$ & $84.4 \%$ & $80.6 \%$ \\
\hline $\begin{array}{l}\text { To visit family or friends } \\
\text { Other }\end{array}$ & $65.6 \%$ & $81.5 \%$ & $85.2 \%$ & $77.3 \%$ & $73.1 \%$ & $74.2 \%$ \\
\hline
\end{tabular}

When traveling within the region, most people currently drive alone, although a notable majority (57\%) also carpool at least some of the time (Figure 72 ). Only a small share of respondents currently uses alternative modes of travel either to or within destinations in the region. 


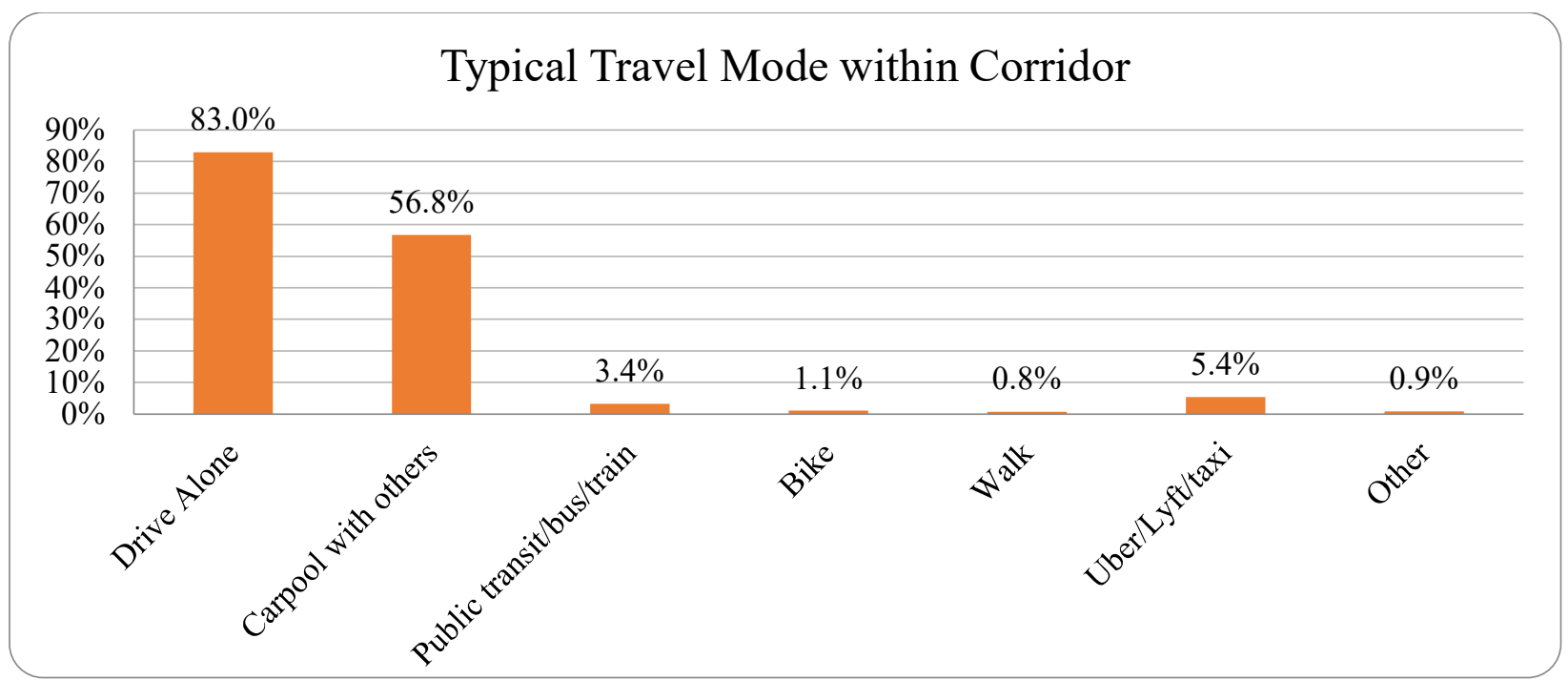

Figure 72. Survey respondent typical travel mode within corridor.

This varies only slightly among parishes, with nearly all trips made by private automobile, either solo or shared (Figure 73). However, in Orleans Parish, a notable minority (7.5\%) take transit either to other destinations within the corridor or upon arrival. Respondents from Jefferson and Ascension parishes, meanwhile, were most likely to indicate the use of taxis or rideshare services to get around when traveling regionally.

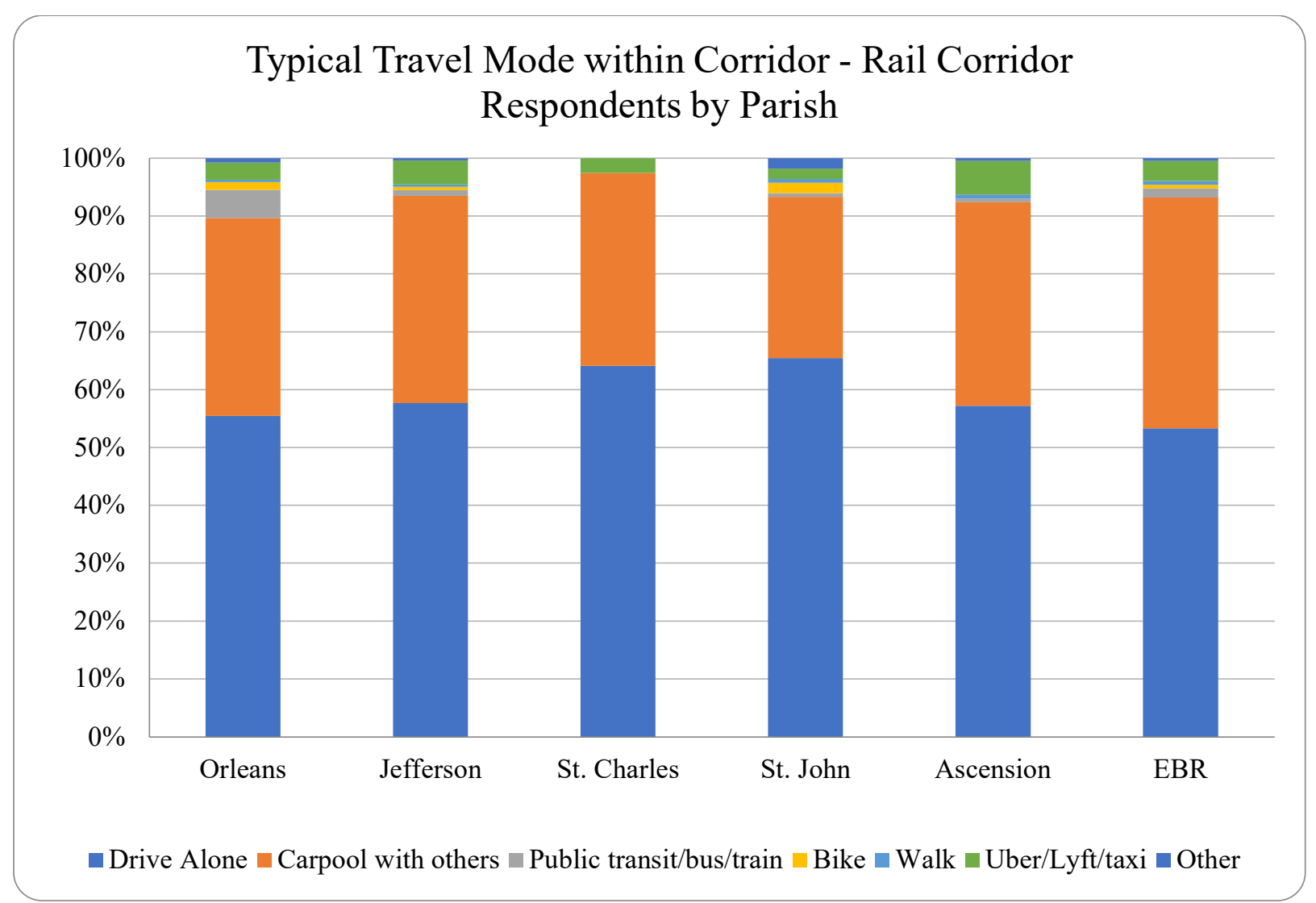

Figure 73. Survey respondent typical travel mode within corridor by parish. 
Most respondents indicate that they tend to travel within the region on weekends, with over half indicating that they typically travel exclusively on weekend days (Figure 74). Again, this has important implications for the potential use and service design of proposed rail service, and reinforces the likelihood that riders would primarily be traveling for non-work trips.

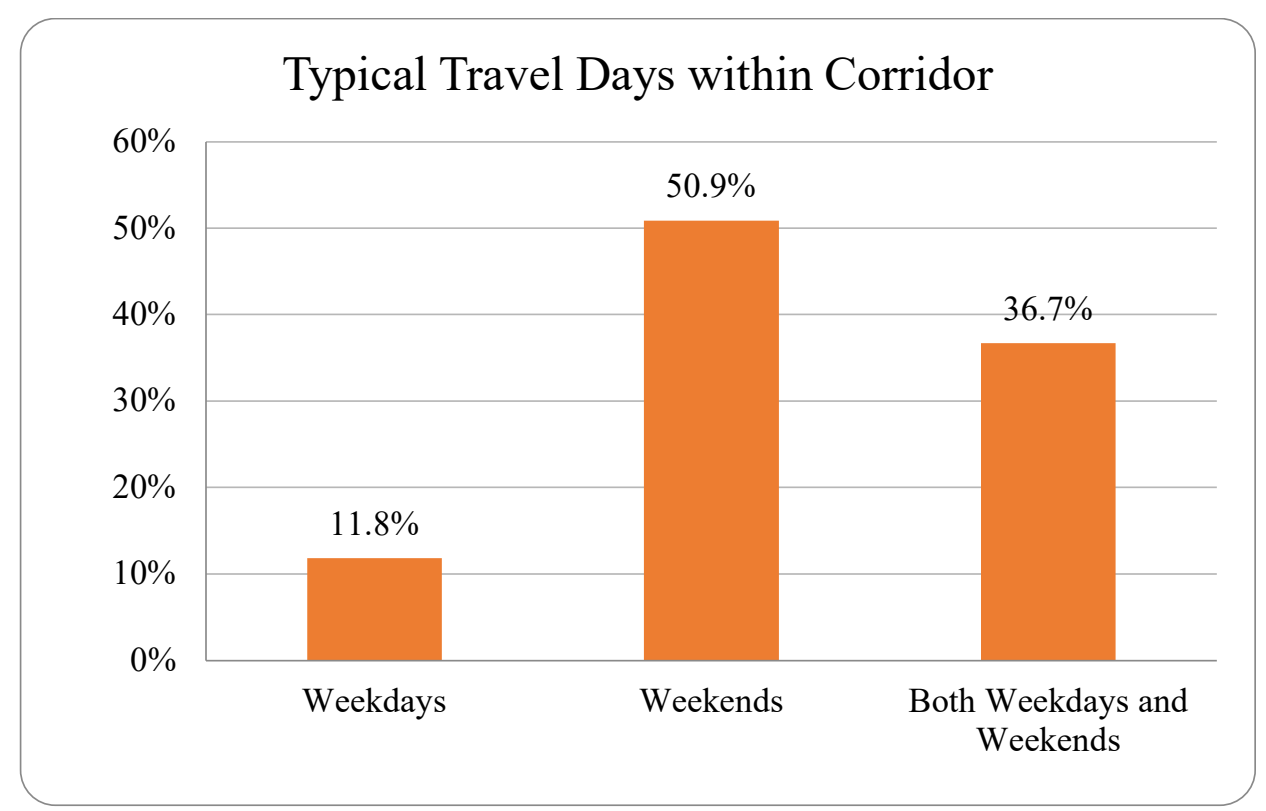

Figure 74. Survey respondent typical travel days within corridor.

This varies slightly by parish, with residents of St. Charles and St. John Parishes less likely to reserve regional travel for the weekend, likely indicating a greater need to access employment, services, or other daily needs outside of their home parish (Figure 75).

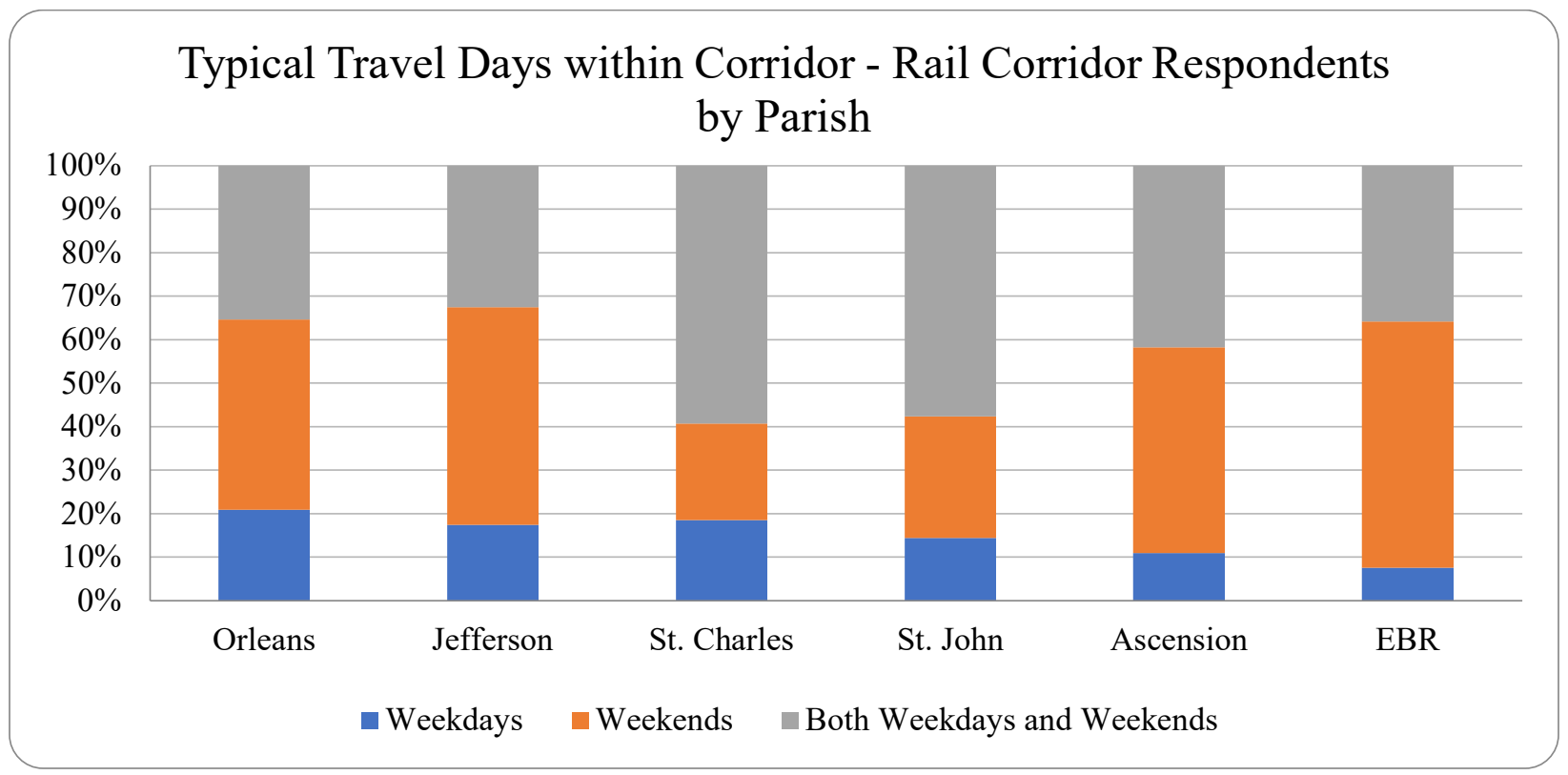

Figure 75. Survey respondent typical travel days within corridor by parish. 
Reported typical travel times align with expectations, with a majority of trips beginning in the morning, and return trips taking place in the evening (Figures $76 \& 77$ ). Depending on anticipated inflows and outflows from each terminus of the proposed route, this may have implications for the timing and spread of service, as demand fluctuates throughout the day. Regional variation is minimal; respondents are most likely to begin travel in the morning, and end travel in the evening, regardless of starting destination. Notably, return travel patterns demonstrate a more pronounced PM "peak," whereas regional trips are more likely to originate throughout the day.

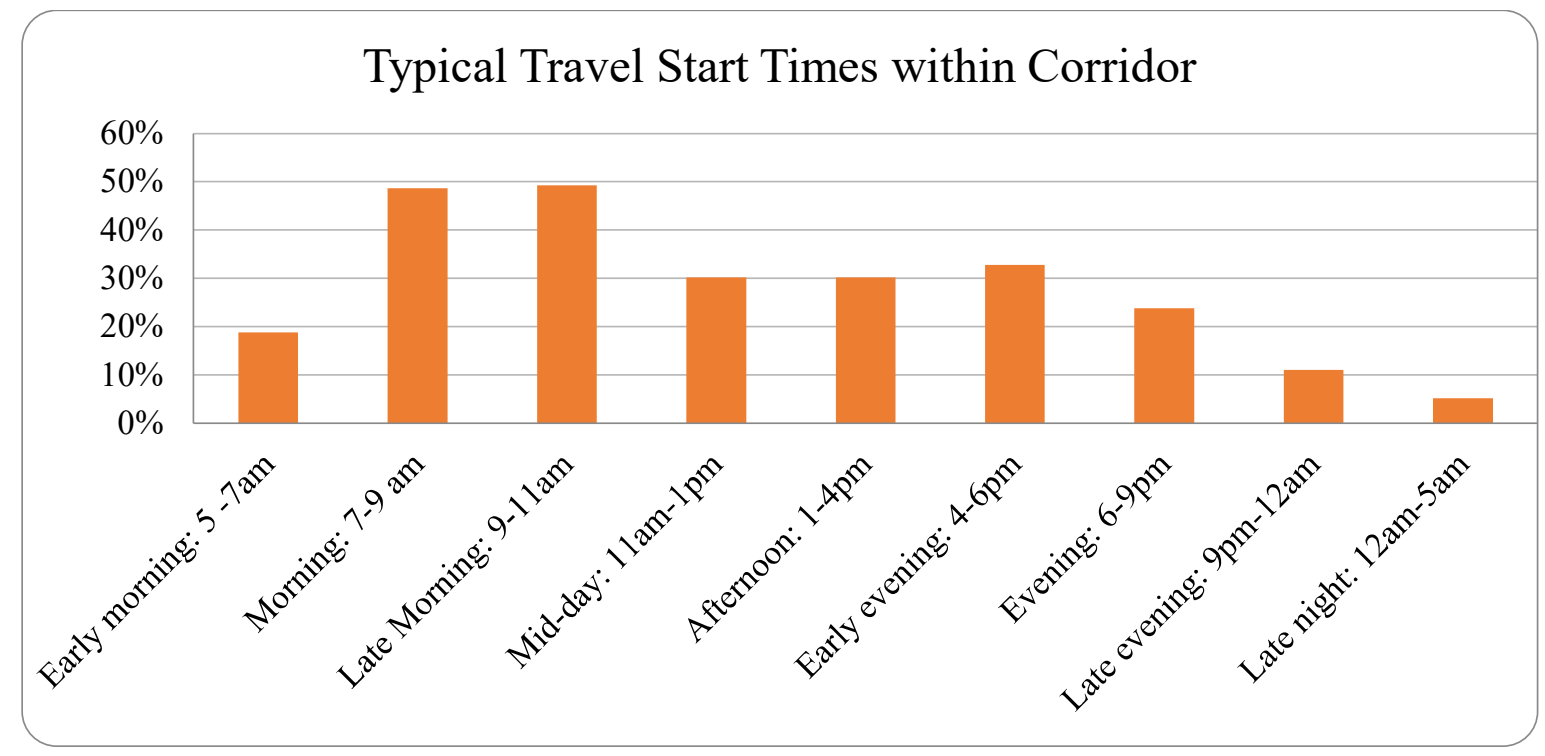

Figure 76. Survey respondent typical travel start times within corridor.

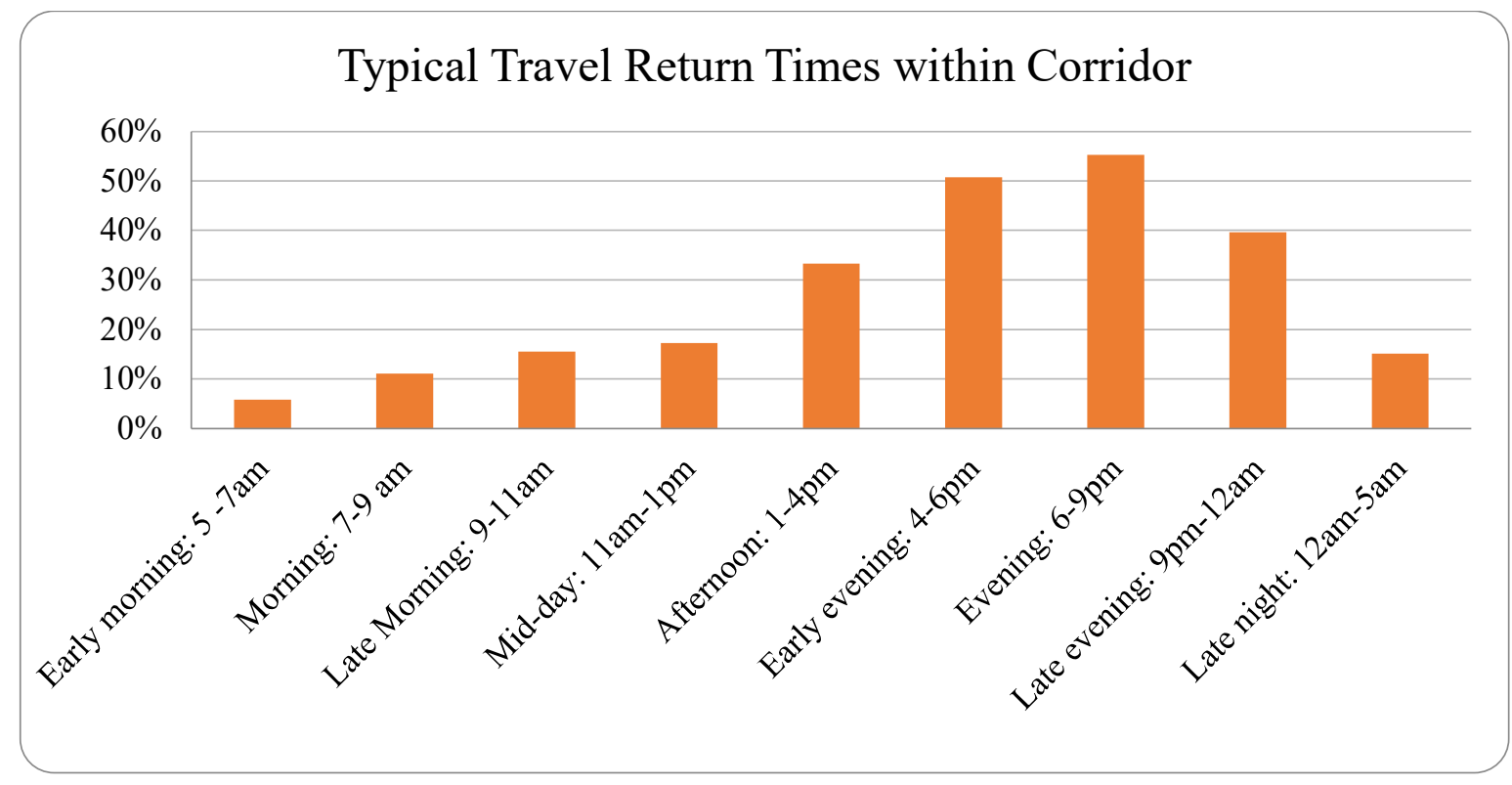

Figure 77. Survey respondent typical travel end times within corridor. 


\subsubsection{Opinions about Transportation Options}

The intent of this study was not to rigorously assess overall public support for the proposed rail service, as a randomized representative sample is outside of the feasible scope of this research. A 2019 poll by the Southern Rail Commission (70) showed that $85 \%$ of respondents think it is important or very important for the state to develop intercity rail service between New Orleans and Baton Rouge, and that $80 \%$ support the state in funding passenger rail, along with highways and airports. Sixty-three percent of respondents indicated that they would use the train, if developed. This builds on a 2010 poll (71) that found that $75 \%$ of corridor residents supported the proposed rail line, potentially indicating that the proposal is gaining favor over time.

In order to frame and contextualize the responses to this study's survey, level of interest in the proposed rail service was assessed. Overall, this survey should be understood to primarily capture the attitudes and preferences of those who are already in support of the proposed rail service, with $95 \%$ either strongly or moderately in favor of its development (Figure 78). This is unsurprising given that in an online, opt-in survey, those most likely to respond are those with an existing interest in the subject matter. However, the results do indicate geographically broad support, reinforcing previous assessments highlighting strong overall interest in and support for regional intercity rail within this corridor.

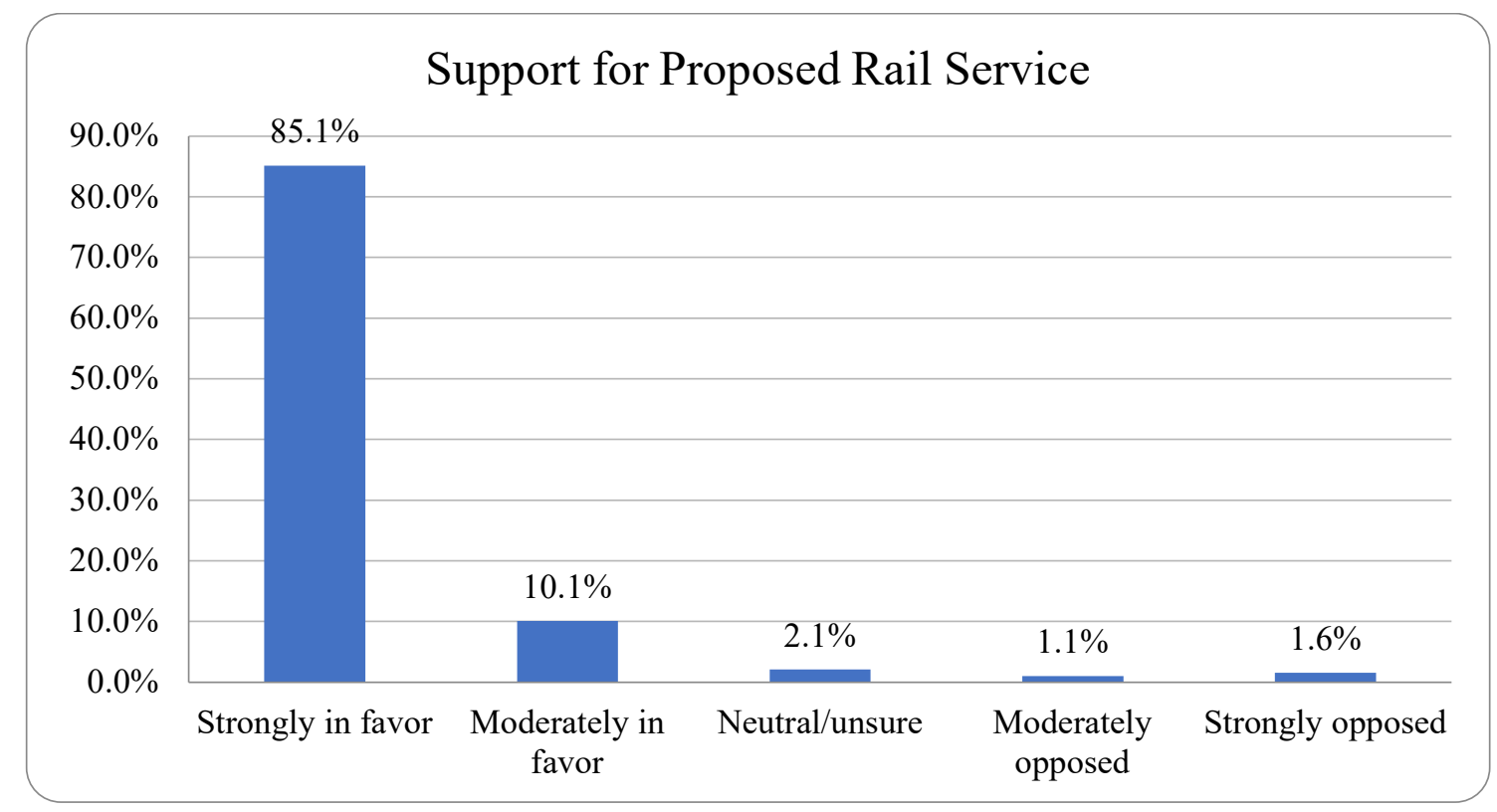

Figure 78. Survey respondent support for proposed rail service.

The most robust support for the proposed rail service is in Orleans and East Baton Rouge Parishes. Support in St. Charles Parish, which is within the study corridor but would not directly benefit from a station within its own borders, is the lowest, but still approaches $90 \%$ of responses (Figure 79). 


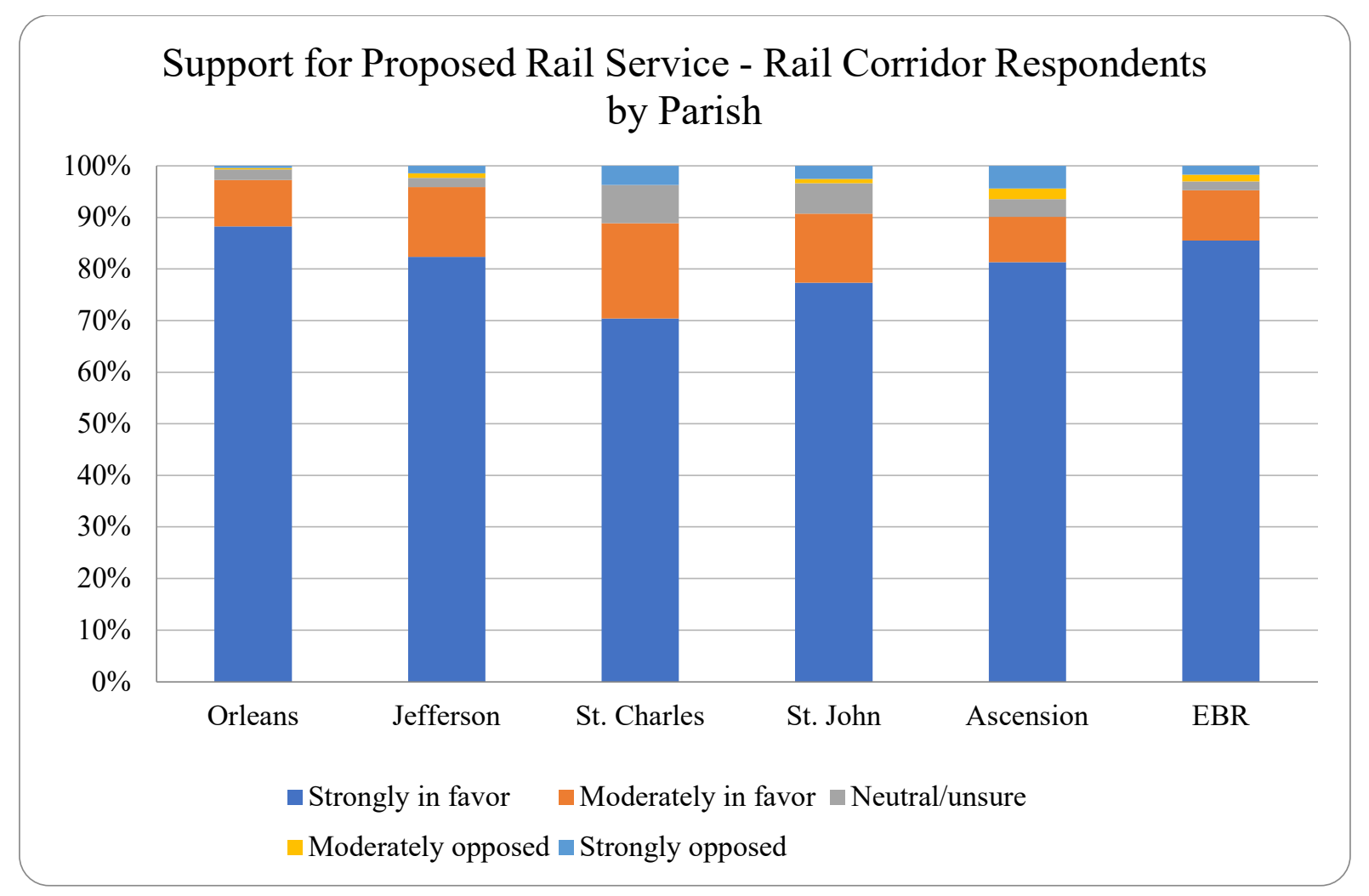

Figure 79. Survey respondent support for proposed rail service by parish.

Respondents were also asked to rate the quality of local transportation options within their community. Overall, respondents expressed dissatisfaction with existing public transit options, with approximately half indicating that transit is either "poor" or "terrible" at present (Figure 80).

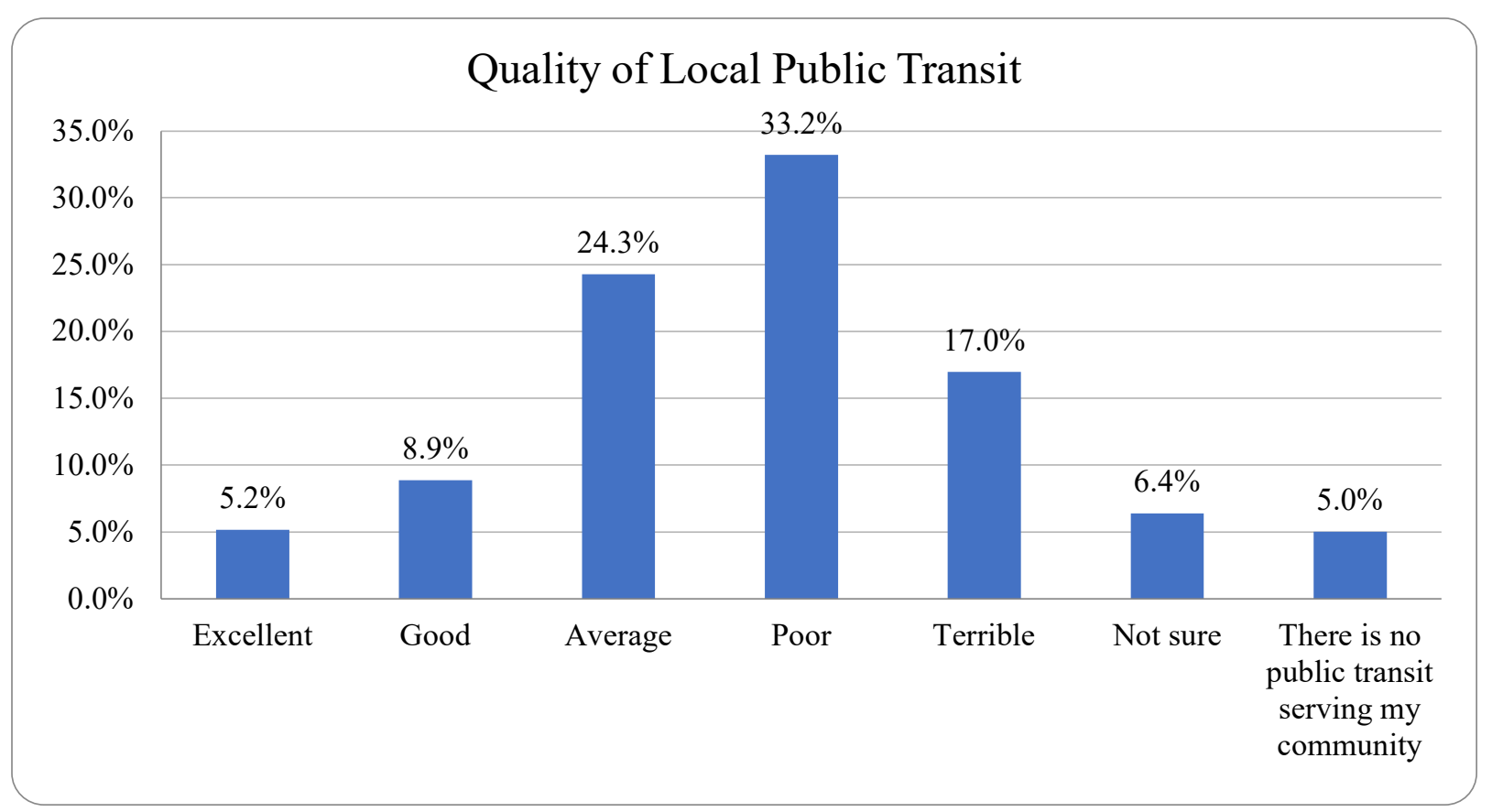

Figure 80. Survey respondent assessment of local public transit quality. 
Residents of Orleans and Jefferson Parish were substantially more likely to indicate at least modest satisfaction with transit provision, whereas fewer than $10 \%$ of Baton Rouge residents affirm that transit services available are "excellent" or "good" (Figure 81). Notably, a portion of respondents from intermediate parishes where transit is generally limited to demand-response options for mobility impaired persons, nonetheless ranked their local public transit services as excellent or good, which may reflect a regional perspective, a lack of familiarity, or a relativistic view of what constitutes adequate transit service for smaller towns and rural areas.

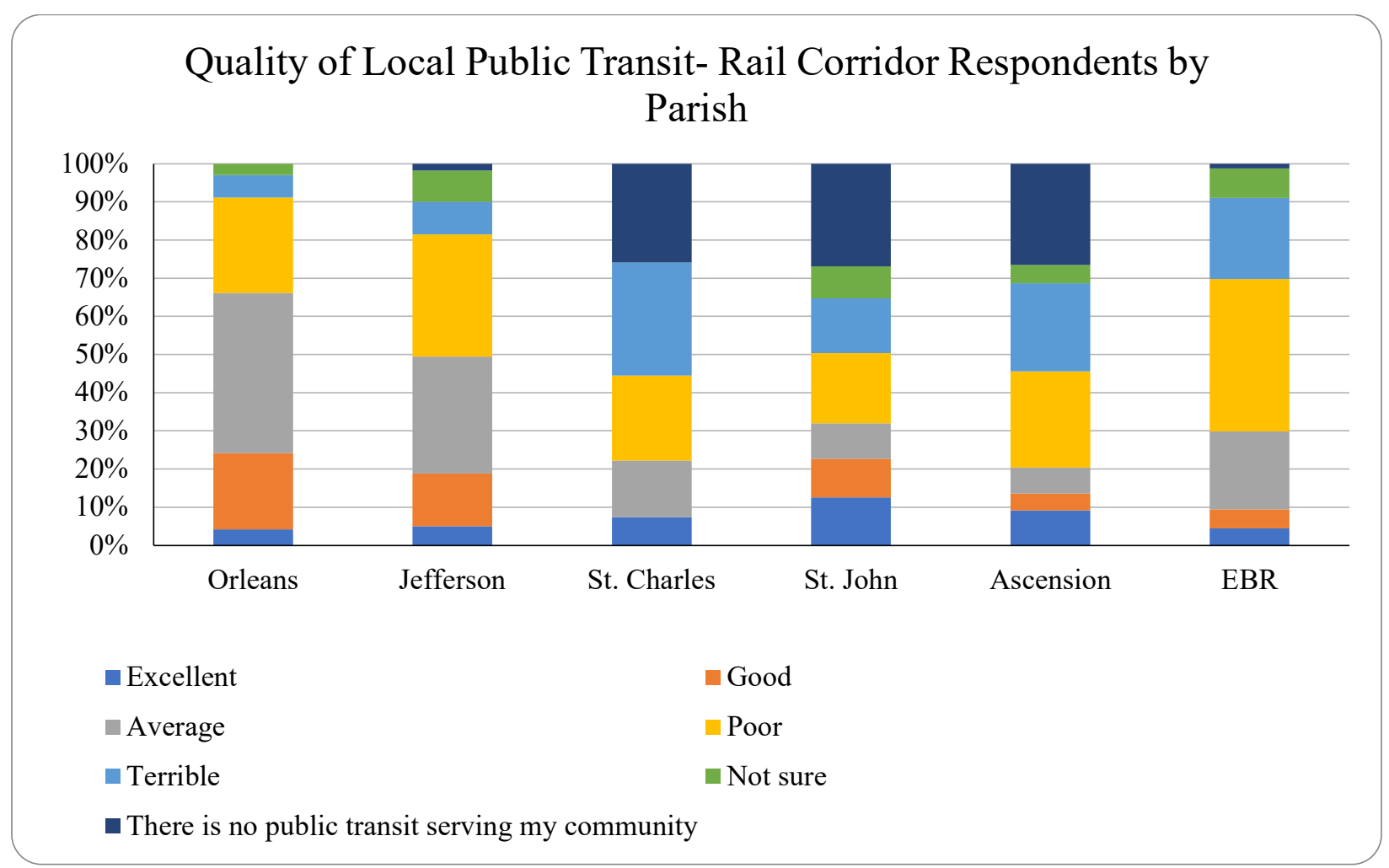

Figure 81. Survey respondent assessment of local public transit quality by parish.

Similarly, the majority of respondents indicated that existing infrastructure for bicycling is subpar (Figure 82), with significant differences by parish (Figure 83). Nearly 1/3 of Orleans Parish residents indicated that bicycle infrastructure is excellent or good, reflecting New Orleans' progress toward implementing a Complete Streets approach to infrastructure. By contrast, less than $8 \%$ of Baton Rouge residents felt that the built environment for bicycling is excellent or good, while $32 \%$ opined that it is "poor" or "terrible." Overall, respondents in Ascension Parish assessed their bike infrastructure most poorly, however, with $19 \%$ indicating that there is no bicycle infrastructure at all and an additional $63 \%$ declaring that what does exist is inadequate. 


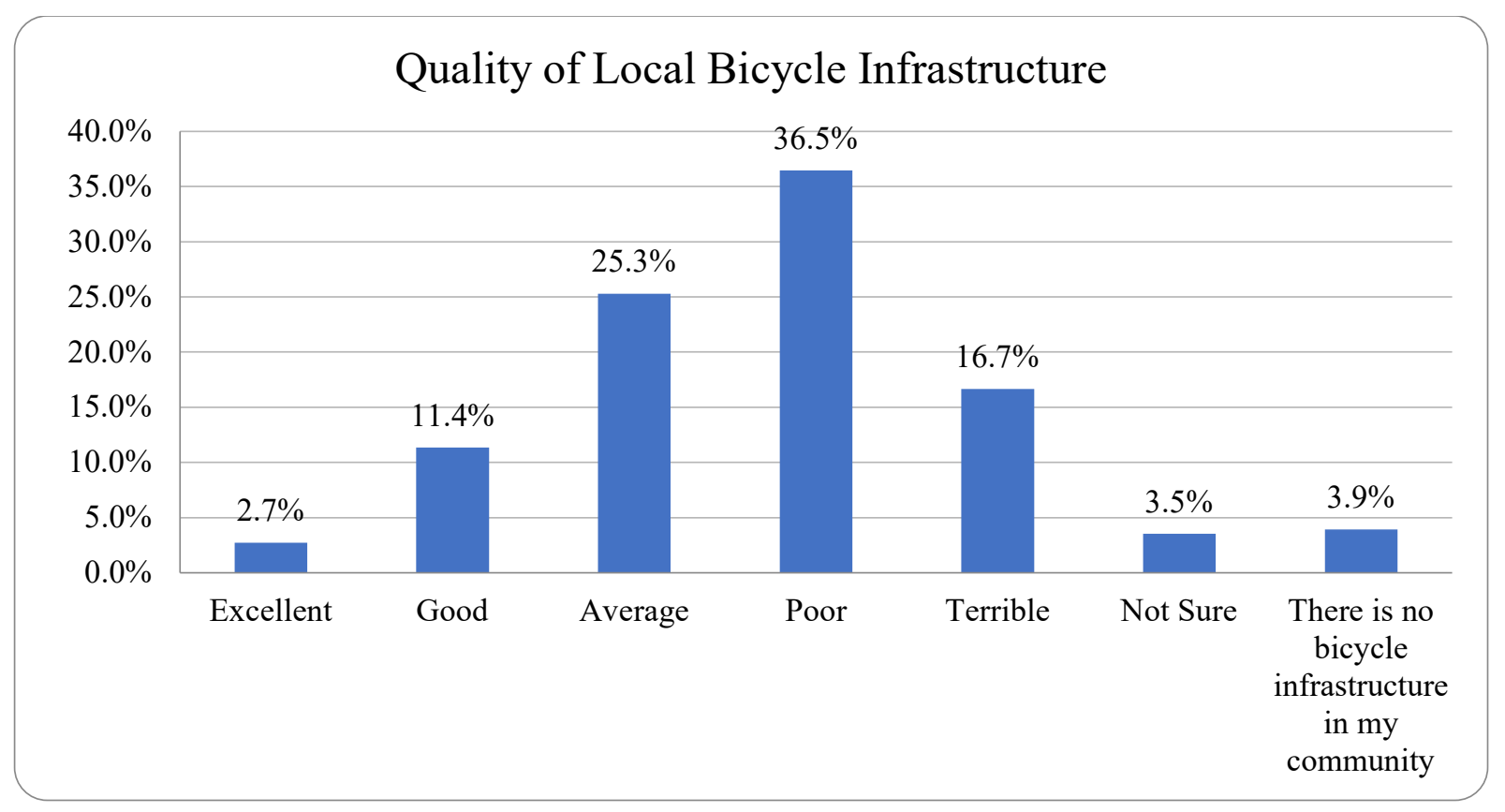

Figure 82. Survey respondent assessment of local bicycle infrastructure quality.

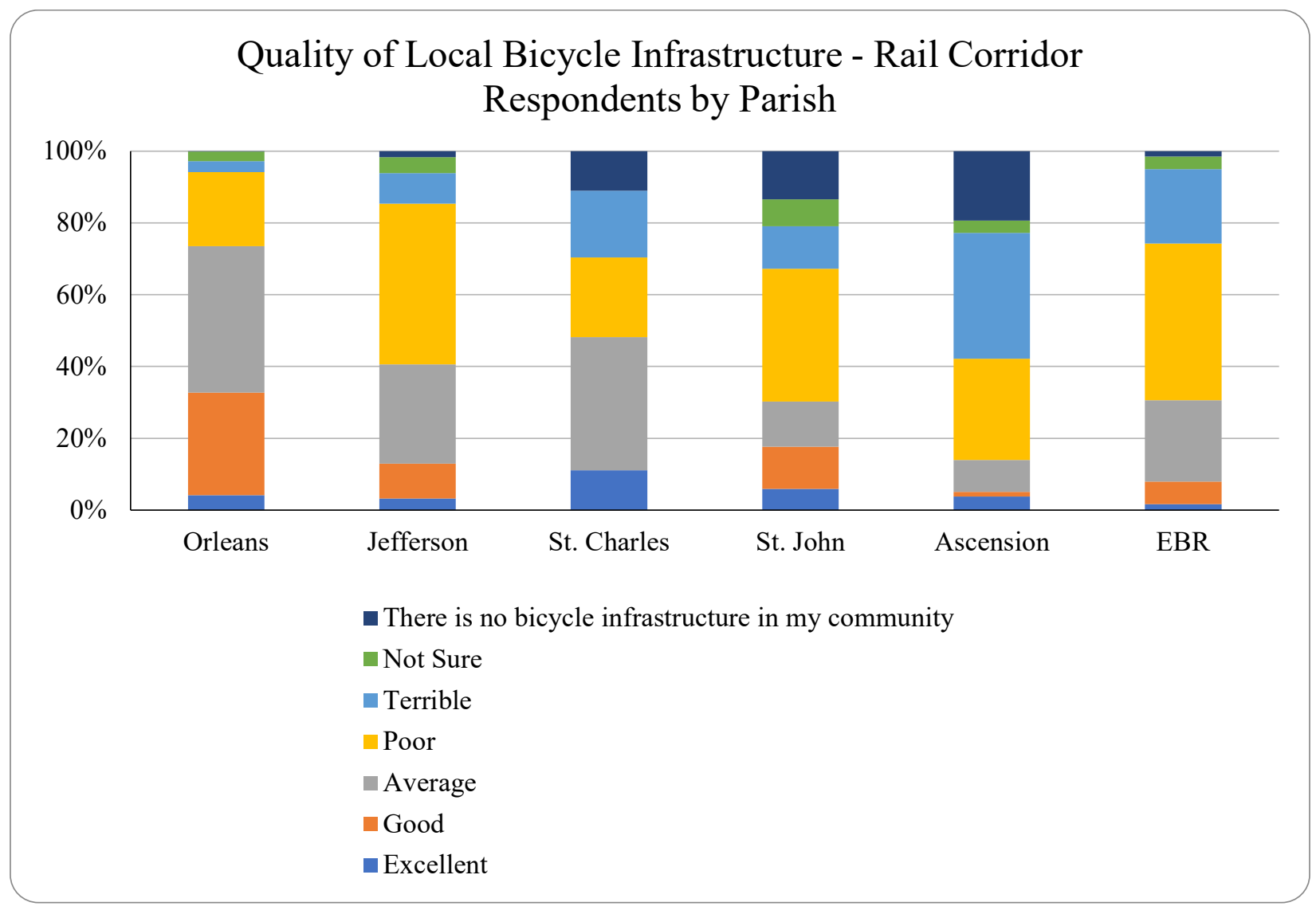

Figure 83. Survey respondent assessment of local bicycle infrastructure quality by parish. 
Finally, survey respondents resoundingly indicate that walking is a challenge in their community, with over $64 \%$ indicating that it is somewhat or very difficult to walk where they live (Figure 84 ). Intraregional disparities are evident here as well, with New Orleans residents overwhelmingly $(70 \%)$ affirming that it is very or moderately easy to walk, compared to similar responses from as few as 4\% of Ascension Parish residents (Figure 85). Lack of a safe and comfortable walking environment can be a major inhibitor of successful transit implementation as well as corresponding efforts to revitalize station areas, thus, this finding is an important consideration for the potential success of the proposed rail link.

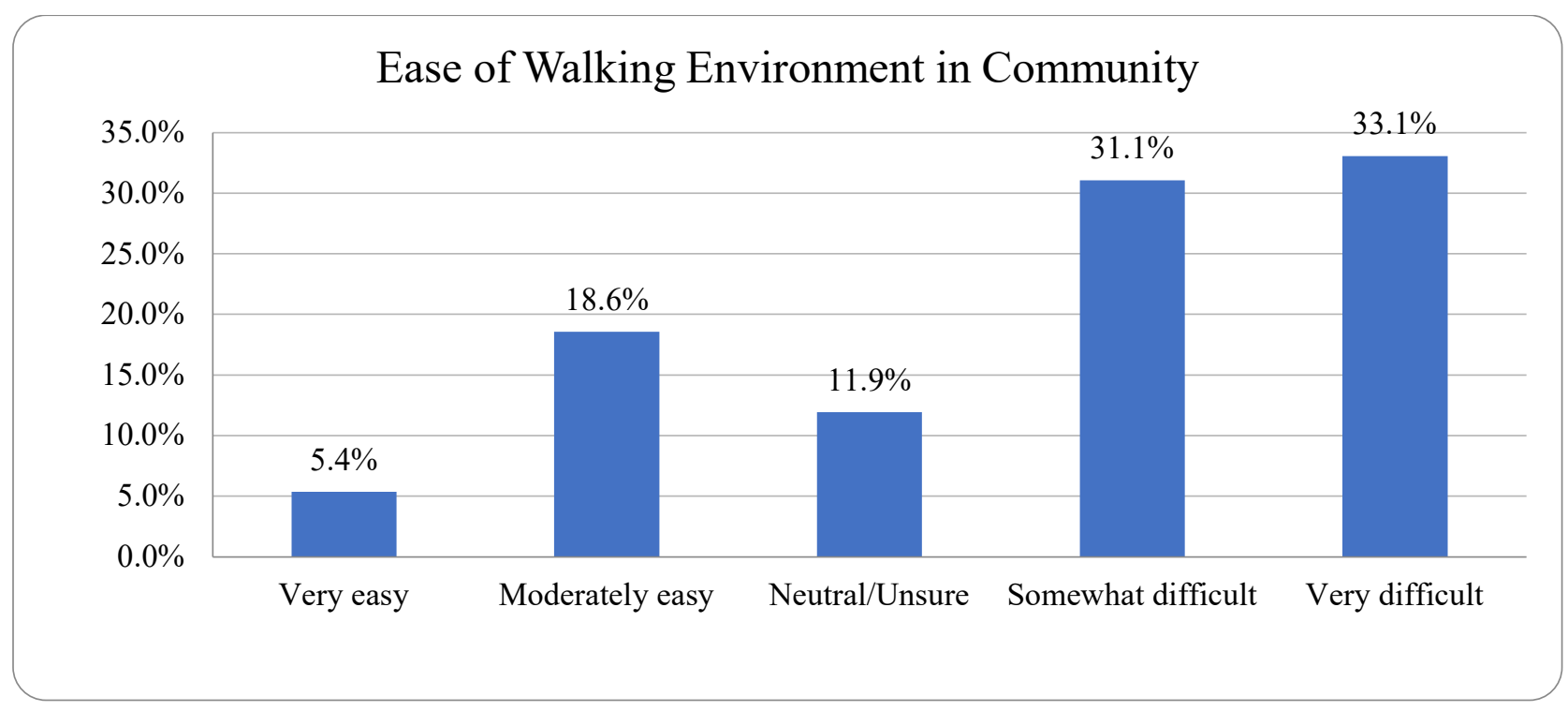

Figure 84. Survey respondent assessment of walking environment in community.

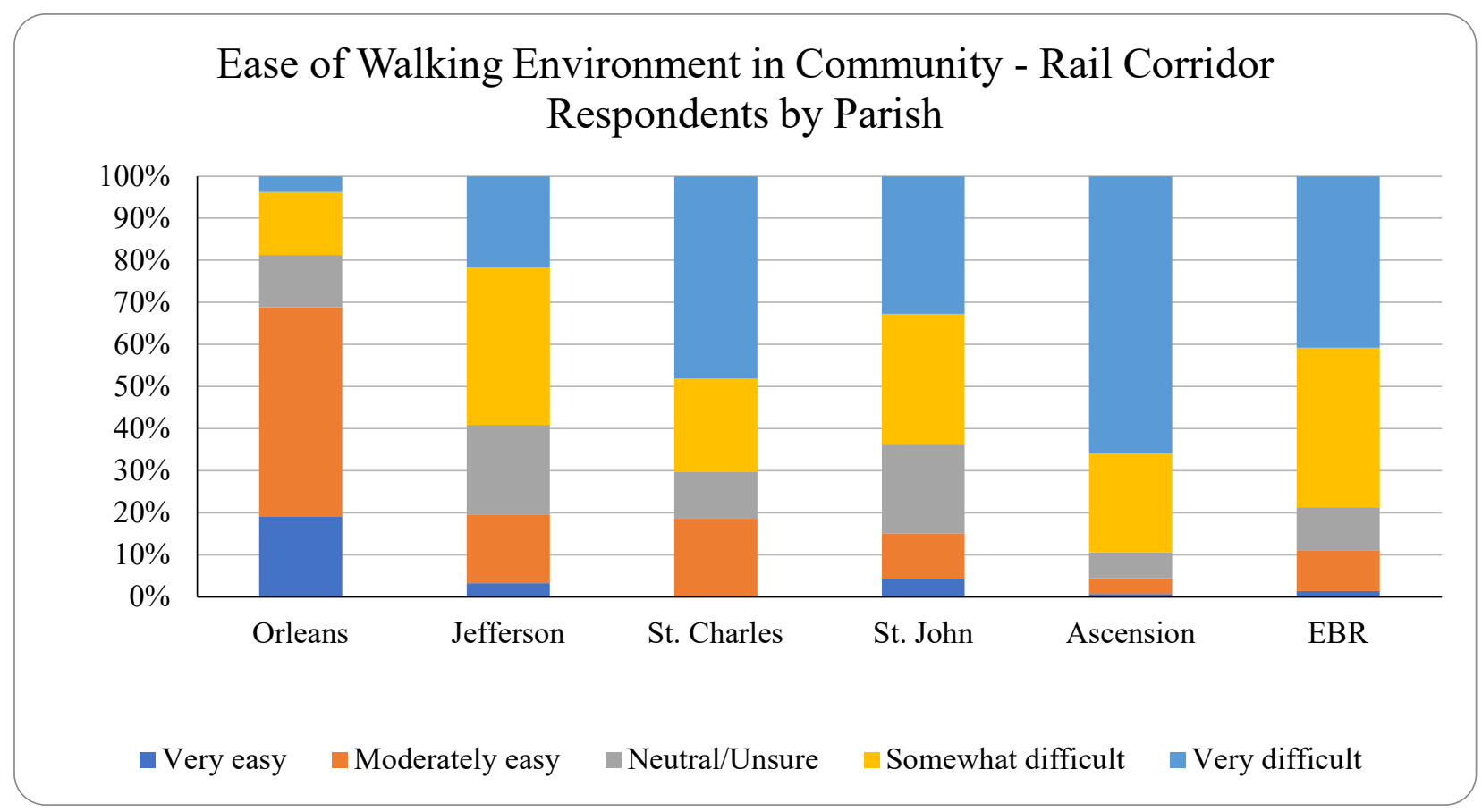

Figure 85. Survey respondent assessment of walking environment in community by parish. 
As a point of comparison to previous surveys by the National Association of Realtors and local partners (72) respondents were asked to identify which of four strategies they preferred to address congestion within the I-10 corridor long-term (Figure 86). Overwhelmingly, respondents indicated that their preferred strategy is indeed development of passenger rail, although it should be noted that this result is reflective primarily of the opt-in nature of the survey instrument, in which enthusiastic rail advocates may be assumed to be overrepresented. These findings are relatively consistent across parishes, with residents of rural/suburban parishes more likely to advocate for highway expansion (Figure 87).

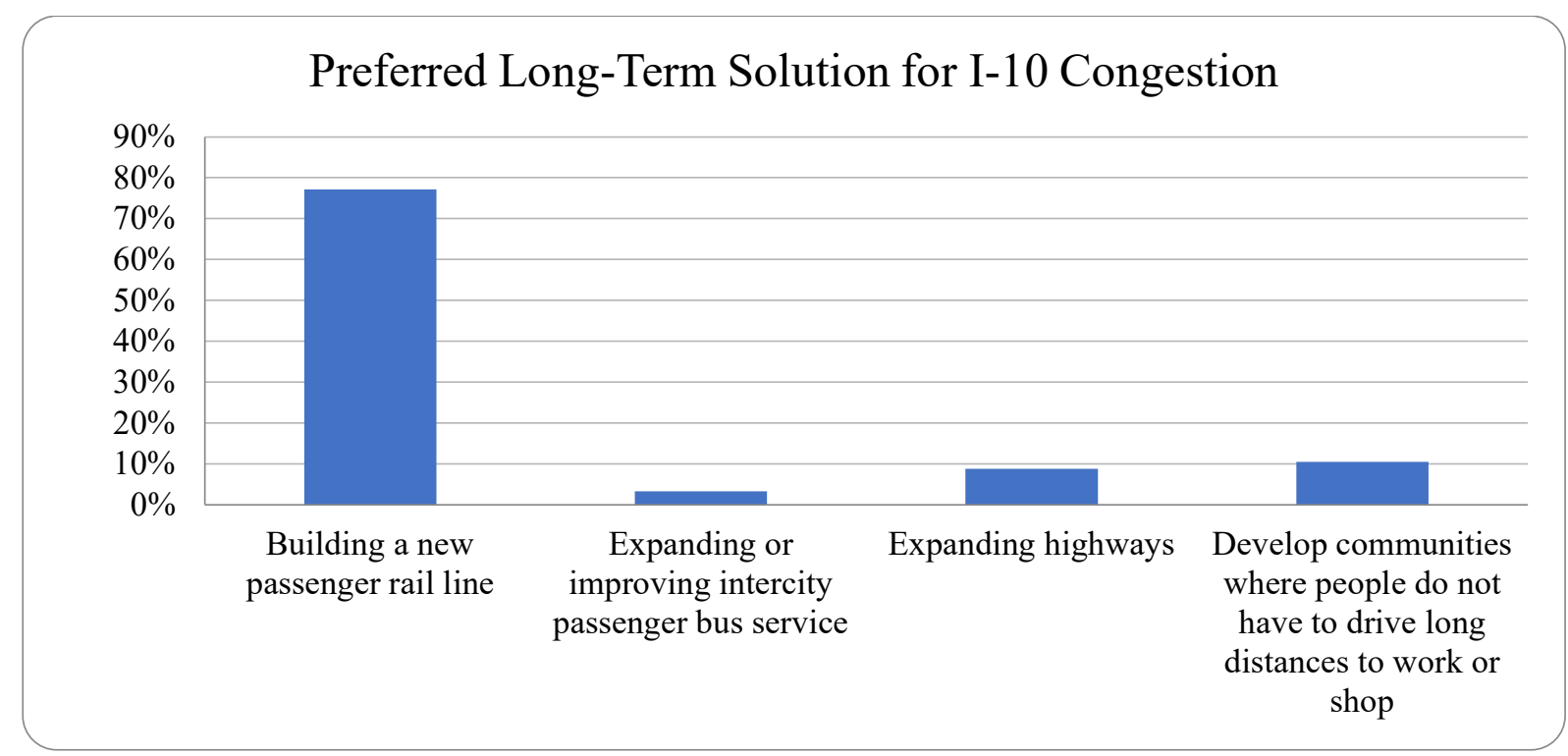

Figure 86. Survey respondent preferred long-term solution for I-10 congestion.

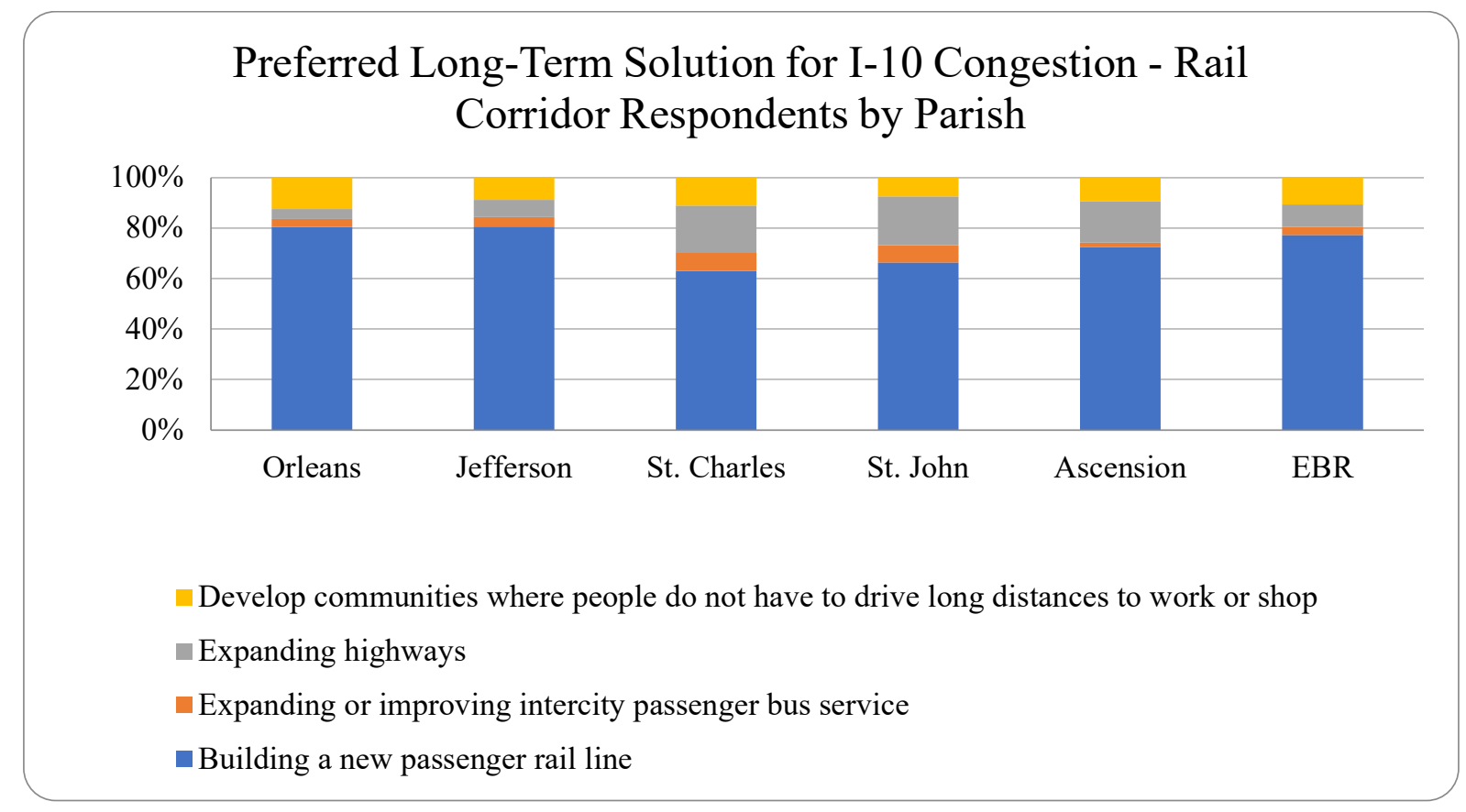

Figure 87. Survey respondent preferred long-term solution for I-10 congestion by parish. 
Finally, respondents were asked to identify, given conditions of the built environment at present for all modes of travel, how they would most likely access the train station, if the proposed rail link were to be developed (Figure 88). The majority of respondents indicate that they would be most likely to drive, either alone $(36 \%)$ or with others in a carpool or taxi/rideshare $(44 \%)$. Approximately $7 \%$ indicated they would take transit or bike to the station, respectively, while only $4 \%$ indicated they would likely walk. This suggests that the proposed stations, as planned and currently situated, are poorly positioned to attract a large number of riders by alternative modes of transport, indicative of perceived deficiencies in these options.

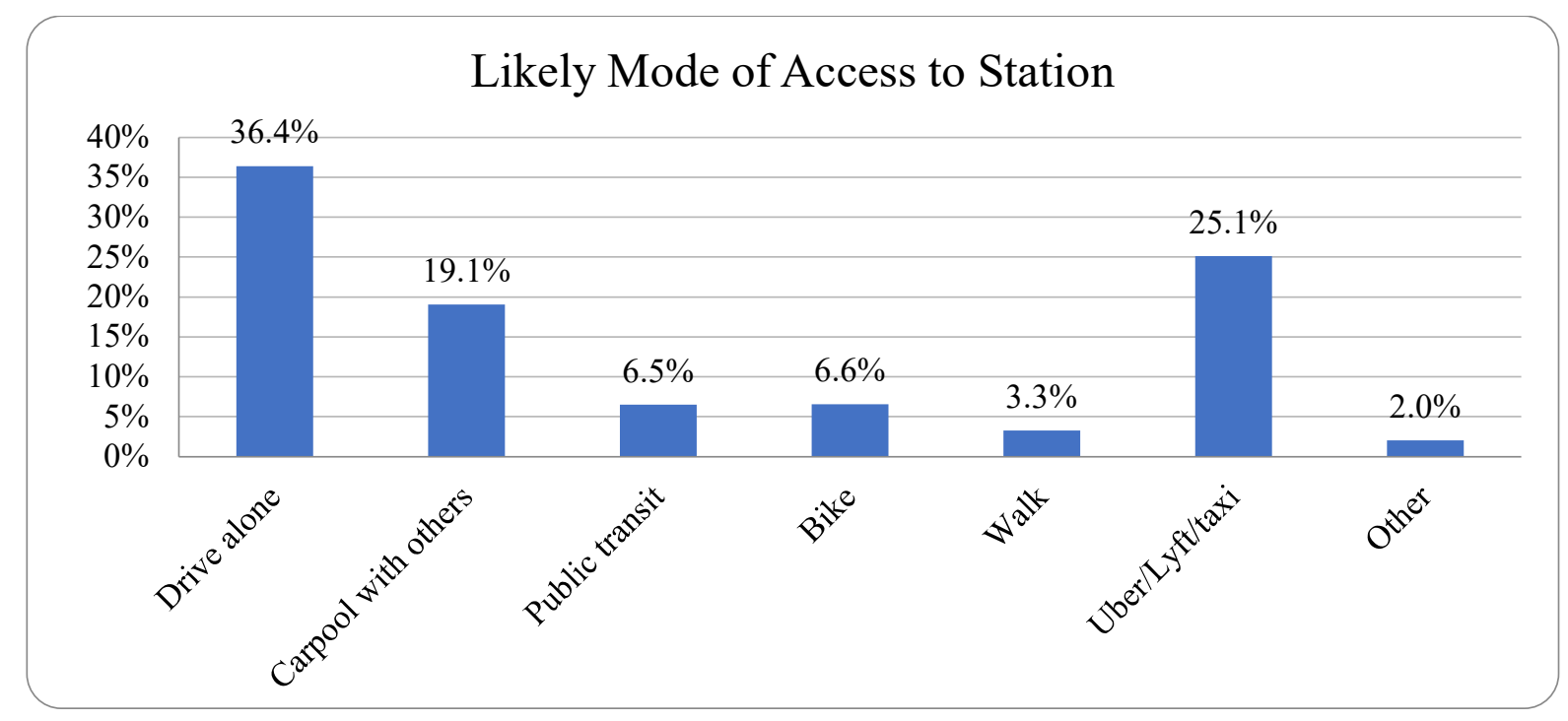

Figure 88. Survey respondent likely mode of access to rail station.

At the parish level, New Orleans residents were more likely (17\% of respondents) to indicate openness to taking transit to reach the station, suggesting that the central, transit-integrated location of NOUPT, paired with the relatively more robust RTA, makes this a viable option for potential train passengers (Figure 89). In addition, Orleans Parish respondents indicated favorability of bicycling to the station (15\% of respondents).

Overall, these results indicate that, even among a largely enthusiastic sample of potential train passengers, with strong stated preferences for intercity train access and a tendency toward multimodal travel behaviors, most can be expected to access passenger rail by automobile under current infrastructure and policy conditions. 


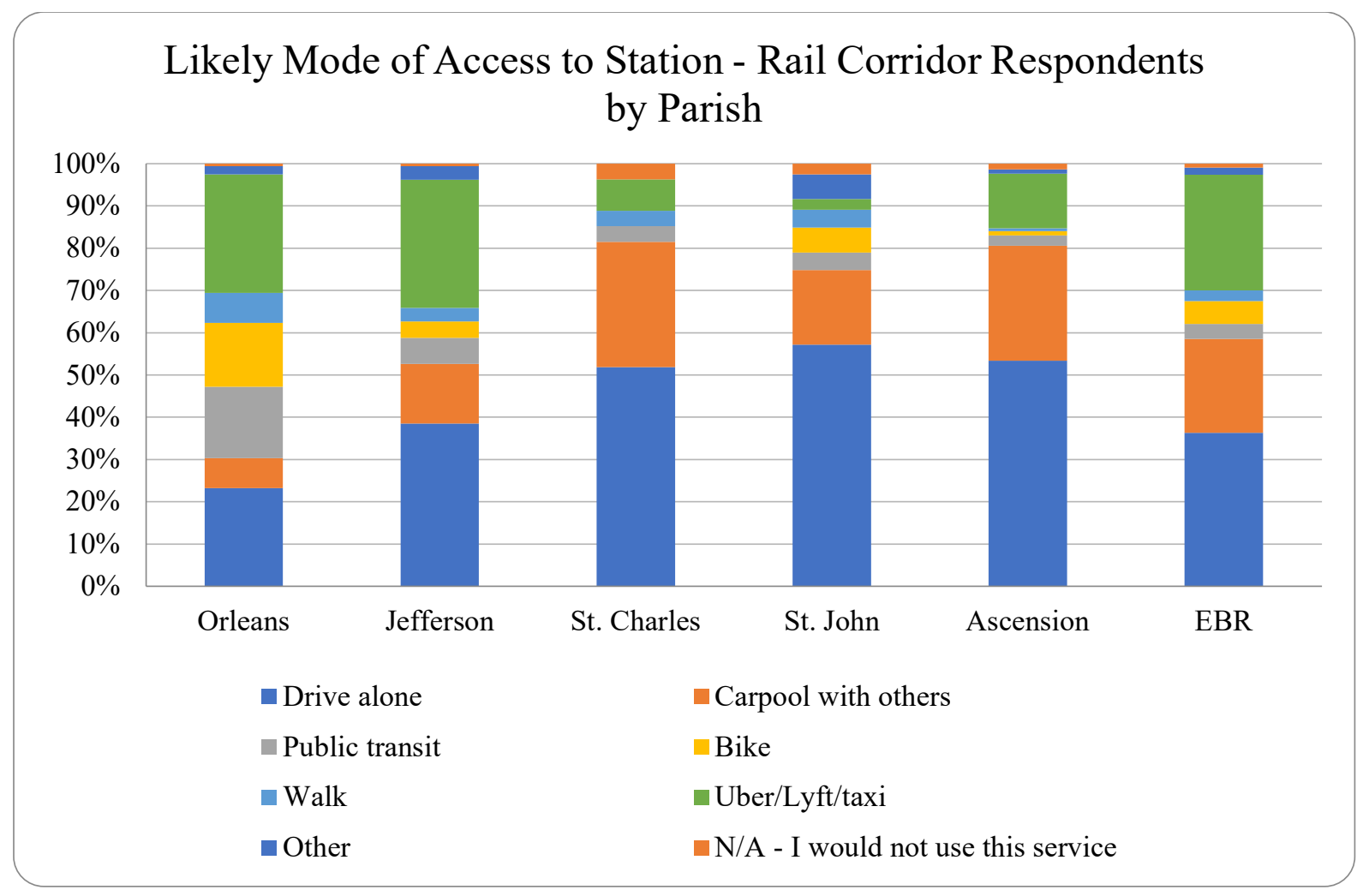

Figure 89. Survey respondent likely mode of access to rail station by parish.

\subsubsection{Impacts of COVID-19 on Travel Behavior}

Respondents were asked to indicate any modes of transport they used to commute to work, both before COVID-19, during the pandemic. They were also asked to indicate how they anticipated commuting to work (if employed outside the home) once the impacts of the pandemic eventually subside (Figure 90, Table 28). While a wide majority of respondents exclusively or primarily commuted to work by driving alone pre-pandemic (81\%, comparable with ACS estimates of $82.7 \%$ of the state's residents who drive alone), a substantial share (9\%) incorporated active modes of transport (bicycling, walking, and/or public transit) into their commute activities at least some of the time. This contrasts sharply with ACS estimates for commute mode share statewide, wherein only $5 \%$ of the population is estimated to commute to work by any means other than a private or shared automobile. Notably, the American Community Survey only permits respondents to indicate the mode of transport used most often, which may result in mode share figures that underrepresent active modes.

Unsurprisingly, at the time of the survey, a majority of respondents reported that they had been primarily working from home, at least part of the time. Use of all other modes of transport for work trips declined sharply. However, when asked to predict their anticipated commute modes in the future, post-pandemic, not all respondents indicated that they would return to the same behaviors previously reported. In fact, a plurality reported that they intend to incorporate the use of more active modes of transport into their commutes. A smaller share indicated that they intend to use carpool, vanpool, or rideshare options more, and another small subset suggest that they plan to switch to commuting exclusively by bicycle in the future. Meanwhile, the number of people indicating that they plan to exclusively carpool, use transit, or walk declined slightly, however, the 
share of respondents who indicated that they intend to use these modes alongside driving each increased.

These findings suggest that while the overwhelming majority of residents within the study region drive as their primary means of transport for work trips, a growing share are open to incorporating other modes of transport into their lives for at least some trips, particularly bicycling. It is also notable that the overall number of respondents who indicate interest in taking public transit or participating in carpools or vanpools for at least some trips increased, despite ongoing concerns about public health stemming from COVID-19. Overall, the results suggest a growing interest in having (and using) more transportation options, rather than relying solely on one mode. In addition, the responses suggest that telecommuting, at least some of the time, is likely to persist for many Louisianans beyond the governmental and public health restrictions imposed during 2020 .

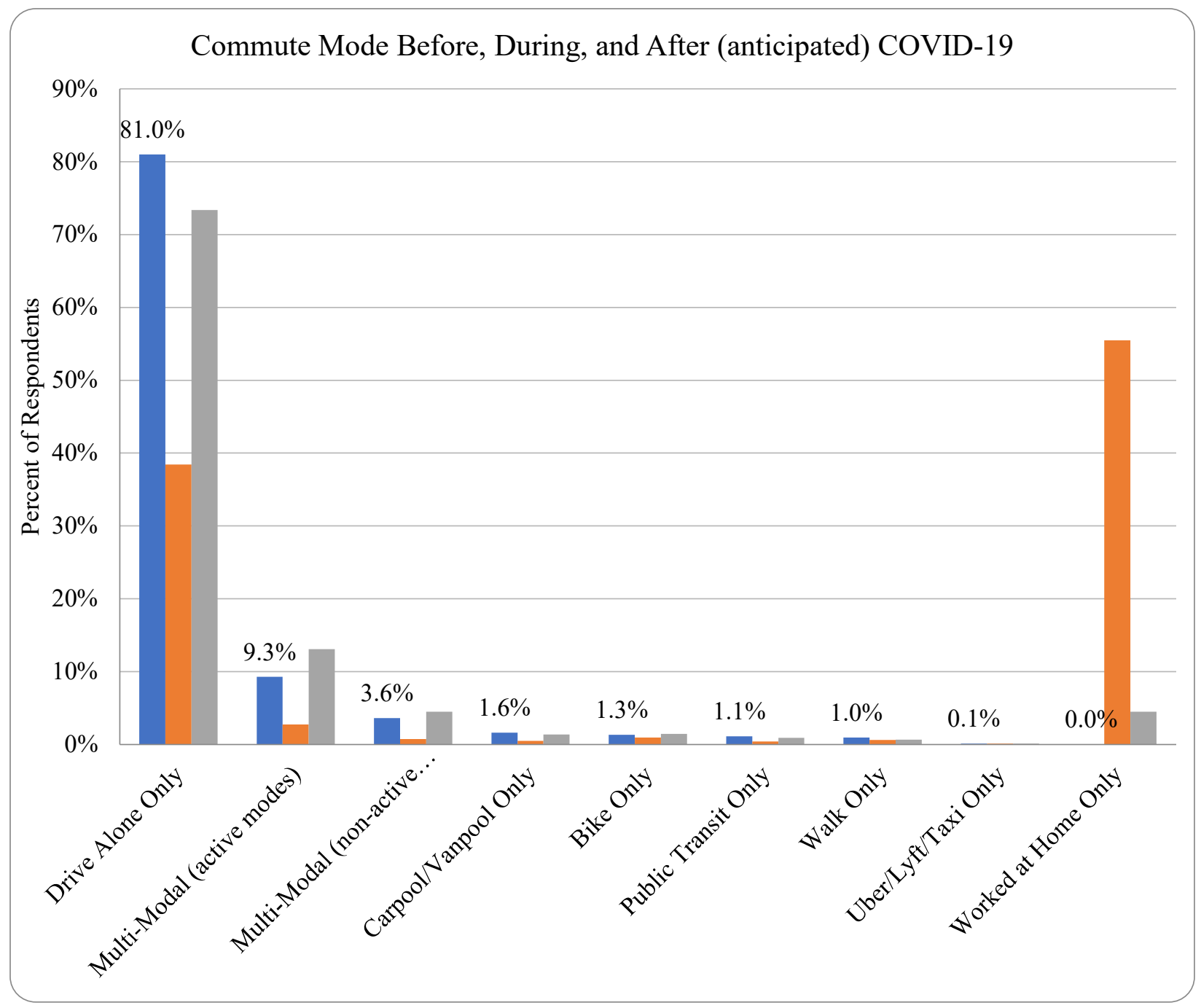

Figure 90. Survey respondent commute mode before, during, and after (anticipated) COVID-19 (modal groups). 
Table 28. Survey respondent commute mode before, during, and after (anticipated) COVID-19 (individual modes).

\begin{tabular}{|l|l|l|}
\hline & $\begin{array}{l}\text { Percent Change, Pre-COVID vs. } \\
\text { During COVID }\end{array}$ & $\begin{array}{l}\text { Percent Change, Pre-COVID vs. } \\
\text { Post-COVID (anticipated) }\end{array}$ \\
\hline Drive Alone & $-58 \%$ & $0 \%$ \\
\hline Carpool/Vanpool with Others & $-79 \%$ & $25 \%$ \\
\hline Public Transit & $-83 \%$ & $35 \%$ \\
\hline Bike & $-69 \%$ & $33 \%$ \\
\hline Walk & $-63 \%$ & $24 \%$ \\
\hline Uber/Lyft/Taxi & $-72 \%$ & $23 \%$ \\
\hline Other & $-16 \%$ & $-12 \%$ \\
\hline Worked at Home & $525 \%$ & $58 \%$ \\
\hline n/a - did not work & $150 \%$ & $8 \%$ \\
\hline
\end{tabular}

Findings diverge slightly at the Parish level, where, among those respondents who work, variances in respondent characteristics emerge (Table 29). Among respondents from Orleans Parish, who reported a highly multimodal commute (less than $80 \%$ indicating that they drive to work alone, even some of the time), as well as in East Baton Rouge Parish, a predilection for active modes of transport may be expected to increase post-pandemic, with more respondents indicating that they plan to incorporate carpooling, transit, bicycling, and walking into their work commutes. In Jefferson Parish, respondents similarly indicated increased intent to incorporate modes other than driving alone into their commute, with the exception that fewer respondents stated that they plan to walk to work. In more rural and suburban St. Charles, St. John, and Ascension parishes, most respondents drive to work alone and plan to do so post-pandemic, although here too, some increased interest in transit, walking, bicycling, and/or carpooling is indicated (although smaller sample sizes tend to distort \% change findings, which may represent only a few respondents per each modal category).

Unsurprisingly, in all corridor parishes, the share of respondents who shifted to working from home during COVID-19 increased exponentially. More notably, the share of those who expect to continue working from home, at least part of the time, once the immediate crisis has subsided, increased substantially, ranging from a $40 \%$ increase in Jefferson Parish to a $75 \%$ increase in St. John the Baptist Parish, or an average of $58 \%$ regionwide.

Again, the demographic characteristics of respondents influence these results, as more affluent communities are more likely to be employed in jobs where remote work is feasible. These figures should not be interpreted to reflect community-wide shifts in commute behavior, but rather, they do reinforce the finding that many people throughout the region anticipate and/or desire to have more options when it comes to their commute, whether that means more active and sustainable modes of transport, or the option to telecommute. 
Table 29. Survey respondent commute mode before, during, and after (anticipated) COVID-19 (individual modes) by parish.

\begin{tabular}{|c|c|c|c|}
\hline & Pre-COVID & During COVID & Anticipated Post-COVID \\
\hline & $\%$ of respondents & $\begin{array}{l}\% \text { Change, Pre-COVID to } \\
\text { During COVID }\end{array}$ & $\begin{array}{l}\% \text { Change, Pre-COVID to } \\
\text { Post-COVID }\end{array}$ \\
\hline \multicolumn{4}{|l|}{ Orleans Parish } \\
\hline Drive Alone & $78.80 \%$ & $-65.90 \%$ & $1.30 \%$ \\
\hline Carpool/Vanpool with Others & $7.20 \%$ & $-81.20 \%$ & $24.60 \%$ \\
\hline Public Transit & $13.80 \%$ & $-84.80 \%$ & $23.50 \%$ \\
\hline Bike & $20.10 \%$ & $-72.90 \%$ & $23.40 \%$ \\
\hline Walk & $9.90 \%$ & $-61.10 \%$ & $34.70 \%$ \\
\hline Uber/Lyft/Taxi & $6.90 \%$ & $-71.20 \%$ & $10.60 \%$ \\
\hline Other & $1.80 \%$ & $-52.90 \%$ & $-5.90 \%$ \\
\hline Worked at Home & $13.70 \%$ & $411.50 \%$ & $52.70 \%$ \\
\hline \multicolumn{4}{|l|}{ Jefferson Parish } \\
\hline Drive Alone & $1.30 \%$ & & $88.80 \%$ \\
\hline Carpool/Vanpool with Others & $24.60 \%$ & & $7.00 \%$ \\
\hline Public Transit & $23.50 \%$ & & $4.00 \%$ \\
\hline Bike & $23.40 \%$ & & $1.80 \%$ \\
\hline Walk & $34.70 \%$ & & $2.10 \%$ \\
\hline Uber/Lyft/Taxi & $10.60 \%$ & & $1.50 \%$ \\
\hline Other & $-5.90 \%$ & & $0.90 \%$ \\
\hline Worked at Home & $52.70 \%$ & & $10.60 \%$ \\
\hline \multicolumn{4}{|l|}{ St. Charles Parish } \\
\hline Drive Alone & $96.00 \%$ & $-66.70 \%$ & $-8.30 \%$ \\
\hline Carpool/Vanpool with Others & $4.00 \%$ & $-100.00 \%$ & $-100.00 \%$ \\
\hline Public Transit & $0.00 \%$ & & \\
\hline Bike & $4.00 \%$ & $-100.00 \%$ & $0.00 \%$ \\
\hline Walk & $0.00 \%$ & & \\
\hline Uber/Lyft/Taxi & $0.00 \%$ & & \\
\hline Other & $0.00 \%$ & & \\
\hline Worked at Home & $12.00 \%$ & $500.00 \%$ & $0.00 \%$ \\
\hline \multicolumn{4}{|l|}{ St. John Parish } \\
\hline Drive Alone & $95.30 \%$ & $-41.20 \%$ & $-2.90 \%$ \\
\hline Carpool/Vanpool with Others & $0.90 \%$ & $0.00 \%$ & $200.00 \%$ \\
\hline Public Transit & $0.00 \%$ & & \\
\hline Bike & $3.70 \%$ & $-25.00 \%$ & $50.00 \%$ \\
\hline Walk & $0.90 \%$ & $0.00 \%$ & $200.00 \%$ \\
\hline Uber/Lyft/Taxi & $0.00 \%$ & & \\
\hline
\end{tabular}




\begin{tabular}{|l|l|l|l|}
\hline Other & $0.00 \%$ & & \\
\hline Worked at Home & $7.50 \%$ & $487.50 \%$ & $75.00 \%$ \\
\hline Ascension Parish & & & \\
\hline Drive Alone & $94.80 \%$ & $-50.40 \%$ & $-0.40 \%$ \\
\hline Carpool/Vanpool with Others & $2.20 \%$ & $-50.00 \%$ & $116.70 \%$ \\
\hline Public Transit & $0.70 \%$ & $-50.00 \%$ & $250.00 \%$ \\
\hline Bike & $0.00 \%$ & & \\
\hline Walk & $0.00 \%$ & & \\
\hline Uber/Lyft/Taxi & $0.40 \%$ & $-100.00 \%$ & $0.00 \%$ \\
\hline Other & $0.70 \%$ & $0.00 \%$ & $-50.00 \%$ \\
\hline Worked at Home & $7.00 \%$ & $647.40 \%$ & $73.70 \%$ \\
\hline East Baton Rouge Parish & & & \\
\hline Drive Alone & $89.90 \%$ & $-57.70 \%$ & $-1.10 \%$ \\
\hline Carpool/Vanpool with Others & $5.50 \%$ & $-79.50 \%$ & $25.20 \%$ \\
\hline Public Transit & $3.10 \%$ & $-84.90 \%$ & $32.90 \%$ \\
\hline Bike & $5.50 \%$ & $-65.60 \%$ & $43.00 \%$ \\
\hline Walk & $3.50 \%$ & $-63.40 \%$ & $24.40 \%$ \\
\hline Uber/Lyft/Taxi & $2.20 \%$ & $-74.00 \%$ & $36.00 \%$ \\
\hline Other & $0.80 \%$ & $-5.30 \%$ & $-36.80 \%$ \\
\hline Worked at Home & $9.60 \%$ & $575.80 \%$ & $64.60 \%$ \\
\hline & & & \\
\hline
\end{tabular}

The survey asked respondents to identify all modes of transport they utilize. The above analysis reflects all responses, in any combination. Further condensed into discrete modal groups of unique combinations (single modes as well as respondents who indicated multiple modes of transport), the overall finding of increased multimodality is reinforced, with a $6 \%$ decrease in the number of respondents who indicated that they intend to only drive alone to work, and a $47 \%$ increase in the number of people who indicated that they intend to commute by active modes (bicycling, walking, or transit) at least some of the time.

The impacts of COVID-19 are further felt in decreases in the number of people who plan to exclusively carpool or vanpool, walk, or take transit, suggesting that concerns over health safety in shared spaces may persist indefinitely. Finally, pre-COVID, only a tiny percentage of employed respondents worked from home exclusively, whereas nearly 200 respondents indicated that they expect to work from home full-time in the future (Table 30). 
Table 30. Respondent commute mode share before, during, and after (anticipated) COVID-19: Modal Groups.

\begin{tabular}{|l|l|l|l|}
\hline & Pre-COVID & $\begin{array}{l}\text { Percent Change, } \\
\text { Pre-COVID vs. } \\
\text { During COVID }\end{array}$ & $\begin{array}{l}\text { Percent Change, Pre- } \\
\text { COVID } \\
\text { COV. } \\
\text { Post- }\end{array}$ \\
\hline Drive Alone Only & $81.0 \%$ & $-55.0 \%$ & $-5.8 \%$ \\
\hline Multi-Modal (active modes) & $9.3 \%$ & $-71.8 \%$ & $46.6 \%$ \\
\hline Multi-Modal (non-active only) & $3.6 \%$ & $-80.1 \%$ & $28.5 \%$ \\
\hline Carpool/Vanpool Only & $1.6 \%$ & $-71.6 \%$ & $-10.4 \%$ \\
\hline Bike Only & $1.3 \%$ & $-30.9 \%$ & $14.5 \%$ \\
\hline Public Transit Only & $1.1 \%$ & $-66.0 \%$ & $-14.9 \%$ \\
\hline Walk Only & $1.0 \%$ & $-40.0 \%$ & $-27.5 \%$ \\
\hline Uber/Lyft/Taxi Only & $0.1 \%$ & $0.0 \%$ & $0.0 \%$ \\
\hline Worked at Home Only & $0.02 \%$ & $218,600 \%$ & $193,000 \%$ \\
\hline
\end{tabular}

Respondents generally (as of June 2020) indicated that, once the COVID-19 crisis subsides (without defining specifically what that means to each individual), they expect to return to similar conditions and travel behaviors. Only a small fraction (2\%) indicated that they anticipated very different behaviors in the future as a result (Figure 91).

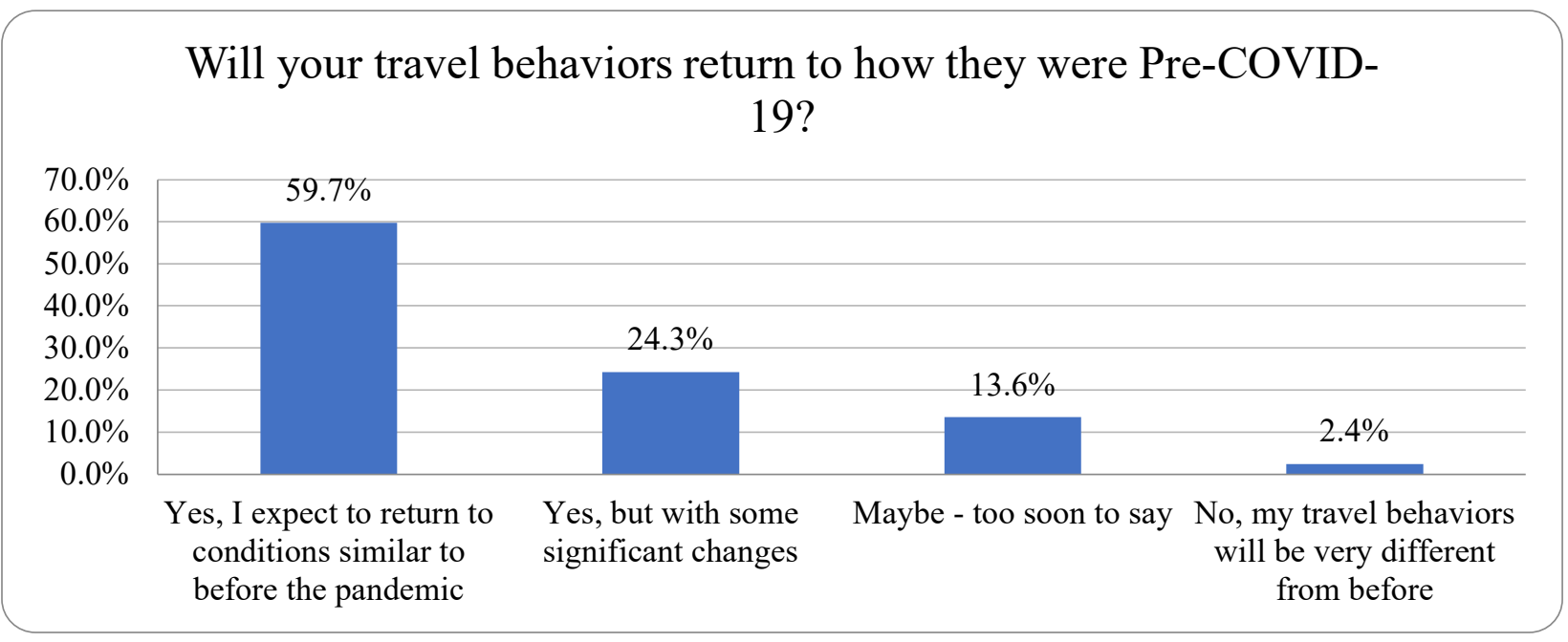

Figure 91. Survey respondent anticipated return to pre-COVID travel behaviors. 
These findings diverged moderately across parishes, with potentially greater changes in travel behaviors anticipated among residents of St. Charles, St. John, and Ascension Parishes (Figure 92).

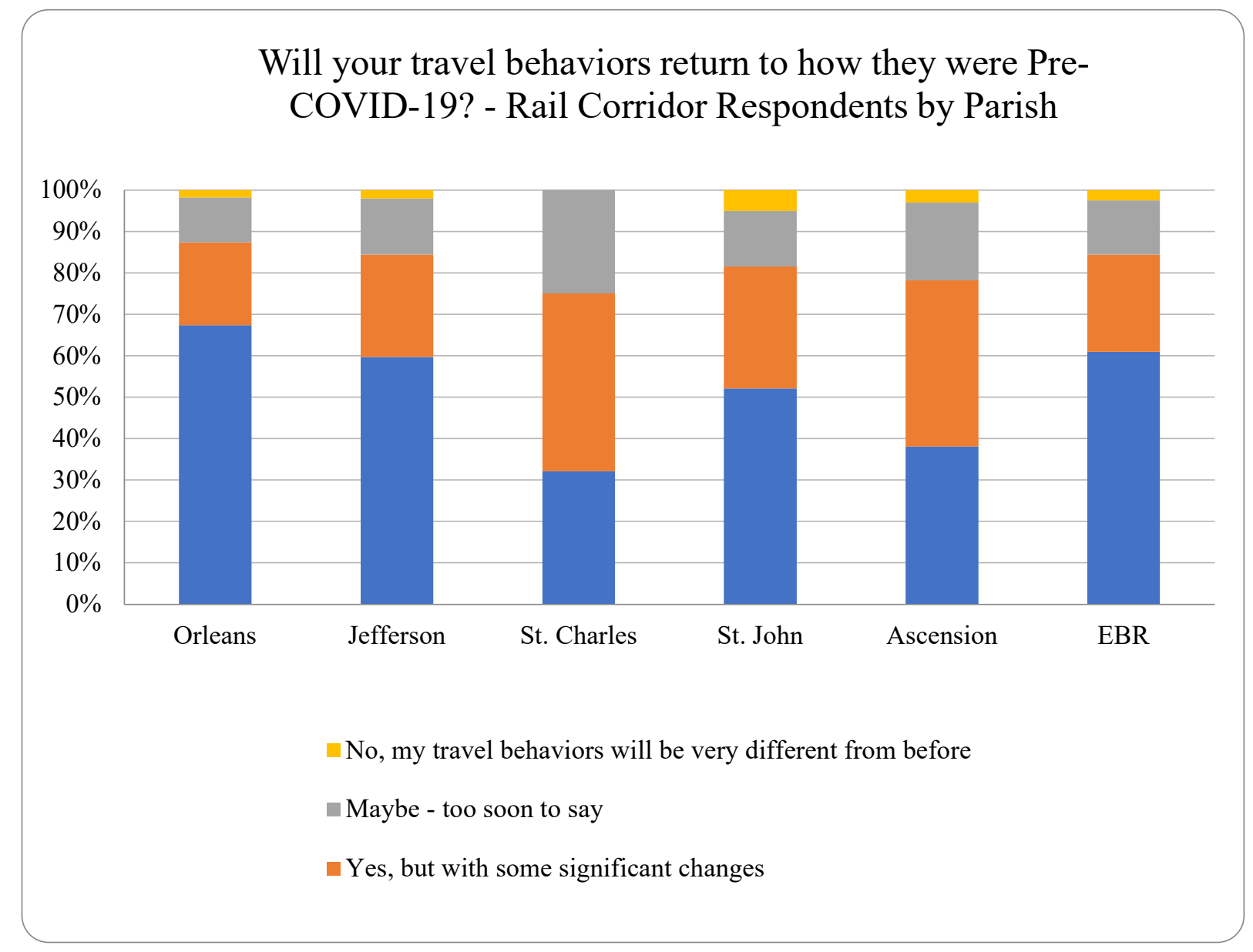

Figure 92. Survey respondent anticipated return to pre-COVID travel behaviors by parish.

Given concerns around utilizing public transit during the pandemic, it was appropriate also to ask respondents to assess whether or not COVID-19 had impacted their attitude toward public transit, overall. Nearly half (47\%) indicated that they do not expect long-term impacts on transit usage, while $19 \%$ indicated that they are less likely to use transit - including intercity trains or bussesthan they were previously (Figure 93). Approximately 7\% indicated that they were more likely to take transit (potentially linked to changes in economic circumstance, e.g.), while the remaining $28 \%$ indicated that they do not currently utilize transit and don't expect to in the future. 


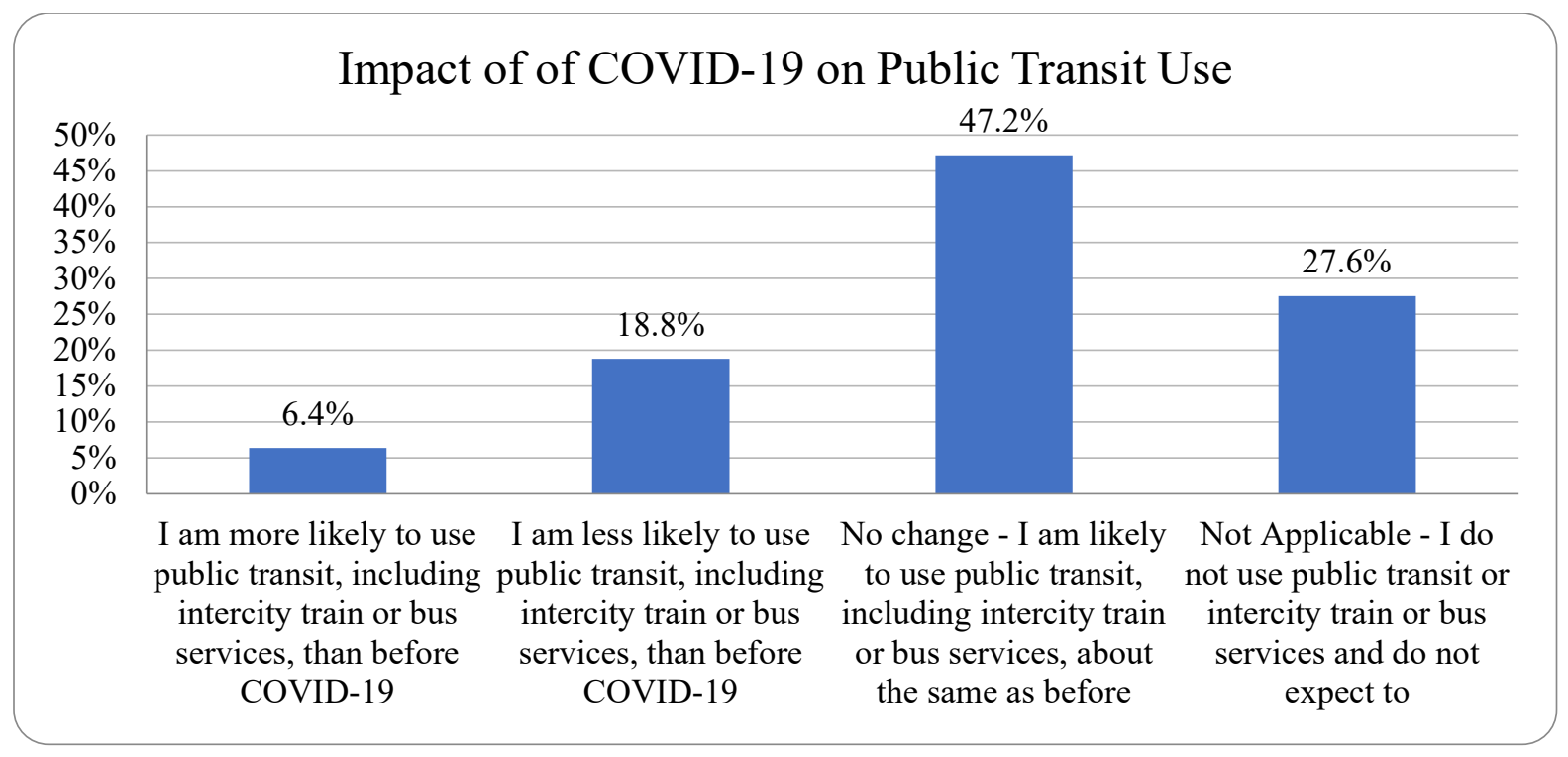

Figure 93. Impact of COVID-19 on survey respondent transit use.

These findings were relatively consistent across parishes (Figure 94), with the exception of respondents in Orleans Parish, who were more likely (26\%) to indicate reticence about transit use (possibly reflective of New Orleans' position as an early COVID-10 hotspot).

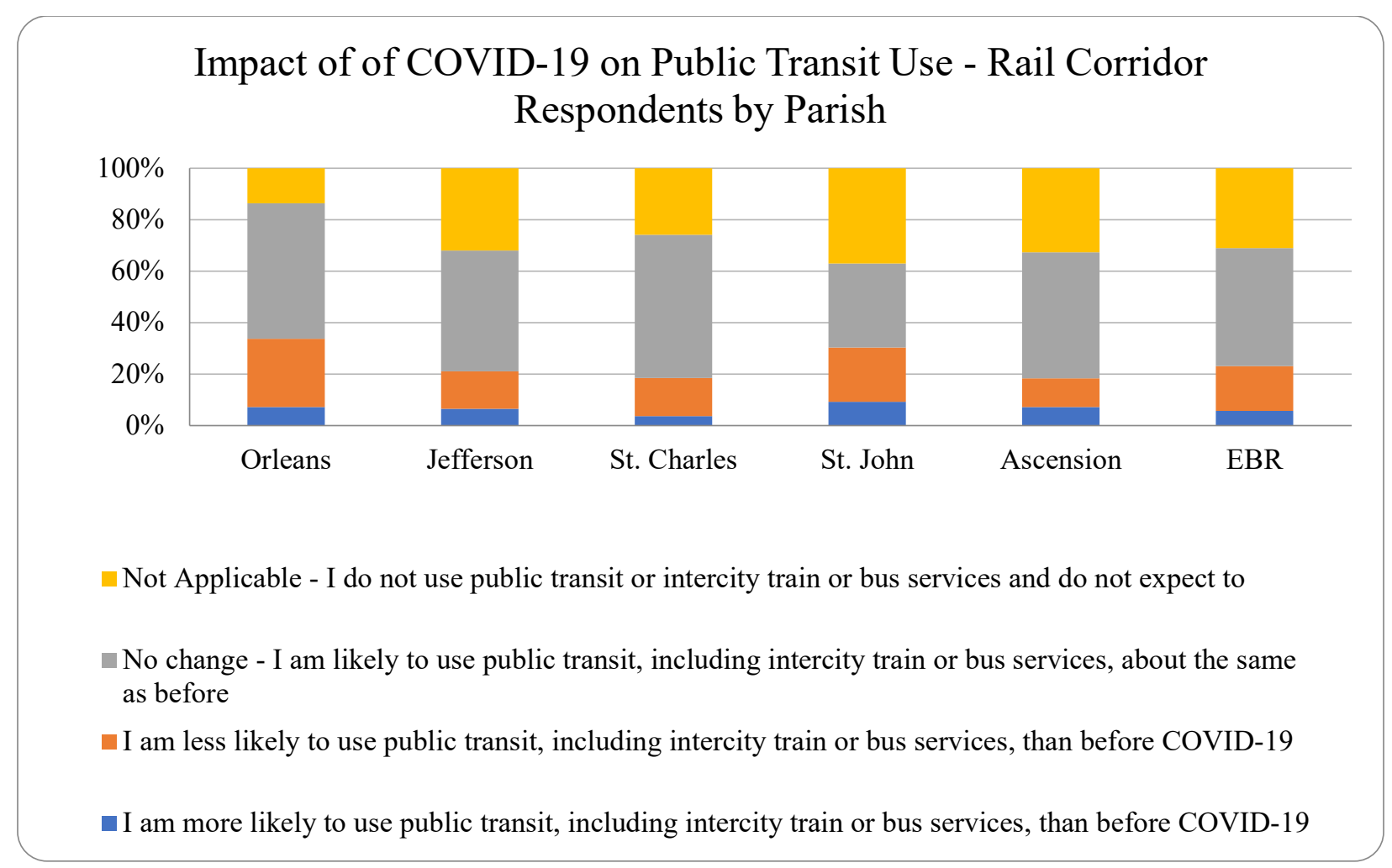

Figure 94. Impact of COVID-19 on survey respondent transit use by parish. 


\subsubsection{Discrete Choice Experiment Results}

As described in Section 4, the DCE component of the survey was utilized to examine, based on survey findings and supplementary data sources, factors that may determine whether a person would take rail or not, in order to extrapolate a model of the wider regional population and estimate ridership under different scenarios, as well as to examine the assumptions of previous feasibility studies regarding assumed trip purposes and regional propensity for rail use. The goal of this experiment is to identify the features of optimal service design - including multimodal connections on either end of the journey - to capture as many riders as possible and identify the threshold of travel time by various modes within origin and destination cities that people are willing to accept in order to make trips by rail.

The coefficients of all attributes included in the DCE analysis were found to have the expected signs, and most of them are significant at the .001 level or beyond. Compared with the reference level of each attribute, a negative coefficient means that this level is less preferred by respondents, and a positive coefficient means that this level is more preferred.

Model 1 - only including variables in the discrete choice experiment: The first model was estimated with only the variables in the discrete choice experiment in order to test the respondents' preferences among the levels of the attributes (Table 31). For the mode of transportation to get to the station, the order of preferred mode is 1) driving, 2) taking ride-sharing service, 3) taking public transit, and 4) walking or biking based on the sign and value of the coefficients or odds ratio. The odds of being chosen for walking or biking to the station is 0.67 times that of driving to the station.

For the travel time to get to the station, it is not surprising that the most preferred option is 15 minutes or less and then 15 to 30 minutes. 30 minutes or more is the least preferred. The odds of being chosen for the least preferred travel time is 0.77 times that of the most preferred.

For the mode of the link between New Orleans and Baton Rouge, a passenger train is strongly preferred comparing with a coach bus. The odds ratio shows that the odds of a train being chosen is 12.95 times that of a bus.

For the mode from the station to the final destination, there is no significant difference between taking local transit and taking ride-sharing services, and both of them are more preferred than walking or bicycling. The preference of travel time from the station to the destination is the same with the one at the origin.

Last, for the cost of the whole trip, there is no significant difference between $\$ 10$ and $\$ 15$, and both of them are more preferred than $\$ 20$, then $\$ 30$. The odds of being chosen for $\$ 30$ is 0.66 times that of $\$ 10$.

Overall, driving to the station and paying to park within 15 minutes or less, boarding a passenger train between New Orleans and Baton Rouge, taking transit or ride-sharing service from the station, and spending less than $\$ 15$ for the whole (one-way) trip are the preferred configurations. 
Table 31. DCE model 1 result.

\begin{tabular}{|c|c|c|c|c|c|}
\hline & Coef. & Std. Err. & T-ratio & P-value & Odds ratio \\
\hline Intercept & -0.644 & & & & \\
\hline \multicolumn{6}{|l|}{ Origin mode: drive* } \\
\hline Origin mode: transit & -0.257 & 0.032 & -7.998 & $<0.001$ & 0.77 \\
\hline Origin mode: walk or bike & -0.405 & 0.038 & -10.624 & $<0.001$ & 0.67 \\
\hline Origin mode: sharing & -0.191 & 0.031 & -6.063 & $<0.001$ & 0.83 \\
\hline \multicolumn{6}{|l|}{ Origin travel time: 15 minutes or less* } \\
\hline Origin travel time: $15-30$ minutes & -0.176 & 0.024 & -7.144 & $<0.001$ & 0.84 \\
\hline Origin travel time: $30+$ minutes & -0.258 & 0.025 & -10.307 & $<0.001$ & 0.77 \\
\hline \multicolumn{6}{|l|}{ Mode: coach bus* } \\
\hline Mode: train & 2.561 & 0.038 & 67.3 & $<0.001$ & 12.95 \\
\hline \multicolumn{6}{|l|}{ Destination mode: transit* } \\
\hline Destination mode: walk or bike & -0.175 & 0.026 & -6.646 & $<0.001$ & 0.84 \\
\hline Destination mode: sharing & - & - & - & - & - \\
\hline \multicolumn{6}{|l|}{ Destination travel time: 15 minutes or less* } \\
\hline Destination travel time: $15-30$ minutes & -0.076 & 0.022 & -3.375 & 0.001 & 0.93 \\
\hline Destination travel time: $30+$ minutes & -0.159 & 0.024 & -6.416 & $<0.001$ & 0.85 \\
\hline \multicolumn{6}{|l|}{ Cost: $\$ 10^{*}$} \\
\hline Cost: $\$ 15$ & - & - & - & - & - \\
\hline Cost: $\$ 20$ & -0.146 & 0.021 & -7.014 & $<0.001$ & 0.86 \\
\hline Cost: $\$ 30$ & -0.417 & 0.028 & -14.792 & $<0.001$ & 0.66 \\
\hline
\end{tabular}

Model 2 - adding sociodemographic and built environment variables: The second model was developed by adding sociodemographic and built environment variables in order to test the different preferences among individuals with different characteristics and neighborhoods with different built environments. All the variables shown previously were tested. There was only one sociodemographic variable and two built environment variables that were found to be statistically significant. All the variables in the discrete choice sets are minimally changed.

The only significant sociodemographic variable is the medium-high income group of households with income between $\$ 75,000$ and $\$ 150,000$. Compared with other individuals, this group is less interested in the proposed rail link between New Orleans and Baton Rouge.

The two significant built environment variables are employment density and proportion of employment within $1 / 2$ mile of a fixed-guideway transit stop. Both variables have positive signs, which indicate that individuals at higher employment density areas or areas with higher job accessibility by transit have higher interest in taking the link between New Orleans and Baton Rouge. 
Table 32. DCE model 2 result.

\begin{tabular}{|c|c|c|c|c|c|}
\hline & Coef. & Std. Err. & T-ratio & P-value & Odds ratio \\
\hline Intercept & -0.644 & & & & \\
\hline \multicolumn{6}{|l|}{ Origin mode: drive* } \\
\hline Origin mode: transit & -0.257 & 0.032 & -8.001 & $<0.001$ & 0.77 \\
\hline Origin mode: walk or bike & -0.405 & 0.038 & -10.629 & $<0.001$ & 0.67 \\
\hline Origin mode: sharing & -0.191 & 0.031 & -6.065 & $<0.001$ & 0.83 \\
\hline \multicolumn{6}{|l|}{ Origin travel time: 15 minutes or less* } \\
\hline Origin travel time: $15-30$ minutes & -0.176 & 0.024 & -7.142 & $<0.001$ & 0.84 \\
\hline Origin travel time: $\mathbf{3 0}+$ minutes & -0.258 & 0.025 & -10.306 & $<0.001$ & 0.77 \\
\hline \multicolumn{6}{|l|}{ Mode: coach bus* } \\
\hline Mode: train & 2.561 & 0.038 & 67.3 & $<0.001$ & 12.95 \\
\hline \multicolumn{6}{|l|}{ Destination mode: transit* } \\
\hline Destination mode: walk or bike & -0.175 & 0.026 & -6.648 & $<0.001$ & 0.84 \\
\hline Destination mode: sharing & - & - & - & - & - \\
\hline \multicolumn{6}{|l|}{ Destination travel time: 15 minutes or less* } \\
\hline Destination travel time: $15-30$ minutes & -0.077 & 0.023 & -3.377 & 0.001 & 0.93 \\
\hline Destination travel time: $30+$ minutes & -0.160 & 0.025 & -6.422 & $<0.001$ & 0.85 \\
\hline \multicolumn{6}{|l|}{ Cost: $\$ 10 *$} \\
\hline Cost: $\$ 15$ & - & - & - & - & - \\
\hline Cost: $\$ 20$ & -0.147 & 0.021 & -7.019 & $<0.001$ & 0.86 \\
\hline Cost: $\$ 30$ & -0.418 & 0.028 & -14.792 & $<0.001$ & 0.66 \\
\hline \multicolumn{6}{|l|}{ sociodemographic variables } \\
\hline Income: medium-high $(75 \mathrm{~K}-150 \mathrm{~K})$ & -0.008 & 0.004 & -1.878 & 0.06 & 0.99 \\
\hline \multicolumn{6}{|l|}{ Built environment variables } \\
\hline Employment density & 0.0003 & 0.0001 & 2.951 & 0.004 & 1.0003 \\
\hline $\begin{array}{l}\text { Transit: Proportion of employment within } 1 / 2 \text { mile of } \\
\text { fixed-guideway transit stop }\end{array}$ & 0.014 & 0.007 & 1.745 & 0.081 & 1.01 \\
\hline
\end{tabular}

Originally, we expected the models would show the different preferences among individuals with different sociodemographic characteristics and living in neighborhoods with different built environments. Then we could use the models to predict potential ridership. However, the majority of the sociodemographic and built environment variables were not statistically significant in the final models. The attributes in the discrete choice sets are all highly significant and fade out the variations among sociodemographic and built environment variables. This prevented us from being able to use the models to predict potential ridership under any scenarios.

There are a few possible reasons. First, the sample is not well distributed within the study area. A large proportion of the respondents were from Baton Rouge. Second, individuals who responded the survey tend to be homogeneous, especially for an online-only survey. People need access to computers or smart phones and internet to be able to participate in the survey. It is also common that people who really like or dislike the topic of a survey are more likely to participate in a survey. 
Last, individuals make their travel choices based on their subjective perceptions on current transportation networks in their neighborhoods, in terms of cost, time, safety, and other factors. In this case, it is generally true across the study area that people's expectation on non-auto travel is not high. For instance, many places in the study area lack of facilities for pedestrians and cyclists, have very few transit stops and/or have only transit routes with infrequent service. All of these factors together very likely lead to no significant variations across sociodemographic and built environment variables within the sample. Therefore, this model was unable to produce meaningful results at a disaggregated level of geography, inhibiting our ability to develop concrete ridership projections.

A secondary methodology for modeling predicted ridership numbers based on reported frequency of travel within the corridor and average transit mode shares was explored, as an alternative approach. This exploratory exercise derives low, medium, and high estimates for how many total trips might be generated, based on respondents answers (Table 33), calculate what percentage of the corridor's population is likely to be making an interparish trip on a typical day (Table 34), and extrapolates what share of these trips (daily and monthly totals, including all trip types and purposes), might be expected to be captured by interparish transit based on national transit mode shares (Table 35), but does not necessarily capture the share of these which would realistically be feasible via the proposed rail line.

Table 33. Ridership estimates: calculation of daily interparish trips (step a).

\begin{tabular}{|l|l|l|l|l|l|l|l|}
\hline $\begin{array}{l}\text { Frequency of } \\
\text { travel within } \\
\text { the New } \\
\text { Orleans-Baton } \\
\text { Rouge } \\
\text { Corridor }\end{array}$ & $\begin{array}{l}\text { Percent } \\
\text { age of } \\
\text { Respond } \\
\text { ents }\end{array}$ & $\begin{array}{l}\text { Number of daily trips - } \\
\text { Low Estimate }\end{array}$ & \multicolumn{2}{l|}{$\begin{array}{l}\text { Number of daily trips - } \\
\text { High Estimate }\end{array}$} & \multicolumn{2}{l|}{$\begin{array}{l}\text { Number of daily trips - } \\
\text { Average Estimate }\end{array}$} \\
\hline Every day & $5.30 \%$ & $1 /$ day & 1 & $1 /$ day & 1 & $1 /$ day & 1 \\
\hline $\begin{array}{l}\text { Several time per } \\
\text { week }\end{array}$ & $8.40 \%$ & $2 /$ week & 0.2857 & $4 /$ week & 0.5714 & $3 /$ week & 0.4286 \\
\hline $\begin{array}{l}\text { At least once } \\
\text { per week }\end{array}$ & $10.50 \%$ & $1 /$ week & 0.1429 & $2 /$ week & 0.2857 & $1.5 /$ week & 0.2143 \\
\hline $\begin{array}{l}\text { A few times per } \\
\text { month }\end{array}$ & $26.60 \%$ & $2 /$ month & 0.0667 & $3 /$ month & 0.1000 & $2.5 /$ month & 0.0833 \\
\hline $\begin{array}{l}\text { At least once } \\
\text { per month }\end{array}$ & $18.90 \%$ & $1 /$ month & 0.0333 & $2 /$ month & 0.0667 & $1.5 /$ month & 0.0500 \\
\hline $\begin{array}{l}\text { Every few } \\
\text { months }\end{array}$ & $23 \%$ & $1 / 6$ months & 0.0056 & $1 / 2$ months & 0.0167 & $1 / 4$ months & 0.0083 \\
\hline $\begin{array}{l}\text { At least once } \\
\text { per year }\end{array}$ & $4.70 \%$ & $1 /$ year & 0.0028 & $2 /$ year & 0.0056 & $1.5 /$ year & 0.0036 \\
\hline $\begin{array}{l}\text { Seldom or } \\
\text { never }\end{array}$ & $2.20 \%$ & & 0 & & 0 & & 0 \\
\hline
\end{tabular}


Table 34. Ridership estimates: calculation of daily interparish trips (step b).

\begin{tabular}{|l|l|l|l|}
\hline & & & \\
$\begin{array}{l}\text { Frequency of travel within } \\
\text { the New Orleans-Baton } \\
\text { Rouge Corridor }\end{array}$ & $\begin{array}{l}\text { Percent of corridor population } \\
\text { making interparish trips - Low } \\
\text { Estimate }\end{array}$ & $\begin{array}{l}\text { Percent of corridor } \\
\text { population making } \\
\text { interparish trips - High } \\
\text { Estimate }\end{array}$ & $\begin{array}{l}\text { Percent of corridor } \\
\text { population making } \\
\text { interparish trips - } \\
\text { Average Estimate }\end{array}$ \\
\hline Every day & $5.3000 \%$ & $5.3000 \%$ & $5.3000 \%$ \\
\hline Several time per week & $2.4000 \%$ & $4.8000 \%$ & $3.6000 \%$ \\
\hline At least once per week & $1.5000 \%$ & $3.0000 \%$ & $2.2500 \%$ \\
\hline A few times per month & $1.7733 \%$ & $2.6600 \%$ & $2.2167 \%$ \\
\hline At least once per month & $0.6300 \%$ & $1.2600 \%$ & $0.9450 \%$ \\
\hline Every few months & $0.1278 \%$ & $0.3833 \%$ & $0.1917 \%$ \\
\hline At least once per year & $0.0131 \%$ & $0.0261 \%$ & $0.0170 \%$ \\
\hline Seldom or never & 0 & 0 & 0 \\
\hline Total & $\mathbf{1 1 . 7 4 4 2 \%}$ & $\mathbf{1 7 . 4 2 9 4 \%}$ & $\mathbf{1 4 . 5 2 0 3 \%}$ \\
\hline
\end{tabular}

Table 35. Ridership estimates: calculation of potential daily and monthly ridership.

\begin{tabular}{|c|c|c|c|c|c|}
\hline & & $\begin{array}{l}\text { Low } \\
\text { Estimate }\end{array}$ & $\begin{array}{l}\text { High } \\
\text { Estimate } \\
\end{array}$ & Average & \\
\hline $\begin{array}{l}\text { Estimated \% of } \\
\text { corridor } \\
\text { population } \\
\text { making } \\
\text { interparish trips }\end{array}$ & & $11.7442 \%$ & $17.4294 \%$ & $14.5203 \%$ & \\
\hline $\begin{array}{l}\text { Population in the } \\
\text { corridor }\end{array}$ & $1,506,333$ & & & & \\
\hline & & 176,906 & 262,545 & 218,724 & Daily crossing-parish trip in the corridor \\
\hline $\begin{array}{l}\text { National transit } \\
\text { mode share - low }\end{array}$ & $1.60 \%$ & 2,831 & 4201 & 3500 & \multirow{3}{*}{ Daily ridership } \\
\hline $\begin{array}{l}\text { National transit } \\
\text { mode share - high }\end{array}$ & $5.5 \%$ & 9,730 & 14,440 & 12030 & \\
\hline $\begin{array}{l}\text { National transit } \\
\text { mode share - } \\
\text { average }\end{array}$ & $2.50 \%$ & 4,423 & 6,564 & 5,468 & \\
\hline & & 84,915 & 433,200 & 164,043 & Monthly ridership \\
\hline
\end{tabular}

Overall, this rough method of estimating suggests that there is robust demand for interparish travel, and that if even a small portion of total trips are captured by passenger rail service, previous ridership projections developed based primarily or exclusively on commute data could easily be met or exceeded. The 2014 feasibility study, for example, predicted a total ridership of 210,240 passengers per year or 779 passengers per day (calculated using Amtrak's established method of dividing annual ridership by 270 to account for seasonal variation) under a scenario of two round 
trip trains per day, whereas our calculation suggests that upwards of 2,800 trips could be captured by transit, if it were available and met riders' needs.

Additional analysis is needed to further explore these findings and to develop ridership estimation models. Future analysis could experiment with weighting cases and running separate modeling for certain groups of respondents. Other improvements can be done in future research including drawing a more representative sample, targeting specific groups (such as current commuters between New Orleans and Baton Rouge), etc. to better define the potential pool(s) of riders and their unique travel needs.

Still, the models show important information about people's preferences on the different configurations of the link between New Orleans and Baton Rouge. Key findings include:

- People overwhelmingly prefer train over bus.

- There is no significant difference between taking transit or ride-sharing service from the station to final destination.

- There are two significant built environment variables- employment density and transit accessibility, and these are positive signs.

- If the whole transportation system is improved toward a multimodal transportation network and transit-oriented land use developments are implemented, people's perception of nonauto travel may change. That will further play a role in their travel decisions leaning to choose non-auto travel, which certainly could lead to increased ridership.

Nevertheless, the results of these models show people's preferences among the difference configurations of the link between New Orleans and Baton Rouge, providing useful data to define the details of the link in order to maximize the ridership if it were built.

\subsubsection{Cohort-based DCE Findings}

As an alternative lens through which to evaluate survey findings, in light of the limited success of the planned ridership model evaluating differences in rail propensity at the neighborhood (census tract) level, the total survey DCE sample, as well as the additional questions, were analyzed directly within the Conjoint.ly software to compare the results of the DCE for various geographic (parish level) and socio-demographic segments. Importantly, this sample includes responses which were manually eliminated from previously described analytic methods (including responses from outside the directly impacted study area, as well as approximately 50 responses which were discarded due to lack of quality or relevance from the cleaned sample) and thus may contain a higher rate of error.

DCE results were evaluated across three dimensions: relative importance by attribute (the degree to which each attribute impacts overall responses), relative value by level (the degree to which the various scenarios/levels offered impact responses), and marginal willingness to pay based on variations in each level.

At the parish level, minimal variation was observed in the relative importance of each attribute, with the vehicle/mode of travel (bus vs. train) clearly marked as the most important characteristic for all corridor parishes as well as the overall sample (Figure 95). 


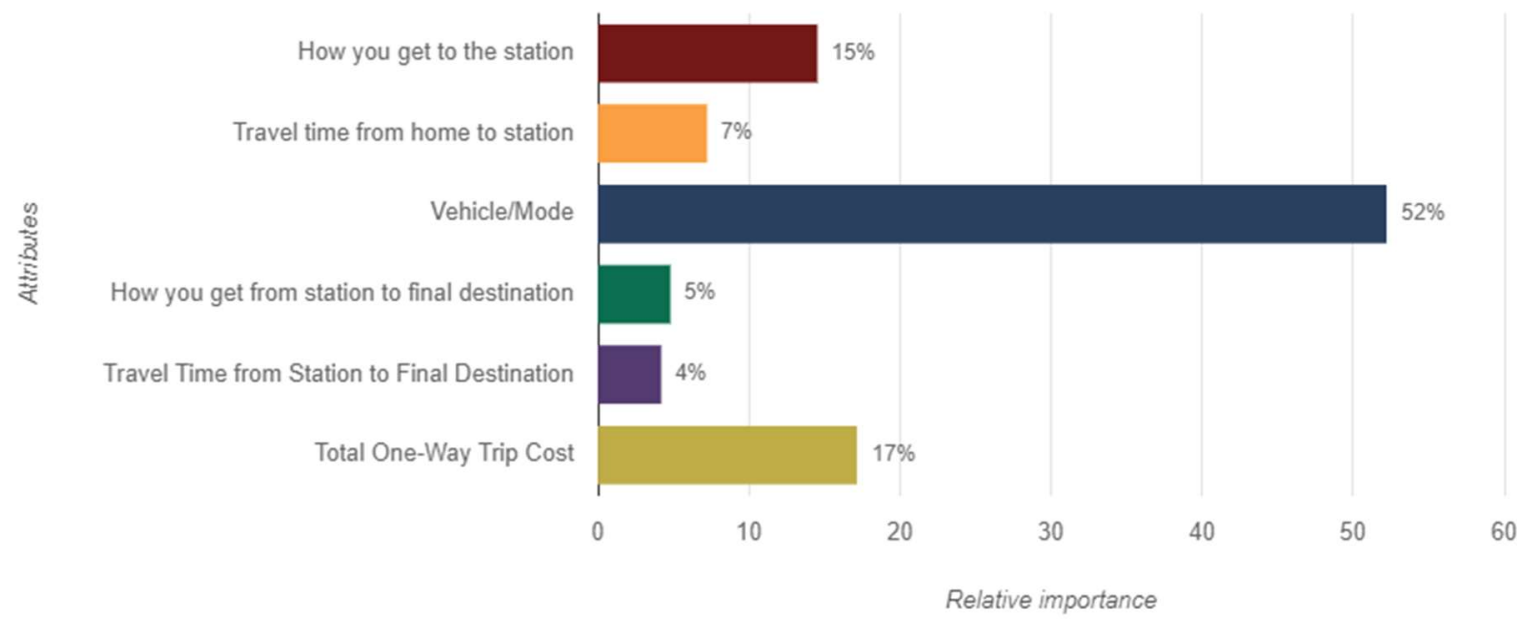

Figure 95. Relative importance of attributes (all respondents).

Slight variations exist in other parishes, with Orleans parish residents again more open to alternative modes of transport to the station, and slightly more cost-conscious than other parishes (Table 36). St. John Parish residents appear to also be sensitive to price, and favor rail over bus transport less strongly (though it is still the most important variable overall).

Table 36. Relative importance of attributes by parish.

\begin{tabular}{|l|l|l|l|l|l|l|l|}
\hline & $\begin{array}{l}\text { All } \\
\text { Respondents }\end{array}$ & Orleans & Jefferson & St. Charles & St. John & Ascension & EBR \\
\hline How you get to the station & $15 \%$ & $9 \%$ & $16 \%$ & $20 \%$ & $19 \%$ & $19 \%$ & $15 \%$ \\
\hline $\begin{array}{l}\text { Travel time from home to } \\
\text { station }\end{array}$ & $7 \%$ & $7 \%$ & $7 \%$ & $8 \%$ & $8 \%$ & $7 \%$ & $7 \%$ \\
\hline Vehicle/Mode & $52 \%$ & $56 \%$ & $48 \%$ & $43 \%$ & $40 \%$ & $46 \%$ & $53 \%$ \\
\hline $\begin{array}{l}\text { How you get from station to } \\
\text { final destination }\end{array}$ & $5 \%$ & $3 \%$ & $7 \%$ & $7 \%$ & $5 \%$ & $7 \%$ & $5 \%$ \\
\hline $\begin{array}{l}\text { Travel time from station to } \\
\text { final destination }\end{array}$ & $4 \%$ & $4 \%$ & $5 \%$ & $4 \%$ & $5 \%$ & $4 \%$ & $4 \%$ \\
\hline Total One-way trip cost & $17 \%$ & $20 \%$ & $17 \%$ & $18 \%$ & $24 \%$ & $17 \%$ & $16 \%$ \\
\hline
\end{tabular}

Among different offered levels for each attribute, the strong preference for rail over bus transport again stands out, as does a clear preference for driving as the primary mode of station access, with walking or bicycling least valued overall (Figure 96). Travel time to the station is of greater importance than travel time from the terminal station to final destination, where taxis or rideshare emerge as the preferred mode of access. One-way trip costs of \$10-15 are similarly tolerated, but it would appear that trip costs of $\$ 20$ would not put off the majority of potential riders.

Variations by parish are again relatively minor, with New Orleanians placing slightly less value on the ability to drive to the station, and Orleans and St. John residents demonstrating the highest cost sensitivity (Table 37). 


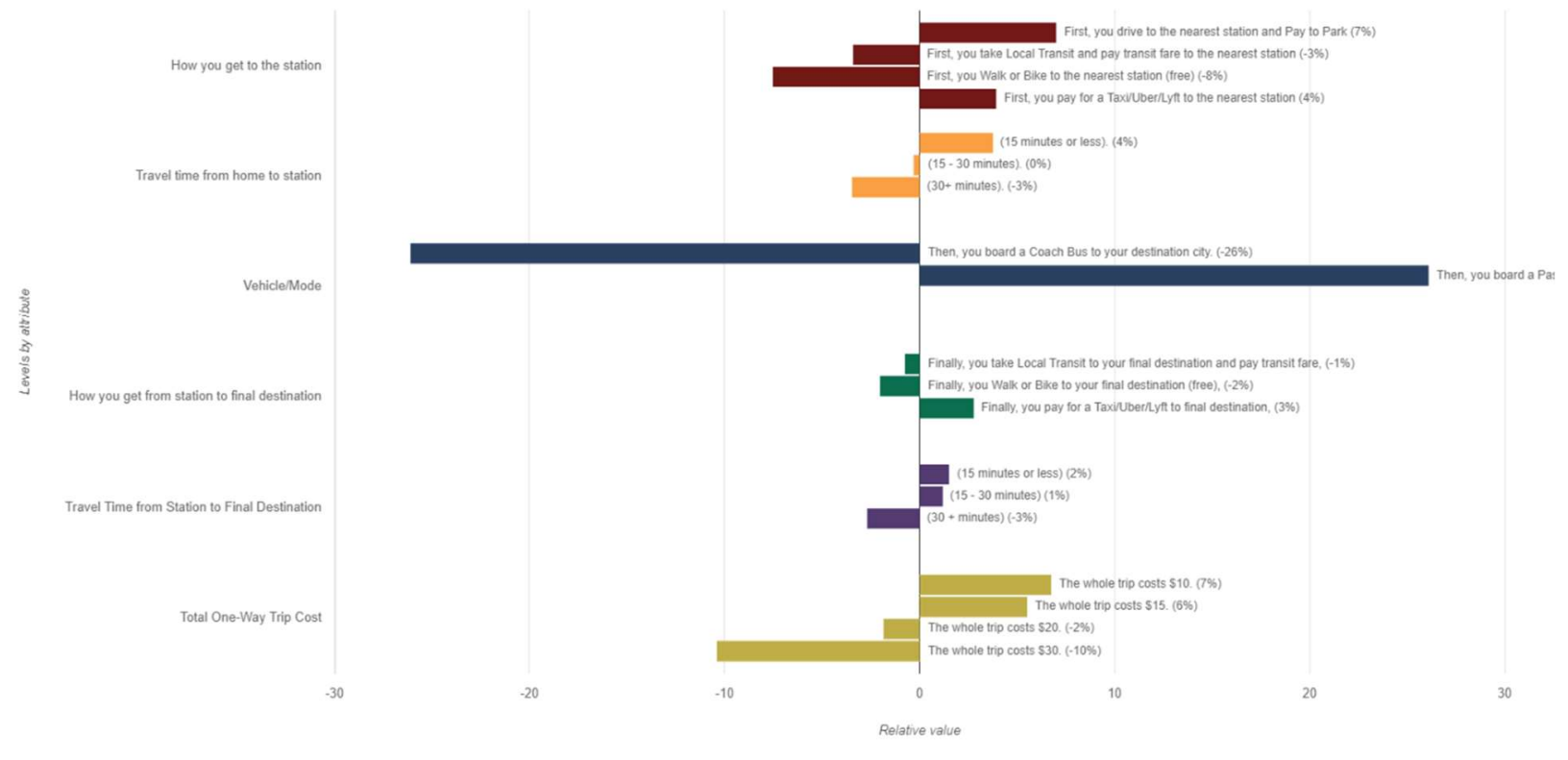

Figure 96. Relative value of levels - all respondents.

Table 37. Relative value of levels by parish.

\begin{tabular}{|c|c|c|c|c|c|c|c|c|}
\hline Relative Value by Level & & $\begin{array}{l}\text { All } \\
\text { Respondents }\end{array}$ & $\begin{array}{l}\text { Orlea } \\
\text { ns }\end{array}$ & $\begin{array}{l}\text { Jeffers } \\
\text { on }\end{array}$ & $\begin{array}{l}\text { St. } \\
\text { Charles }\end{array}$ & $\begin{array}{l}\text { St. } \\
\text { John }\end{array}$ & $\begin{array}{l}\text { Ascens } \\
\text { ion }\end{array}$ & EBR \\
\hline & $\begin{array}{l}\text { Drive and Pay } \\
\text { to Park }\end{array}$ & $7 \%$ & $5 \%$ & $8 \%$ & $10 \%$ & $9 \%$ & $9 \%$ & $7 \%$ \\
\hline & Local Transit & $-3 \%$ & $-3 \%$ & $-4 \%$ & $-3 \%$ & $-2 \%$ & $-3 \%$ & $-4 \%$ \\
\hline & Walk or Bike & $-8 \%$ & $-4 \%$ & $-9 \%$ & $-10 \%$ & $-9 \%$ & $-10 \%$ & $-8 \%$ \\
\hline How you get to the station & $\begin{array}{l}\text { Taxi/Uber/Ly } \\
\mathrm{ft}\end{array}$ & $4 \%$ & $3 \%$ & $5 \%$ & $3 \%$ & $2 \%$ & $4 \%$ & $4 \%$ \\
\hline \multirow{3}{*}{$\begin{array}{l}\text { Travel time from home to } \\
\text { station }\end{array}$} & $<15$ minutes & $4 \%$ & $4 \%$ & $4 \%$ & $4 \%$ & $4 \%$ & $4 \%$ & $4 \%$ \\
\hline & 15-30 minutes & $0 \%$ & $0 \%$ & $0 \%$ & $0 \%$ & $0 \%$ & $0 \%$ & $0 \%$ \\
\hline & $>30$ minutes & $-3 \%$ & $-4 \%$ & $-3 \%$ & $-4 \%$ & $-4 \%$ & $-3 \%$ & $-3 \%$ \\
\hline \multirow[b]{2}{*}{ Vehicle/Mode } & Coach Bus & $-26 \%$ & $-28 \%$ & $-24 \%$ & $-21 \%$ & $-20 \%$ & $-23 \%$ & $-27 \%$ \\
\hline & $\begin{array}{l}\text { Passenger } \\
\text { Train }\end{array}$ & $26 \%$ & $28 \%$ & $24 \%$ & $21 \%$ & $20 \%$ & $23 \%$ & $27 \%$ \\
\hline \multirow[b]{3}{*}{$\begin{array}{l}\text { How you get from station } \\
\text { to final destination }\end{array}$} & Local Transit & $-1 \%$ & $-1 \%$ & $0 \%$ & $1 \%$ & $1 \%$ & $0 \%$ & $-1 \%$ \\
\hline & Walk or Bike & $-2 \%$ & $-1 \%$ & $-3 \%$ & $-4 \%$ & $-3 \%$ & $-3 \%$ & $-2 \%$ \\
\hline & $\begin{array}{l}\text { Taxi/Uber/Ly } \\
\mathrm{ft}\end{array}$ & $3 \%$ & $2 \%$ & $4 \%$ & $3 \%$ & $2 \%$ & $3 \%$ & $3 \%$ \\
\hline \multirow{3}{*}{$\begin{array}{l}\text { Travel time from station } \\
\text { to final destination }\end{array}$} & $<15$ minutes & $2 \%$ & $2 \%$ & $2 \%$ & $2 \%$ & $2 \%$ & $1 \%$ & $1 \%$ \\
\hline & $15-30$ minutes & $1 \%$ & $1 \%$ & $1 \%$ & $1 \%$ & $1 \%$ & $1 \%$ & $1 \%$ \\
\hline & $>30$ minutes & $-3 \%$ & $-3 \%$ & $-3 \%$ & $-2 \%$ & $-3 \%$ & $-3 \%$ & $-3 \%$ \\
\hline \multirow[b]{4}{*}{ Total one-way trip cost } & $\$ 10$ & $7 \%$ & $8 \%$ & $7 \%$ & $7 \%$ & $10 \%$ & $7 \%$ & $6 \%$ \\
\hline & $\$ 15$ & $6 \%$ & $6 \%$ & $6 \%$ & $5 \%$ & $6 \%$ & $5 \%$ & $5 \%$ \\
\hline & $\$ 20$ & $-2 \%$ & $-2 \%$ & $-2 \%$ & $-2 \%$ & $-2 \%$ & $-2 \%$ & $-2 \%$ \\
\hline & $\$ 30$ & $-10 \%$ & $-12 \%$ & $-10 \%$ & $-11 \%$ & $-14 \%$ & $-10 \%$ & $-10 \%$ \\
\hline
\end{tabular}


Analysis of marginal willingness to pay based on the various attributes and levels highlights, with most-preferred alternatives set as baseline, further illuminates these findings, with relative important translated to dollar values. Again, taking transit or walking/bicycling to the station emerge as the strongest deterrents to ridership, likely reflecting the difficulty of these options under current conditions, for most region residents (Figure 97).

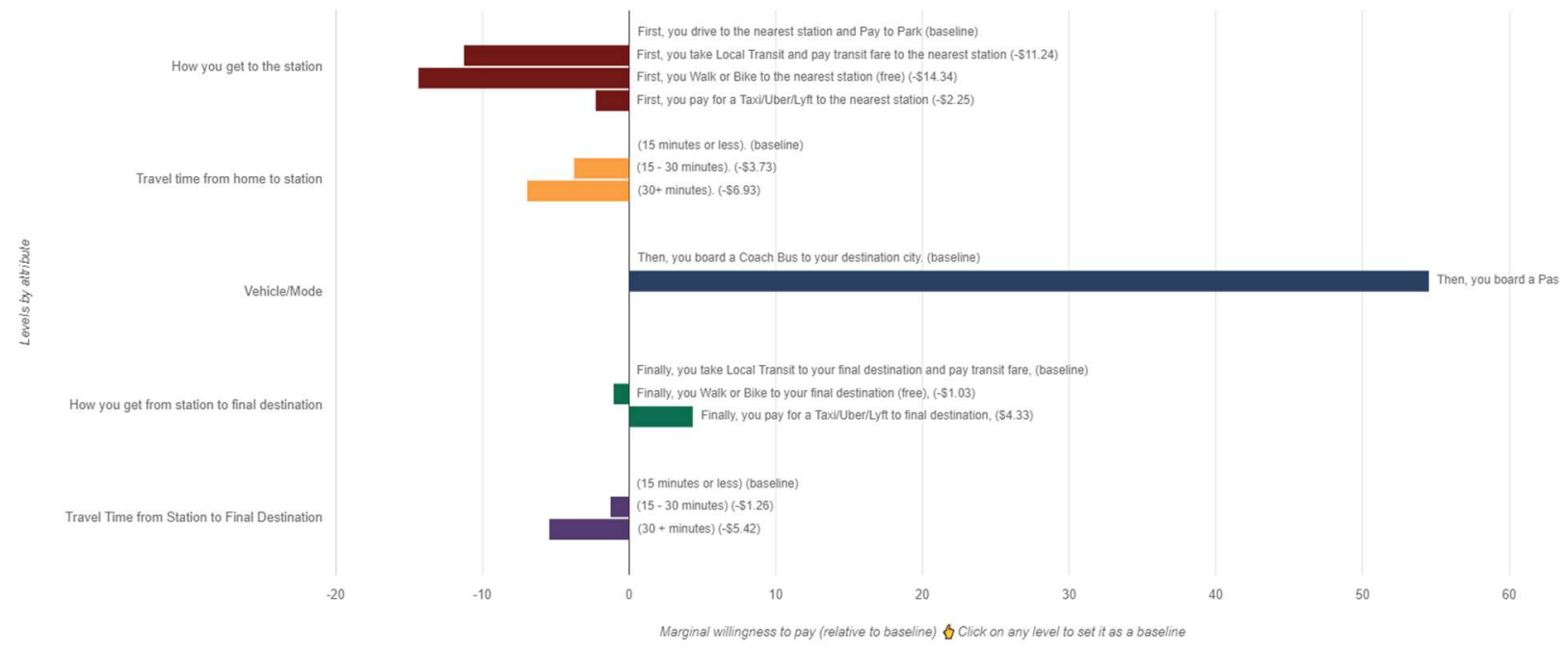

Figure 97. Marginal willingness to pay - all respondents.

Findings at the parish level mirror those identified above, with greatly reduced sensitivity to mode of access in Orleans Parish, and a stronger-than-average aversion to transit, walking, or bicycling in auto-oriented St. Charles and Ascension Parishes (Table 38). Travel time sensitivity to the station is highest among Ascension and Baton Rouge residents, although these differences are minimal for travel time from station to final destination, were respondents appear to have a greater tolerance for longer segment durations. Baton Rouge residents place the highest premium on rail as the mode of transport over bus, while New Orleanians note a slight but distinctive preference for walking or bicycling at their trip destinations (possibly reflecting the paucity of transit service in the rest of the region relative to New Orleans). 
Table 38. Marginal willingness to pay by parish.

\begin{tabular}{|c|c|c|c|c|c|c|c|c|}
\hline $\begin{array}{l}\text { Marginal } \\
\text { Willingness } \\
\text { to Pay }\end{array}$ & & $\begin{array}{l}\text { All } \\
\text { Respondents }\end{array}$ & Orleans & Jefferson & $\begin{array}{l}\text { St. } \\
\text { Charles }\end{array}$ & St. John & $\begin{array}{l}\text { Ascensio } \\
\text { n }\end{array}$ & EBR \\
\hline \multirow{4}{*}{$\begin{array}{l}\text { How you get } \\
\text { to the station }\end{array}$} & $\begin{array}{l}\text { Drive and Pay } \\
\text { to Park }\end{array}$ & (baseline) & & & & & & \\
\hline & Local Transit & $\$(11.24)$ & $\$(7.06)$ & $\$(11.92)$ & $\$(13.02)$ & $\$(9.36)$ & $\$(13.64)$ & $\$(12.77)$ \\
\hline & Walk or Bike & $\$(14.34)$ & $\$(7.50)$ & $\$(16.15)$ & $\$(19.78)$ & $\$(14.51)$ & $\$(20.52)$ & $\$(15.96)$ \\
\hline & Taxi/Uber/Lyft & $\$(2.25)$ & $\$(0.91)$ & $\$(1.96)$ & $\$(5.94)$ & $\$(4.90)$ & $\$(4.56)$ & $\$(2.13)$ \\
\hline \multirow{3}{*}{$\begin{array}{l}\text { Travel time } \\
\text { from home to } \\
\text { station }\end{array}$} & $<15$ minutes & (baseline) & & & & & & \\
\hline & $15-30$ minutes & $\$(3.73)$ & $\$(3.16)$ & $\$(4.00)$ & $\$(2.99)$ & $\$(2.77)$ & $\$(4.10)$ & $\$(4.04)$ \\
\hline & $>30$ minutes & $\$(6.93)$ & $\$(5.98)$ & $\$(7.26)$ & $\$(6.78)$ & $\$(5.75)$ & $\$(7.57)$ & $\$(7.37)$ \\
\hline \multirow{2}{*}{$\begin{array}{l}\text { Vehicle/Mod } \\
\text { e }\end{array}$} & Coach Bus & (baseline) & & & & & & \\
\hline & Passenger Train & $\$ 54.00$ & $\$ 50.00$ & $\$ 50.00$ & $\$ 42.00$ & $\$ 32.00$ & $\$ 51.00$ & $\$ 60.00$ \\
\hline \multirow{3}{*}{$\begin{array}{l}\text { How you get } \\
\text { from station } \\
\text { to final } \\
\text { destination }\end{array}$} & Local Transit & (baseline) & & & & & & \\
\hline & Walk or Bike & $\$(1.03)$ & $\$ 0.76$ & $\$(2.23)$ & $\$(4.67)$ & $\$(3.40)$ & $\$(3.35)$ & $\$(0.91)$ \\
\hline & Taxi/Uber/Lyft & $\$ 4.33$ & $\$ 3.02$ & $\$ 4.95$ & $\$ 2.91$ & $\$ 0.67$ & $\$ 4.47$ & $\$ 5.21$ \\
\hline \multirow{3}{*}{$\begin{array}{l}\text { Travel time } \\
\text { from station } \\
\text { to final } \\
\text { destination }\end{array}$} & $<15$ minutes & (baseline) & & & & & & \\
\hline & $15-30$ minutes & $\$(1.26)$ & $\$(1.04)$ & $\$(1.32)$ & $\$(1.21)$ & $\$(1.08)$ & $\$(1.26)$ & $\$(1.34)$ \\
\hline & $>30$ minutes & $\$(5.42)$ & $\$(4.97)$ & $\$(5.64)$ & $\$(4.65)$ & $\$(4.26)$ & $\$(5.54)$ & $\$(5.69)$ \\
\hline
\end{tabular}

In addition, we evaluate these differences across various socio-demographic segments of interest, including gender, race/ethnicity, income level, and vehicle access (Tables 39-41).

Few pronounced differences appear across gender lines, with women placing slightly greater importance on travel mode to the station (with a stronger aversion to walking, bicycling, and transit) and men noting a stronger prioritization of rail over bus service.

Race appears to factor in more clearly, with respondents identifying as Black placing a substantively greater importance on travel mode to and from stations, and less importance on whether the intercity service is a train or a bus. In particular, Black respondents indicate an unwillingness to walk or bike to stations and are more likely than the overall pool to prefer to drive to the station and take a taxi or rideshare to their final destination. Respondents identifying as Hispanic, on the other hand, were less likely than the overall pool to prioritize mode of access to and from stations, and instead indicated stronger sensitivity to cost.

Unsurprisingly, respondents at the lower end of the income spectrum (less than $\$ 50 \mathrm{k}$ ) indicated that trip cost is of high importance, second only to intercity travel mode, where preference for rail was weighted only slightly less highly than the overall pool. This group was also less likely to prefer taxis or rideshare relative to less expensive alternatives.

Similarly, among respondents who have limited or no access to a personal vehicle, the mode of transport to and from stations matter less, and trip cost matters more overall. Notably, this group appears to be most sensitive to travel time but is not significantly less preferential toward rail over bus transport.

Full raw DCE results, including cohort segmentation, are available in Appendix D. 
Table 39. Relative importance of attributes by gender, race/ethnicity, income, and vehicle access.

\begin{tabular}{|c|c|c|c|c|c|c|c|c|}
\hline & \multirow[b]{2}{*}{$\begin{array}{l}\text { All } \\
\text { Respondents }\end{array}$} & \multicolumn{2}{|c|}{ Gender } & \multicolumn{2}{|c|}{ Race/Ethnicity } & \multicolumn{2}{|l|}{ Income } & \multirow{2}{*}{$\begin{array}{l}\begin{array}{l}\text { Vehicle } \\
\text { Access }\end{array} \\
\text { None or } \\
\text { limited }\end{array}$} \\
\hline & & Male & Female & Black & $\begin{array}{l}\text { Hispanic } \\
\text { /Latino }\end{array}$ & $\begin{array}{l}\text { Less than } \\
\text { \$50k/year }\end{array}$ & $\begin{array}{l}\$ 50- \\
100 \mathrm{k} / \text { year }\end{array}$ & \\
\hline $\begin{array}{l}\text { How you get to the } \\
\text { station }\end{array}$ & $15 \%$ & $13 \%$ & $16 \%$ & $22 \%$ & $11 \%$ & $12 \%$ & $15 \%$ & $4 \%$ \\
\hline $\begin{array}{l}\text { Travel time from } \\
\text { home to station }\end{array}$ & $7 \%$ & $7 \%$ & $7 \%$ & $8 \%$ & $8 \%$ & $8 \%$ & $7 \%$ & $9 \%$ \\
\hline Vehicle/Mode & $52 \%$ & $55 \%$ & $50 \%$ & $39 \%$ & $50 \%$ & $48 \%$ & $50 \%$ & $50 \%$ \\
\hline $\begin{array}{l}\text { How you get from } \\
\text { station to final } \\
\text { destination }\end{array}$ & $5 \%$ & $4 \%$ & $6 \%$ & $9 \%$ & $2 \%$ & $3 \%$ & $5 \%$ & $1 \%$ \\
\hline $\begin{array}{l}\text { Travel time from } \\
\text { station to final } \\
\text { destination }\end{array}$ & $4 \%$ & $4 \%$ & $4 \%$ & $4 \%$ & $5 \%$ & $5 \%$ & $4 \%$ & $6 \%$ \\
\hline $\begin{array}{l}\text { Total One-way trip } \\
\text { cost }\end{array}$ & $17 \%$ & $17 \%$ & $17 \%$ & $19 \%$ & $23 \%$ & $24 \%$ & $18 \%$ & $30 \%$ \\
\hline
\end{tabular}

Table 40. Relative value of levels by gender, race/ethnicity, income, and vehicle access.

\begin{tabular}{|c|c|c|c|c|c|c|c|c|c|}
\hline & & & Gend & & Race/ & thnicity & Income & & $\begin{array}{l}\text { Vehicle } \\
\text { Access }\end{array}$ \\
\hline & & $\begin{array}{l}\text { Respon } \\
\text { dents }\end{array}$ & Male & Female & Black & $\begin{array}{l}\text { Hispanic } \\
\text { Latino }\end{array}$ & $\begin{array}{l}\text { Less than } \\
\$ 50 \text { k/year }\end{array}$ & $\begin{array}{l}\$ 50- \\
100 \mathrm{k} / \text { year }\end{array}$ & $\begin{array}{l}\text { None or } \\
\text { limited }\end{array}$ \\
\hline \multirow{4}{*}{$\begin{array}{l}\text { How you get } \\
\text { to the station }\end{array}$} & $\begin{array}{l}\text { Drive and Pay } \\
\text { to Park }\end{array}$ & $7 \%$ & $7 \%$ & $7 \%$ & $9 \%$ & $5 \%$ & $6 \%$ & $7 \%$ & $-2 \%$ \\
\hline & Local Transit & $-3 \%$ & $-3 \%$ & $-3 \%$ & $-2 \%$ & $-2 \%$ & $-2 \%$ & $-3 \%$ & $2 \%$ \\
\hline & Walk or Bike & $-8 \%$ & $-7 \%$ & $-8 \%$ & $-12 \%$ & $-6 \%$ & $-6 \%$ & $-8 \%$ & $-1 \%$ \\
\hline & Taxi/Uber/Lyft & $4 \%$ & $4 \%$ & $4 \%$ & $4 \%$ & $3 \%$ & $3 \%$ & $4 \%$ & $2 \%$ \\
\hline \multirow{3}{*}{$\begin{array}{l}\text { Travel time } \\
\text { from home to } \\
\text { station }\end{array}$} & $<15$ minutes & $4 \%$ & $4 \%$ & $4 \%$ & $4 \%$ & $4 \%$ & $4 \%$ & $4 \%$ & $4 \%$ \\
\hline & $15-30$ minutes & $0 \%$ & $0 \%$ & $0 \%$ & $0 \%$ & $0 \%$ & $0 \%$ & $0 \%$ & $0 \%$ \\
\hline & $>30$ minutes & $-3 \%$ & $-3 \%$ & $-3 \%$ & $-4 \%$ & $4 \%$ & $-4 \%$ & $-4 \%$ & $-5 \%$ \\
\hline \multirow[b]{2}{*}{$\begin{array}{l}\text { Vehicle/Mod } \\
\text { e }\end{array}$} & Coach Bus & $-26 \%$ & $-27 \%$ & $-25 \%$ & $-19 \%$ & $-25 \%$ & $-24 \%$ & $-25 \%$ & $-25 \%$ \\
\hline & $\begin{array}{l}\text { Passenger } \\
\text { Train }\end{array}$ & $26 \%$ & $27 \%$ & $25 \%$ & $19 \%$ & $25 \%$ & $24 \%$ & $25 \%$ & $25 \%$ \\
\hline \multirow{3}{*}{$\begin{array}{l}\text { How you get } \\
\text { from station } \\
\text { to final } \\
\text { destination }\end{array}$} & Local Transit & $-1 \%$ & $-1 \%$ & $-1 \%$ & $1 \%$ & $0 \%$ & $0 \%$ & $0 \%$ & $0 \%$ \\
\hline & Walk or Bike & $-2 \%$ & $-1 \%$ & $-3 \%$ & $-5 \%$ & $-1 \%$ & $-1 \%$ & $-2 \%$ & $0 \%$ \\
\hline & Taxi/Uber/Lyft & $3 \%$ & $2 \%$ & $3 \%$ & $4 \%$ & $1 \%$ & $2 \%$ & $3 \%$ & $0 \%$ \\
\hline \multirow{3}{*}{$\begin{array}{l}\text { Travel time } \\
\text { from station } \\
\text { to final } \\
\text { destination }\end{array}$} & $<15$ minutes & $2 \%$ & $1 \%$ & $2 \%$ & $2 \%$ & $2 \%$ & $2 \%$ & $2 \%$ & $3 \%$ \\
\hline & $15-30$ minutes & $1 \%$ & $1 \%$ & $1 \%$ & $1 \%$ & $1 \%$ & $1 \%$ & $1 \%$ & $1 \%$ \\
\hline & $>\mathbf{3 0}$ minutes & $-3 \%$ & $-3 \%$ & $-3 \%$ & $-3 \%$ & $-3 \%$ & $-3 \%$ & $-3 \%$ & $-3 \%$ \\
\hline \multirow{4}{*}{$\begin{array}{l}\text { Total one- } \\
\text { way trip cost }\end{array}$} & $\$ 10$ & $7 \%$ & $7 \%$ & $7 \%$ & $8 \%$ & $9 \%$ & $10 \%$ & $7 \%$ & $13 \%$ \\
\hline & $\$ 15$ & $6 \%$ & $5 \%$ & $5 \%$ & $5 \%$ & $6 \%$ & $7 \%$ & $6 \%$ & $8 \%$ \\
\hline & $\$ 20$ & $-2 \%$ & $-2 \%$ & $-2 \%$ & $-2 \%$ & $-2 \%$ & $-2 \%$ & $-2 \%$ & $-2 \%$ \\
\hline & $\$ 30$ & $-10 \%$ & $-10 \%$ & $-10 \%$ & $-11 \%$ & $-14 \%$ & $-14 \%$ & $-11 \%$ & $-18 \%$ \\
\hline
\end{tabular}


Table 41. Marginal willingness to pay by gender, race/ethnicity, income, and vehicle access.

\begin{tabular}{|c|c|c|c|c|c|c|c|c|c|}
\hline & & & Gender & & Race/Et & nicity & Income & & $\begin{array}{l}\text { Vehicle } \\
\text { Access }\end{array}$ \\
\hline & & $\begin{array}{l}\text { All } \\
\text { Respond } \\
\text { ents }\end{array}$ & Male & Female & Black & $\begin{array}{l}\text { Hispa } \\
\text { nic/La } \\
\text { tino }\end{array}$ & $\begin{array}{l}\text { Less than } \\
\$ 50 k / \text { year }\end{array}$ & $\begin{array}{l}\$ 50- \\
100 k / \\
\text { year }\end{array}$ & $\begin{array}{l}\text { None or } \\
\text { limited }\end{array}$ \\
\hline \multirow{4}{*}{$\begin{array}{l}\text { How you get } \\
\text { to the station }\end{array}$} & $\begin{array}{l}\text { Drive and Pay } \\
\text { to Park }\end{array}$ & (baseline) & & & & & & & \\
\hline & Local Transit & $\$(11.24)$ & $\$(10.98)$ & $\$(11.73)$ & $\$(10.77)$ & $\$(7.02)$ & $\$(6.83)$ & $\$(10.30)$ & $\$ 2.08$ \\
\hline & Walk or Bike & $\$(14.34)$ & $\$(13.20)$ & $\$(15.66)$ & $\$(20.07)$ & $\$(8.44)$ & $\$(8.92)$ & $\$(14.01)$ & $\$ 0.96$ \\
\hline & Taxi/Uber/Lyft & $\$(2.25)$ & $\$(2.04)$ & $\$(2.44)$ & $\$(4.12)$ & $\$(1.93)$ & $\$(1.87)$ & $\$(2.70)$ & $\$ 2.85$ \\
\hline \multirow{3}{*}{$\begin{array}{l}\text { Travel time } \\
\text { from home to } \\
\text { station }\end{array}$} & $<15$ minutes & (baseline) & & & & & & & \\
\hline & 15-30 minutes & $\$(3.73)$ & $\$(3.60)$ & $\$(3.90)$ & $\$(3.73)$ & $\$(3.12)$ & $\$(3.10)$ & $\$(3.50)$ & $\$(2.68)$ \\
\hline & $>30$ minutes & $\$(6.93)$ & $\$(6.83)$ & $\$(7.08)$ & $\$(7.03)$ & $\$(6.05)$ & $\$(5.98)$ & $\$(6.75)$ & $\$(5.61)$ \\
\hline \multirow[b]{2}{*}{$\begin{array}{l}\text { Vehicle/ } \\
\text { Mode }\end{array}$} & Coach Bus & (baseline) & & & & & & & \\
\hline & $\begin{array}{l}\text { Passenger } \\
\text { Train }\end{array}$ & $\$ 54.00$ & $\$ 58.00$ & $\$ 52.00$ & $\$ 37.00$ & $\$ 39.00$ & $\$ 36.00$ & $\$ 49.00$ & $\$ 31.00$ \\
\hline \multirow{3}{*}{$\begin{array}{l}\text { How you get } \\
\text { from station } \\
\text { to final } \\
\text { destination }\end{array}$} & Local Transit & (baseline) & & & & & & & \\
\hline & Walk or Bike & $\$(1.03)$ & $\$(0.25)$ & $\$(1.71)$ & $\$(6.02)$ & $\$(0.15)$ & $\$(0.80)$ & $\$(1.53)$ & $\$(0.08)$ \\
\hline & Taxi/Uber/Lyft & $\$ 4.33$ & $\$ 4.19$ & $\$ 4.62$ & $\$ 2.54$ & $\$ 1.76$ & $\$ 1.97$ & $\$ 3.48$ & $\$ 0.15$ \\
\hline \multirow{3}{*}{$\begin{array}{l}\text { Travel time } \\
\text { from station } \\
\text { to final } \\
\text { destination }\end{array}$} & $<15$ minutes & (baseline) & & & & & & & \\
\hline & $15-30$ minutes & $\$(1.26)$ & $\$(1.20)$ & $\$(1.30)$ & $\$(1.46)$ & $\$(1.19)$ & $\$(1.14)$ & $\$(1.26)$ & $\$(1.35)$ \\
\hline & $>30$ minutes & $\$(5.42)$ & $\$(5.46)$ & $\$(5.43)$ & $\$(4.88)$ & $\$(4.92)$ & $\$(4.48)$ & $\$(5.22)$ & $\$(4.13)$ \\
\hline
\end{tabular}

\subsubsection{Qualitative and Open-Ended Responses}

The survey instrument also asked respondents three (optional) questions requiring a free response, pertaining to the DCE scenario exercise, anticipated changes to current behaviors (primarily related to COVID-19), and a final question soliciting any other thoughts about the survey or the topic overall. These questions were:

- Would you like to share any other thoughts about the scenarios presented? Do you have questions about the potential intercity service options or local connection scenarios that you would like us to address in our report?

- In what ways do you expect your transportation habits, specifically, to change in coming months and years?

- Would you like to share any other thoughts or ideas with the research team about transportation needs, challenges, or possibilities in the New Orleans-Baton Rouge region?

In order to analyze the $\sim 6000$ resulting responses (Appendix, the responses were converted to a tabular format (one response per cell, in a row with its associated respondent reference ID) and queried by a variety of key words and sorted according to theme in Google Sheets in order to more efficiently review responses for general attitude (e.g., positive or negative associations), recurring themes (e.g., special interest groups), and overall number of references, as well as to identify potential data gaps or limitations of the survey instrument to be aware of (Table 42). 
Table 42. Open-ended responses: number of references by keyword/theme.

\begin{tabular}{|l|l|l|l|}
\hline & DCE & COVID & Other \\
\hline Public Transit/transit & 240 & 200 & 145 \\
\hline Bicycling/bike & 198 & 210 & 115 \\
\hline Walking/walk & 248 & 157 & 71 \\
\hline Bus & 443 & 128 & 167 \\
\hline timing/schedule/frequency & 51 & 23 & 30 \\
\hline Parking & 92 & 10 & 43 \\
\hline cost/fare/price/money & 156 & 40 & 95 \\
\hline College/University/School & 52 & 47 & 70 \\
\hline Sports & 51 & 20 & 68 \\
\hline Airplane/Airport & 21 & 59 & 18 \\
\hline Festival/Events & 56 & 65 & 53 \\
\hline Elderly/Disabled & 6 & 1 & 7 \\
\hline Children & 26 & 40 & 18 \\
\hline Equity/race/poverty & 0 & 3 & 14 \\
\hline Jobs/economy & 69 & 36 & 99 \\
\hline
\end{tabular}

Select highlights from review of the open-response questions include:

- Reiteration of respondents' strong preference for train over bus travel

- Concerns about personal safety/security either on the train or at/accessing stations

- Dissatisfaction with current transit service availability and/or bicycling infrastructure

- Necessity of trip speeds that are competitive with driving/emphasis on "high speed" rail

- Desire to access the airport via train

- Discomfort with walking/bicycling due to weather

- Interest in bringing bikes on trains

- Concerns over cleanliness of public transit

- Concerns over accessibility of options for people with mobility impairments

- Imperative to improve walkability in neighborhoods

- Need for public information/marketing campaign to promote use of transit for recreational/special event travel

- Prevalence of responses indicating disinterest in local transit, but strong interest in proposed passenger rail

- Necessity of train schedules that support recreational/entertainment trip purposes (e.g., evenings and weekends)

- Availability of discounted fares for regular users and/or low-income riders

A full inventory of responses to open-ended questions, along with queried results by keyword/theme, is available in Appendix E. 


\subsubsection{Spatial Distribution of Select Variables and Survey Responses}

Throughout the research process, we also evaluated select population and employment variables, as well as key indicator responses, at the census tract or individual geocoded response level to visualize both the overall distribution of survey responses within the study area, as well as to explore spatial variation at the neighborhood/census tract scale, particularly within $1 / 2$ mile and 2mile buffers of the proposed stations.

First, the total population (ACS 2019 5-year estimates) is summarized at the census tract level, to estimate the approximate number of people living within walking (1/2 mile) and bicycling (2 mile) distances of the proposed stations (calculated by summarizing the total population for census tracts whose centroids are within the buffer area). By this rough method, we estimate that over 250,000 people live within two miles of a proposed rail station, and approximately 10,000 live within half of a mile. In the following map series, population is symbolized by relative population density (classified by quantiles) for the entire corridor study area, to illustrate areas of higher population density more likely to be transit-supportive.

In Baton Rouge, approximately 3000 people within $1 / 2$ mile of the downtown station; the Suburban Baton Rouge station does not contain the centroid of any of the four tracts which intersect its $1 / 2$ mile walkshed. Approximately 33,000 people live within two miles of the downtown station, generally considered (provided adequate infrastructure exists) to be a reasonable distance to bicycle. Nearly 30,000 people also live within two miles of the suburban station (Figure 98). Importantly, these estimates are based on Euclidean distance measurements and do not take into account boundaries or barriers which inhibit walking or bicycling. Additional network analysis is recommended to calculate more refined walk/bikesheds based on actual street networks and infrastructure.

In addition, a buffer representing all areas within $1 / 2$ mile of a fixed-route transit stop were developed to calculate the approximate number of residents within walking distance of the transit system. In Baton Rouge, approximately 220,000 people are within this area, although, critically, this does not reflect frequency of services available or ease of connection to proposed stations (Figure 99).

Finally, the number of jobs within $1 / 2$ and two-mile buffers were also calculated, using LEHD/LODES Origin and Destination data summarizing the total number of jobs per census block. In Baton Rouge, there are over 350 jobs within $1 / 2$ mile of the proposed downtown station, and over 1800 within $1 / 2$ mile of the proposed suburban station. Expanding the buffer out to two miles, there are approximately 9000 jobs within two miles of the downtown station and 13,000 within theoretical bicycling distance of the suburban station, reflecting this area's prominence as a hub of employment within the region (Figure 100). In total, over 55,000 jobs are within $1 / 2$ mile of a transit stop, but notably, there are several areas of high employment density within the greater metro area which fall outside of CATS' service area (Figure 101). 


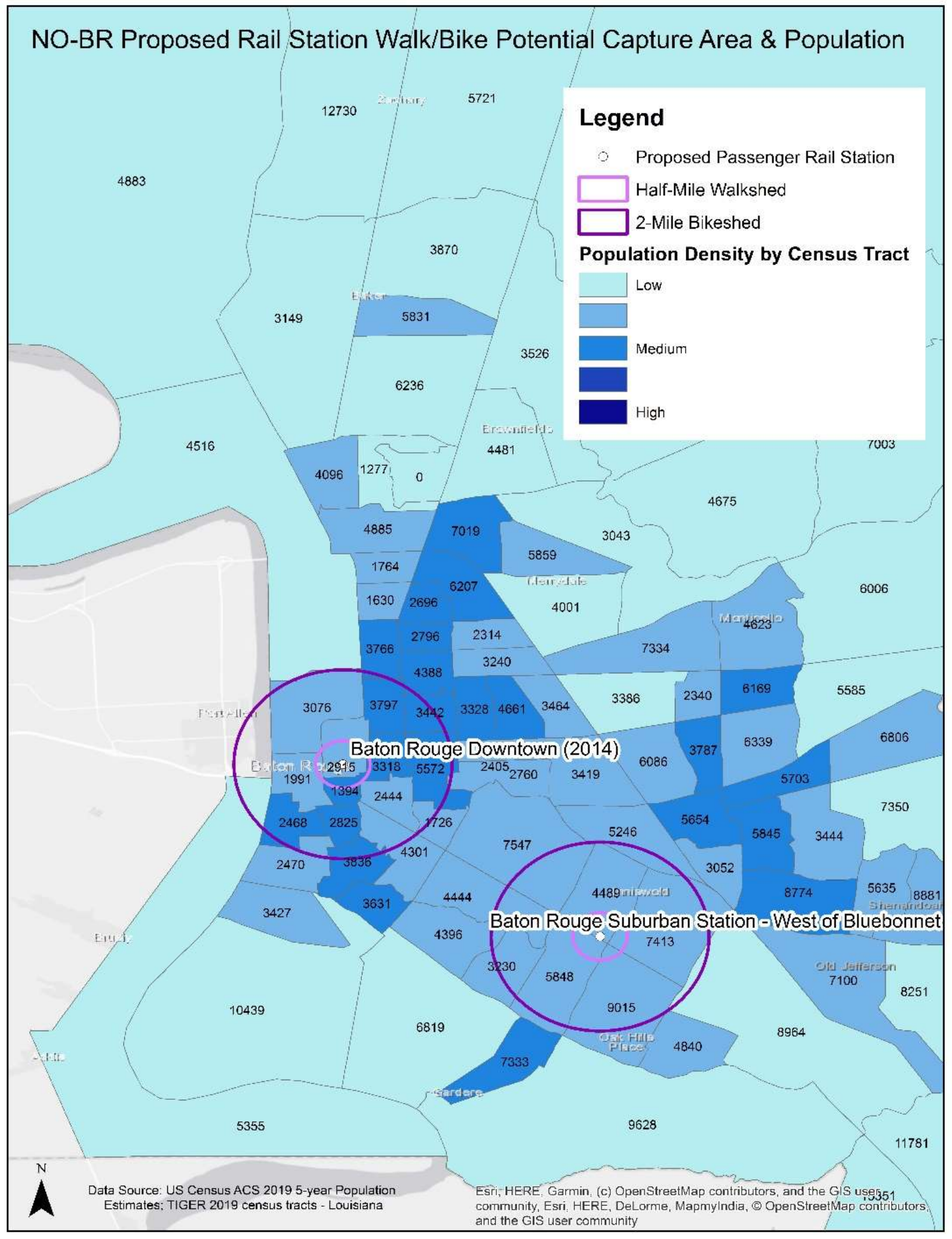

Figure 98. Walk/bike potential capture area and population: Baton Rouge proposed stations. 


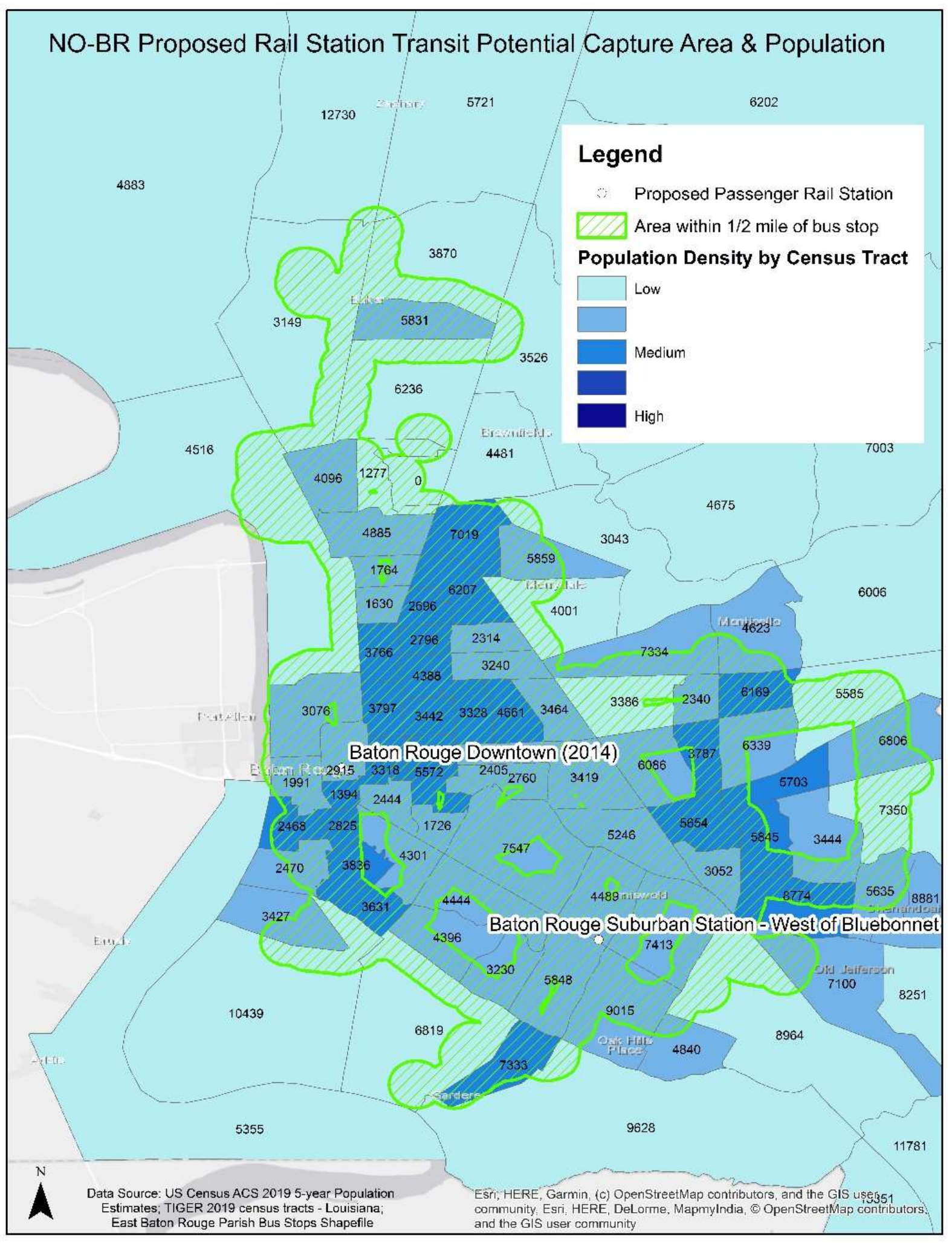

Figure 99. Transit potential capture area and population: Baton Rouge proposed stations. 
NO-BR Proposed Rail Station Walk/Bike Potential Capture Area \& Total Jobs

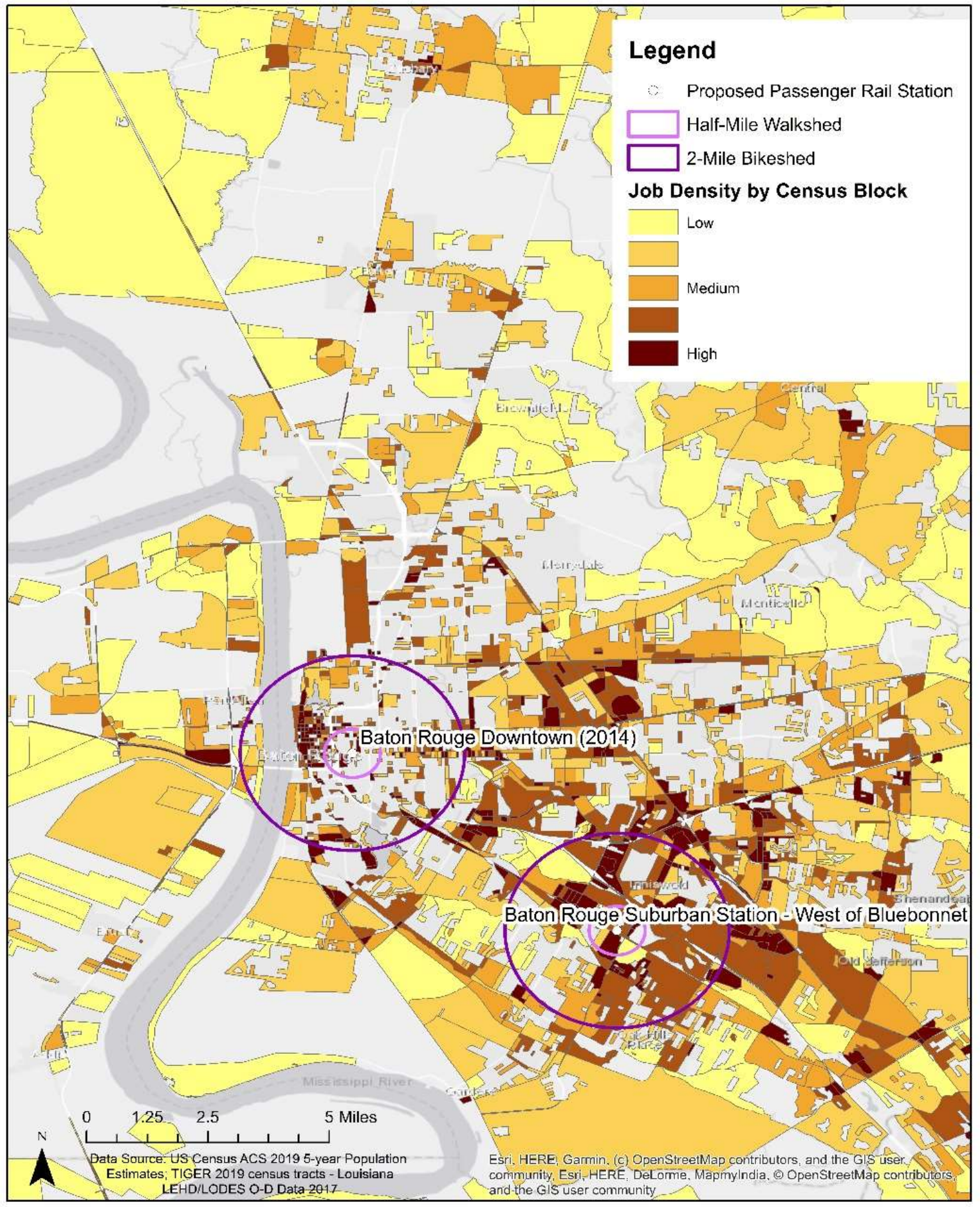

Figure 100. Walk/bike potential capture area and jobs: Baton Rouge proposed stations. 


\section{NO-BR Proposed Rail Station Transit Potential Capture Area \& Total Jobs}

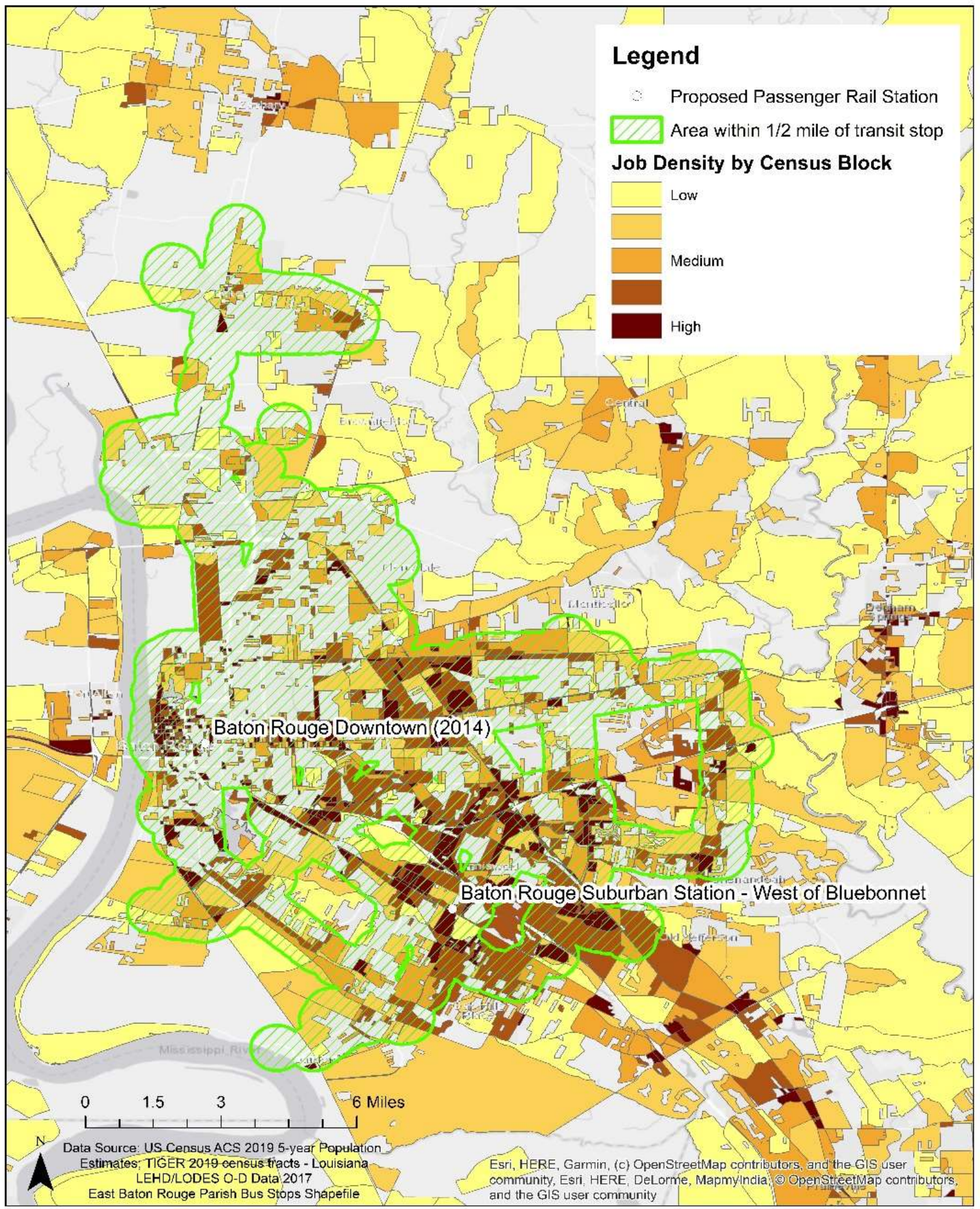

Figure 101. Transit potential capture area and population: Baton Rouge proposed stations. 
In neighboring Gonzales, approximately 13,000 residents live within the two-mile bikeshed (no census tracts have their centroid within $1 / 2$ mile of the proposed station), indicating significant potential for the proposed site to serve a significant portion of the area's population (Figure 102). There are over 2700 jobs within two miles of the Gonzales station area, and 1200 within $1 / 2$ mile (Figure 103).

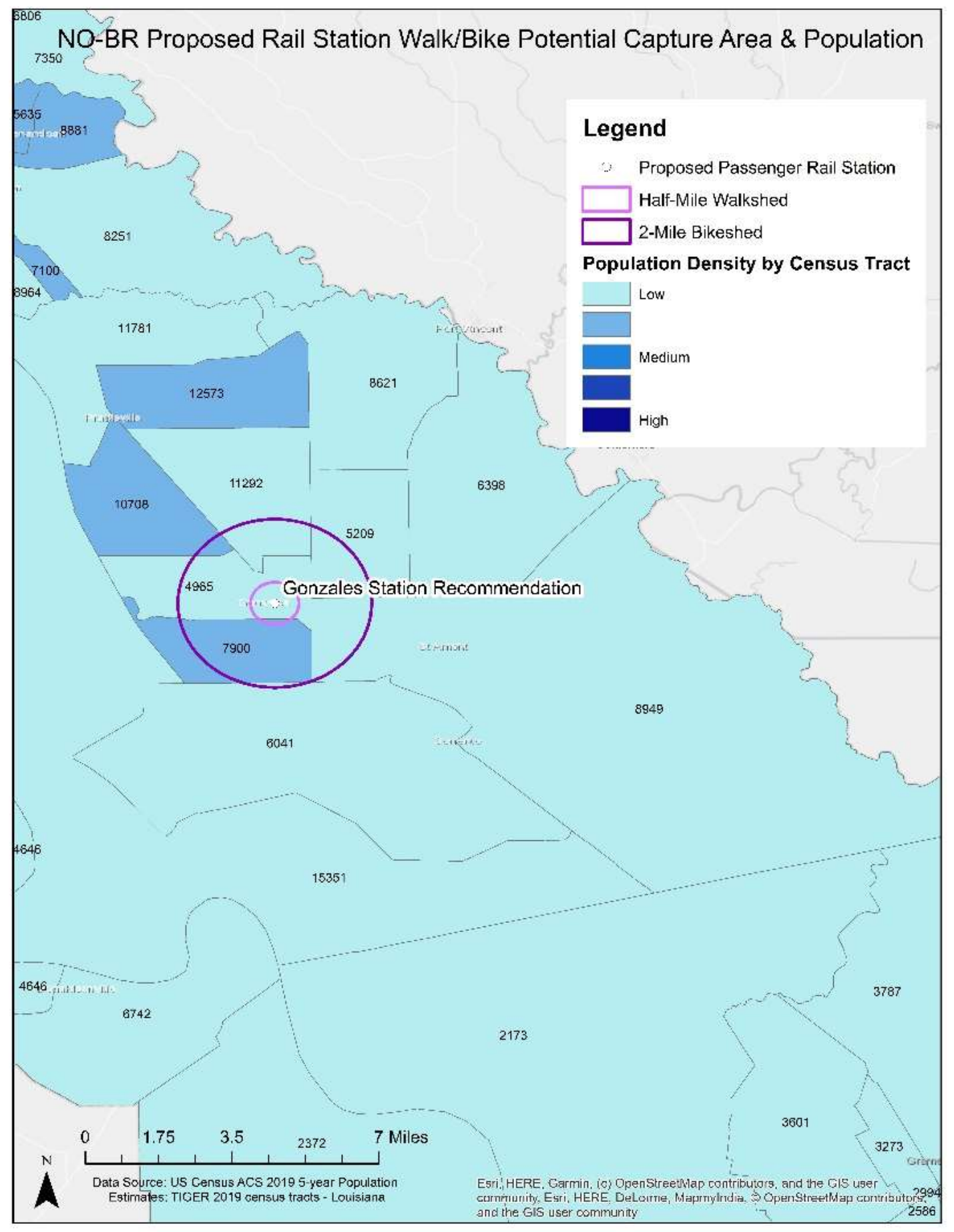

Figure 102. Walk/bike potential capture area and population: Gonzales proposed station. 
NO-BR Proposed Rail Station Walk/Bike Potential Capture Area \& Total Jobs

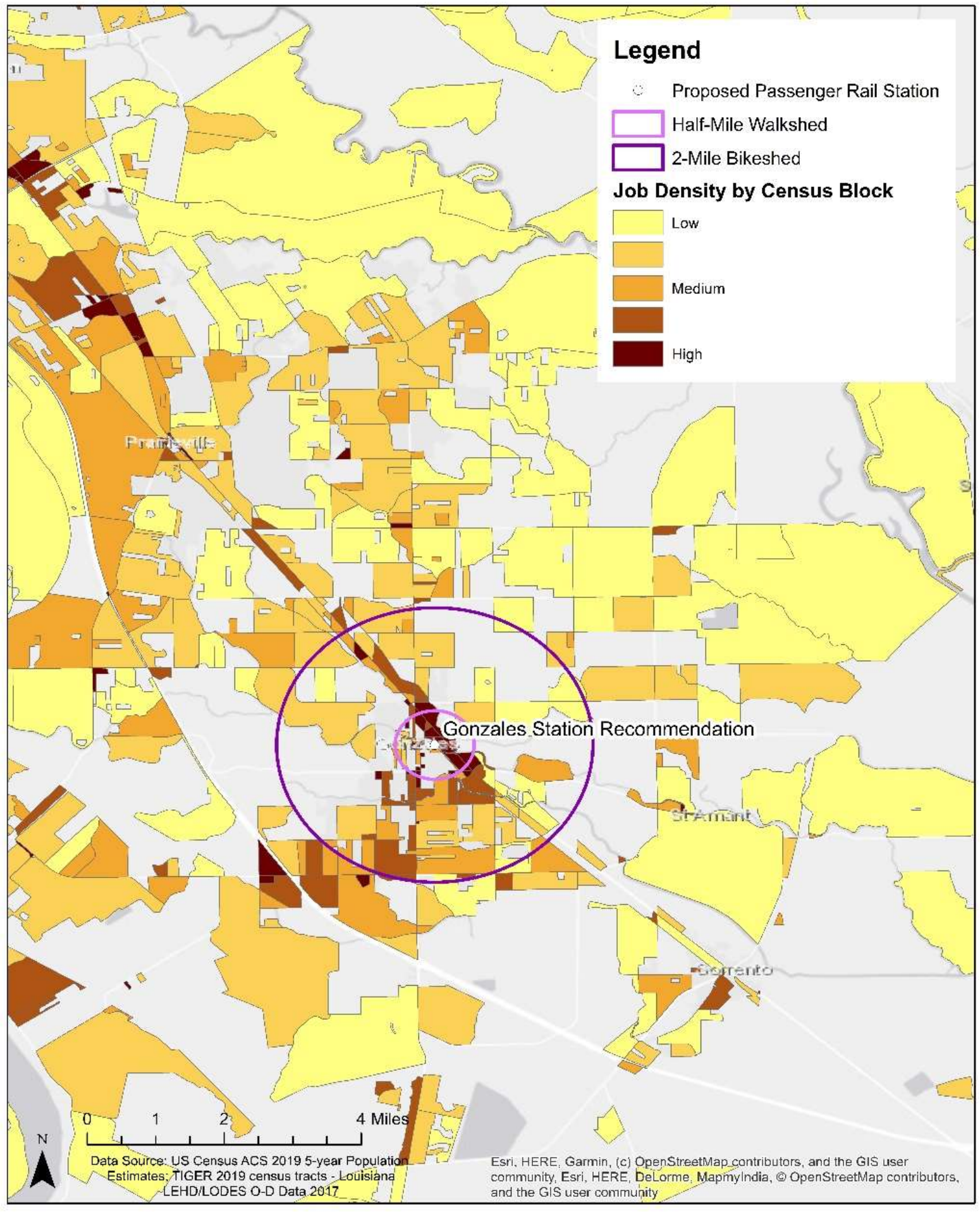

Figure 103. Walk/bike potential capture area and jobs: Gonzales proposed station. 
Similarly, in LaPlace, approximately 23,000 people live within 2 miles of the proposed station, with no tracts whose centroid falls within $1 / 2$ mile (Figure 104). There are an estimated 300 jobs within $1 / 2$ mile of the station area, and 1500 within two miles (Figure 105).

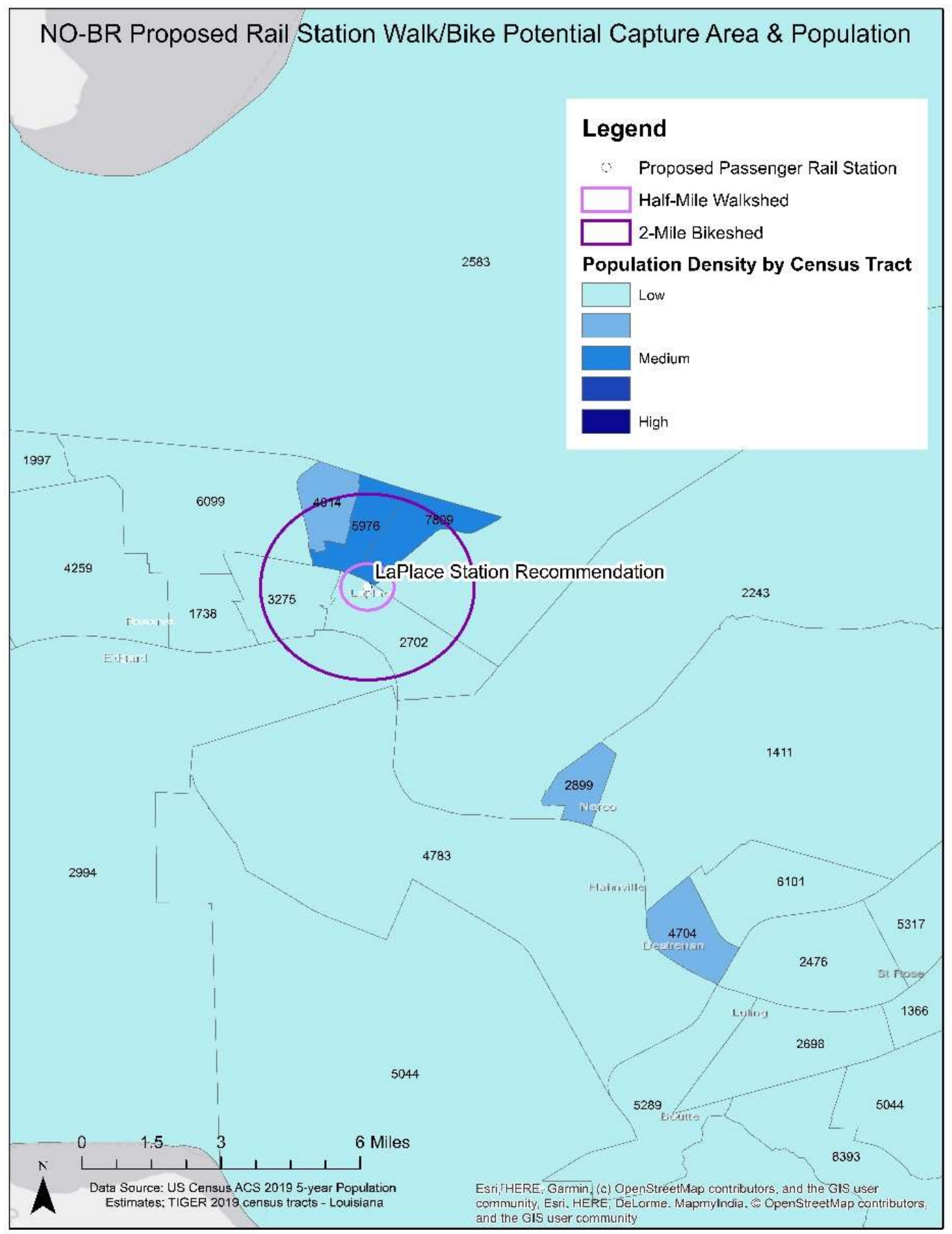

Figure 104. Walk/bike potential capture area and population: LaPlace proposed station. 


\section{NO-BR Proposed Rail Station Walk/Bike Potential Capture Area \& Total Jobs}

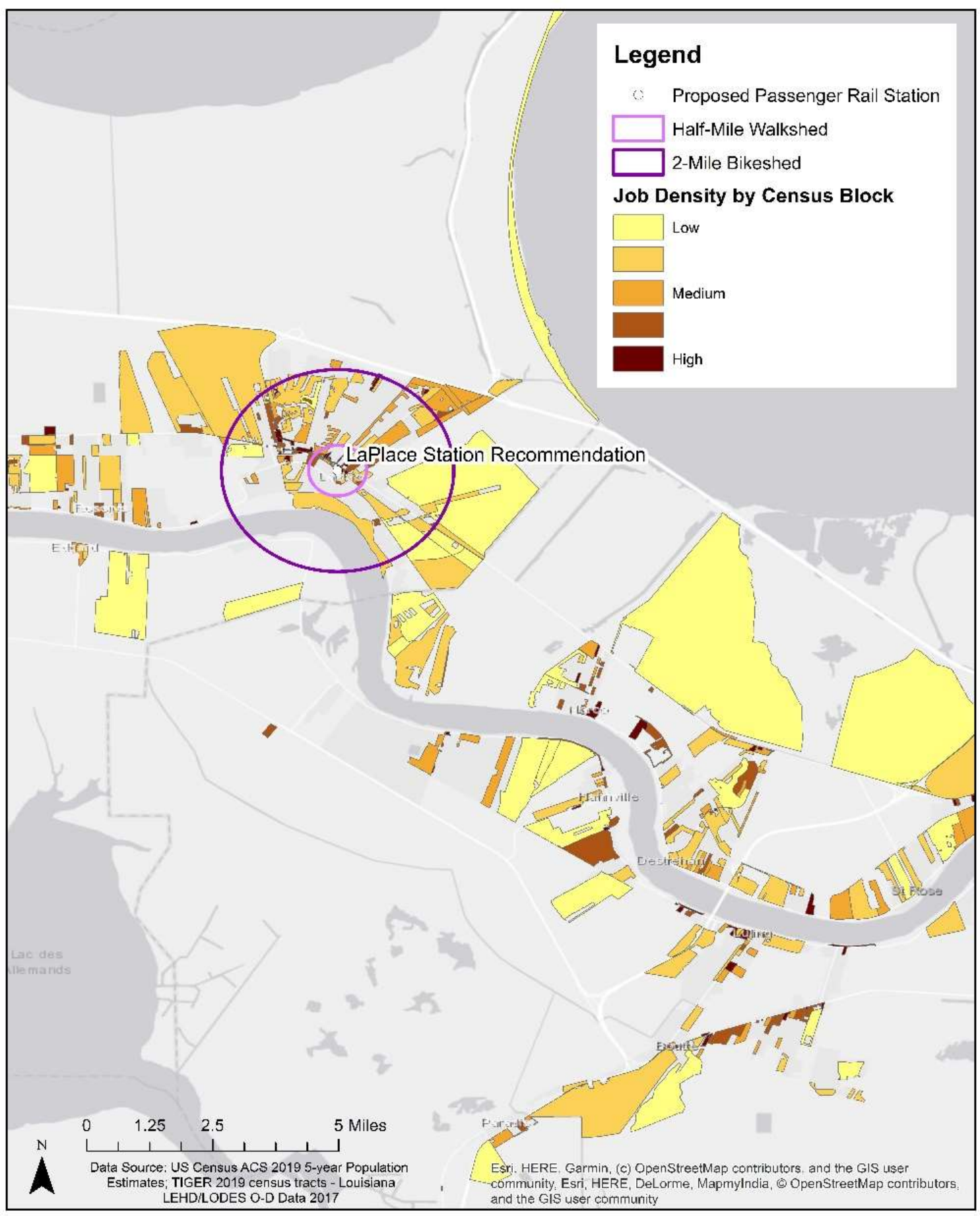

Figure 105. Walk/bike potential capture area and jobs: LaPlace proposed station. 
In Jefferson Parish, there are approximately 1700 people in the census tract whose centroid is within $1 / 2$ mile of the station area (although this tract extends well outside of this boundary), and over 70,000 within two miles of either of the proposed stations (which share overlapping 2-mile bike/walkshed buffer areas (Figure 106). Notably, neither station is in a particularly densely populated portion of Jefferson Parish (though both proposed stations serve major employment/activity generators).

There are an estimated 300 jobs within $1 / 2$ mile of the Metairie station, and 200 within $1 / 2$ mile of the Kenner station (not including the airport), and a total of approximately 9,500 jobs within the 2-mile buffer of both stations (including some census blocks on the Westbank which would not realistically be feasible to walk or bicycle to) (Figure 107).

Finally, in New Orleans, with considerably higher relative population density, there are approximately 6000 residents within $1 / 2$ mile of NOUPT (although as in other locations this ignores geographic barriers, including that presented by the railway itself). Over 120,000 live within two miles (again ignoring key barriers, such as the Mississippi River) (Figure 108). There are an estimated 4,600 jobs within 1/2 mile of the terminal, and over 26,000 within two miles (Figure 109).

The adjacent, and in some cases interconnected transit systems of Orleans and Jefferson Parish were evaluated together to assess the number of residents and jobs with at least nominal transit access under the current network structure. Approximately 700,000 people in the metro area have access (within $1 / 2$ mile) of at least one transit stop (Figure 110), although as noted previously, this does not reflect the duration of trips by transit, number of transfers required to access a destination, frequency of service, etc. The proposed New Links transit redesign would reduce overall coverage (fewer total people would have close access to the system) but prioritizes improved service where there are the most existing or potential riders, potentially making transit access a more meaningful measure of actual mobility in the region.

Similarly, most metro area jobs (over 85,000 ) are within $1 / 2$ mile of a bus or streetcar stop, although once again this does not necessarily mean it all jobs are practical to access via transit, given available frequencies and the number of transfers required (Figure 111). 


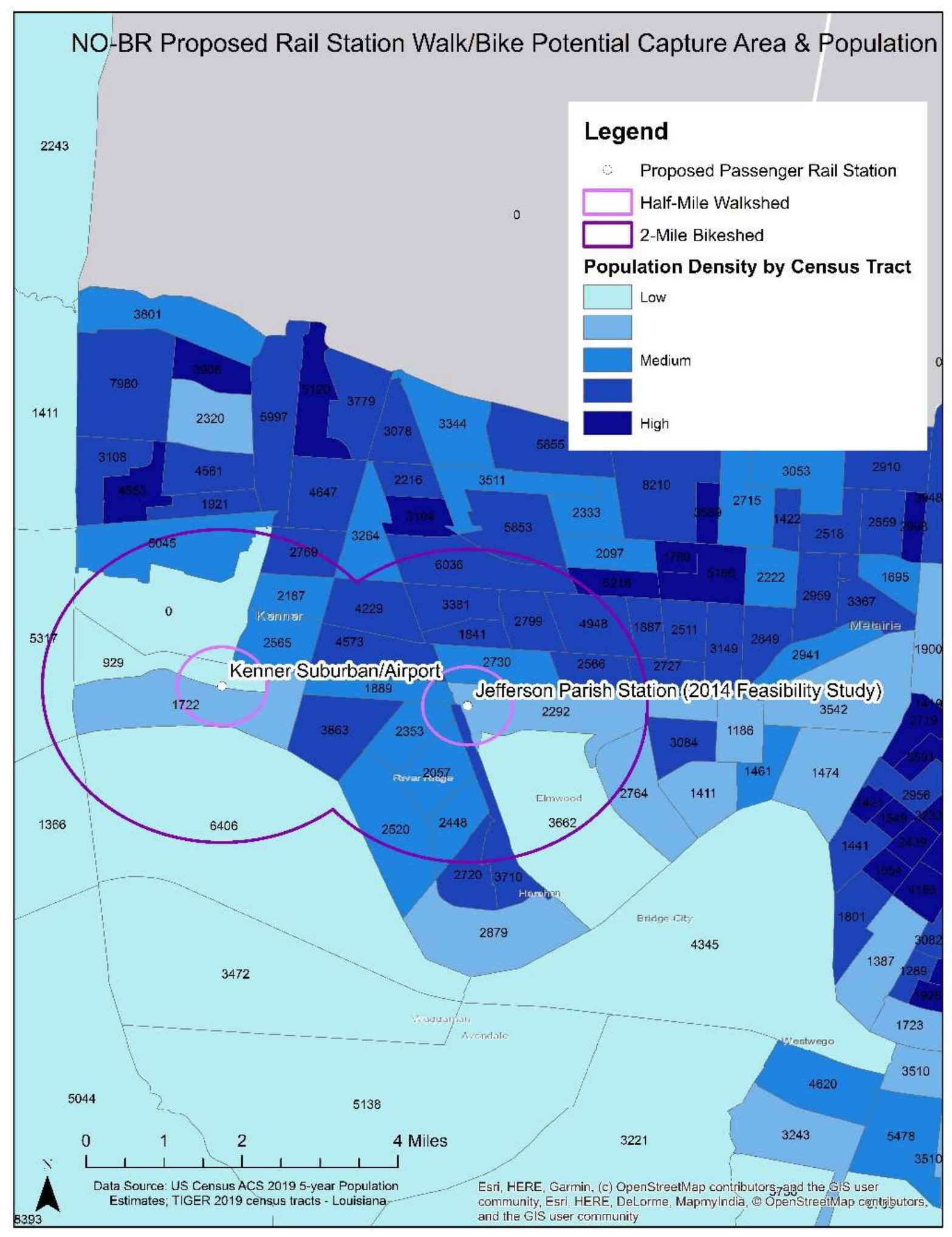

Figure 106. Walk/bike potential capture area and population: Jefferson Parish proposed stations. 


\section{NO-BR Proposed Rail Station Walk/Bike Potential Capture Area \& Total Jobs}

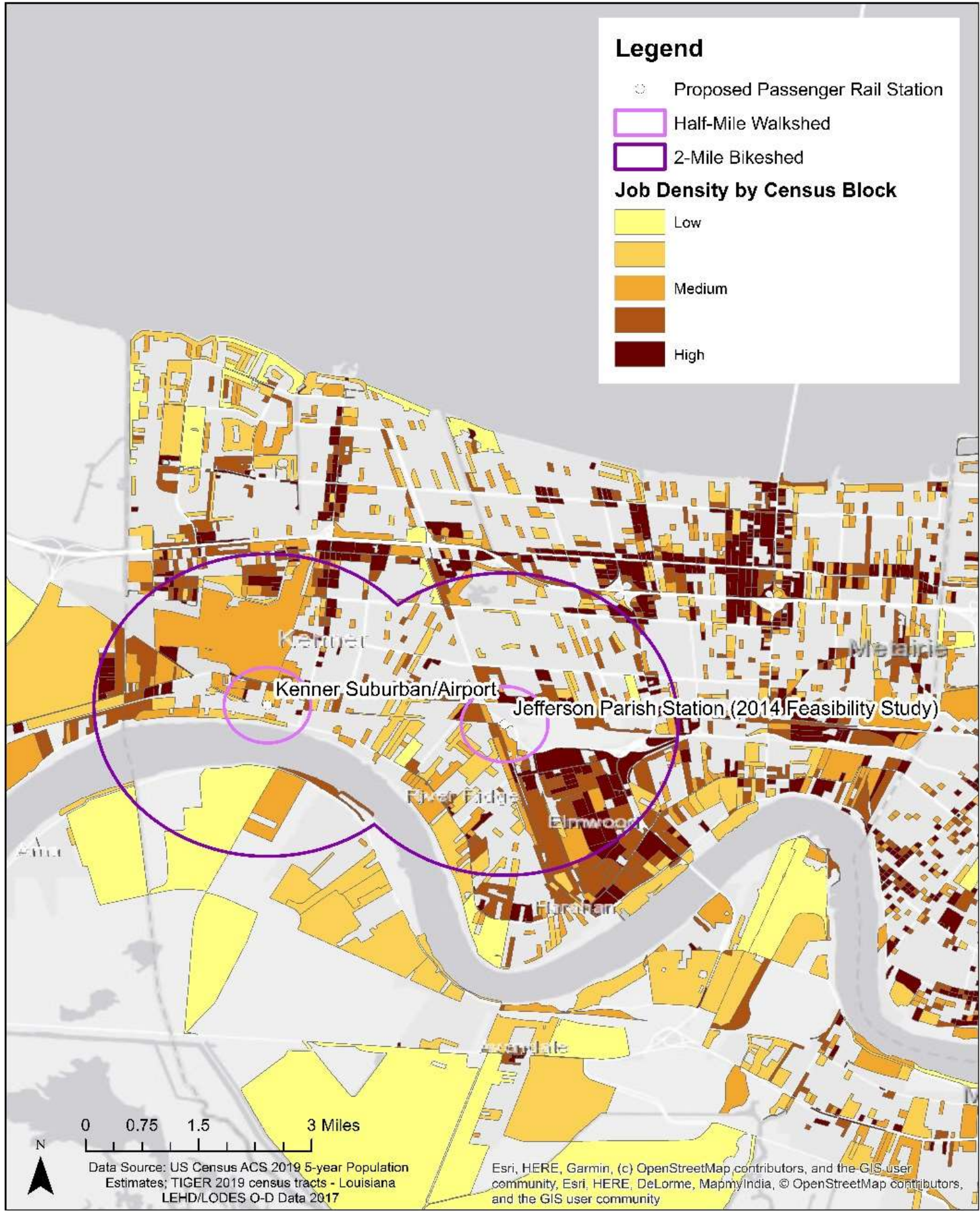

Figure 107. Walk/bike potential capture area and jobs: Jefferson Parish proposed stations. 


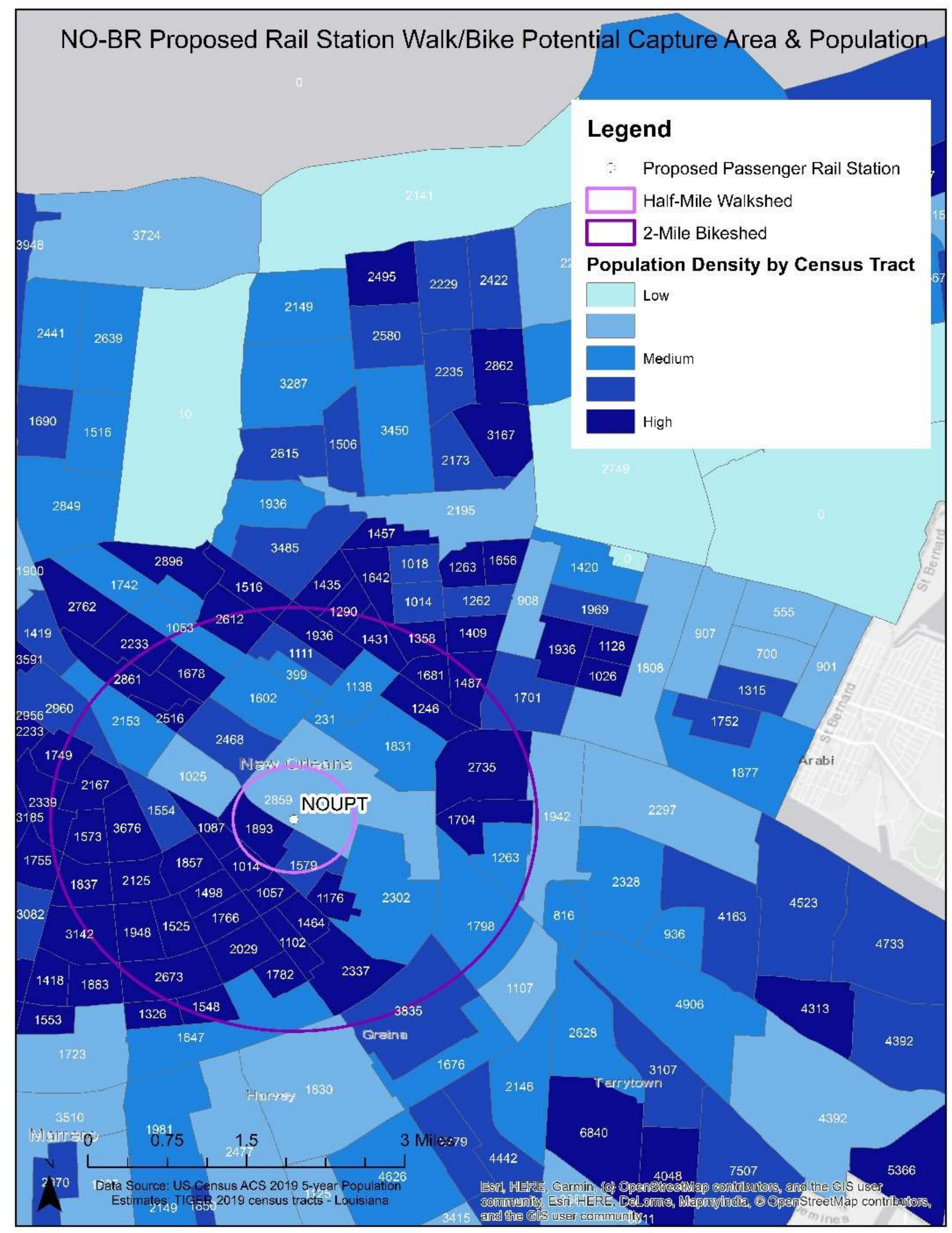

Figure 108. Walk/bike potential capture area and population: NOUPT. 
NO-BR Proposed Rail Station Walk/Bike Potential Capture Area \& Total Jobs

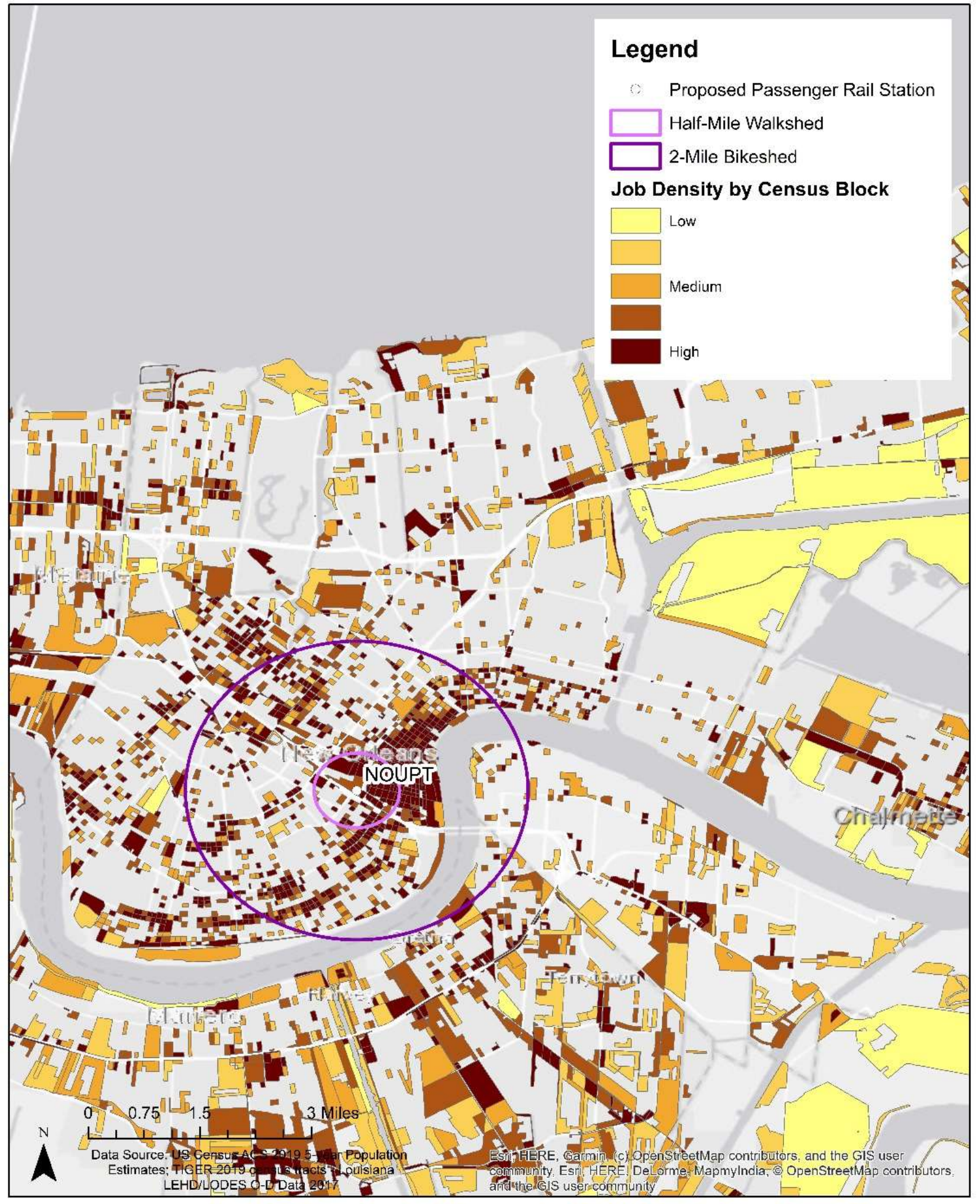

Figure 109. Walk/bike potential capture area and jobs: NOUPT. 


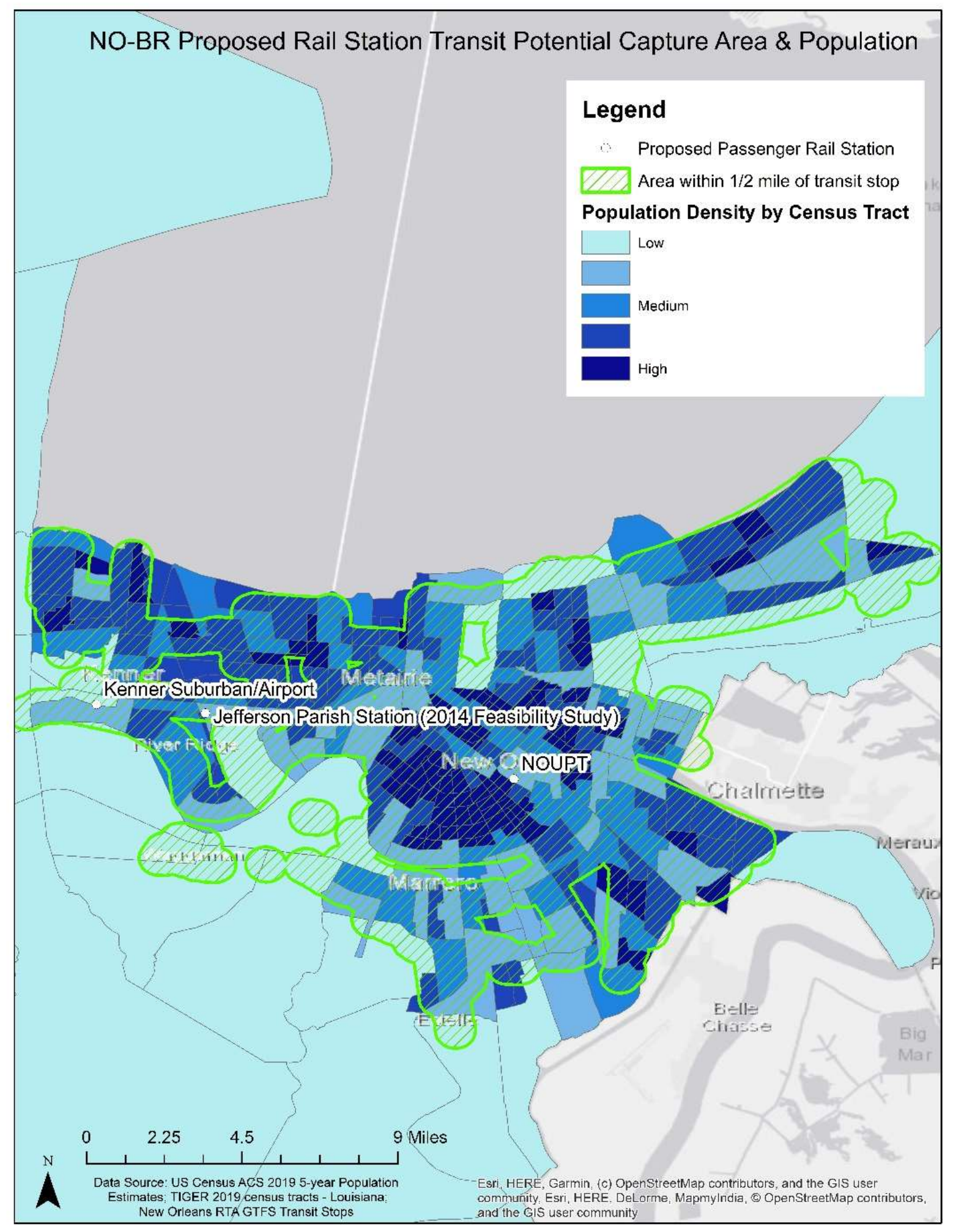

Figure 110. Transit potential capture area and population: NOUPT. 


\section{NO-BR Proposed Rail Station Transit Potential Capture Area \& Total Jobs}

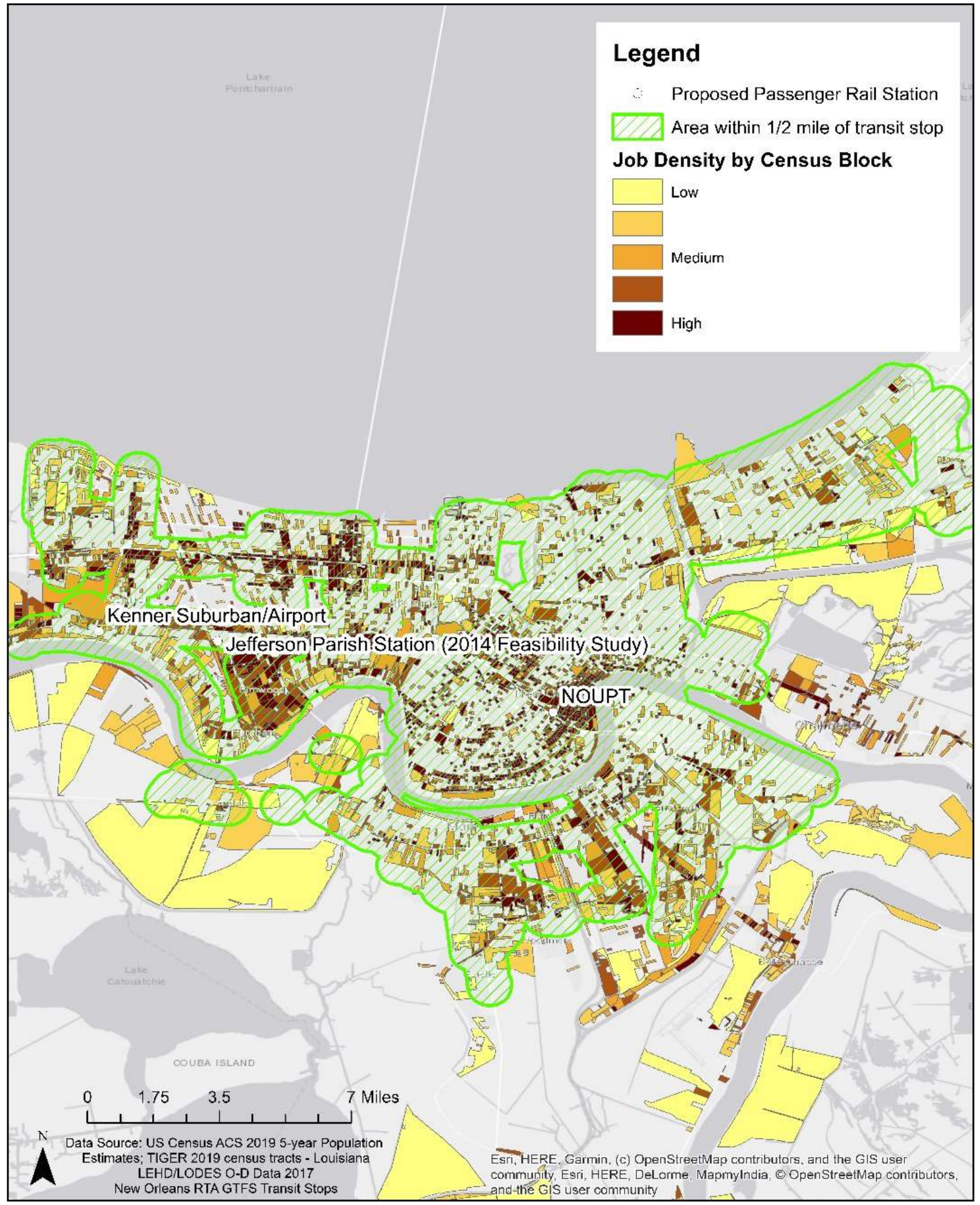

Figure 111. Transit potential capture area and population: NOUPT. 
Next, the distribution of actual survey responses (for which geocoded home address data could be developed at the census tract level or smaller) is symbolized to reflect the broad distribution of the survey instrument within the study area (most census tracts within the corridor returned at least one response), as well as to show the relative overrepresentation of responses from the southern portion of Baton Rouge (Figure 112).

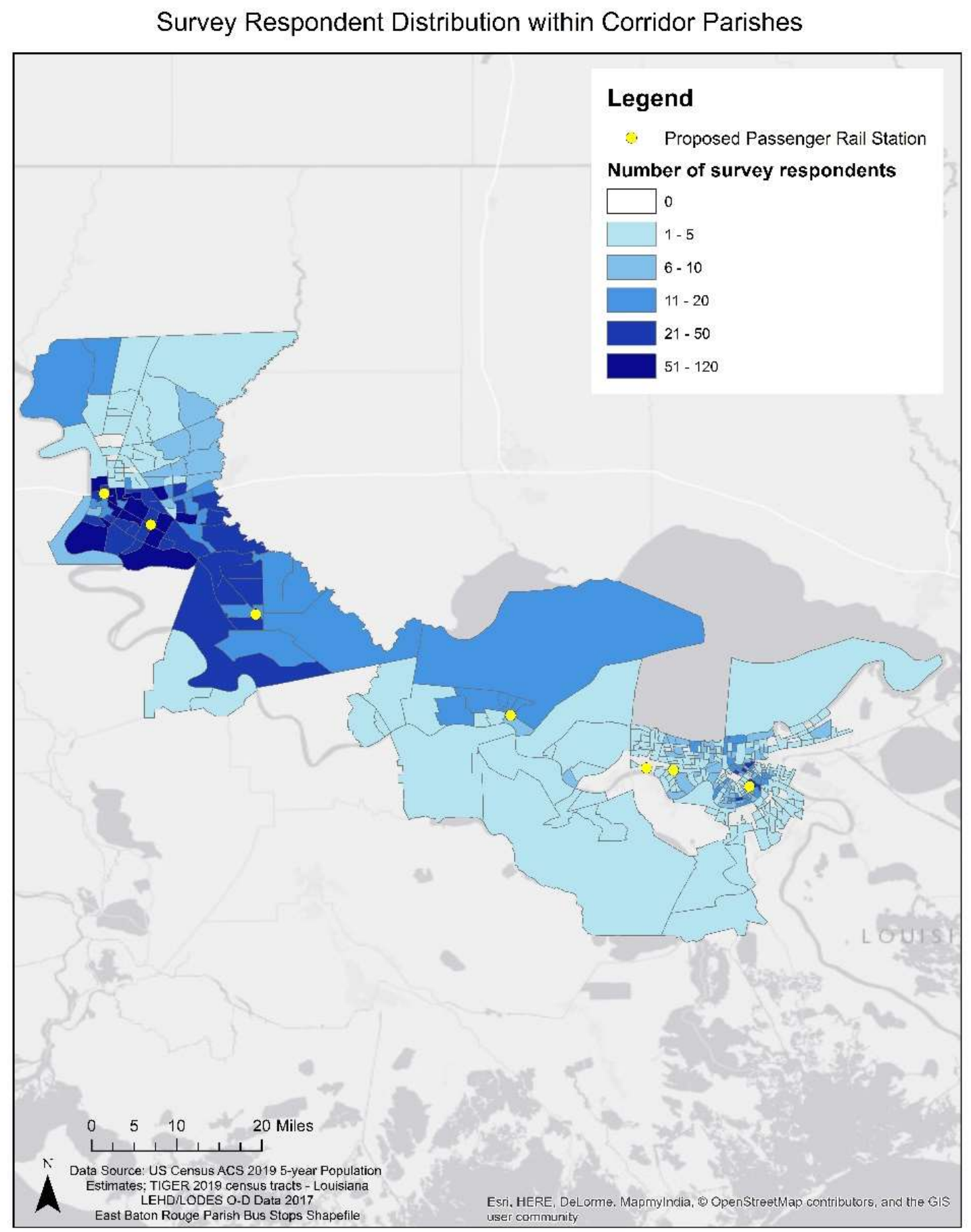

Figure 112. Survey respondent distribution within corridor parishes. 
A selection of other survey responses was visualized at the individual response level to explore spatial variation and/or themes that may emerge at a finer spatial scale. As noted in Section 5.6.5, the sample turned out to be relatively homogenous in terms of attitudes, behaviors, and characteristics, limiting the utility of disaggregated spatial evaluation. However, these distributions reinforce findings identified at the parish level, as well as illustrate the share of respondents located within 2 miles of the proposed stations. All geocoded addresses are slightly generalized to protect respondent privacy.

Throughout the study area, the majority of respondents strongly or moderately support the proposed rail service. Few patterns in the spatial distribution of respondents who oppose its development are readily apparent. In Baton Rouge, a sizeable concentration of respondents both live within the proposed station area(s) and strongly support passenger rail development (Figure 113). In all corridor parishes, geolocation of responses facilitates closer examination of neighborhoods where opinions are clearly underrepresented (as discussed in Section 5.6.1) (Figures 114-116).

Another dimension examined visually to better understand aggregate findings includes respondents' opinions about the relative ease of walking to destinations of interest in their community. Overwhelmingly, respondents throughout the region--other than in New Orleans-note that walking is difficult or very difficult in their community, although a slightly greater number of respondents indicate greater ease in neighborhoods within or near downtown Baton Rouge and central LaPlace (Figures 117-120). Conversely, in New Orleans, respondents throughout the urban core of the city indicate that walking is relatively easy, reflecting the advantages of the city's historic street grid and investments in a complete streets approach (Figure 121).

Finally, although a clear majority of respondents indicated that they would expect to drive, carpool, or take rideshare or taxi services to access the station if service were to be developed, the distribution of responses was evaluated to determine whether respondents who live near proposed stations are more likely to indicate interest in walking, bicycling, or transit. In Baton Rouge (Figure 122) Garden District and Mid-City residents appear to be more likely to indicate interest in accessing the proposed station on foot, for example, while a notable minority of respondents in the Plank Road and Nicholson corridors indicate a preference for transit, perhaps indicative of the anticipated Plank Road BRT project's potential impact. In suburban Gonzales and LaPlace, a handful of bicycling enthusiasts appear, most of whom are within the two-mile buffer area (Figures 123 and 124). In Jefferson parish, few surveys were collected from respondents near the proposed Kenner/Airport station, and most Metairie respondents indicate a preference for auto-based modes (Figure 125). Finally, in New Orleans, anticipated modal split is more evenly mixed, with residents of the urban core of the city again more likely to indicate a preference for walking or bicycling, and a modest number of individuals who would opt to take transit distributed throughout the city (Figure 126). 


\section{Overall Support for Proposed Passenger Rail Service}

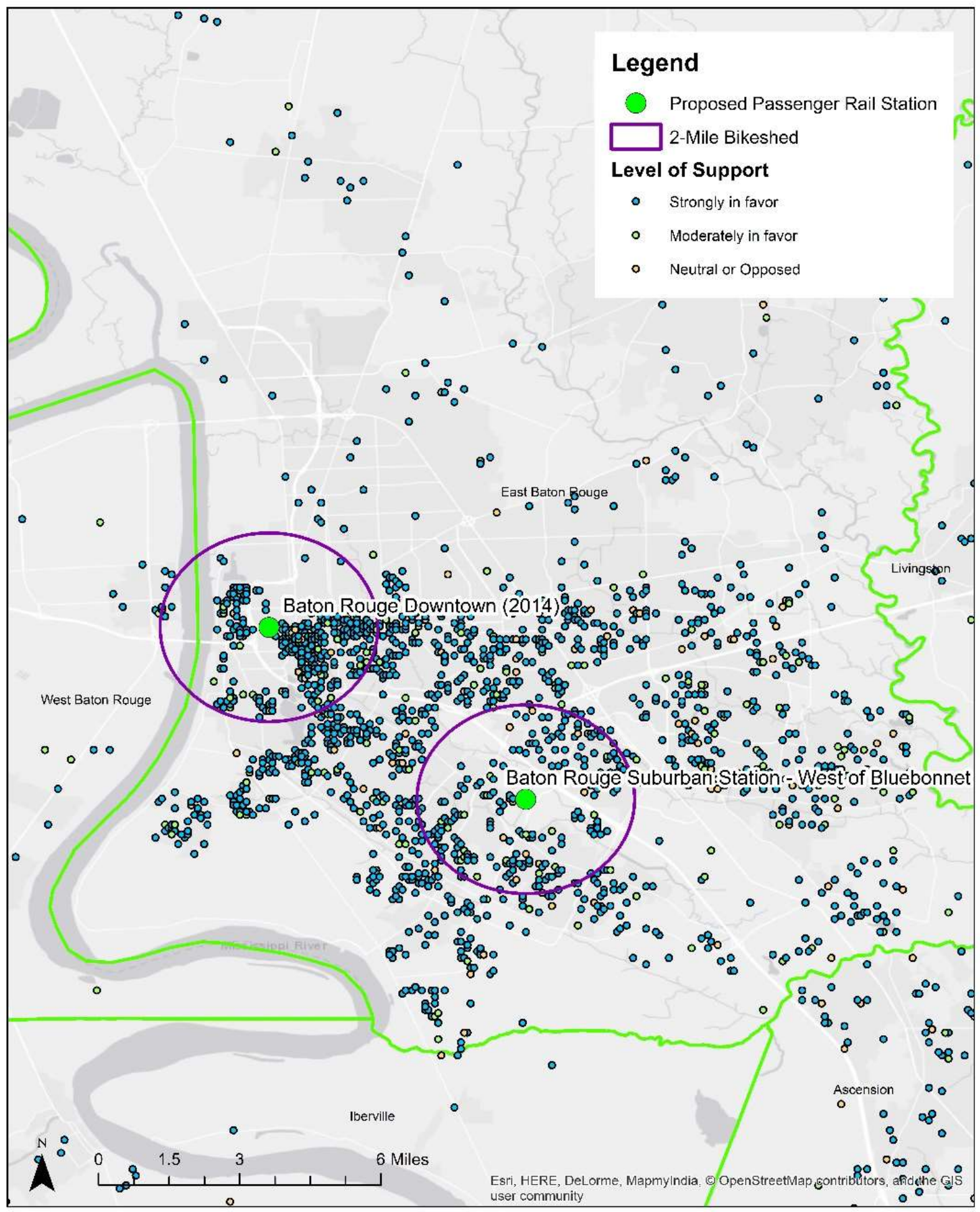

Figure 113. Overall support for proposed passenger rail service: Baton Rouge. 
Overall Support for Proposed Passenger Rail Service

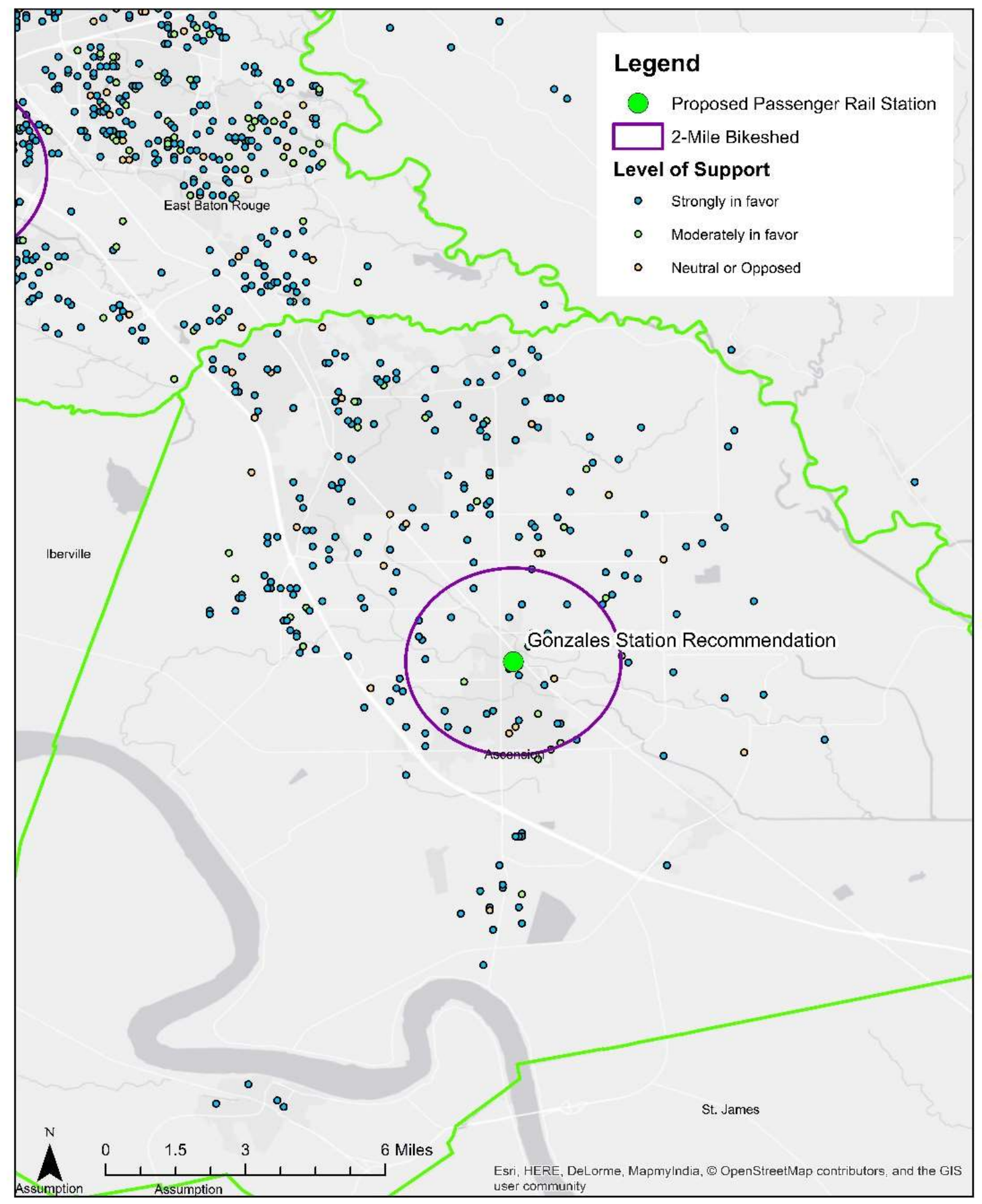

Figure 114. Overall support for proposed passenger rail service: Gonzales. 


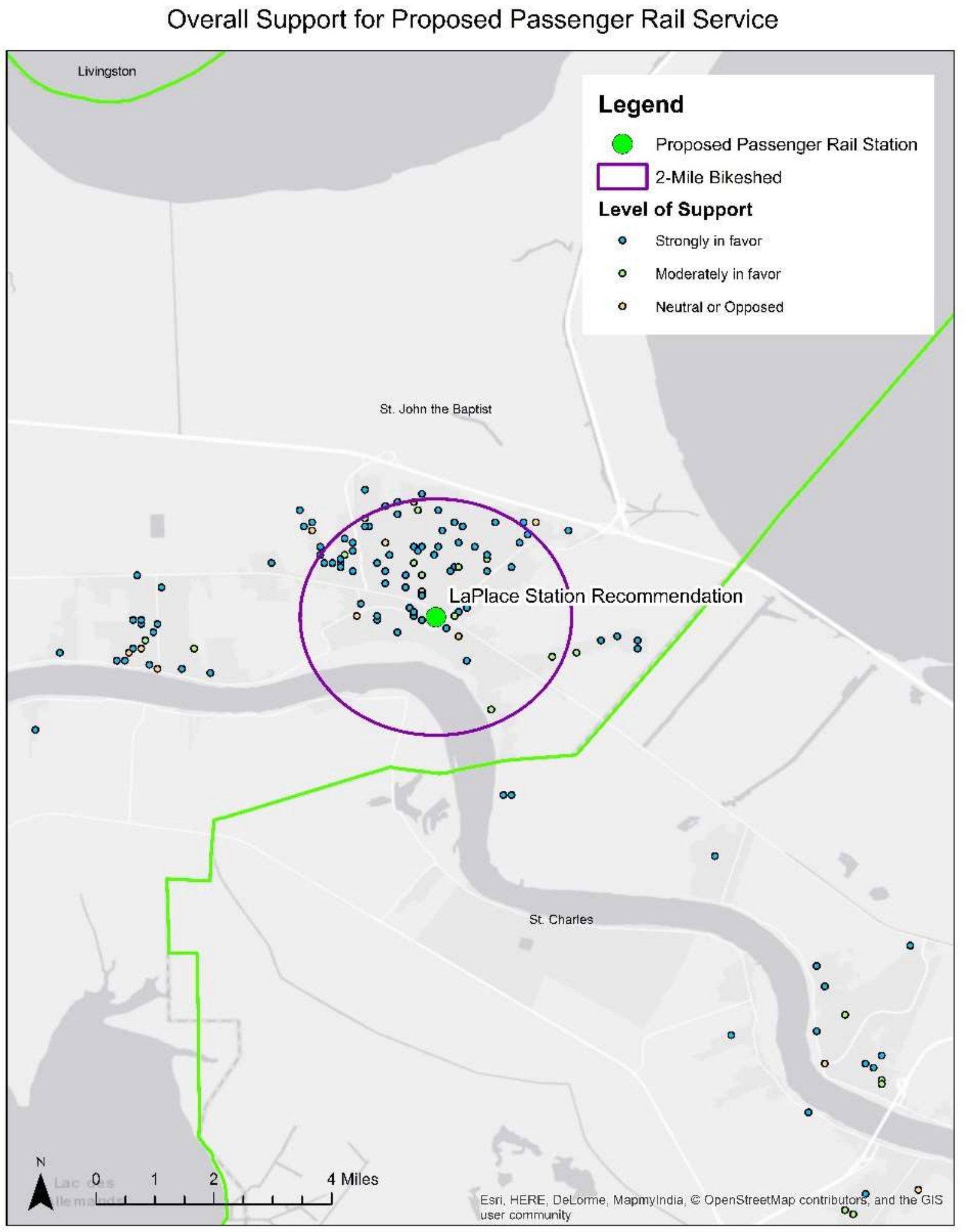

Figure 115. Overall support for proposed passenger rail service: LaPlace. 
Overall Support for Proposed Passenger Rail Service

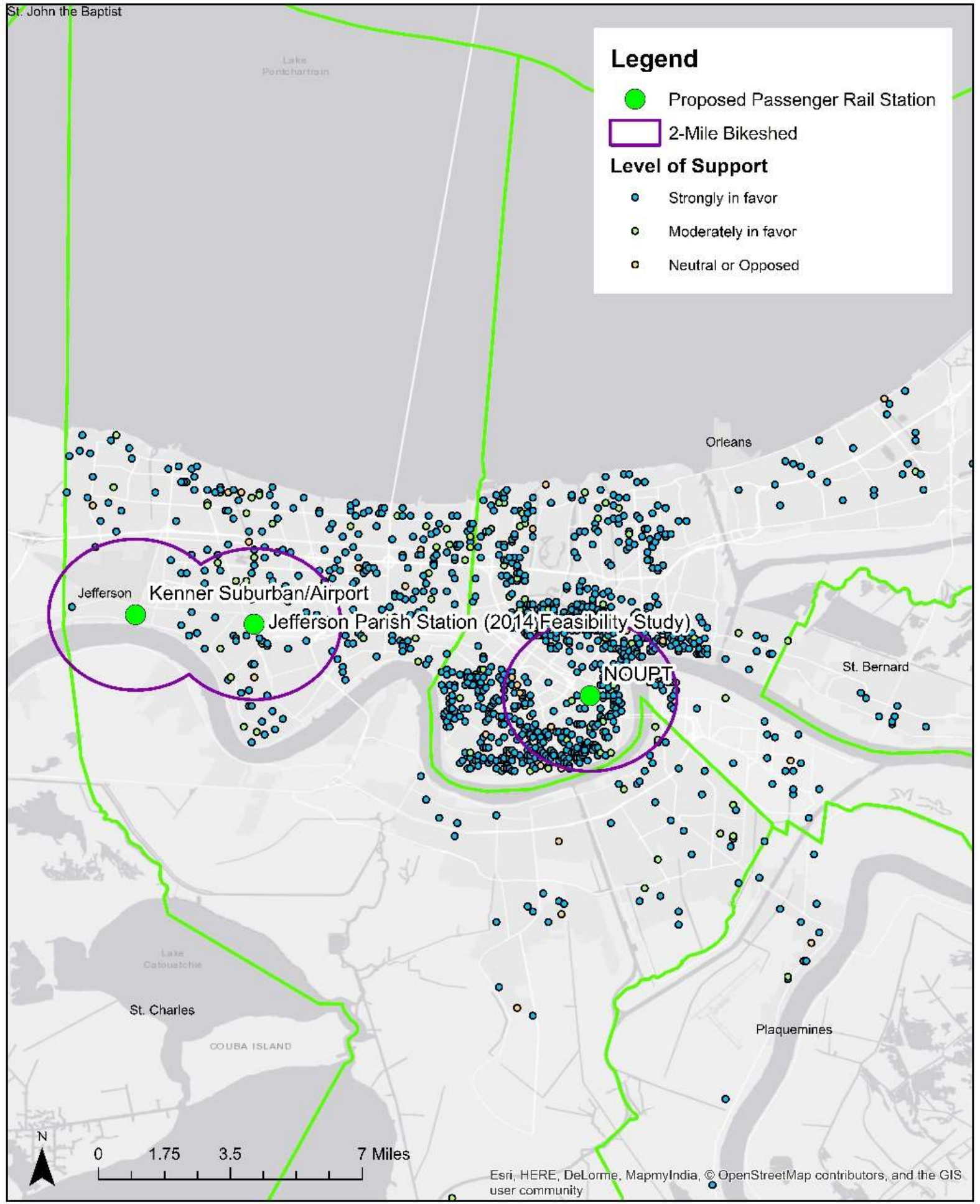

Figure 116. Overall support for proposed passenger rail service: Jefferson and Orleans Parish. 
Ease of walkability to destinations of interest in community

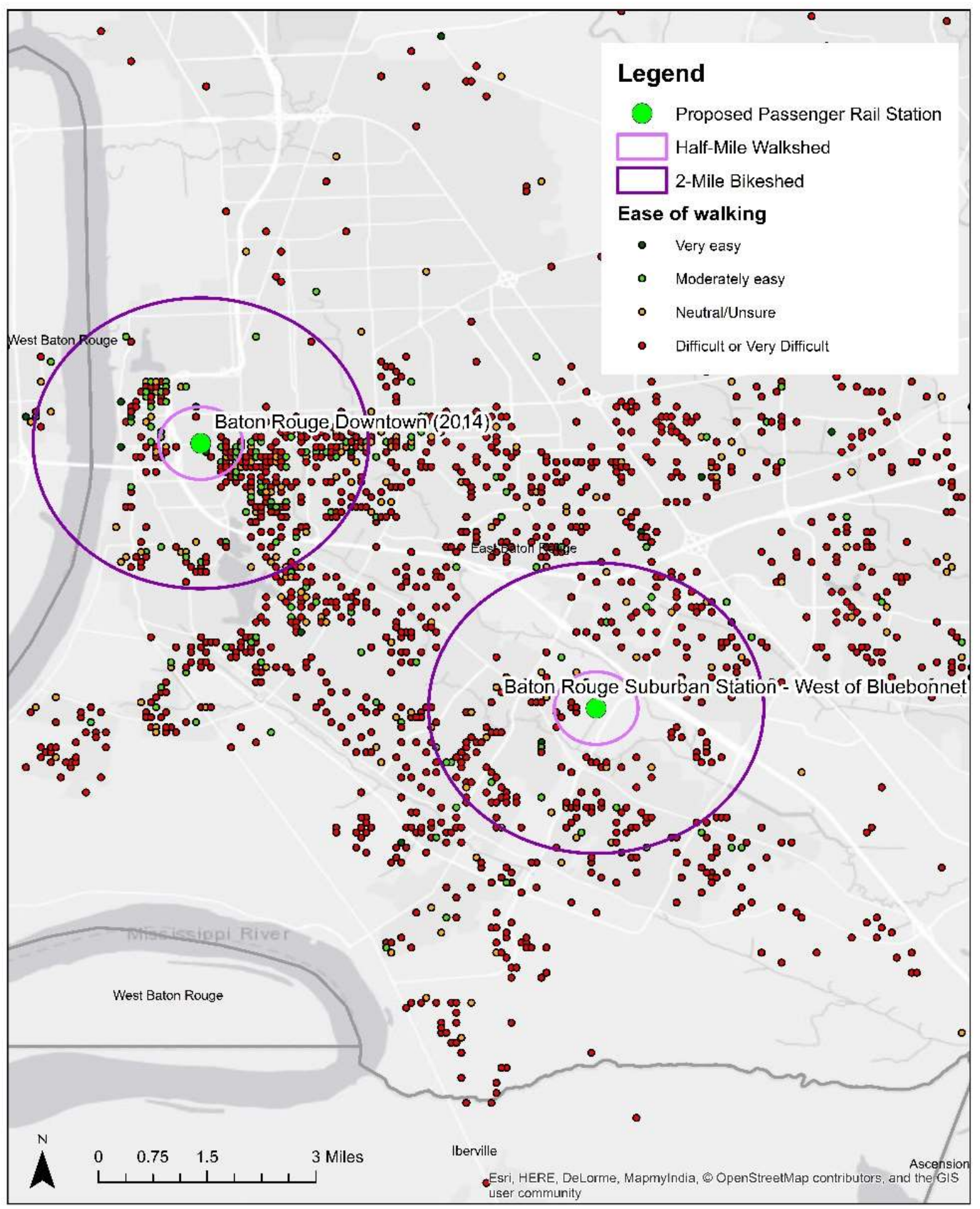

Figure 117. Ease of walkability to destinations of interest in community: Baton Rouge. 


\section{Ease of walkability to destinations of interest in community}

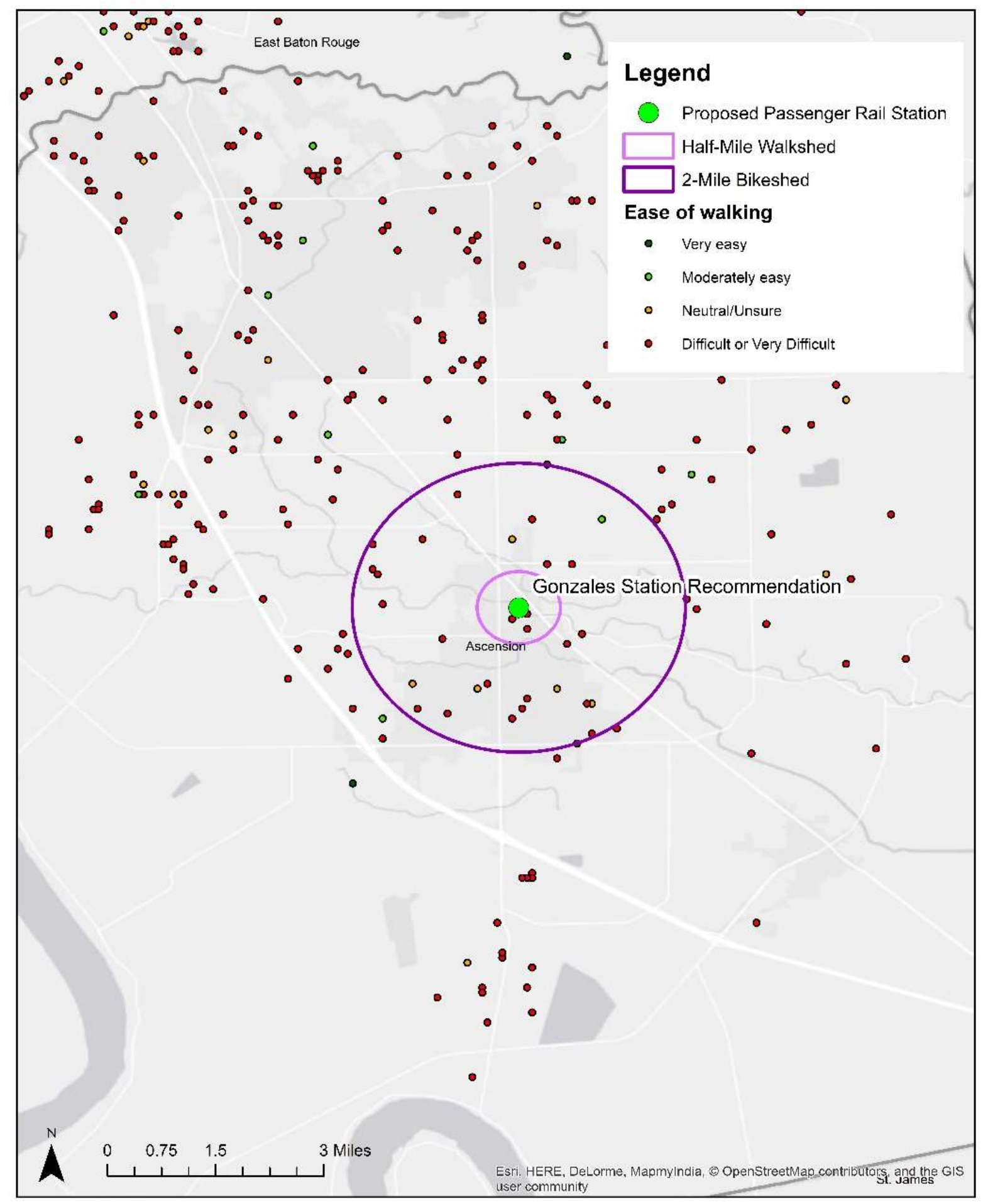

Figure 118. Ease of walkability to destinations of interest in community: Gonzales. 


\section{Ease of walkability to destinations of interest in community}

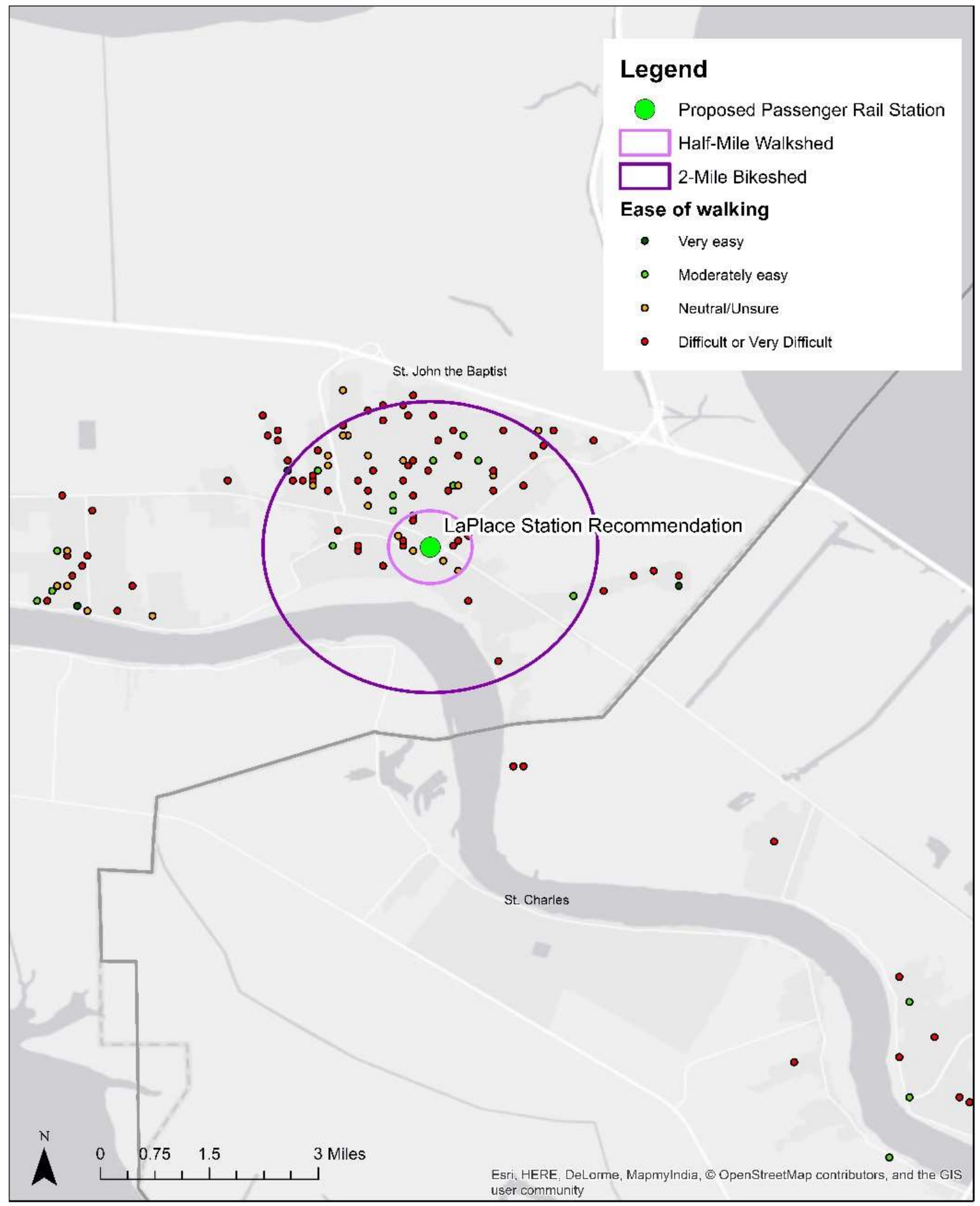

Figure 119. Ease of walkability to destinations of interest in community: LaPlace. 
Ease of walkability to destinations of interest in community

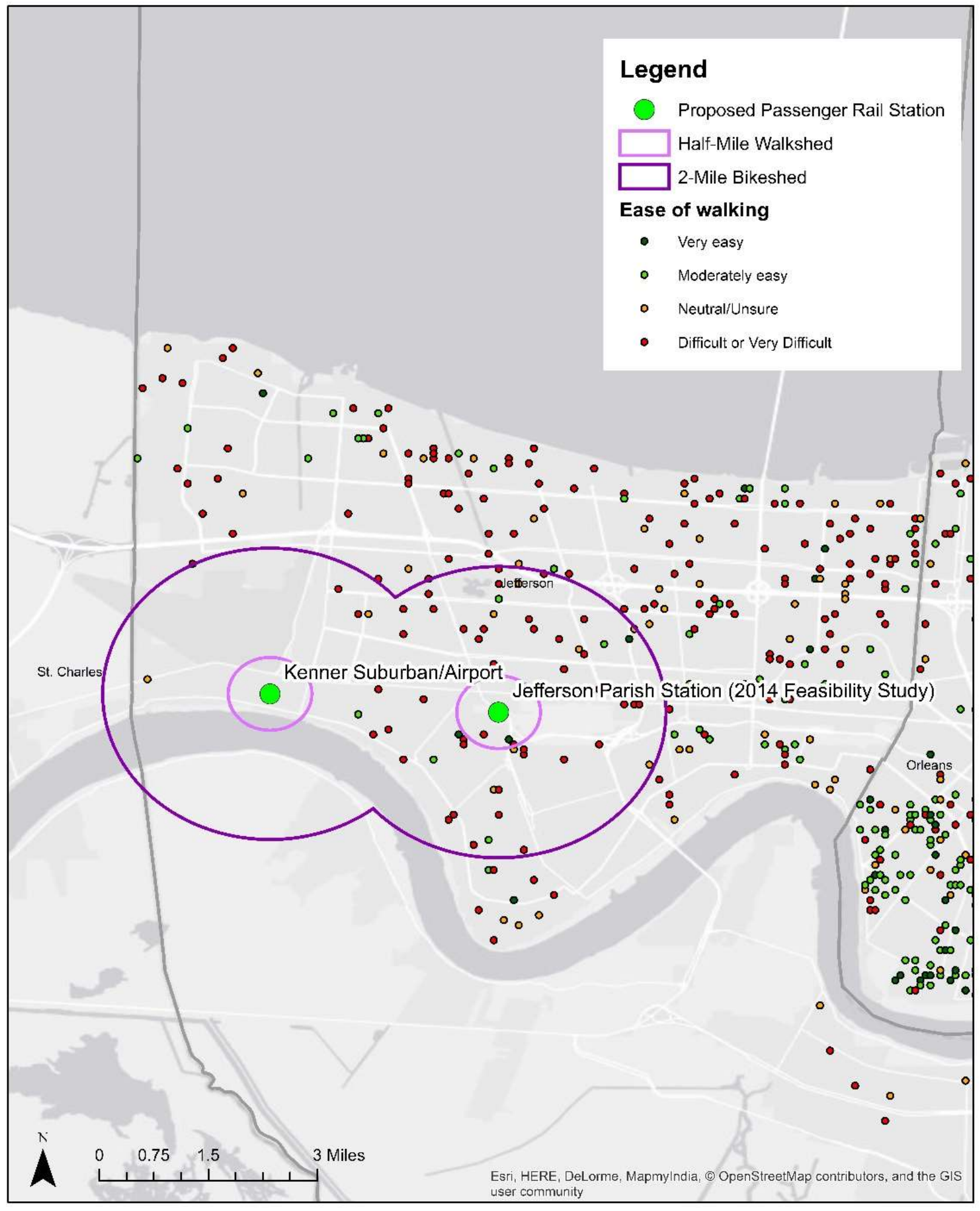

Figure 120. Ease of walkability to destinations of interest in community: Jefferson Parish. 
Ease of walkability to destinations of interest in community

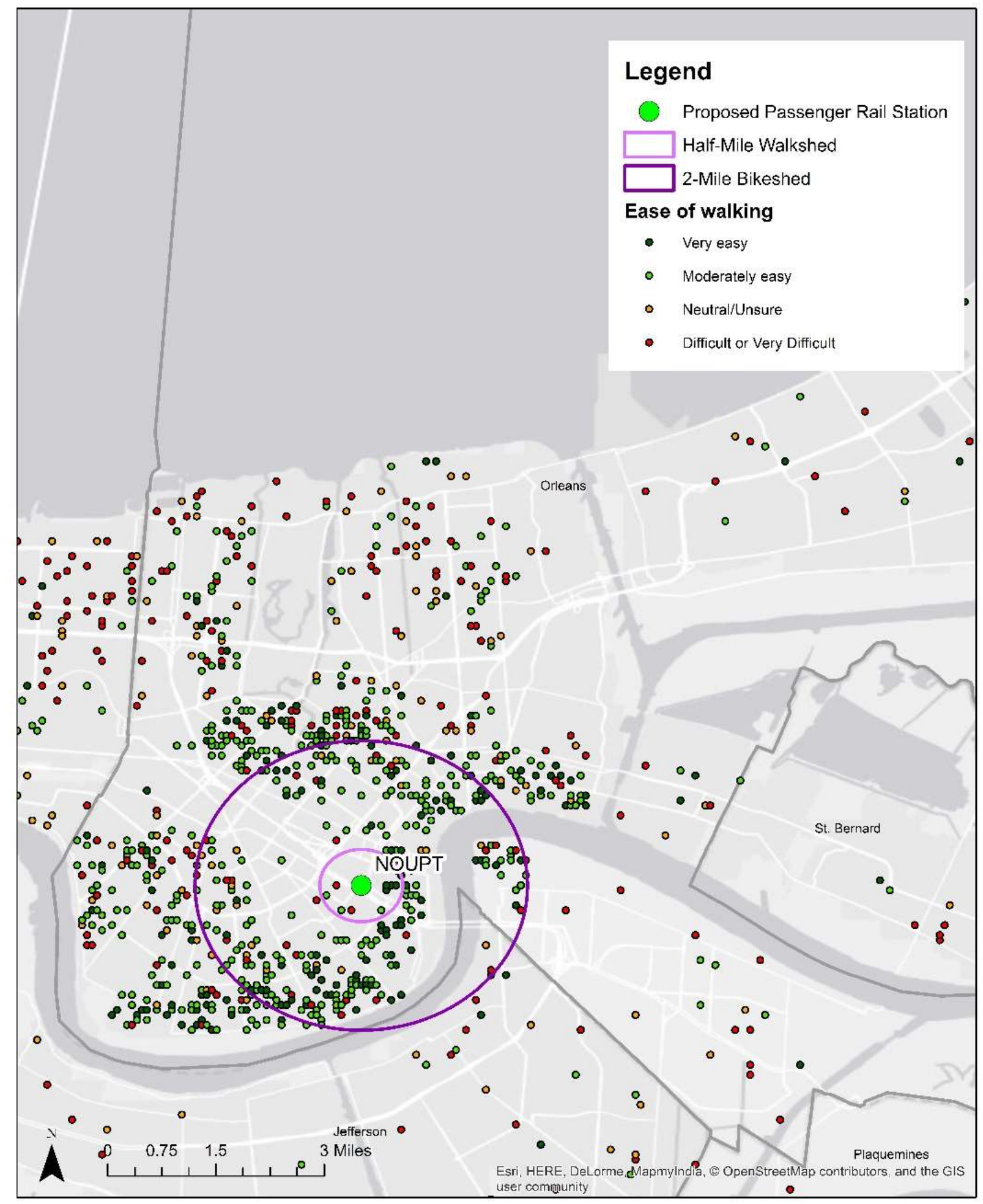

Figure 121. Ease of walkability to destinations of interest in community: New Orleans. 
Anticipated mode of travel to future rail station

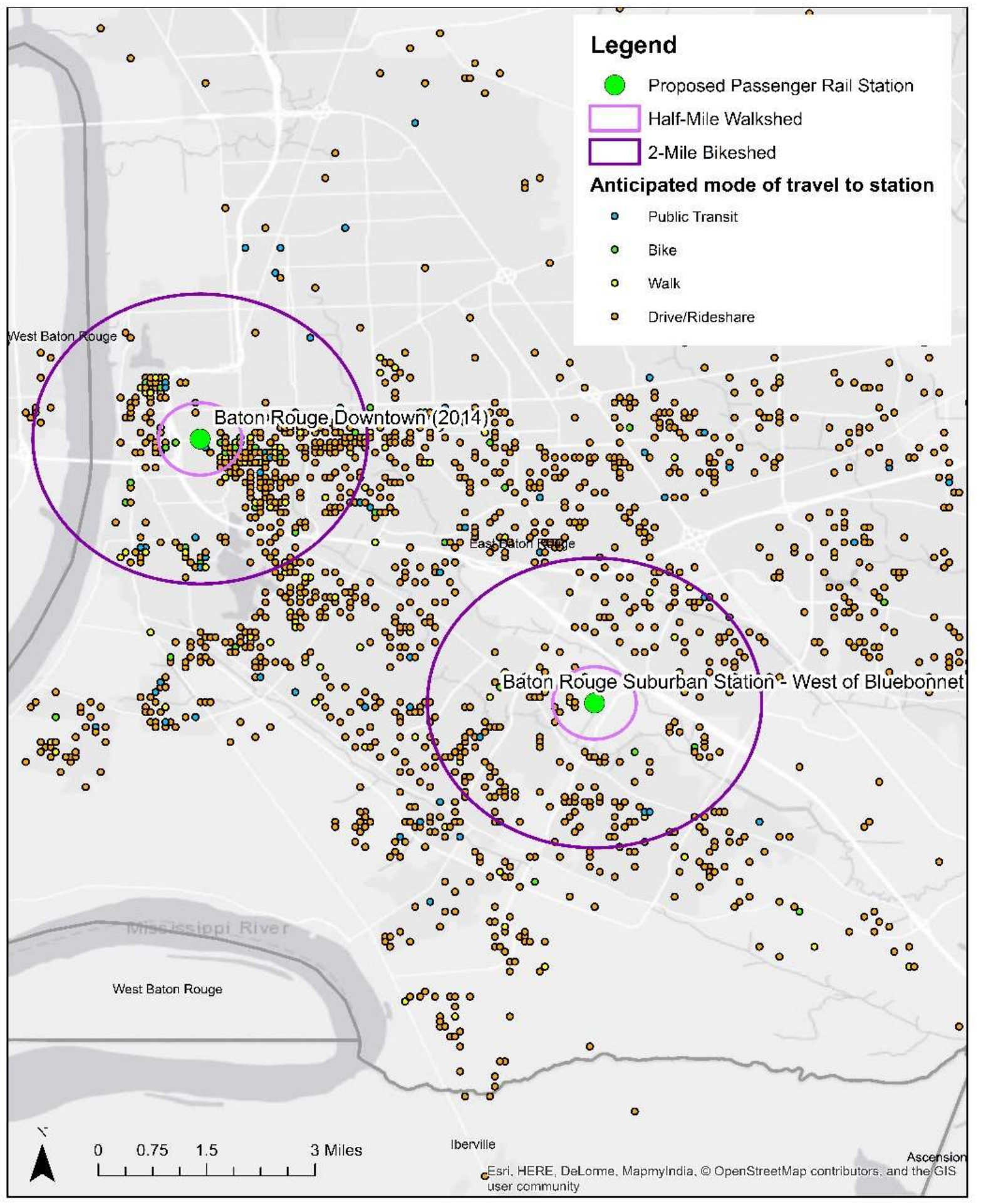

Figure 122. Anticipated mode of travel to future rail station: Baton Rouge. 
Anticipated mode of travel to future rail station

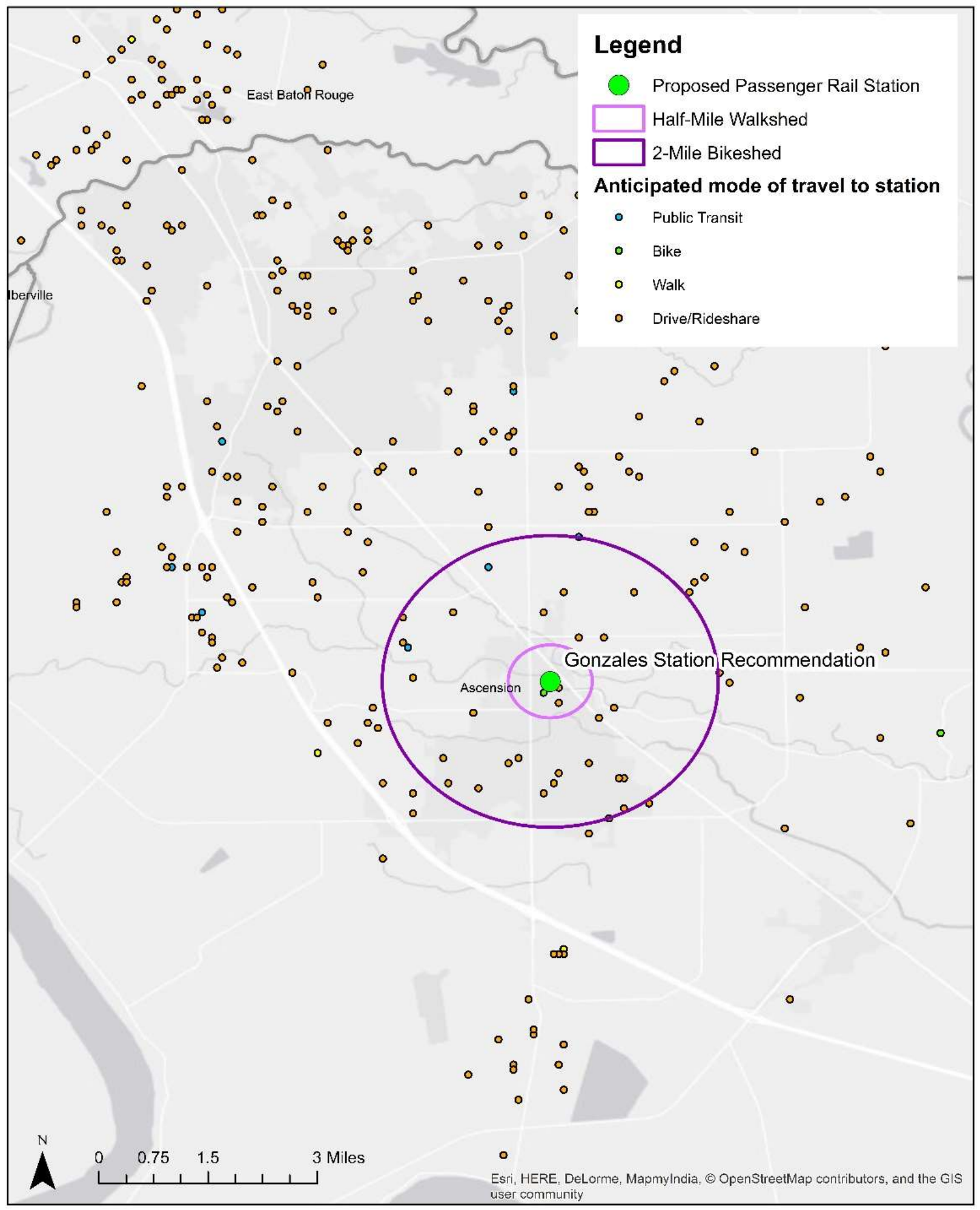

Figure 123. Anticipated mode of travel to future rail station: Gonzales. 
Anticipated mode of travel to future rail station

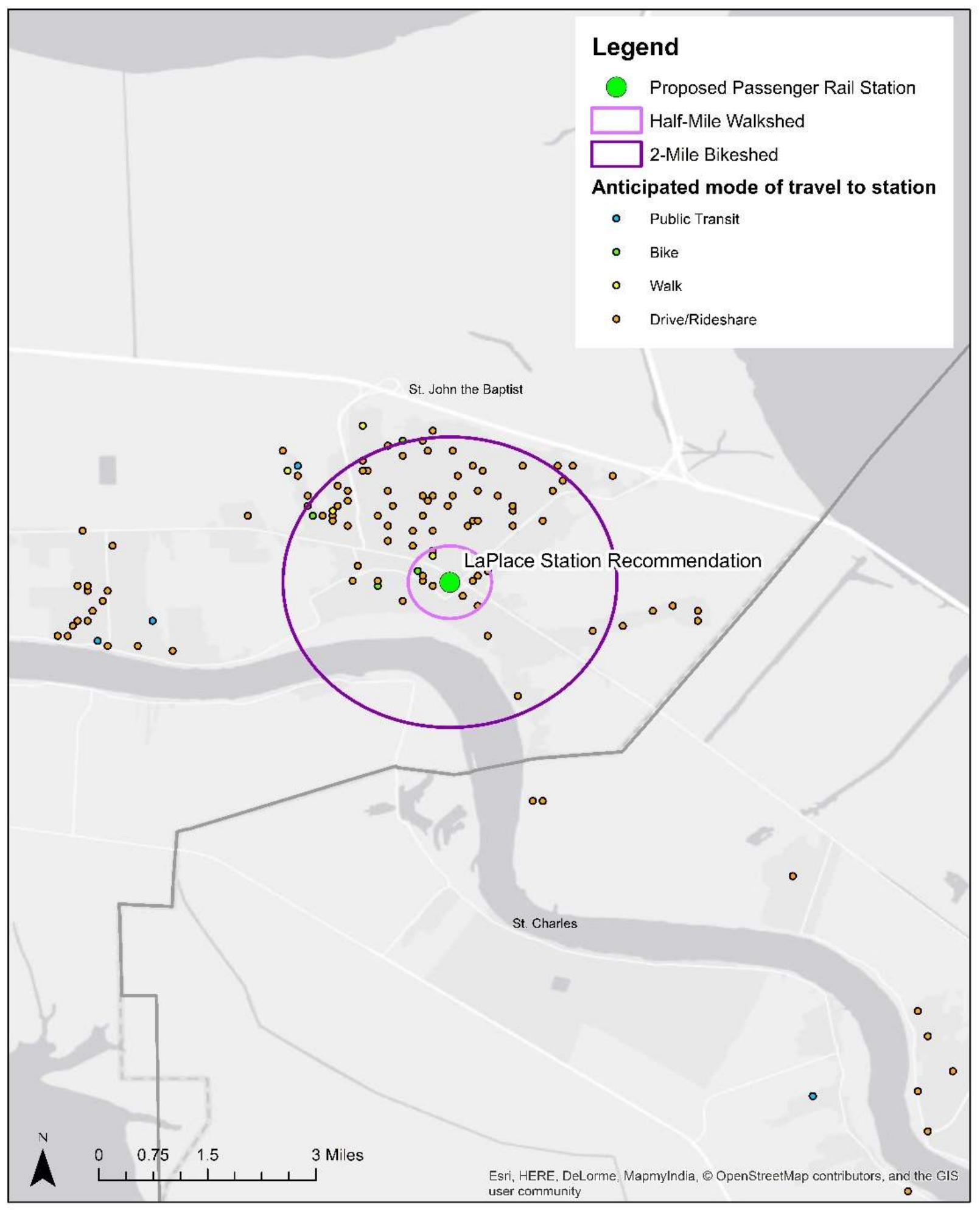

Figure 124. Anticipated mode of travel to future rail station: LaPlace. 
Anticipated mode of travel to future rail station

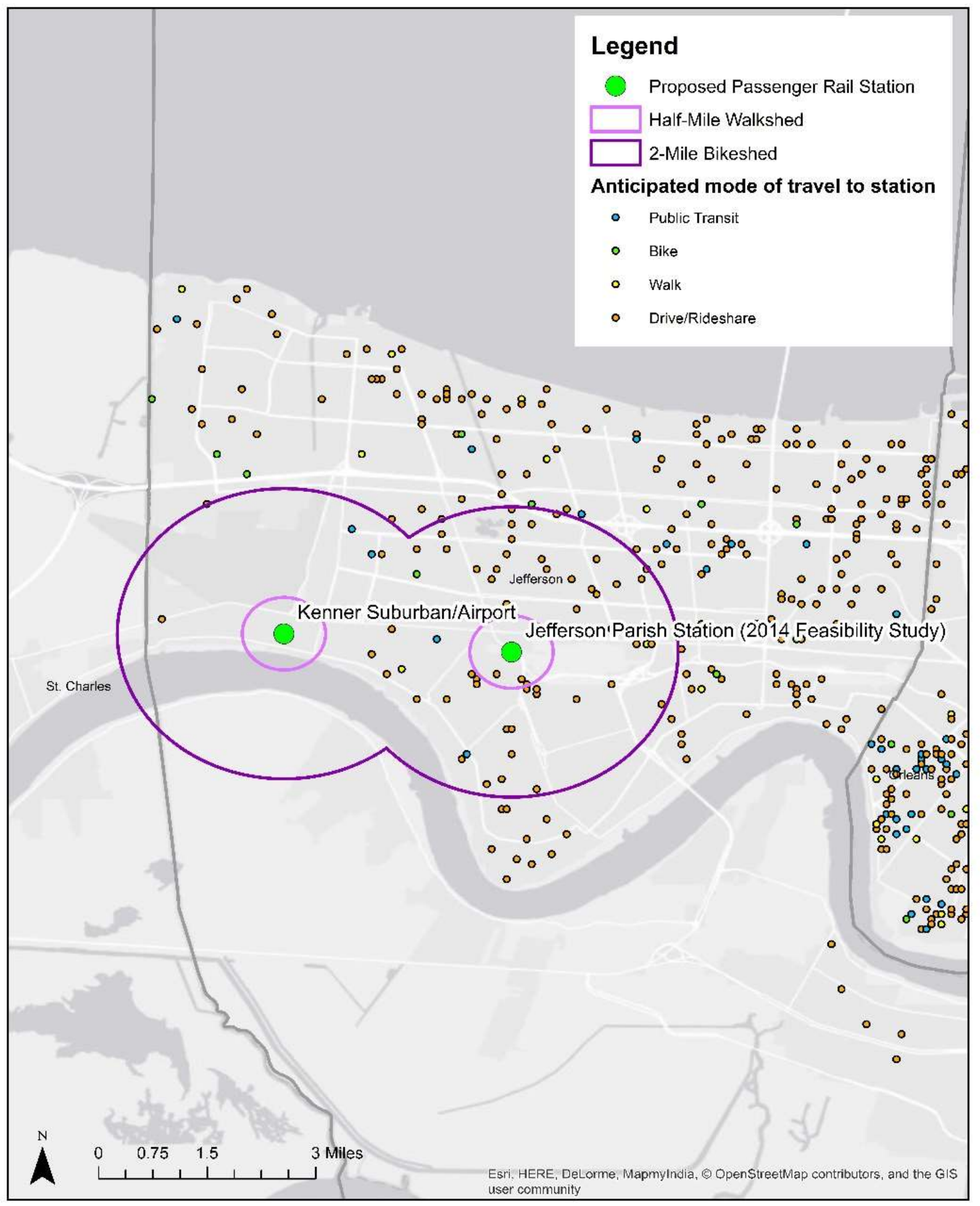

Figure 125. Anticipated mode of travel to future rail station: Jefferson Parish. 


\section{Anticipated mode of travel to future rail station}

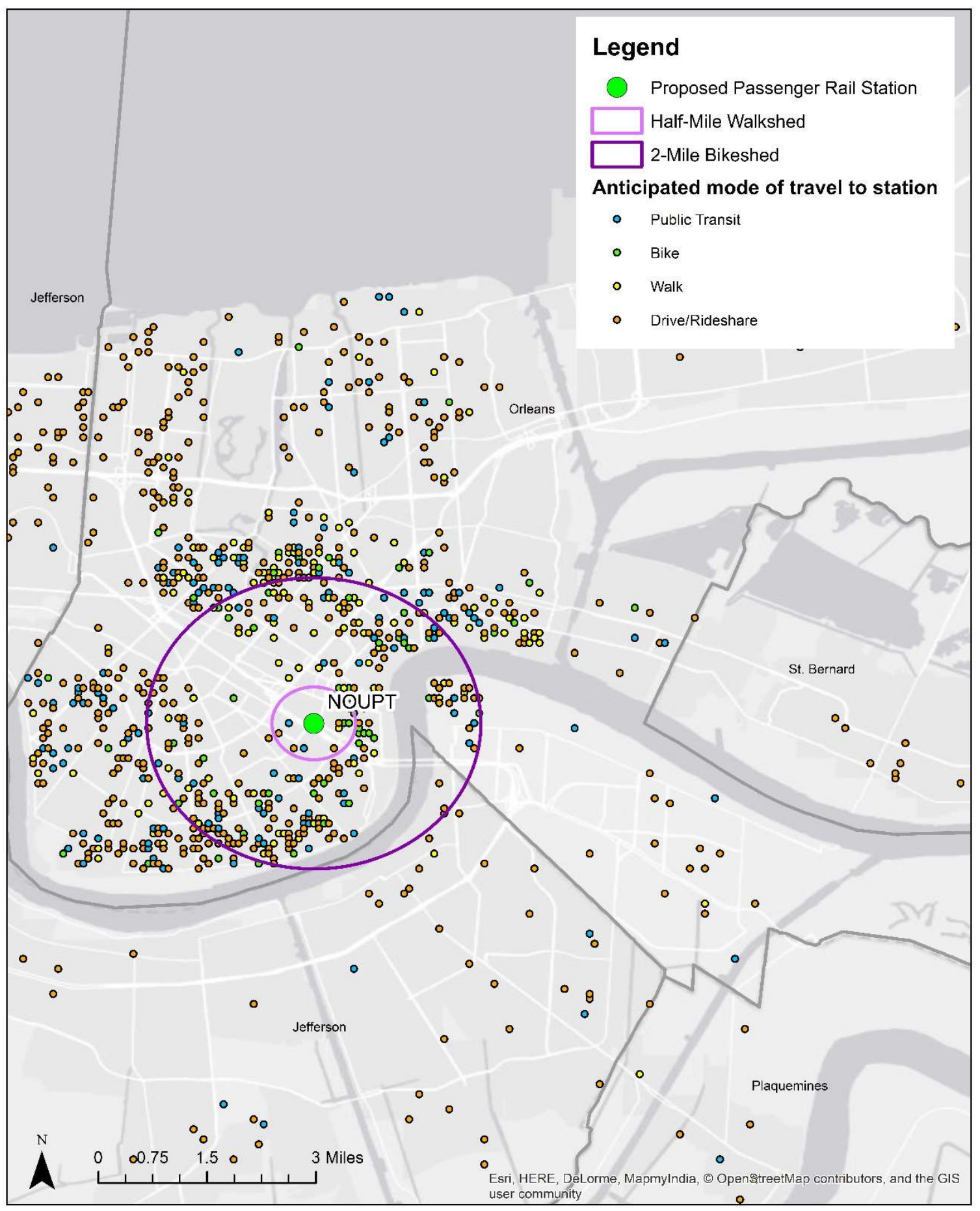

Figure 126. Anticipated mode of travel to future rail station: New Orleans. 


\section{CONCLUSIONS}

The idea of reconnecting Louisiana's two largest cities by rail has been discussed for decades, and has garnered broad local and regional support. However, concerns persist about operating costs, potential ridership and revenue, and how the service will integrate into local transportation networks to provide a viable option for residents and visitors alike. The intent of this study was to evaluate existing and planned connections between the proposed rail stations served by the route, and the existing public transportation systems (including active transportation networks) to which this service would connect the region's 2.2 million people to its 1 million jobs (1) as well as to other economic/tourism/activity centers within the region.

The success of commuter-oriented or short-distance intercity trains hinges on the presence of highquality connections to end destinations, including airports, campuses, recreation areas, and businesses. Thus, it is imperative to find out where riders are actually trying to go, and when. This study reveals that this does not always (or even most often) mean evaluating where they work. Previous planning efforts have dedicated insufficient attention to the needs of non-commute riders, as well as to vulnerable/special populations including people who lack vehicle access, the elderly, students, tourists, and people with mobility impairments. This study begins to explore the range of these populations and some potential implications for service design, but additional research is needed.

Ultimately, success means ridership. It may also be defined by mobility and access gains (to employment as well as medical facilities, social infrastructure, and recreation) for local residents (particularly communities of concern). Success can also be measured by the extent to which transportation investments spur local economic development: the less room required to be dedicated for parking (particularly surface parking lots) to meet rider demand, the greater the opportunity for TOD that mutually boosts local tax revenue and rail ridership.

\subsection{Existing and Future Conditions}

Evaluation of previously developed studies and plans reveals a wealth of foundational planning that creates a blueprint for the proposed rail's development, including station area plans for four of the six proposed new stations (not including the existing NOUPT). These planning documents are generally thorough, data-driven, and conscientious of the need to maximize multimodal connectivity for end users at stations by including facilities for bicyclists, creating new or improved pedestrian connections to and throughout adjacent neighborhoods, and planning for stations to serve double-duty as local transit hubs (even, in the case of LaPlace where fixed-route transit does not currently exist).

Baton Rouge's station area plans provide a clear groundwork for site plans, intermodal connections, TOD, and next steps toward implementation, although significant investment will be needed to bring these plans to fruition. Meanwhile the city's growing bikeshare system provides a valuable asset for facilitating first-and last-mile connections to stations, in tandem with the implementation of the city's bicycle master plan.

Gonzales' rail station master plan applies a complete street approach to downtown revitalization that offers benefits beyond strictly access and mobility for rail passengers. While the physical form and constraints of Ascension parish make it likely that most potential rail passengers will continue to prefer or need to drive to the station area, opportunity exists to foster transit-supportive 
development that meets the needs of all types of families and households in the area, including those who favor more walk-friendly communities.

LaPlace's transportation center plan both reinforces and is bolstered by the in-progress LASAFE Airline and main project. In all cases, local jurisdictions are taking steps now to move toward a more multimodal, less auto-dependent future which will be key to the proposed passenger rail service's success.

On the other hand, plans are underdeveloped for specific station sites and connections in Jefferson Parish, including connections to the new airport terminal, though complementary activities redesigning transit routes to better meet current demand and developing the first phases of a network of new dedicated bikeways will significantly enhance opportunities for last-mile connections.

In all intermediate station areas, opportunities to develop employer-based connections in lieu of or supplementing available local transit options should continue to be explored. However, it is likely that demand to and from these stops may not be primarily oriented around work trips. This presents an opportunity, as it is likely that rail can offer a more competitive alternative to driving for discretionary trips (special events, social activities, recreation, etc.) where door-to-door travel time is less critical.

Finally, New Orleans' rapid development of a bikeway network builds on the city's existing strength as place where alternative modes of transport present a viable option for many residents, while complementary activities focused on placemaking (including but not limited to those in response to COVID-19) infuse activity into spaces in downtown and beyond. Massive investments in housing and retail in the immediate station area create conditions inherently supportive of continued expansion of transportation options, although recent planning initiatives fail to center NOUPT as a key locus of transportation activity, and pedestrian connectivity falters in some locations. Finally, the ongoing impacts of COVID-19 on the city's financial stability and longterm outlook remain a concern as it is not yet known how long tourism will remain depressed and associated direct and indirect economic impacts will be felt.

\subsection{Survey Results}

The online, opt-in survey garnered over 4600 completed, in-state responses, revealing insights into the current and anticipated travel behaviors, modal preferences, cost and trip duration sensitivities, and origins and destinations of a geographically diverse range of likely passenger rail riders, as well as preliminary hints at the long-term impacts of COVID-19 on travel and employment. The sample pool overrepresented white, wealthy, and younger adult populations, as well as East Baton Rouge parish generally.

The survey results indicate that residents of the New Orleans- Baton Rouge corridor travel frequently among parishes and strongly support passenger rail development, though not necessarily primarily as a substitute for driving for commute trips. Rather, the respondents expressed a desire to have transportation options for trips related to sports, entertainment, special events, social activities, family visits, airport trips, and recreation. Accordingly, rail service design would need to accommodate trips at various times of day (including later evenings), perhaps especially on weekends and holidays. This indicates an important opportunity to meet rider needs and optimize revenue: rather than focusing on a commute-oriented service schedule, with one AM 
and one PM trip per day, it may be more appropriate for initial/pilot service design to focus on weekend/special event travelers and plan schedules accordingly. Furthermore, focusing attention on non-work trips would allow riders to experience the service under lower-stakes conditions, potentially assuaging concerns about travel time, safety, or reliability that were expressed.

Modeling of the survey results revealed a clear, pronounced preference for rail over intercity bus travel (despite the former popularity of the LA Swift bus, limited support for new or enhanced coach bus service was demonstrated), as well as a preference for faster total travel times and lower fares. Notably, no significant difference was found between $\$ 10$ and $\$ 15$ trip costs (although some demographic segments appear to be more price-sensitive than the overall group). Overwhelmingly, respondents also prefer to drive to their origin station, likely reflecting the currently underdeveloped state of bicycling and transit connections throughout much of the corridor, as well as the overall geographically dispersed nature of the region. Respondents who live closer to proposed stations are somewhat more likely to express interest in bicycling or walking (particularly in New Orleans) but many of even those who live very close to station areas generally prefer to drive. In order to minimize the demand for parking suggested by these findings, significant improvements in multimodal connectivity are needed. As noted above, these improvements are already underway in several corridor communities. Finally, respondents appear to be more open to taking transit as a last-mile solution, and accordingly are less sensitive to travel time for the final leg of their hypothetical trip.

\subsection{Ridership Projections}

Sociodemographic and spatial modeling of the data yielded limited results. Only three of a wide range of variables were found to be statistically significant: a negative relationship between uppermiddle (\$75-150k) incomes and ridership, and positive correlations with employment density and employment transit proximity. These findings suggest that implementation and future planning should focus on creating strong connections between proposed rail stations and local employment hubs, and that ridership is likely to be stronger among lower and middle income groups (perhaps more likely to view fuel and maintenance savings from avoiding driving trips as a benefit, and including no-vehicle households for whom the service would represent substantially increased mobility), as well as upper-income groups (who are likely to have time and resources for more leisure trips).

Otherwise, responses were relatively consistent across demographic groups and neighborhoods, indicating that the region's residents, while diverse, tend to share common patterns and preferences when it comes to transportation. This insight is useful in challenging the assumptions made in previous studies and reports, which tend to assume a large contingent of intercity commuters willing to switch to rail for daily travel. While some such users do exist (with numerous freeresponse answers indicating a desire to use the proposed service for daily commutes), the "typical" NO-BR rail rider is more likely to be traveling on the weekend for entertainment or an event, and plans to drive and park at the station, and catch a rideshare service to their final destination. Continued development of alternative modes of transport to improve public perceptions of the quality and safety of transit, bicycling, and walking infrastructure is needed before the general population--even among passenger rail enthusiasts--will be willing to try unfamiliar alternatives.

In an effort to further develop these findings, corridor-wide estimation of reported frequency of travel was extrapolated to develop rough potential ridership estimates that explicitly include non- 
work travel. Although limited in application and needing further refinement and testing, this exercise resulted in estimates that compare favorably to those previously developed, suggesting that, if not constrained by supply/service schedule, and if supported by effective local transportation choices, the demand for regional rail could be greater than previously projected.

\subsection{Next Steps and Recommendations}

Additional research is needed to more fully explore the transportation needs of populations underrepresented in this study due to constraints of online-opt in sampling and the forced cancellation of intercept surveys of existing transit riders. Future research should endeavor to fill these gaps in sample diversity, either by targeting underrepresented groups through intercept surveys or other outreach, or by conducting a representative randomized poll. In addition, although model variables and techniques are based on established methods that are believed to provide a strong foundation for future research, results were inconclusive. Subsequent methods of projecting potential ridership employed are exploratory and require further testing and development.

COVID-19 has upended travel patterns globally and locally, with a large number of respondents indicating that they expect to experience long-term changes in their transportation habits; namely, an increased interest in integrating multiple, active modes of transportation into their commute trips, as well as a permanent increase in telecommuting, at least part time, even while indicating that overall, most respondents expect things to generally return to "normal" without major impacts to lifestyle or behaviors. These findings reveal important deficiencies in datasets typically used for travel demand planning and illustrate strong support for communities that offer a variety of safe and convenient transportation choices that meet an increasingly flexible, hybridized travel patterns that incorporate different modes for different types of trips in different contexts. At the same time, public enthusiasm for active transportation and transit are currently significantly hindered in much of the region by poor perceptions of existing conditions. Continued development of complete streets, transit service, and newer transportation options (such as bikeshare) that is clean, reliable, and competitive is needed to realize visions for a less auto-dependent southeast Louisiana.

In order to advance implementation of the proposed rail service, additional research on potential funding streams and mechanisms to support operational costs is needed. Moreover, gaps remain in planning for service design and station area development, including developing value-capture mechanisms to support TOD, refining station locations and vision for Jefferson Parish stations, and overcoming regulatory or legal barriers to implementation.

Finally, renewed and sustained effort is required to organize the broad network of stakeholder advocates as well as grassroots public support for the proposed rail service, in order to be prepared for anticipated changes in federal infrastructure policy and spending that are likely to present key opportunities to advance project implementation and ultimately, help the state achieve the promise of reducing traffic congestion, reducing environmental impacts of vehicles, and promoting connections to economic opportunity within the Southeast Louisiana mega-region 


\section{REFERENCES}

1. HNTB. Baton Rouge - New Orleans Intercity Rail Feasibility Study: Technical Memoranda. Prepared for the New Orleans Regional Planning Commission, Capital Region Planning Commission, Baton Rouge Area Foundation. State and Federal Project Numbers: H.010052, H.010053, 2014.

2. City of Gonzales. Gonzales Passenger Rail Station Master Plan, 2018. https://gonzalesla.com/wp-content/uploads/2018/09/Final-Gonzales-Master-Plan-1.pdf. Accessed October 20, 2020.

3. Southern Rail Commission. Louisiana. https://www.southernrailcommission.org/louisiana/ Accessed October 20, 2020.

4. Amdal, J.R. Rails to Recovery: The Role of Passenger Rail Transportation in PostKatrina New Orleans and Louisiana. UNOTI Publications, Paper 6, 2011. https://scholarworks.uno.edu/unoti_pubs/6. Accessed October 20, 2020.

5. Rainey, R. Commuter rail linking New Orleans to Baton Rouge has broad support, big obstacles. The Times-Picayune | Nola.com. August 8, 2015. https://www.nola.com/futureofneworleans/2015/07/baton_rouge to new_orleans_com.html. Accessed September 15, 2019.

6. Anderson, E Despite Gov. Bobby Jindal's opposition, business leaders want high-speed rail between Baton Rouge, New Orleans. The Times-Picayune | Nola.com, February 22, 2010. https:/www.nola.com/news/politics/article_47859fbf-b699-570b-84a5-9dcf561a0480.html. Accessed October 20, 2020.

7. Landry, A.O. Lacking matching funds, DOTD not applying for passenger rail grant. Business Report. September 27, 2018. https://www.businessreport.com/business/lackingmatching-funds-dotd-not-applying-passenger-rail-grant-2. Accessed October 20, 2020.

8. Goldman, Ben. (2019). Improving Intercity Passenger Rail Service in the United States. (CRS Report No. R45783). Retrieved from Congressional Research Service website: https://fas.org/sgp/crs/misc/R45783.pdf. Accessed October 20, 2020.

9. Gatien, A. and Mas Baghaie, A. (2019). Improving Active Transportation and Public Transit Integration: A Guidebook for Policy and Planning. The Centre for Active Transportation at Clean Air Partnership.

10. Kline, S., Wampler, E., \& Yake, C.. (2013). Intercity Rail and Transit-Oriented Development: Making Connections, Building Communities. Center for Transit-Oriented Development (CTOD).

11. U.S. Government Accountability Office. (2013). Intermodal Transortation: A Variety of Factors Influence Airport Intercity Passenger Rail Connectivity. (Publication No. GAO-13691). https://www.gao.gov/assets/660/656553.pdf.

12. Antolin, Brian, Schwieterman, J. P., \& Jacques, M.. (2019) New Directions: 2019 Outlook for the Intercity Bus Industry in the United States. Chaddick Institute for Metropolitan Development at DePaul University. 
13. Losada-Rojas, L. L., Gkartzonikas, C., Gkritza, K., \& Pyrialakou, V. D. (2017). Evaluating opportunities to enhance Hoosier State Train ridership through a survey of riders' opinions and an assessment of access to the line (Joint Transportation Research Program Publication No. FHWA/IN/JTRP-2017/20). West Lafayette, IN: Purdue University. https:// doi.org/10.5703/1288284316574

14. Suraci, Dan. (2018) Bicycle and Transit Integration: A Practical transit Agency Guide to Bicycle Integration and Equitable Mobility. APTA Standards Development Program.

15. Feinsod, S., Romo Urroz, E., Haas, P. J., \& Griffith, J. (2016). International Lessons for Promoting Transit Connections to High-Speed Rail Systems. Mineta Transportation Institute Publications.

16. Kornfield, M. (2018). "Brightline train stations boost new development in South Florida's downtowns." South Florida Sun-Sentinel, July 3, 2018. https:/www.sunsentinel.com/news/transportation/fl-reg-brightline-stations-redevelopment-20180703-story.html Accessed October 20, 2020.

17. Lyons, D. (September 30, 2020). "FL: Brightline shut down commuter service for months. When will the trains run again?". South Florida Sun Sentinel. https:/www.sunsentinel.com/coronavirus/fl-ne-coronavirus-brightline-weighs-service-resumption-20200930mra764bogfestpnymvajoyzcqm-story.html Accessed October 20, 2020.

18. "From Charlotte to Raleigh, a welcome Railvolution." (2016). The Charlotte Observer. https://www.charlotteobserver.com/opinion/op-ed/article61260932.html Accessed October 20, 2020.

19. Stradling, R. (13 May, 2020). "NCDOT suspends Piedmont train service between Raleigh and Charlotte to save money." The Raleigh News \& Observer.

https://www.newsobserver.com/news/local/article242698691.html\#: :text=The\%20cash\%2Dstra pped $\% 20$ state $\% 20$ Department,travel $\% 20$ during $\% 20$ the $\% 20$ coronavirus $\% 20$ outbreak. Accessed October 20, 2020.

20. Transportation Research Board. (2007). Metropolitan Travel Forecasting: Current Practice and Future Direction (No. Special Report 288; p. 147). Retrieved from Transportation Research Board of the National Academies website: http://onlinepubs.trb.org/onlinepubs/sr/sr288.pdf Accessed October 20, 2020

21. Flyvbjerg, B. (2007). Cost Overruns and Demand Shortfalls in Urban Rail and Other Infrastructure. Transportation Planning and Technology, 30(1), 9-30. doi: 10.1080/03081060701207938

22. Littman, T. (2020). Evaluating Public Transit Benefits and Costs: Best Practices Guidebook. Victoria Transport Policy Institute. https://www.vtpi.org/tranben.pdf Accessed October 20, 2020.

23. Weber, S. (2019). A Step-by-Step Procedure to Implement Discrete Choice Experiments in Qualtrics. Social Science Computer Review 1-19. DOI 10.1177/0894439319885317

24. Greene, W. H. (2018). Econometric Analysis (8th Edition). Pearson. 
25. Tian, G., Ewing, R., \& Greene, W. (2015). Desire for smart growth: A survey of residential preferences in the Salt Lake region of Utah. Housing Policy Debate, 25(3), 446-462.

26. Raudenbush, S. W., \& Bryk, A. S. (2002). Hierarchical linear models (2 ${ }^{\text {nd }}$ ed.). Thousand Oaks, CA: Sage Publications.

27. Meng, L., Taylor, M., ad Holyoak, N. (2012). Stated preference survey experiment design for transit-oriented development modeling. Australasia Transport Research Forum, 26-28 September 2012, Perth, Australia. http://www.patrec.org/atrf.aspx

28. LADOTD. (2003). Louisiana Statewide Rail Plan.

http://wwwsp.dotd.la.gov/Inside_LaDOTD/Divisions/Multimodal/Marine_Rail/Misc\%20Docum ents/Louisiana\%20Rail\%20Plan.pdf Accessed October 20, 2020

29. Southern Rail Commission. (2019). Reviving Passenger Rail Along America'S Gulf Coast: Louisiana Briefing Book. https://static1.squarespace.com/static/5302778ee4b07a6f640874ef/t/5cab7ad2f4e1fc285ba95ba9/ 1554741978608/Capital+Hill+Briefing+Book LA 2019.pdf Accessed October 20, 2020.

30. Amdal, James R. (2011). Rails to Recovery: The Role of Passenger Rail Transportation in Post-Katrina New Orleans and Louisiana. UNOTI Publications. Paper 6. https://scholarworks.uno.edu/unoti pubs/6 Accessed October 20, 2020.

31. Southern Rail Commission. (2015). Connecting Baton Rouge and New Orleans by Intercity Passenger Rail: Gubernatorial Briefing Book. https://static1.squarespace.com/static/55c3a31ee4b044158f9e0553/t/560945b3e4b0f2630d44a2e 5/1443448243354/SRC_GBB_web_final.pdf Accessed October 20, 2020.

32. LA DOTD. (2020). Louisiana State Rail Plan.

http://wwwsp.dotd.la.gov/Inside_LaDOTD/Divisions/Multimodal/Marine_Rail/Misc\%20Docum ents/2020\%20Louisiana\%20Rail\%20Plan.pdf. Accessed October 20, 2020.

33. Burk-Kleinpeter, Inc (2010). Baton Rouge - New Orleans Intercity Passenger Rail Service Development Plan. Southern High Speed Rail Commission. Retrieved from: http://www.norpc.org/assets/pdf-documents/studies-and-plans/BR-NO_Pass_Rail-Vol1_2010.pdf Accessed October 20, 2020.

34. HNTB. (2014). Baton Rouge - New Orleans intercity rail feasibility study, Technical memoranda. Prepared for the New Orleans Regional Planning Commission, Capital Region Planning Commission, Baton Rouge Area Foundation. Retrieved from http://www.norpc.org/assets/pdf-documents/studies-and-plans/BRNOLA\%20Rail_Technical\%20Memoranda_FINAL_February\%202014.pdf Accessed October $20,2020$.

35. Nobles, Wilborn P. (2018). UNO Institute gets $\$ 150,000$ grant to study Louisiana's rail systems. Nola.com | Times Picayune, October 29, 2018.

https://www.nola.com/education/2018/10/uno-institute-gets-150000-grant-to-study-louisianasrail-systems.html Accessed October 20, 2020.

36. Federal Railroad Administration (2019). Federal Railroad Administration Announces More Than \$326 Million in Grants to Support Railroad Infrastructure. June 12, 2019. 
https://railroads.dot.gov/press-releases/federal-railroad-administration-announces-more-326million-grants-support-railroad Accessed October 20, 2020.

37. Karlin, Sam. (2018). Planners to unveil proposed Baton Rouge rail stations for passenger service to New Orleans. The Advocate, Baton Rouge, June 19 2018. Retrieved from https://www.theadvocate.com/baton_rouge/news/business/article_10e8c7e6-73d2-11e8-b6ce67ad9d4fbe0d.html Accessed October 20, 2020.

38. East Baton Rouge Redevelopment Authority. (2019). Baton Rouge Passenger Rail Station Master Plan: Downtown and Suburban Stations. https://buildbatonrouge.org/wpcontent/uploads/2020/01/BR_railstationplan_compressed.pdf Accessed October 20, 2020.

39. Baton Rouge Area Foundation (2015). Health District Master Plan. https://www.braf.org/braf-research/2016/2/29/health-district-master-plan Accessed October 20, 2020.

40. City of Gonzales. (2018). Gonzales Passenger Rail Station Master Plan. Retrieved from http://www.gonzalesla.com/wp-content/uploads/2018/09/Final-Gonzales-Master-Plan-1.pdf Accessed October 20, 2020.

41. St. John the Baptist Parish (2019). LaPlace Multi-Modal Transportation Center Plan. http://sjbparish.com/pdfs/LPMMTC\%20-\%20Full\%20Document\%206-6-2019.pdf Accessed October 20, 2020.

42. City of Kenner. (2015). Pattern for Progress: City of Kenner Comprehensive Plan. http://www.kenner.la.us/2/Comp_Plan_Final_6-22-15.pdf Accessed October 20, 2020..

43. Crescent City Aviation Team. (2013). Louis Armstrong New Orleans International Airport: Long-Term Infrastructure Development Plan. https://www.nola.gov/getattachment/1ade5ff6-b3f7-4cd7-941b597cd21c126f/MSY_Long_Term_Development_Executive_Summary.pdf/ Accessed October 20, 2020.

44. Jefferson Parish. (2019). Envision Jefferson 2040: The Jefferson Parish Comprehensive Plan. https://jefferson-parishgovernment.azureedge.net/documents/departments/planning/envision2040/EnvisionJefferson2040.pdf Accessed October 20, 2020.

45. City of New Orleans (2018). The Plan for the $21^{\text {st }}$ Century. https://www.nola.gov/nola/media/One-Stop-Shop/CPC/Mayor-s-Office-Chapter-11-nomarkup.pdf Accessed October 20, 2020.

46. City of New Orleans (2019). Mayor Cantrell Celebrates $\$ 6.643 m$ Project To Renovate Union Passenger Terminal. September 4, 2019. https://nola.gov/mayor/news/september2019/mayor-cantrell-celebrates-\$6-643m-project-to-renovate-union-passenger-terminal/ Accessed October 20, 2020.

47. Buchanan, S. (June 23, 2013). South Louisiana's affordable LA Swift bus, started after Katrina, might be saved. Louisiana Weekly. https://www.huffpost.com/entry/south-louisianasaffordab b 3488219? guccounter=1\&guce referrer=aHR0cHM6Ly93d3cuZ29vZ2x1LmNvbS8\& guce referrer sig=AQAAAEFedvtimfEwPU tedCfoeE32XlkeR5uX669fbLGkkkiM7jEHxPHv 
iAhIWjrBm9PnMTWUiVnbbSgkEnkJBuyJaXBgAqm3u bGmiNmhooHYrV5cV_BHsbHrQya OuRVvKReReenjSojFfnvHnlMqGZa8WYXAXj_w8gsx21tVu9WYq Accessed October 20, 2020.

48. Commuter Krewe of Louisiana. (2018). March 2018 Commuter Krewe Newsletter. https://krewe.rideproweb.com/rp2/documents/Search Accessed October 20, 2020.

49. Pelican Bus. (2020). Northshore - New Orleans Commuter Bus Service.

https://pelicanbus.com/northshore-new-orleans-commuter-bus-service/. Accessed October 20, 2020.

50. East Baton Rouge Parish (2020). Pedestrian and Bicycle Master Plan.

http://ebrpedbike.org/docs/Digital_Baton_Rouge_Master\%20Plan_13Mar2020-V2.pdf Accessed October 20, 2020.

51. Capital Area Transit System. (2018). Strategic Plan 2017-2022.

https://www.brcats.com/assets/docs/Planning/CATSstrategicplan2018.pdf Accessed October 20, 2020.

52. Build Baton Rouge. (2019). Imagine Plank Road: Plan for Equitable Development https://buildbatonrouge.org/wp-content/uploads/2020/02/Imagine-Plank-Road_FinalReport_2019.11.06_web.pdf Accessed October 20, 2020.

53. East Baton Rouge Parish. (2018). FutureBR Comprehensive Plan. https://www.brla.gov/662/FUTUREBR. Accessed October 20, 2020.

54. Louisiana State University. (n.d.) Tiger Trails. https://www.1su.edu/parking/transportation/tigertrails.php. Accessed October 20, 2020.

55. Capital Area Transit System. (2019). The Five Year Capital Improvements and Investments Plan. https://www.brcats.com/assets/docs/Planning/cats2018 capitalplan.pdf. Accessed October 20, 2020.

56. Hardy, S. (Jan 11, 2019). "New rideshare in Baton Rouge? Bus agency invests in new "uber-esque' pilot. The Advocate. https://www.theadvocate.com/baton_rouge/news/article_e81ce25c-15b6-11e9-874ecba0349ca07c.html. Accessed October 20, 2020.

57. East Baton Rouge Redevelopment Authority. (2016). Southern Rail Commission Grant Application: City of Baton Rouge- Passenger Rail Station and Surrounding Area Planning and Construction.

http://hdlegisuite.brgov.com/attachments/2016/City\%20Parish_Rail\%20Station\%20Match_BBA D0911.pdf) Accessed October 20, 2020.

58. WBRZ. (October 26, 2020). Baton Rouge receives \$5 million award to fund Plank Road Masterplan. https:/www.wbrz.com/news/baton-rouge-receives-5-million-award-to-fund-plankroad-masterplan/ Accessed October 26, 2020.

59. Thomas, R. (2019). Mayor Broome announces \$15 million grant for Plank to Nicholson bus project, $W A F B$. November 7, 2019)https://www.wafb.com/2019/11/07/mayor-broomeannounces-million-grant-plank-nicholson-bus-project/ 
60. https://www.brcats.com/news/591 Accessed October 20, 2020.

61. City of Gonzales. (2015) Gonzales Comprehensive Plan. https://gonzalesla.com/wpcontent/uploads/2015/09/Gonzales_Comprehensive_Plan_08.24.15 web.pdf Accessed October 20, 2020.

62. GCR, Inc et al.. (2013). Jefferson Parish Bicycle Master Plan. https://jefferson-parishgovernment.azureedge.net/documents/departments/planning/envision-2020/bicycle-masterplan/JPBicycleMasterPlan-2013-12-27.pdf Accessed October 20, 2020.

63. JeT (2019). Jefferson Parish Public Transit Strategic Plan http://www.norpc.org/wpcontent/uploads/2020/06/JeT-Strategic-Plan_Final-Report-042019.pdf Accessed October 20, 2020 .

64. New Links (2020). Report on the Proposed Network. https://www.norpc.org/wpcontent/uploads/2020/11/NewLinks-Proposed-Network-Report-202010-Spreads.pdf Accessed November 10, 2020.

65. New Orleans RTA. (2018). Strategic Mobility Plan.

http://www.norta.com/RTA/media/RTA-PDF-Files/SMP/Strategic-Mobility-Plan.pdf?ext=.pdf Accessed October 20, 2020.

66. New Orleans Regional Transit Authority. (2020). New Orleans Downtown Transit Center Alternatives Analysis: Final Report. http://www.norta.com/RTA/media/RTA-PDF-

Files/Transit\%20Hub/New-Orleans-Transit-Center-FINAL-Draft-Report-2-2020 .pdf Accessed October 20, 2020.

67. Moving New Orleans Bikes (2020). New Orleans Bikeway Blueprint.

https://nola.gov/nola/media/transportation/New-Orleans-Bikeway-Blueprint-091020.pdf

Accessed October 20, 2020.

68. FTA. (2013). An Overview of STOPS.

https://www.transit.dot.gov/sites/fta.dot.gov/files/docs/STOPS.overview-web-final.pdf Accessed October 20, 2020.

69. Mercer et al (2018). For Weighting Online Opt-In Samples, What Matters Most? Pew Research Center. https://www.pewresearch.org/methods/2018/01/26/for-weighting-online-optin-samples-what-matters-most// Accessed October 20, 2020.

70. Southern Rail Commission (2019). Poll Shows Wide Support of New Orleans to Baton Rouge Passenger Rail Service. https://www.southernrailcommission.org/pressreleases/2020/8/26/poll-shows-wide-support-of-new-orleans-to-baton-rouge-passenger-railservice Accessed October 20, 2020.

71. Center for Planning Excellence (2011). One Great Region: Working Together to Build a Sustainable 'Super Region' Connecting New Orleans and Baton Rouge. http://www.reconnectingamerica.org/assets/Uploads/CPEX-One-Great-Region.pdf Accessed October 20, 2020.

72. Louisiana Realtors Association and Center for Planning Excellence (2010). Poll of Residents in Parishes Intersected by the Proposed BR/NO Commuter Rail Corridor, December 2010. 


\section{APPENDIX A: Survey Instruments}

Survey 1 - NO-BR Regional Intercity Transit Choices Survey (Online)

1. Q1 Intro text: No respondent input

(Required; Show Go Back button)

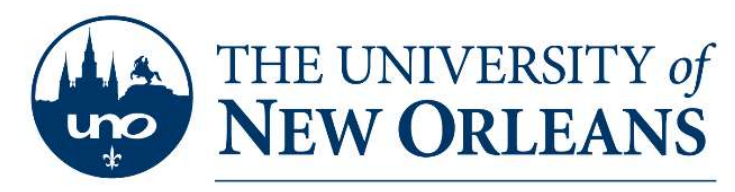

UNO TRANSPORTATION INSTITUTE Welcome and thank you for participation in the NO-BR Regional Intercity Transit Choices Survey!

The objective of this study is to evaluate connections between proposed and potential intercity rail/transit terminals in New Orleans, Baton Rouge, and points in between, to surrounding public transportation systems. The goal is to optimize future investments in regional transportation, including the proposed development of a new passenger rail service.

This survey is being conducted by UNO Transportation Institute, on behalf of the LSU TranSET Research Consortium, Project 19PPLSU11 - Rails to Resilience: Evaluating New Orleans and Baton Rouge Rail Terminals and Transit Links.

The survey will focus on your level of interest in intercity regional transportation options, identifying your regional travel needs, and understanding your preferences among different potential service scenarios for new or improved rail or bus services connecting destinations.

This survey will take approximately 15 minutes to thoughtfully complete. The results of this survey will be released to the public later in 2020. All responses and data will be fully anonymous. If you choose to provide your contact info, you will be entered into a random drawing for one of two $\$ 50$ Visa gift cards.

If you have any questions about this study, please contact:

Tara M Tolford, AICP

tmtolfor@uno.edu

504.280 .6516

\section{Q2 Multiple choice}

(One response required; One response allowed; Place options in 1 column; Show Go Back button) 
In which parish do you live?

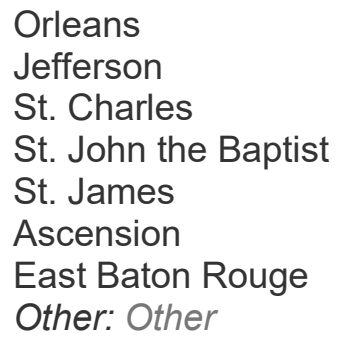

3. Q3 Short answer

(Required; Show Go Back button)

What is your home address? (You may list your actual Street address, or generalize such as "800 block of Main Street" or "Main Street at Anytown Avenue." All answers will be generalized to the Census Tract level).

\section{Q4 Multiple choice}

(One response required; One response allowed; Place options in 1 column; Show Go Back button)

Understanding that this may be in flux or uncertain right now due to the ongoing COVID-19 pandemic, what is your current employment status?

- Employed full-time

Employed part-time

Self-employed (full or part-time)

Student, not employed or employed less than 25 hours per week

Student, employed 25+ hours per week

Homemaker

Retired

Not currently employed - Temporary COVID-19-related layoff or furlough; expect to return to previous employer or industry when restrictions are lifted

- Not currently employed - Permanent layoff/seeking new position

- Not currently employed - Do not anticipate returning to previous position and not seeking new work

\section{Q5 Multiple choice}

(One response required; One response allowed; Place options in 3 columns; Show Go Back button)

During typical conditions (e.g. outside of the period when COVID-19 restrictions are or were in place) do you regularly report to a place of work outside your home?

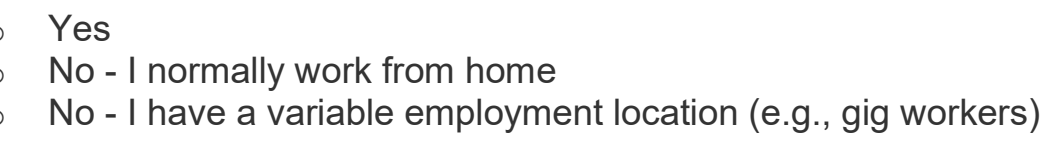

\section{Show this question only if the following conditions are met:}


If all of these conditions are met:

Answer to question "Q4 Understanding that this may be in flux or uncertain right now due to the ongoing COVID-19 pandemic, what is your current employment status? " is among Employed full-time, Employed part-time, Self-employed (full or part-time), Student, not employed or employed less than 25 hours per week, Student, employed $25+$ hours per week, Not currently employed - Temporary COVID-19-related layoff or furlough; expect to return to previous employer or industry when restrictions are lifted, Not currently employed - Permanent layoff/seeking new position

\section{Q6 Short answer}

\section{(Required; Show Go Back button)}

What is the address of your workplace? (You may list the actual Street address, or generalize such as "800 block of Main Street" or "Main Street at Anytown Avenue." All answers will be generalized to the Census Tract level).

\section{Show this question only if the following conditions are met:}

If all of these conditions are met:

Answer to question "Q4 Understanding that this may be in flux or uncertain right now due to the ongoing COVID-19 pandemic, what is your current employment status? " is among Employed full-time, Employed part-time, Self-employed (full or part-time), Student, employed 25+ hours per week, Not currently employed - Temporary COVID19-related layoff or furlough; expect to return to previous employer or industry when restrictions are lifted

\section{Q7 Short answer}

\section{(Required; Show Go Back button)}

Where do you expect to attend school for the Fall, 2020 term?

\section{Show this question only if the following conditions are met:}

If all of these conditions are met:

Answer to question "Q4 Understanding that this may be in flux or uncertain right now due to the ongoing COVID-19 pandemic, what is your current employment status? " is among Student, not employed or employed less than 25 hours per week, Student, employed $25+$ hours per week

\section{Q8 Multiple choice}

(One response required; Place options in 1 column; Show Go Back button)

Before the COVID-19 pandemic, how did you typically commute to work? (Select all that apply)

$\circ$ Drive alone 


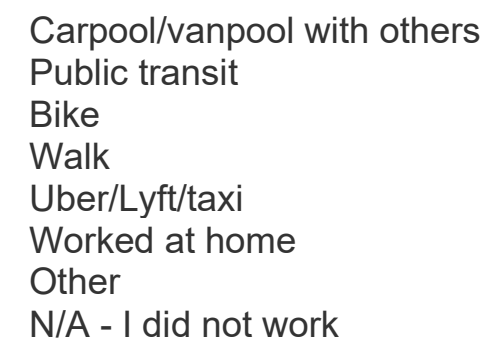

9. Q9 Multiple choice

(One response required; Place options in 1 column; Show Go Back button)

During the COVID-19 pandemic, how did/do you typically commute to work? (Select all that apply)

Worked at home
Drive alone
Carpool/vanpool with others
Public transit
Bike
Walk
Uber/Lyft/taxi
Other
N/A - I did not work

10. Q10 Multiple choice

(One response required; One response allowed; Place options in 3 columns; Show Go Back button)

Do you own or have regular access to a vehicle?
- Yes
- No
- Sometimes

11. Q11 Multiple choice

(One response required; Place options in 1 column; Show Go Back button)

For the next several questions, we ask you to consider how and where you expect to travel after COVID-19 social distancing restrictions are lifted, the immediate public health threat has subsided, and you begin to return to routine travel and activities (i.e., "normal conditions.")

We recognize that there is still likely to be much uncertainty, just use your best guess about your future plans.

Under normal conditions post-COVID-19, how do you anticipate commuting to work? (Select all that apply)

$\begin{array}{ll}\circ & \text { Drive alone } \\ \circ & \text { Carpool/vanpool with others } \\ \circ & \text { Public transit } \\ \circ & \text { Bike } \\ \circ & \text { Walk } \\ \circ & \text { Uber/Lyft/taxi }\end{array}$ 
- Work at home

Other

N/A - I do not plan to work

12. Q12 Multiple choice

(One response required; One response allowed; Place options in 1 column; Show Go Back button)

Under normal conditions, how often do you travel within the New Orleans-Baton Rouge corridor, outside of your home city or parish? (Select all that apply)

- Every day

- Several times per week

At least once per week

A few times per month

At least once per month

Every few months

At least once per year

Seldom or never

13. Q13 Multiple choice

(One response required; Place options in 3 columns; Show Go Back button)

Under normal conditions, which of the following parishes do you visit at least once per year? (Select all that apply, excluding your own parish, if applicable)

Orleans (New Orleans)

Jefferson (e.g. Metairie, Kenner)

St. Charles (e.g. Norco, Destrehan, Luling)

St. John the Baptist (e.g. LaPlace, Reserve, Garyville)

St. James (e.g. Lutcher, Grammercy, Vacherie)

Ascension (e.g. Gonzales, Prairieville, Sorrento)

East Baton Rouge (e.g. Baton Rouge, Zachary, Central)

Other: Other

14. Q14 Multiple choice

(One response required; Place options in 3 columns; Show Go Back button)

Under normal conditions, for what purposes do you travel to these destinations? (Select all that apply)

- Work

- To attend sporting events

To attend cultural events/activities (festivals, concerts, etc)

Other recreation or entertainment

To visit family or friends

Other: Other

15. Q15 Multiple choice

(One response required; Place options in 1 column; Show Go Back button) 
Under normal conditions, when you visit or commute to destinations outside of your city or parish within the New Orleans-Baton Rouge region, how do you typically travel? (Select all that apply)

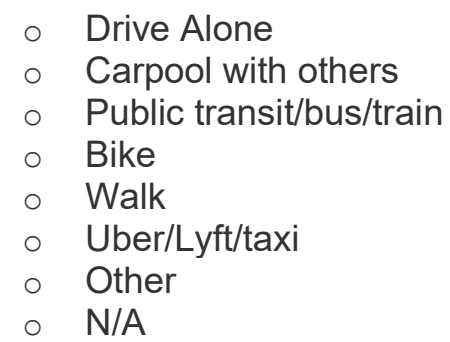

16. Q16 Multiple choice

(One response required; Place options in 1 column; Show Go Back button)

Under normal conditions, on which days of the week are you most likely to travel to destinations outside of your city or parish within the New Orleans-Baton Rouge region? (select all that apply)

- Weekdays

- Weekends

- None/Not Applicable

17. Q17 Multiple choice

(One response required; Place options in 1 column; Show Go Back button)

Under normal conditions, during which times of day are you most likely to start travel to destinations outside of your city or parish within the New Orleans - Baton Rouge region?
Early morning: 5 -7am
Morning: 7-9 am
Late Morning: 9-11am
Mid-day: $11 \mathrm{am}-1 \mathrm{pm}$
Afternoon: $1-4 \mathrm{pm}$
Early evening: 4-6pm
Evening: 6-9pm
Late evening: $9 \mathrm{pm}-12 \mathrm{am}$
Late night: 12am-5am
None/Not Applicable

18. Q18 Multiple choice

(One response required; Place options in 1 column; Show Go Back button)

Under normal conditions, during which times of day are you most likely to return from travel to destinations outside of your city or parish within the New Orleans-Baton Rouge region?
Early morning: 5 -7am
Morning: 7-9 am
Late Morning: 9-11am
Mid-day: $11 \mathrm{am}-1 \mathrm{pm}$
Afternoon: $1-4 \mathrm{pm}$ 
○ Early evening: 4-6pm

$\circ$ Evening: 6-9pm

- Late evening: $9 \mathrm{pm}-12 \mathrm{am}$

- Late night: 12am-5am

- None - Not Applicable

19. Q19 Intro text: No respondent input

(Required; Show Go Back button; Force respondents to stay on this question for 5 seconds)

Next, we would like to ask you about your preferences for different options for getting around the region.

For this exercise, imagine you need to travel to a destination in the New Orleans - Baton Rouge region, and driving is not an option.

You will see a series of potential trip scenarios that represent possible trade-offs in terms of time, cost, and means of transport you could take to complete the trip. You will see ten pairs of scenarios; many of them will seem similar, but are all slightly different.

For each screen, please look closely at the options and tell us which one you would choose, if these were the only options available to complete your essential trip. When making your decision, please assume that the only differences between the scenarios are those listed on each screen.

It is important that you carefully choose among $\mathrm{EACH}$ of the ten scenario pairs.

\section{Q20 Block of conjoint questions [see Appendix B: Survey Design]}

\section{Q21 Open-ended response}

\section{(Show Go Back button)}

Would you like to share any other thoughts about the scenarios presented? Do you have questions about the potential intercity service options or local connection scenarios that you would like us to address in our report? (optional)

\section{Q22 Multiple choice}

(One response required; One response allowed; Place options in 1 column; Show Go Back button)

Great work! Next, we would like to ask a few quick questions about your opinions about transportation choices in your community.

How would you describe your level of interest in a proposed New Orleans-Baton Rouge Passenger rail service, in general? 

- Strongly in favor
- Moderately in favor
- Neutral/unsure
- Moderately opposed
- Strongly opposed

\section{Q23 Multiple choice}

(One response required; One response allowed; Place options in 1 column; Show Go Back button)

How would you describe the quality/usefulness of the public transit system in your community?

\section{Q24 Multiple choice}

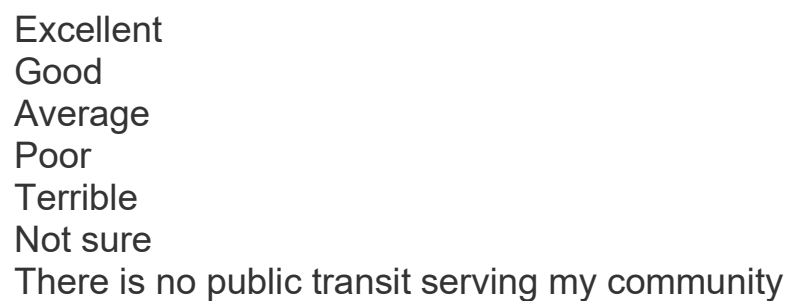

(One response required; One response allowed; Place options in 1 column; Show Go Back button) How would you describe the quality/usefulness of bicycle infrastructure in your community?

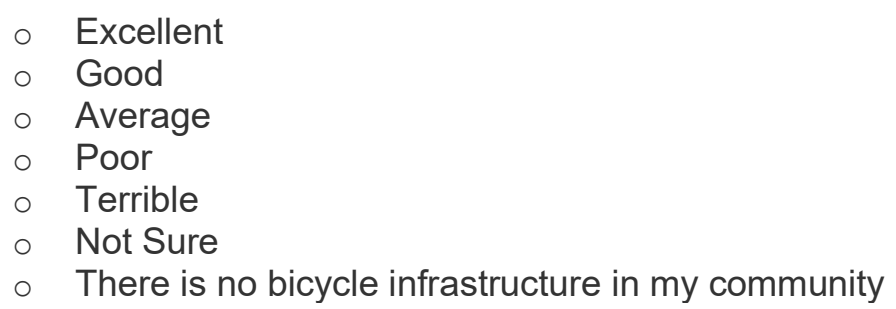

(One response required; One response allowed; Place options in 1 column; Show Go Back button) How would you describe how easy or difficult it is to walk to destinations of interest in your community?

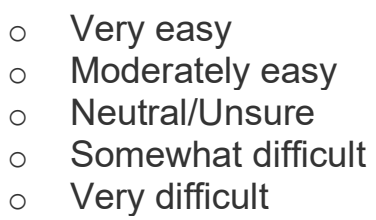

26. Q26 Multiple choice

(One response required; One response allowed; Randomise order of options; Place options in 1 column; Show Go Back button)

Which of the following is the best long-term solution to reducing traffic congestion in the I-10 corridor between New Orleans and Baton Rouge? 
- Building a new passenger rail line

- Expanding or improving intercity passenger bus service

- Expanding highways

- Develop communities where people do not have to drive long distances to work or shop

\section{Q27 Multiple choice}

(One response required; One response allowed; Place options in 1 column; Show Go Back button)

Imagine that a new passenger rail service connecting New Orleans, Metairie, Kenner/MSY, LaPlace, Gonzales, and Baton Rouge just opened, and you are planning a trip. How will you get to the station?

- Drive alone

- Carpool with others

- Public transit

- Bike

○ Walk

- Uber/Lyft/taxi

- Other

- N/A - I would not use this service

28. Q28 Multiple choice

(One response required; One response allowed; Place options in 1 column; Show Go Back button)

Finally, we know COVID-19 has had serious impacts on how Louisianans choose to get around, where we're traveling, and what our priorities are as we recover. We have asked you to predict how you will travel in the future, even though we do not yet know what the new "normal" will look like.

After the immediate crisis has subsided, businesses are open, and stay-home restrictions are lifted, do you anticipate that your travel behaviors (when, how, and how much) will return to how they were pre-pandemic?

- Yes, I expect to return to conditions similar to before the pandemic

- Yes, but with some significant changes

- Maybe - too soon to say

- No, my travel behaviors will be very different from before

\section{Q29 Open-ended response}

\section{(Show Go Back button)}

In what ways do you expect your transportation habits, specifically, to change in coming months and years?

\section{Q30 Multiple choice}

(One response required; One response allowed; Place options in 1 column; Show Go Back button)

Specifically, how (if at all) has the COVID-19 outbreak impacted your liklihood to utilize local or intercity public transit options? 
- I am more likely to use public transit, including intercity train or bus services, than before COVID-19

- I am less likely to use public transit, including intercity train or bus services, than before COVID-19

- No change - I am likely to use public transit, including intercity train or bus services, about the same as before

- Not Applicable - I do not use public transit or intercity train or bus services and do not expect to

\section{Q31 Multiple choice}

(One response required; One response allowed; Place options in 3 columns; Show Go Back button)

Thank you for your responses so far! Your input is valuable in understanding current and future needs of Louisianans as we recover from the impacts of COVID-19 and look to our region's future. Just a couple more questions about you for classification purposes only.

What is your age?

\begin{tabular}{ll}
$\circ$ & Less than 18 years \\
$\circ$ & $19-24$ \\
$\circ$ & $25-34$ \\
0 & $35-44$ \\
$\circ$ & $45-54$ \\
$\circ$ & $55-64$ \\
\hline & $65+$
\end{tabular}

32. Q32 Multiple choice

(One response allowed; Place options in 3 columns; Show Go Back button)

Gender

- Male

- Female

- Other/Non-Binary

33. Q33 Multiple choice

(Place options in 3 columns; Show Go Back button)

Race (select all that apply)

- Black or African American

White

American Indian or Alaska Native

Asian

Native Hawaiian or other Pacific Islander

HIspanic or Latino (of any race)

34. Q34 Multiple choice

(One response required; One response allowed; Place options in 1 column; Show Go Back button)

Household income 


$$
\begin{aligned}
& \text { Less than } \$ 10,000 \\
& \$ 10,000-\$ 24,999 \\
& \$ 25,000-\$ 34,999 \\
& \$ 35,000-\$ 49,999 \\
& \$ 50,000-\$ 74,999 \\
& \$ 75,000-\$ 99,999 \\
& \$ 100,000-\$ 149,999 \\
& \$ 150,000-\$ 199,999 \\
& \$ 200,000 \text { or more }
\end{aligned}
$$

35. Q35 Open-ended response

(Show Go Back button)

Would you like to share any other thoughts or ideas with the research team about transportation needs, challenges, or possibilities in the New Orleans-Baton Rouge region?

36. Q36 Short answer

\section{(Show Go Back button)}

Thank you so much for your time and input! If you would like to be entered to win a $\$ 50$ Visa Gift Card, please provide your email address so we can get in touch. Your email will not be shared or used for any other purpose. 


\section{Survey 2: New Orleans - Baton Rouge Regional Transit Passenger Questionnaire (Intercept)}

This survey, conducted by the University of New Orleans Transportation Institute, is intended to better understand the needs of people traveling between New Orleans, Baton Rouge, and points in between on intercity bus services, and to help plan for future improvements within our region, including bus service or terminal enhancements, changes to connecting transit services to make it easier to reach your final destination, and potential future rail service within the region.

We are requesting your participation in this survey for our research. This questionnaire is anonymous and your participation is voluntary. We thank you for sharing your views with us today.

If you have any questions about this study, please take a business card and call or email the project lead, Tara Tolford, AICP at tmtolfor@uno.edu or 504.280.5616

* Required

1. Survey Time and Date

2. Survey Location

3. What is your destination today?

Mark only one oval.

New Orleans

Kenner/Airport

LaPlace

Gonzalez

Baton Rouge

Other (End Survey)

4. What bus service are you riding?

Mark only one oval.

Greyhound

Megabus

FlixBus

About the Transit Rider

5. Age

Mark only one oval.

Other:

15-18 years old

18-25 years old 
25-35 years old

$35-45$ years old

45-55 years old

55-65 years old

$65+$

6. Race

Mark only one oval.

Other:

Black or African American

White

American Indian and Alaska Native

Asian

Hispanic or Latin American

Two or more races

73. Gender

Mark only one oval.

Other:

Male

Female

Gender Non Conforming

74.

Mark only one oval.

$0-\$ 20,000$

$\$ 20,000$ to $\$ 35,000$

$\$ 35,00$ to $\$ 50,000$

$\$ 50,000$ to $\$ 75,000$

$\$ 75,000-\$ 100,000$

Over $\$ 100,000$

75. What is your current employment status?

Mark only one oval.

Employed full-time

Employed part time

Unemployed and currently looking for work

Undemployed and not currently looking for work

Student

Retired

Homemaker

Self-Employed

Unable to work

About your Travel

10. Do you Own a Car?

Mark only one oval.

Yes

No

11. Do you have access to a vehicle for regular use?

Mark only one oval.

Yes

No

Sometimes

12. Purpose of Your Trip 
Mark only one oval.

Other:

Work

School

Attending a leisure activity (i.e. concert or sporting event)

Visiting family or friends

13. What is your home zip code?

14. What is your destination (zip code, place name, or address)?

Travel Time

15. Frequency of Trips Taken on Regional Transit

Mark only one oval.

Daily

1-3 times per week

Weekly

Monthly

Every few months

Annually

This is my first trip

16. How long did it take you from your origin to get to the transit station?

Mark only one oval.

Other:

Less than 10 minutes

10-20 minutes

20-40 minutes

40-60 minutes

Over 1 hour

17. How did you travel to the station?

Mark only one oval.

Took Local transit

Walked

Bicycled

Drove a personal car

Got a ride

18. If you got a ride who drove you?

19. If you took transit, what route(s) did you take?

20. How long does it take you to access your final destination from the transit station? Mark only one oval.

Other:

Less than 10 minutes

10-20 minutes 
20-40 minutes

40-60 minutes

Over 60 minutes

21. How are you traveling from the transit station to your final destination?

Mark only one oval.

Other:

Taking transit

Walking

Bicycling

Driving your own car

Getting a ride

22. If you are getting a ride to your final destination who is driving you?

23. If you are taking transit to your final destination, what route will you take?

\section{Traveler Satisfaction}

24. Please rate the following ( 1 being least satisfied and 5 being most satisfied *

Mark only one oval per row.

12345

Overall trip experience

Cleanliness of stations

On time reliability

Your safety at regional transit stations

Your safety from your origin to transit station

Your safety from transit station to your

destination

Safety on transit bus/train

Price of regional transit fare

Clear information about accessing route info

Ease of purchasing tickets for regional

transit

Bus Schedules and times that meet your

travel needs

Frequency of service

\section{Survey Respondent Personal Comments}

Please explain any additional information you'd like us to know about your regional transit experience and/or changes you'd like to see in the future to make it easier for you to travel within the New Orleans - Baton Rouge region 


\section{IRB Approval Memo}

\section{University Committee for the Protection of Human Subjects in Research University of New Orleans}

Campus Correspondence

Principal Investigator: Tara Tolford

Co-Principal Investigator: James Amdal

Date: Nov. 20, 2019

Protocol Title: Evaluating New Orleans and Baton Rouge Rail Terminals and Transit Links

IRB\#:

03Oct19

The IRB has deemed that the research and procedures of the above-named protocol are compliant with the University of New Orleans and federal guidelines and meets the standard for being exempt from further IRB review according to:

CFR 46.104 (d)(2): Research that only includes interactions involving educational tests (cognitive, diagnostic, aptitude, achievement), survey procedures, interview procedures, or observation of public behavior (including visual or auditory recording) and at least one of the following criteria is met:

(i) The information obtained is recorded by the investigator in such a manner that the identity of the human subjects cannot readily be ascertained, directly or through identifiers linked to the subjects;

(ii) Any disclosure of the human subjects' responses outside the research would not reasonably place the subjects at risk of criminal or civil liability or be damaging to the subjects' financial standing, employability, educational advancement, or reputation; or

(iii) The information obtained is recorded by the investigator in such a manner that the identity of the human subjects can readily be ascertained, directly or through identifiers linked to the subjects, and the IRB has conducted a limited IRB review and determined that there are adequate provisions to protect the privacy of subjects and maintain the confidentiality of data.

Researchers maintain the responsibility for ethical research practices in exempt research. Any changes to the procedures or protocols that change the eligibility of the study for exemption must be reviewed and approved by the IRB prior to implementation.

I wish you much success with your research project. If you any questions, please do not hesitate to contact me at 280-7386.

Sincerely,

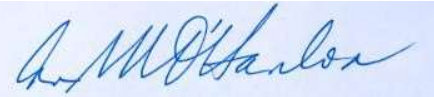

Ann O'Hanlon, Chair

UNO Committee for the Protection of Human Subjects in Research 


\section{Press Release Copy \\ FOR IMMEDIATE RELEASE: SHARE OUR TRANSIT SURVEY! UNO TRANSPORTATION INSTITUTE SEEKING PUBLIC INPUT ON REGIONAL TRANSIT PROJECT}

May 29, 2020

\section{Rails to Resilience: Evaluating New Orleans and Baton Rouge Rail Terminals and Transit Links}

The UNO Transportation institute is seeking public input to model potential passenger rail ridership between Baton Rouge, Gonzales, LaPlace, Kenner, and New Orleans. The survey is anonymous and will be used to inform future transit, passenger rail and multimodal planning efforts. Questions in the survey are aimed at understanding the public's interest in using regional transit and identifying recommendations for improving connections to proposed rail stations, as well as existing intercity bus services, via transit, walking, and bicycling.

Residents and frequent visitors of New Orleans, Baton Rouge, and all points in between are encouraged to participate. Survey respondents will be entered to win a \$50 Visa gift card.

"The purpose of this survey is to get in-depth insight into how different people throughout the region travel, and how people anticipate that may change as we head into the post-pandemic new-normal" says UNO Transportation Institute's Tara Tolford: "Importantly, we want to make sure that if Louisiana does invest in new or improved regional transportation options, we can design the service, stations, and surrounding community connections to ensure that they are as useful and convenient as possible to travelers."

This research effort, sponsored by the LSU Tran-SET research consortium, builds on previous feasibility studies supporting the proposed rail project, seeking to specifically address last-mile connections between potential stations and where people live, work, and play, expanding choices for the thousands who regularly travel along this corridor. In addition, the project seeks to develop recommendations that will improve travel for Louisianians who already use bus and transit services to connect to employment, family, and cultural opportunities across the region.

\section{Access Survey Here (https://run.conjoint.ly/study/72517/01bnxzagl9)}

Sample questions include:

- Where, when, how, and why do you travel within the New Orleans - Baton Rouge region?

- What factors most influence your interest in taking rail or using transit for regional travel?

- How has COVID-19 changed your attitudes about travel and commuting?

- If the proposed rail connection is eventually developed, what would make it convenient and appealing to use?

Please help us SHARE this public survey in your community:

- SHARE OUR FACEBOOK POST ON YOUR FACEBOOK PAGE

- POST A DIRECT LINK TO THE SURVEY IN YOUR NEXT NEWSLETTER

- $\quad$ EMAIL THE SURVEY LINK TO YOUR STAKEHOLDERS AND CONTACT LISTS

- SHARE TO THE PUBLIC

For more information on the UNO Rails to Resilience project please contact:

Tara Tolford, AICP

Research Associate

UNO Transportation Institute

Mineburg, Room 273

2000 Lakeshore Drive

New Orleans, LA 70148

Office 504-280-6516

Mobile: 504-638-4462

tmtolfor@uno.edu 


\section{APPENDIX B: Experimental Design}

[Excel Attachment]

\section{APPENDIX C: Survey Responses}

[Excel attachment]

Note: survey responses have been scrubbed of personally identifying information and generalized to the census tract level to protect respondent privacy

\section{APPENDIX D: DCE Results}

[Excel attachment]

Note: survey responses have been scrubbed of personally identifying information.

\section{APPENDIX E: Open-Ended Responses (Queried)}

[Excel attachment]

Note: survey responses have been scrubbed of personally identifying information. 